$$
\begin{gathered}
\text { Universidade de SÃo Paulo - USP } \\
\text { Instituto de Química de São Carlos - IQSC }
\end{gathered}
$$

NANOMATERIAIS LUMINOMAGNÉTICOS VISANDO APLICAÇÕES BIOLÓGICAS: SÍNTESE, PROPRIEDADES, FUNCIONALIZAÇÃO E ESTABILIDADE COLOIDAL

CAIO GUILHERME SECCO DE SOUZA

SÃO CARLOS 


\section{NANOMATERIAIS LUMINOMAGNÉTICOS VISANDO APLICAÇÕES BIOLÓGICAS: SÍNTESE, PROPRIEDADES, FUNCIONALIZAÇÃO E ESTABILIDADE COLOIDAL}

Tese apresentada ao Instituto de Química de São Carlos da Universidade de São Paulo, como parte dos requisitos necessários para obtenção do título de Doutor em Química, no curso de Pós-Graduação em Química.

Área de concentração: Físico-Química

Orientador: Prof. Dr. Laudemir Carlos Varanda

\section{SÃO CARLOS}


Eu dedico este trabalho a Deus, aos meus pais Grace e João, aos meus irmãos Thaís, Camila, César e Milena e à minha amada Luana, por todo o amor, carinho e dedicação durante toda a minha jornada. 


\section{AGRADECIMENTOS}

Agradeço de maneira geral a todos envolvidos direta ou indiretamente na conclusão deste trabalho e na minha formação pessoal e profissional.

Aos meus pais e irmãos por fornecerem todo amor, carinho e apoio durante toda a minha vida. Em especial aos meus pais Grace e João, que cada qual com sua forma de carinho, sempre me apoiaram e me deram muita força. Obrigado por tudo, amo muito todos vocês e não seria nada sem a presença e carinho marcante de vocês.

À minha amada e parceira Luana, que desde o início de todo esse processo esteve sempre ao meu lado, me fornecendo muito amor, carinho, ajuda, amizade e confiança. Espero sempre estar ao seu lado em toda minha jornada e conquistas, meu amor. Eu te amo muito!

A todos meus parentes, entre eles: Tia Nilza, Tia Nitinha, Tia Ana, Vó Cida, Vô Zé, Tio Ananias, Tio Zé, Tia Cidinha, Tio Ivan, Andréia, Fernanda, Natália, Bruna, entre outros, que sempre me deram muito carinho e força. Obrigado a todos! Amo vocês.

Ao Prof. Dr. Laudemir Carlos Varanda, que me dou ao direito de chamar de Mí, por todo apoio, ensinamentos, compreensão, oportunidades e proximidade que me propiciou durante estes seis anos de orientação e convivência. Tenho certeza que aprendi e evolui muito como profissional e pessoa, após todos esses anos de convivência. Obrigado por tudo!

Aos amigos do Laboratório de Materiais Coloidais, Beck, Tiago (Jeca), Daniel, João, Herbert (Perereca), Rafael (Piá), Mônica, Rebecca, Dani, Nayane e Gustavo por todo apoio, aprendizagem, risadas e, sobretudo, pela amizade. Em especial ao Beck e Tiago que iniciaram o processo de mestrado e doutorado junto comigo e sempre me apoiaram, suportaram e ajudaram em diversas ocasiões. A todos podem contar sempre com minha amizade!

Ao Prof. Dr. Hedi Mattoussi, por todo o ensinamento e a oportunidade de trabalhar em seu grupo. Também agradeço a todos os integrantes do grupo do Prof. Mattoussi, entre eles: Goutam, Dinesh, Woody, Naiqian, Sookie, Anshika, Birong, Xin e Wentao, que facilitaram muito a minha vida e meu aprendizado nos EUA. E aos amigos brasileiros, Daniel e Bruno que também me deram um grande apoio e amizade por lá. Em especial, agradeço a Goutam que sempre me ajudou e me ensinou muito durante a minha estadia no grupo. Obrigado a todos! 
A todos amigos que de alguma forma alegraram, facilitaram e me ensinaram durante todos os anos da minha vida, desde os tempos de colégio, de graduação, de mestrado e de doutorado.

A todos amigos que conheci na USP e em São Carlos, que me receberam muito bem e sempre tive ótimos momentos.

A todos os funcionários do IQSC/USP e da Florida State University que direta ou indiretamente ajudaram no desenvolvimento deste trabalho. E também, a toda infra-estrutura oferecida e o corpo docente qualificado na minha formação pessoal e profissional.

À CAPES pela bolsa concedida durante o doutorado e ao CNPq durante o estágio realizado no exterior. 
“A entrada para a mente do homem é o que ele aprende, a saída é o que ele realiza. Se sua mente não for alimentada por um fornecimento contínuo de novas idéias, que ele põe a trabalhar com um propósito, e se não houver uma saída por uma ação, sua mente torna-se estagnada."

Jeremias W. Jenks

“A mente que se abre a uma nova idéia jamais voltará ao seu tamanho original.”

Albert Einsten

“O valor das coisas não está no tempo em que elas duram, mas na intensidade com que acontecem. Por isso existem momentos inesquecíveis, coisas inexplicáveis e pessoas incomparáveis.”

Fernando Pessoa 


\section{RESUMO}

Neste trabalho, foi realizado um estudo da obtenção de nanomateriais luminomagnéticos visando potenciais aplicações biológicas, a partir de dois diferentes tipos de estruturas, sendo elas: a formação de heteronanoestruturas luminomagnéticas de NPM de $\mathrm{FePt} / \mathrm{Fe}_{3} \mathrm{O}_{4}-\mathrm{CdSe}$ recobertas com sílica; e a formação de nanomateriais luminomagnéticos por ligação covalente entre NPM de $\mathrm{FePt} / \mathrm{Fe}_{3} \mathrm{O}_{4}$-Dopa-PIMA-PEG-NH $\mathrm{N}_{2}$ e pontos quânticos de CdSe/ZnS-LA-PEG-COOH.

Para o primeiro tipo de nanomaterial citado, foram testadas duas metodologias para obtenção das heteronanoestruturas: a mudança da estabilidade coloidal pela adição de pequenas quantidades de $\mathrm{NaCl}$ no meio contendo as NPM e os pontos quânticos previamente sintetizados; e o método de injeção a quente do precursor de selênio em um meio contendo as NPM como sementes, o precursor de cádmio e os agentes de superfície. O método de injeção a quente foi o que apresentou melhores condições para a formação das heteronanoestruturas. Para providenciar estabilidade coloidal em meio aquoso e superfície com biocompatibilidade, foi realizado o recobrimento com sílica na superfície das heteronanoestruturas luminomagnéticas com melhores condições. Para essa amostra, o tamanho médio obtido foi de 25,0 $\mathrm{nm}$, com polidispersividade de 8,4 \%, Ms $=11,1 \mathrm{emu} . \mathrm{g}^{-1} \mathrm{e}$ comportamento superparamagnético, além de duas bandas de emissão (com excitação de $400 \mathrm{~nm}$ ) centradas em $452 \mathrm{~nm}$ e $472 \mathrm{~nm}$, respectivamente.

Já para o segundo tipo de nanomaterial obtido neste trabalho, foram primeiramente obtidas NPM de $\mathrm{FePt} / \mathrm{Fe}_{3} \mathrm{O}_{4}$ pelo método do poliol modificado acoplado à metodologia do crescimento, e pontos quânticos luminescentes de $\mathrm{CdSe} / \mathrm{ZnS}$ pelo método de decomposição térmica de precursores organometálicos, sendo que ambas nanoestruturas apresentaram superfície hidrofóbica. Para a troca de ligantes para transferência das nanoestruturas para a fase aquosa e para providenciar biocompatibilidade visando aplicações biológicas, foram previamente preparados ligantes poliméricos de Dopa-PIMA-PEG-NH $\mathrm{N}_{2}$ para recobrimento das NPM e de LA-PEG-COOH para recobrimento dos pontos quânticos. A conjugação química entre as nanoestruturas de $\mathrm{FePt} / \mathrm{Fe}_{3} \mathrm{O}_{4}$ Dopa-PIMA-PEG-NH 2 e CdSe/ZnS-LA-PEG-COOH foi realizada pelo método da carbodiimida em solução aquosa para a formação de uma ligação covalente amida entre os grupos amina e carboxilato em cada uma das nanoestruturas. Os nanomateriais luminomagnéticos obtidos apresentaram estabilidade coloidal em meio aquoso, com estreita distribuição de tamanho, apresentando $\mathrm{R}_{\mathrm{H}}$ de $79,96 \mathrm{~nm}$, Ms de, aproximadamente, $10 \mathrm{emu}^{-1} \mathrm{~g}^{-1}$ com coercividade e remanência quase nulos e intensa banda de emissão centrada em $580 \mathrm{~nm}$.

Espera-se que os nanomateriais obtidos neste trabalho possam ser promissores nanomateriais com propriedades multifuncionais para potenciais aplicações biológicas.

Palavras-chave: nanomateriais luminomagnéticos, nanomateriais multifuncionais, estabilidade coloidal, aplicações biológicas. 


\begin{abstract}
Here, luminomagnetic nanomaterials were obtained for potential biological applications. We have studied two different types of luminomagnetic nanomaterials, which are: formation of silicacoated $\mathrm{FePt} / \mathrm{Fe}_{3} \mathrm{O}_{4}-\mathrm{CdSe}$ heteronanostructures; and formation of luminomagnetic nanomaterials from covalent bond between $\mathrm{FePt} / \mathrm{Fe}_{3} \mathrm{O}_{4}$-Dopa-PIMA-PEG- $\mathrm{NH}_{2}$ magnetic nanoparticles and $\mathrm{CdSe} / \mathrm{ZnS}-\mathrm{LA}-\mathrm{PEG}-\mathrm{COOH}$ luminescent quantum dots.

For the first type of luminomagnetic nanomaterials obtained, two methodologies were studied for formation of heteronanostructures, which are: modification of colloidal stability by addition of small amounts of $\mathrm{NaCl}$ into a solution with hydrophobic magnetic nanoparticles and luminescent quantum dots; and hot injection method of selenium precursor into a solution with magnetic nanoparticles seeds, cadmium precursors and surface agents. The hot injection method obtained better results than the other method studied for formation of heteronanostructures. To provide colloidal stability in aqueous solution and biocompatibility, the heteronanostructures were coated using silica shell. After silica coating, the heteronanostructures showed average diameter of $25 \mathrm{~nm}$ and polidispersivity of $8.4 \%$, with $\mathrm{Ms}=11.1$ emu. $\mathrm{g}^{-1}$ and superparamagnetic behavior. Moreover, these nanomaterials showed two emission peaks centered at 452 and $472 \mathrm{~nm}$.

For the second type of nanomaterials obtained, $\mathrm{FePt} / \mathrm{Fe}_{3} \mathrm{O}_{4}$ magnetic nanoparticles were synthesized by modified polyol method coupled to seeded-mediated growth, and $\mathrm{CdSe} / \mathrm{ZnS}$ luminescent quantum dots were obtained by thermal decomposition of organometallic precursors. For the ligand exchange to transfer the nanostructures from organic media to aqueous solution, were used DopaPIMA-PEG-NH $\mathrm{N}_{2}$ and LA-PEG-COOH polymers to provide colloidal stability and biocompatibility on magnetic nanoparticle surface and quantum dot surface, respectively. The chemical conjugation between $\mathrm{FePt} / \mathrm{Fe}_{3} \mathrm{O}_{4}$-Dopa-PIMA-PEG-NH $\mathrm{N}_{2}$ and $\mathrm{CdSe} / \mathrm{ZnS}-\mathrm{LA}-\mathrm{PEG}-\mathrm{COOH}$ nanostructures was obtained by EDC coupling in aqueous solution, which linked amine and carboxylate groups in each nanostructure to provide the formation of amide bond. The luminomagnetic nanomaterials obtained showed colloidal stability in aqueous solution, narrow size distribution, with $\mathrm{R}_{\mathrm{H}}$ equal to $79.96 \mathrm{~nm}$, $\mathrm{M}_{\mathrm{S}}$ around 10 emu. $\mathrm{g}^{-1}$ with low coercivity and remanent magnetization, and intense emission peak centered at $580 \mathrm{~nm}$.
\end{abstract}

We expect these luminomagnetic nanomaterials be promisor nanomaterials with multifunctional properties for potential biological applications.

Keywords: luminomagnetic nanomaterials, multifunctional nanomaterials, colloidal stability, biological applications. 


\section{LISTA DE FIGURAS}

Figura 1 - Principais tipos de nanomateriais luminomagnéticos com diferentes estruturas e recobrimentos.

Figura 2 - Representações esquemáticas dos (a) domínios magnéticos como regiões com grupos de dipolos magnéticos alinhados em um mesmo sentido (setas vermelhas), separados por paredes de domínio (linhas azuis); e (b) mudança gradual dos dipolos magnéticos na região da parede entre os domínios magnéticos.

Figura 3 - Representação esquemática da (a) magnetização do material até sua Ms; e (b) curva de histerese com um ciclo de magnetização e desmagnetização do material ferromagnético.

Figura 4 - Gráfico da coercividade em função do diâmetro da partícula e o limite superparamagnético.

Figura 5 - Esquema ilustrativo para representação da influência do tamanho nas propriedades ópticas de pontos quânticos luminescentes de $\mathrm{CdSe}$.

Figura 6 - Esquema ilustrativo dos diferentes tipos de pontos quânticos com estrutura caroço/casca em cada tipo de regime de emissão de fluorescência.

Figura 7 - Diferentes modos de crescimento para formação de heteronanoestruturas entre duas diferentes nanoestruturas.

Figura 8 - Esquemas ilustrativos de nanomateriais (vermelho) recobertos com sílica (azul) sintetizados de três maneiras: (a) método de microemulsão por micela reversa; (b) recobrimento com sílica mediado por surfactantes ou polímeros (camada verde intermediária na estrutura do tipo caroço/casca); e (c) nanopartículas de sílica auto-organizadas sobre nanomateriais (a camada verde retrata uma típica arquitetura camada-por-camada).

Figura 9 - Utilização da microemulsão convencional no processo de recobrimento de nanoestruturas (em vermelho) com sílica (em azul), por duas diferentes rotas sintéticas.

Figura 10 - Principais tipos de recobrimento de polímeros baseados em PEG sobre a superfície de nanoestruturas visando aplicações biológicas.

Figura 11 - Fluxograma do procedimento utilizado para síntese das NPM de FePt (a); e $\mathrm{FePt} / \mathrm{Fe}_{3} \mathrm{O}_{4}(\mathrm{~b})$.

Figura 12 - Fluxograma (a) e patamares e rampas de aquecimento com o tempo (b) do procedimento utilizado para síntese dos pontos quânticos de CdSe.

Figura 13 - Fluxograma do procedimento utilizado para síntese das heteronanoestruturas luminomagnéticas de NPM de $\mathrm{FePt} / \mathrm{Fe}_{3} \mathrm{O}_{4}$ conjugadas com pontos quânticos de $\mathrm{CdSe}$, a partir da mudança de estabilidade coloidal do meio por adição de sal.

Figura 14 - Fluxograma do procedimento utilizado para síntese das heteronanoestruturas luminomagnéticas de NPM de $\mathrm{FePt} / \mathrm{Fe}_{3} \mathrm{O}_{4}$ conjugadas com pontos quânticos de $\mathrm{CdSe}$, a partir do método de injeção à quente do precursor de selênio no meio reacional.

Figura 15 - Fluxograma do procedimento utilizado para recobrimento com sílica na superfície das heteronanoestruturas luminomagnéticas. 
Figura 16 - (a) MET e (b) histograma de distribuição de tamanho com ajuste gaussiano da amostra A01.

Figura 17 - DRX com os respectivos padrões de difração da amostra A01

Figura 18 - Curva de magnetização da amostra A01. Em destaque, região ampliada da curva de magnetização da mesma amostra.

Figura 19 - (a) MET e (b) histograma de distribuição de tamanho com ajuste gaussiano da amostra $\mathrm{A} 02$.

Figura 20 - DRX com o respectivo padrão de difração do CdSe com estrutura cúbica da amostra A02.

Figura 21 - Espectros de absorção (a) e de emissão (excitação em 400 nm) (b) para a amostra A02.

Figura 22 - Esquema ilustrativo do método da mudança de estabilidade coloidal para a formação das heteronanoestruturas luminomagnéticas de $\mathrm{FePt} / \mathrm{Fe}_{3} \mathrm{O}_{4}$ conjugadas aos pontos quânticos de CdSe previamente preparados.

Figura 23 - MET das amostras: A03 (a), A04 (b) e A05 (c); e histograma de distribuição de tamanho com ajuste gaussiano da amostra A04 (d)

Figura 24 - (a) Espectros de absorção e (b) de emissão (excitação em 400 nm) das amostras: A03 (em preto), A05 (em vermelho) e A04 (em azul).

Figura 25 - DRX com os respectivos padrões de difração da amostra A04.

Figura 26 - MET das amostras: A04 (a) e A06 (b); e histograma de distribuição de tamanho com ajuste gaussiano da amostra A06 (c).

Figura 27 - (a) Espectros de absorção e (b) de emissão (excitação em 400 nm) das amostras: A04 (em preto) e A06 (em azul).

Figura 28 - DRX com os respectivos padrões de difração da amostra A06.

Figura 29 - Esquema ilustrativo da formação das heteronanoestruturas luminomagnéticas de $\mathrm{FePt} / \mathrm{Fe}_{3} \mathrm{O}_{4}-\mathrm{CdSe}$ pelo método de injeção a quente na presença de NPM como sementes. 68

Figura 30 - MET das amostras: A07 (a), A08 (b), A09 (c), A10 (d) e A11 (e); e histograma de distribuição de tamanho com ajuste gaussiano da amostra A09 (f).

Figura 31 - (a) Espectros de absorção e (b) de emissão (excitação em 400 nm) das amostras: A07 (em preto) e A09 (em azul), A08 (em vermelho), A11 (em verde), A10 (em amarelo).

Figura 32 - DRX com os respectivos padrões de difração da amostra A09.

Figura 33 - MET das amostras: A09 (a), A12 (b), A13 (c), e histograma de distribuição de tamanho com ajuste gaussiano da amostra A12 (d).

Figura 34 - (a) Espectros de absorção e (b) de emissão (excitação em 400 nm) das amostras: A12 (em preto), A09 (em azul), A13 (em vermelho).....

Figura 35 - DRX com os respectivos padrões de difração da amostra A12. 
Figura 36 - MET das amostras: A12 (a), A14 (b), A15 (c), e histograma de distribuição de tamanho com ajuste gaussiano da amostra A15 (d).

Figura 37 - (a) Espectros de absorção e (b) de emissão (excitação em $400 \mathrm{~nm}$ ) das amostras: A12 (em preto), A15 (em vermelho), A14 (em azul)..

Figura 38 - DRX com os respectivos padrões de difração da amostra A15.

Figura 39 - MET das amostras: A12 (a) e A16 (b); e histograma de distribuição de tamanho com ajuste gaussiano da amostra A16 (c).

Figura 40 - (a) Espectros de absorção e (b) de emissão (excitação em 400 nm) das amostras: A12 (em preto), A16 (em azul).

Figura 41 - DRX com os respectivos padrões de difração da amostra A16.

Figura 42 - Esquema ilustrativo do processo de recobrimento das heteronanoestruturas de $\mathrm{FePt} / \mathrm{Fe}_{3} \mathrm{O}_{4}-\mathrm{CdSe}$ pelo processo de microemulsão por micela reversa.

Figura 43 - MET da amostra A17 (a) e (b); e histograma de distribuição de tamanho com ajuste gaussiano da mesma amostra (c).....

Figura 44 - (a) Espectros de absorção e (b) de emissão (excitação em $400 \mathrm{~nm}$ ) das amostras: A12 (em preto), A17 (em azul).

Figura 45 - Curvas de magnetização das amostras: A01 (em preto), A12 (em vermelho) e A17 (em azul). Em destaque região ampliada das curvas de magnetização das mesmas amostras. 86

Figura 46 - Fotografias da amostras A12 e A17 na ausência (a) e (c) e na presença de campo magnético externo (b) e (d); e sob de luz UV: na ausência (e) e (g) e na presença (f) e (h) de campo magnético externo, respectivamente.

Figura 47 - Esquema ilustrativo para formação de LA-PEG-COOH a partir de moléculas de PEG.

Figura 48 - Espectro de RMN de $\mathrm{H}^{1}$ dos ligantes de LA-PEG-COOH

Figura 49 - Esquema ilustrativo da obtenção dos ligantes de Dopa-PIMA-PEG-NH2.

Figura 50 - Espectro de $\mathrm{RMN}$ de $\mathrm{H}^{1}$ dos ligantes de Dopa-PIMA-PEG- $\mathrm{NH}_{2}$

Figura 51 - Espectros de absorção (a) e emissão (b) para a amostra de CdSe/ZnS recobertos com os ligantes de TOP/TOPO.

Figura 52 - Fotografias dos pontos quânticos de CdSe/ZnS com TOP/TOPO na superfície: na ausência (a) e na presença de luz UV (b).

Figura 53 - Esquema ilustrativo para a troca de ligantes na superfície dos pontos quânticos de $\mathrm{CdSe} / \mathrm{ZnS}$.

Figura 54 - Fotografias dos pontos quânticos de CdSe/ZnS, antes da troca de ligantes dispersos em hexano, na ausência (a) e na presença de luz UV (b); e após o processo de troca de ligantes com LA-PEG-COOH, dispersos em água, na ausência (c) e na presença de luz UV (d).

Figura 55 - (a) Espectros de absorção e (b) de emissão (excitação em $380 \mathrm{~nm}$ ) para os pontos quanticos de $\mathrm{CdSe} / \mathrm{ZnS}$ recobertos com LA-PEG-COOH. 
Figura 56 - Esquema ilustrativo para a troca de ligantes com Dopa-PIMA-PEG- $\mathrm{NH}_{2}$ na superfície das $\mathrm{NPM}$ de $\mathrm{FePt} / \mathrm{Fe}_{3} \mathrm{O}_{4}$

Figura 57 - Fotografias das $\mathrm{NPM}$ de $\mathrm{FePt} / \mathrm{Fe}_{3} \mathrm{O}_{4}$ dispersas em hexano, antes a troca de ligantes (a); e dispersas em água, após a troca com os ligantes de Dopa-PIMA-PEG- $\mathrm{NH}_{2}$

Figura 58 - Medida de DLS para a amostra contendo as NPM de $\mathrm{FePt} / \mathrm{Fe}_{3} \mathrm{O}_{4}$ recobertas com Dopa-PIMA-PEG-NH

Figura 59 - Testes de estabilidade coloidal com o tempo das NPM de FePt/Fe ${ }_{3} \mathrm{O}_{4}$-Dopa-PIMAPEG- $\mathrm{NH}_{2}$ dispersas em solução PBS preparada em diferentes condições de $\mathrm{pH}$ e salinidade.

Figura 60 - Curva de histerese magnética para a amostra com as NPM de $\mathrm{FePt} / \mathrm{Fe}_{3} \mathrm{O}_{4}-\mathrm{Dopa}-$ PIMA-PEG-NH

Figura 61 - Esquema ilustrativo da reação de conjugação das NPM de $\mathrm{FePt} / \mathrm{Fe}_{3} \mathrm{O}_{4}$-Dopa-PIMAPEG-NH $\mathrm{N}_{2}$ e os pontos quânticos de CdSe/ZnS-LA-PEG-COOH, utilizando-se o método da carbodiimida.

Figura 62 - Medida de DLS para a amostra contendo os nanomateriais luminomagnéticos das NPM de $\mathrm{FePt} / \mathrm{Fe}_{3} \mathrm{O}_{4}$ com os pontos quânticos de $\mathrm{CdSe} / \mathrm{ZnS}$ recobertos com os polímeros baseados em PEG.

Figura 63 - MET da amostra dos nanomateriais luminomagnéticos das NPM de $\mathrm{FePt} / \mathrm{Fe}_{3} \mathrm{O}_{4} \mathrm{com}$ os pontos quânticos de $\mathrm{CdSe} / \mathrm{ZnS}$ recobertos com os polímeros baseados em PEG.

Figura 64 - Espectros de absorção (a) e emissão (b) para as amostras de pontos quânticos de $\mathrm{CdSe} / \mathrm{ZnS}$ recobertos com TOP/TOPO (em azul), de CdSe/ZnS recobertos com LA-PEG$\mathrm{COOH}$ (em vermelho), e de CdSe/ZnS-LA-PEG-COOH após a conjugação com as NPM de $\mathrm{FePt} / \mathrm{Fe}_{3} \mathrm{O}_{4}$-Dopa-PIMA-PEG-NH $\mathrm{N}_{2}$ (em verde). 


\section{LISTA DE TABELAS}

Tabela 1 - Condições de síntese e reagentes utilizados para obtenção das heteronanoestruturas luminomagnéticas de NPM de $\mathrm{FePt} / \mathrm{Fe}_{3} \mathrm{O}_{4}$ conjugadas com pontos quânticos de $\mathrm{CdSe}$, a partir da mudança de estabilidade coloidal do meio por adição de sal.

Tabela 2 - Condições de síntese e reagentes utilizados para obtenção das heteronanoestruturas luminomagnéticas de $\mathrm{NPM}$ de $\mathrm{FePt} / \mathrm{Fe}_{3} \mathrm{O}_{4}$ conjugadas com pontos quânticos de $\mathrm{CdSe}$, a partir do método de injeção a quente do precursor de selênio no meio reacional. 


\section{LISTA DE ABREVIATURAS E SIGLAS}

Cd(acac)2 - Acetilacetonato de cádmio

DCC - N,N-diciclohexilcarbodiimida

DLS - Espalhamento de luz dinâmico (do inglês, dynamic light scattering)

DMAP - 4-(N,N-dimetilamino)piridina

Dopa - Dopamina

DRX - Difração de raios-X

EDC - N-(3-dimetilaminopropil)-N'-etilcarbodiimida

Et3 $\mathbf{N}$ - Trietilamina

EtOAc - Acetato de etila

$\mathbf{F e}(\mathbf{a c a c}) 3$ - Acetilacetonato de ferro(III)

HDA - Hexadecilamina

HNE - Heteronanoestruturas

LA - Ácido lipóico (do inglês, lipoic acid)

MET - Microscopia eletrônica de transmissão

MsCl - Cloreto de metanossufonila

NHS - N-hidroxisuccinimida

NP - Nanopartículas

NPM - Nanopartículas magnéticas

PBS - Solução fosfato salina (do inglês, phosphate buffered saline)

PEG - Polietilenoglico

PIMA - Poli(isobutileno-alt-anidrido maléico)

$\mathbf{P P h}_{3}$ - Trifenilfosfina

$\operatorname{Pt}(\mathbf{a c a c})_{2}$ - Acetilacetonato de platina

$\mathbf{R M N}$ de $\mathbf{H}^{\mathbf{1}}$ - Ressonância magnética nuclear de próton

THF - Tetrahidrofurano

TOP - Trioctilfosfina (do inglês, trioctylphosphine)

TOPO - Óxido de trioctilfosfina (do inglês, trioctylphosphine oxide)

VSM - Magnetometria de amostra vibrante (do inglês, vibrating sample magnetometer) 


\section{SUMÁRIO}

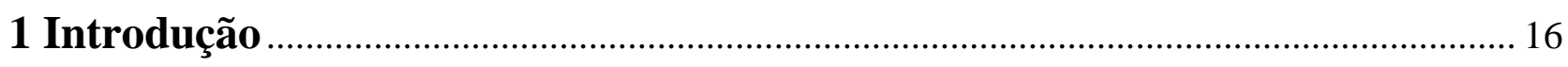

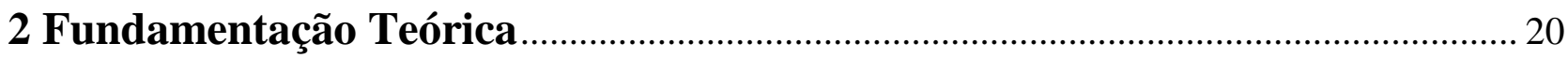

2.1 Nanopartículas magnéticas e suas propriedades .............................................................. 20

2.2 Pontos quânticos luminescentes e suas propriedades....................................................... 24

2.3 Princípios fundamentais para formação de heteronanoestruturas ........................................ 27

2.4 Recobrimentos de superfície para aplicações biológicas ................................................ 28

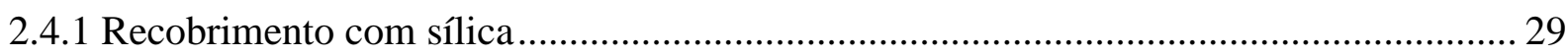

2.4.2 Recobrimento com polímeros baseados em polietilenoglicol (PEG)........................... 32

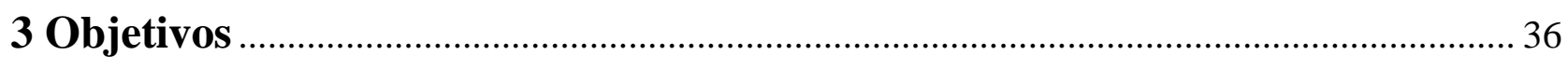

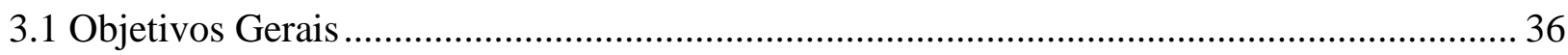

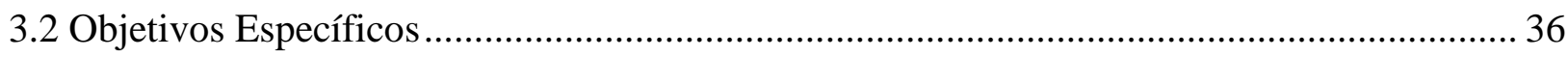

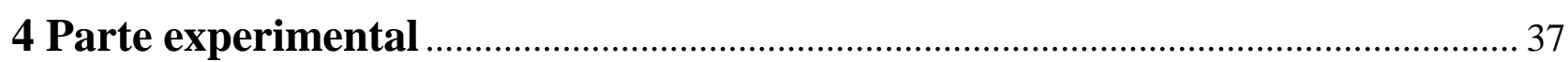

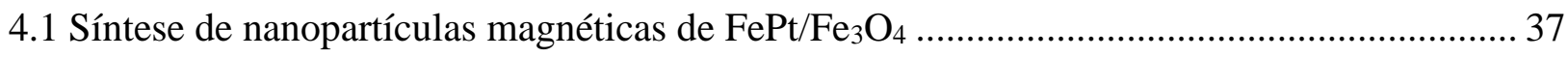

4.2 Obtenção de heteronanoestruturas de $\mathrm{FePt} / \mathrm{Fe}_{3} \mathrm{O}_{4}-\mathrm{CdSe}$ recobertas com sílica .................... 38

4.2.1 Síntese de pontos quânticos de CdSe .......................................................................... 38

4.2.2 Síntese dos nanomateriais luminomagnéticos de $\mathrm{FePt} / \mathrm{Fe}_{3} \mathrm{O}_{4}$ conjugados com $\mathrm{CdSe}$.... 39

4.2.2.1 Método de mudança da estabilidade coloidal do meio por adição de sal ................ 39

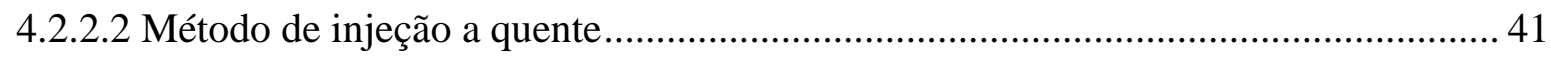

4.2.3 Recobrimento das heteronanoestruturas luminomagnéticas com sílica ........................ 43

4.3 Síntese dos nanomateriais luminomagnéticos de $\mathrm{FePt} / \mathrm{Fe}_{3} \mathrm{O}_{4}$ e $\mathrm{CdSe} / \mathrm{ZnS}$ recobertos com

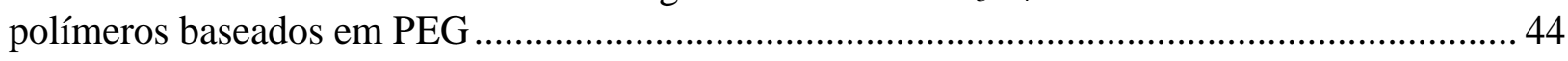

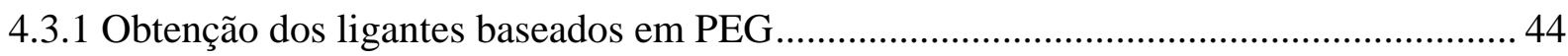

4.3.1.1 Obtenção do LA-PEG-COOH............................................................................. 44

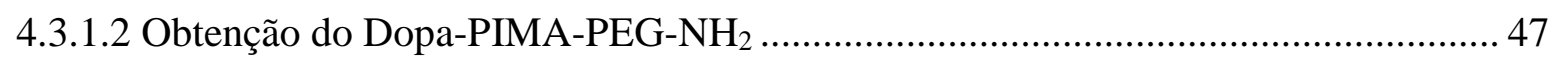

4.3.2 Síntese de CdSe/ZnS pelo método de decomposição térmica........................................ 47

4.3.3 Recobrimento dos pontos quânticos de CdSe/ZnS com LA-PEG-COOH..................... 49

4.3.4 Recobrimento das NPM de $\mathrm{FePt} / \mathrm{Fe}_{3} \mathrm{O}_{4}$ com Dopa-PIMA-PEG-NH $\mathrm{NH}_{2}$......................... 49

4.3.5 Conjugação de FePt/Fe $\mathrm{O}_{4}$-Dopa-PIMA-PEG-NH 2 e CdSe/ZnS-LA-PEG-COOH....... 50

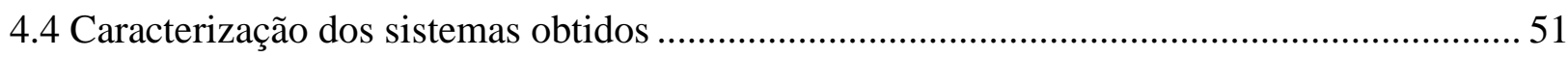

4.4.1 Microscopia Eletrônica de Transmissão (MET) …...................................................... 51

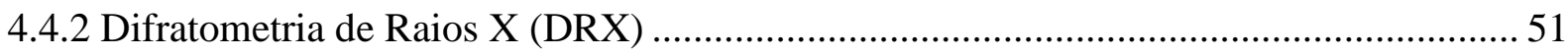




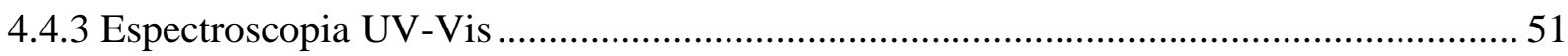

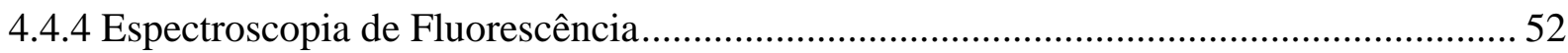

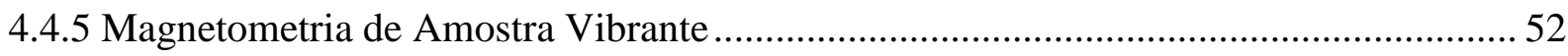

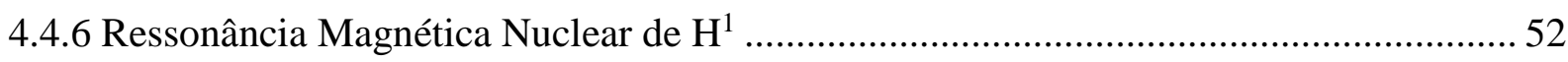

4.4.7 Espalhamento de Luz Dinâmico (DLS) ................................................................. 52

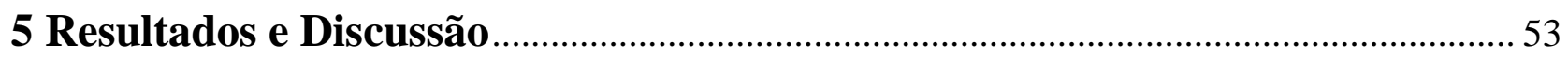

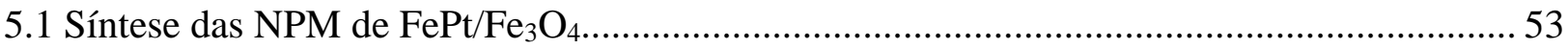

5.2 Obtenção de heteronanoestruturas de $\mathrm{FePt} / \mathrm{Fe}_{3} \mathrm{O}_{4}-\mathrm{CdSe}$ recobertas com sílica.................... 56

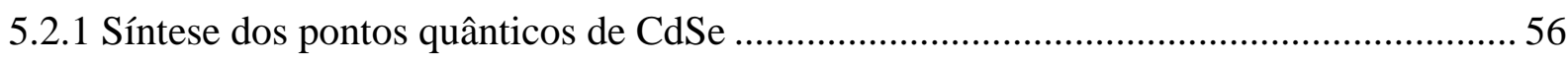

5.2.2 Obtenção das heteroestruturas luminomagnéticas de $\mathrm{NPM}$ de $\mathrm{FePt} / \mathrm{Fe}_{3} \mathrm{O}_{4}$ e pontos

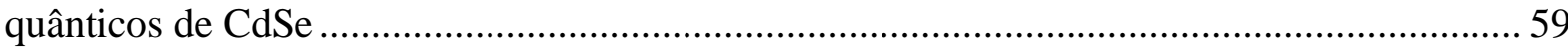

5.2.2.1 Método de modificação da estabilidade coloidal do meio reacional por adição de sal

5.2.2.1.1 Efeito da concentração de cloreto de sódio .................................................... 61

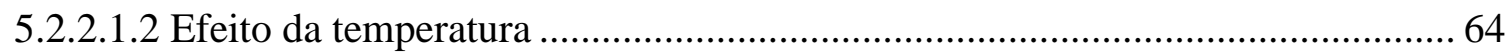

5.2.2.2 Método de injeção a quente na presença de sementes de NPM ............................. 67

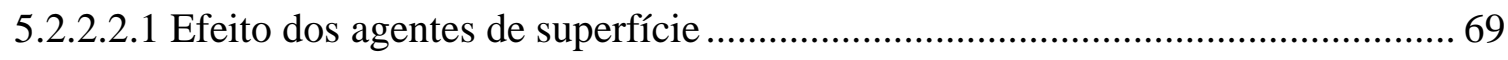

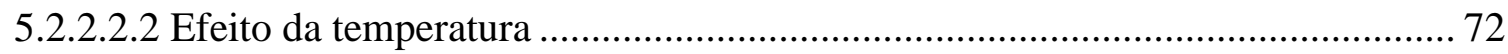

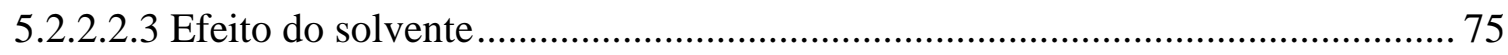

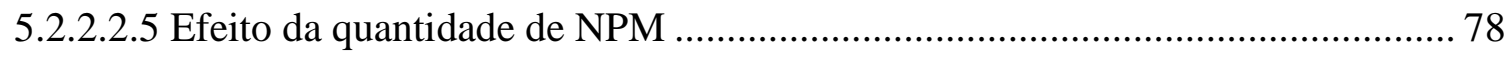

5.2.4 Recobrimento com sílica na superfície das heteronanoestruturas luminomagnéticas .... 81

5.3 Nanomateriais luminomagnéticos de $\mathrm{FePt} / \mathrm{Fe}_{3} \mathrm{O}_{4}$ e $\mathrm{CdSe} / \mathrm{ZnS}$ recobertos com polímeros

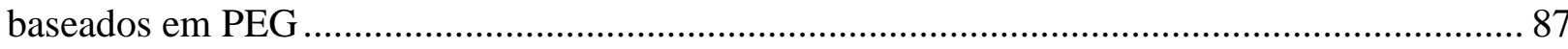

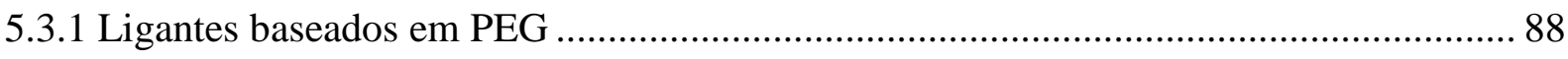

5.3.2 Pontos Quânticos de CdSe/ZnS por decomposição térmica .......................................... 92

5.3.3 Troca de ligantes fotoinduzida dos pontos quânticos de CdSe/ZnS utilizando LA-PEG-

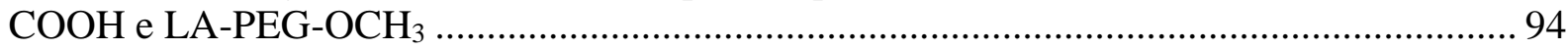

5.3.4 Trocas de ligantes das NPM de FePt/ $\mathrm{Fe}_{3} \mathrm{O}_{4}$ utilizando Dopa-PIMA-PEG- $\mathrm{NH}_{2} \ldots \ldots \ldots \ldots . . . .96$

5.3.5 Conjugação das NPM e dos pontos quânticos utilizando carbodiimida em meio aquoso

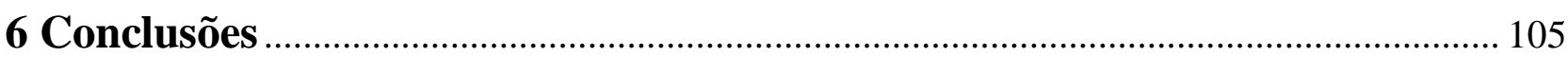

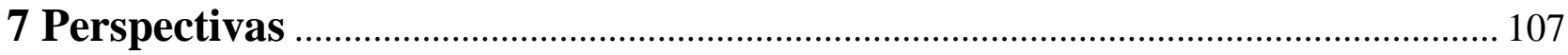

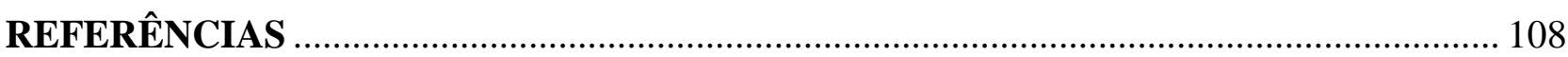




\section{Introdução}

A síntese de materiais em escala nanométrica apresenta um crescimento acentuado nas últimas décadas. Atualmente, nanopartículas (NP) de distintos materiais são utilizadas em diversas aplicações tecnológicas e biotecnológicas. ${ }^{1-3}$ Considerável destaque é dado às nanopartículas magnéticas (NPM) multifuncionais ${ }^{1,4-8}$ que exibem fenômenos superparamagnéticos e tunelamento quântico de magnetização, uma vez que cada partícula pode ser considerada como um monodomínio magnético. Adicionalmente, tais partículas podem apresentar diferentes funcionalidades advindas de sistemas nanoestruturados ou de biomoléculas associadas. ${ }^{1,5,6}$

Dentre os nanomateriais multifuncionais, destacam-se os nanomateriais luminomagnéticos, que apresentam propriedades magnéticas e luminescentes conjugadas. ${ }^{9-15}$ Essas propriedades oferecem potencial para diversas aplicações biológicas, tais como: tratamentos anti-tumorais por magneto-hipertermia ${ }^{16-18}$, realce de contrastes em imagens por ressonância magnética ${ }^{16,19}$, diagnóstico por microscopias confocal e de fluorescência ${ }^{3,20}$, separação magnética de células e moléculas, sensoriamento e carreadores de fármacos ${ }^{21-23}$. Dependendo das potenciais aplicações, nanomateriais luminomagnéticos têm sido obtidos com diferentes tipos de estruturas e conjugação, conforme exemplificado na Figura 1.

Figura 1 - Principais tipos de nanomateriais luminomagnéticos com diferentes estruturas e recobrimentos. Modificado de 12

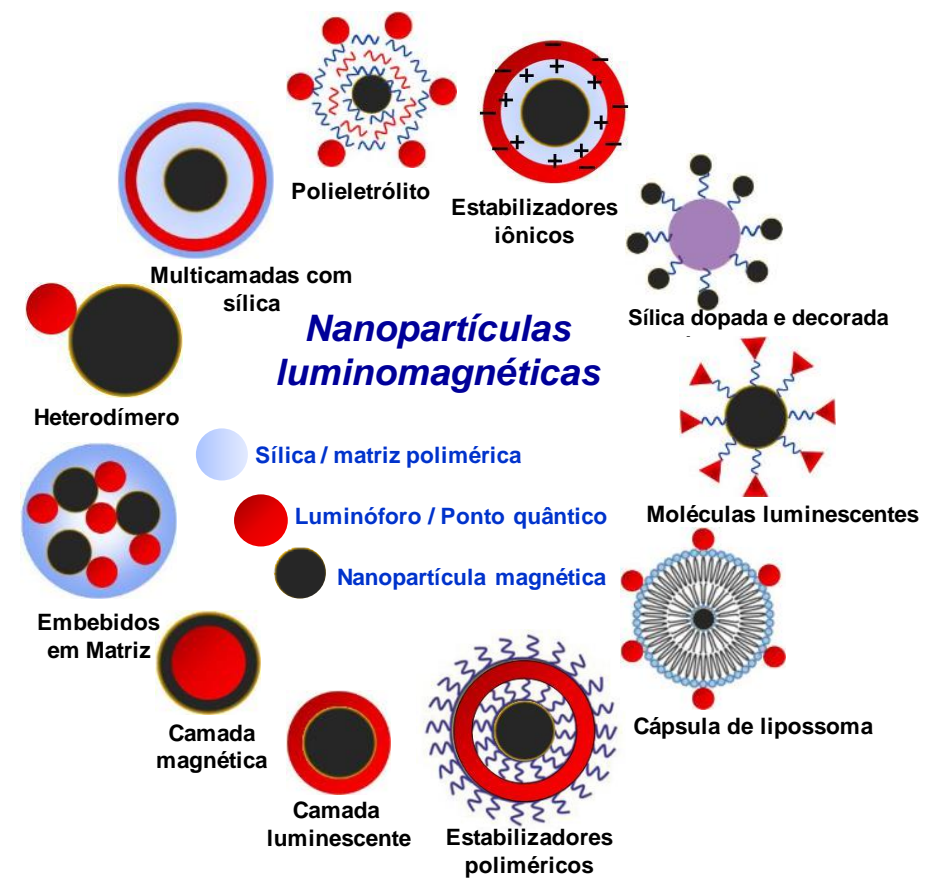


Dentre os diferentes tipos de nanomateriais luminomagnéticos, duas classes podem ser destacadas:

(1) as heteronanoestruturas (HNE), nas quais as NPM e os pontos quânticos luminescentes são ligados na superfície inorgânica de ambos nanomateriais (por exemplo, heterodímeros); (2) conjugação covalente entre as NPM e os pontos quânticos luminescentes por intermédio de cadeias poliméricas ou por moléculas.

Esses nanomateriais apresentam propriedades convenientes às aplicações biológicas, pois unem as propriedades de duas ou mais nanoestruturas no mesmo nanomaterial e podem, potencialmente, atuar em mais de um tipo de aplicação simultaneamente. ${ }^{20,24,25}$

Para a primeira classe de nanomateriais destacada anteriormente (HNE), existem muitas estratégias de síntese para a obtenção de HNE de diferentes nanomateriais luminescentes e magnéticos ${ }^{12,26-29}$. Duas estratégias podem ser destacadas para a formação destas HNE: (1) Mudança da estabilidade coloidal pela adição de sais ou de agentes desestabilizantes. ${ }^{30}$ Essa estratégia pode ser realizada com a presença de duas ou mais nanoestruturas dispersas em quantidades adequadas de agentes de superfície e em alta temperatura, para a formação de HNE devido à mudança na estabilidade coloidal das nanoestruturas individuais; e (2) Injeção à quente (do inglês, hot injection) $)^{24,26,27}$, na qual utilizam-se sementes de uma nanoestrutura, sobre a superfície da qual será formada uma segunda nanoestrutura, pela injeção a quente dos precursores desta nanoestrutura adicional. Adicionalmente, a síntese de HNE requer o controle das taxas de nucleação e crescimento, sendo que alguns dos parâmetros são: natureza e concentração dos precursores; método de adição dos precursores; temperatura de reação e taxas de aquecimento para controlar os estágios de nucleação e de crescimento; composição e propriedades físicas e químicas do solvente; e natureza e concentração dos agentes de superfície para o controle do crescimento e da conformação das HNE. ${ }^{25,26,31-34}$

Para aplicações biológicas há, muitas vezes, a necessidade de recobrimento da superfície das HNE luminomagnéticas com moléculas que aumentem sua estabilidade coloidal em meio aquoso. ${ }^{4,20,35,36}$ Essas moléculas também podem propiciar biocompatibilidade, aumentar o tempo de circulação no organismo, e diminuir a toxicidade dessas HNE em sistemas biológicos. Com esse intuito, são utilizadas estratégias de recobrimento com materiais inorgânicos, poliméricos, surfactantes e biológicos. ${ }^{37-42}$ Dentre esses materiais, a sílica tem obtido destaque na literatura. ${ }^{10,43-46}$ Usualmente, o recobrimento com sílica na superfície das HNE luminomagnéticas previne a agregação no líquido, promovendo estabilidade química e diminuição da toxicidade. Além disso, o recobrimento com sílica tem muitas vantagens decorrentes de sua estabilidade em soluções aquosas, por ser de fácil modificação de superfície 
e de fácil controle das interações inter-partículas, tanto em solução como dentro das estruturas. ${ }^{1,7,46,47}$

Já para a segunda classe de nanomateriais destacada anteriormente (ligação covalente das nanoestruturas por intermédio de polímeros), a obtenção de nanomateriais luminomagnéticos pela conjugação covalente de cadeias poliméricas ou moléculas na superfície das NPM e dos pontos quânticos luminescentes pode ser realizada a partir de diversas estratégias. ${ }^{48,49}$ Uma das estratégias mais utilizadas na literatura é a conjugação de diferentes nanoestruturas pela ligação covalente entre cadeias de polietilenoglicol (PEG) modificadas nas suas extremidades pela adição de grupos reativos, os quais possam atuar tanto na ligação destas cadeias poliméricas à superfície da nanoestrutura por uma de suas extremidades, quanto na formação de uma ligação covalente entre cadeias de PEG distintas, para união das diferentes nanoestruturas. ${ }^{50,51}$ Usualmente, para ligação covalente entre os diferentes polímeros ou mesmo diferentes moléculas na superfície de nanoestruturas, um dos métodos mais eficientes e utilizados na literatura é a formação de uma ligação amida, a partir de grupos carboxilato e amina nas extremidades de cada um dos polímeros ou moléculas. ${ }^{36,49,52}$

Entre os maiores benefícios da obtenção de nanomateriais luminomagnéticos a partir da ligação covalente entre cadeias poliméricas de PEG, é que além da estrutura como um todo ter alta estabilidade química devido à ligação covalente formada entre as estruturas, as cadeias de PEG já propiciam estabilidade coloidal, baixa toxicidade e aumento de tempo de circulação, visando aplicações biológicas. ${ }^{49,53,54}$

Desta forma, uma das propostas deste trabalho foi a obtenção de HNE luminomagnéticas com propriedades adequadas para potenciais aplicações biológicas. Com esse intuito, inicialmente, estudou-se a formação de HNE luminomagnéticas compostas por NPM de $\mathrm{FePt} / \mathrm{Fe}_{3} \mathrm{O}_{4}$ conjugadas com pontos quânticos de $\mathrm{CdSe}$. Para adequação de um procedimento ideal para obtenção destas HNE, realizaram-se duas estratégias de síntese, sendo: (1) Injeção a quente de precursor de selênio na presença de sementes de NPM e de precursor de cádmio no meio reacional; e (2) Adição de $\mathrm{NaCl}$ para mudança da estabilidade coloidal, na presença de sementes de NPM de $\mathrm{FePt} / \mathrm{Fe}_{3} \mathrm{O}_{4}$ e de pontos quânticos de $\mathrm{CdSe}$, em alta temperatura no meio reacional. Foram realizadas algumas modificações nos principais parâmetros dessas duas estratégias de síntese, com o intuito de encontrar as condições mais adequadas para a obtenção de HNE luminomagnéticas com propriedades desejadas visando potenciais aplicações biológicas. Adicionalmente, com o objetivo de aumentar a estabilidade coloidal e propiciar biocompatibilidade em sistemas biológicos, as $\mathrm{HNE}$ luminomagnéticas de $\mathrm{FePt} / \mathrm{Fe}_{3} \mathrm{O}_{4}-\mathrm{CdSe}$ 
foram recobertas com camada de sílica, a partir de um processo de microemulsão por micela reversa.

A outra proposta deste trabalho foi a obtenção de NPM de $\mathrm{FePt} / \mathrm{Fe}_{3} \mathrm{O}_{4}$ e pontos quânticos de CdSe/ZnS recobertos com polímeros baseados em PEG e conjugadas por ligação amida entre as cadeias de PEG. Para isso, primeiramente foram realizadas modificações químicas nos polímeros de PEG para alterações em suas extremidades, sendo em uma extremidade a adição de grupos funcionais para interagir com as nanoestruturas magnéticas e luminescentes e na outra extremidade a adição de grupos reativos de ácido carboxílico e amina para posterior ligação covalente entre as cadeias poliméricas. Foram sintetizadas nanoestruturas de $\mathrm{FePt} / \mathrm{Fe}_{3} \mathrm{O}_{4}$ e $\mathrm{CdSe} / \mathrm{ZnS}$ com superfícies hidrofóbicas e, após isso, foram realizadas troca de ligantes com polímeros de PEG modificados, para transferência das nanoestruturas de meio orgânico para meio aquoso, além de propiciar estabilidade coloidal para ambas nanoestruturas, magnética e luminescente. E, finalmente, foi realizada a ligação covalente entre os grupos ácido carboxílico e amina em cada uma das superfícies das nanoestruturas, para formação de ligação amida e consequente obtenção dos nanomateriais luminomagnéticos.

Para avaliação das estratégias utilizadas e da viabilidade dos nanomateriais obtidos, os sistemas, foram caracterizados quanto à distribuição de tamanho e morfologia por microscopia eletrônica de transmissão (MET) e/ou espalhamento de luz dinâmico (DLS, do inglês dynamic light scattering); estrutura cristalográfica por difração de raios-X (DRX); propriedades magnéticas e luminescentes por magnetometria de amostra vibrante (VSM, do inglês, vibrating sample magnetometer) e espectroscopia de fluorescência. Para algumas amostras foi medida a estabilidade coloidal com o tempo; e para a etapa de obtenção dos ligantes baseados em PEG, foi utilizado ressonância magnética nuclear de próton ( $\mathrm{RMN}$ de $\mathrm{H}^{1}$ ) para caracterização das cadeias poliméricas. 


\section{Fundamentação Teórica}

\subsection{Nanopartículas magnéticas e suas propriedades}

As propriedades magnéticas macroscópicas de um material são oriundas basicamente dos momentos magnéticos associados a cada elétron do material ${ }^{55}$. Há dois tipos de movimentos do elétron, o movimento orbital e o movimento de spin, e cada um desses tem um momento magnético associado, sendo estes: o momento magnético orbital e o momento magnético de $\operatorname{spin}^{55,56}$.

Para um átomo que possui muitos elétrons, os momentos magnéticos orbital e de spin de cada elétron, somam-se entre si de tal forma que o momento magnético do átomo é a soma vetorial de todos os momentos magnéticos eletrônicos, e duas possibilidades podem ocorrer:

1. Os momentos magnéticos de todos os elétrons podem estar orientados de tal forma que eles se cancelem um ao outro, e o átomo como um todo não tem momento magnético resultante. Essa condição é chamada de diamagnetismo ${ }^{56}$.

2. O cancelamento dos momentos magnéticos eletrônicos é somente parcial, e o átomo ficará com um momento magnético atômico resultante. Essa condição é chamada de paramagnetismo ${ }^{56}$.

Em sólidos estendidos, ou seja, materiais constituídos por diversos átomos, os tipos mais comuns de magnetismo que podem ocorrer são: o diamagnetismo e o paramagnetismo, entretanto, para átomos paramagnéticos, é possível ocorrer o fenômeno de ferromagnetismo, e adicionalmente podem ocorrer fenômenos como o ferrimagnetismo e antiferromagnetismo, que não serão tratados neste trabalho. Porém, todos os materiais normalmente exibem ao menos um desses tipos de magnetismo e o comportamento depende da resposta dos dipolos magnéticos eletrônicos e atômicos sob a aplicação de um campo magnético externo ${ }^{57}$.

No diamagnetismo, na ausência de um campo magnético aplicado, os átomos não apresentam momentos magnéticos resultantes e por este motivo os materiais estendidos não apresentam também um momento magnético resultante. Porém, com a aplicação de um campo magnético externo, é induzida a formação de momentos magnéticos atômicos resultantes, devido a uma mudança no movimento orbital dos elétrons. A magnitude do momento magnético induzido é extremamente pequena e em sentido oposto àquele do campo externo aplicado ${ }^{55,56}$.

No paramagnetismo, na ausência de um campo magnético externo os átomos individuais possuem momentos magnéticos atômicos resultantes, porém, suas orientações são aleatórias de tal forma que o material estendido com esse tipo de magnetismo não possui momento magnético 
total resultante. Com a aplicação de um campo magnético externo, estes dipolos atômicos estão livres para experimentarem uma rotação, de tal forma, que se alinham no mesmo sentido que o campo magnético externo, e se somam, ampliando assim a magnitude do campo magnético total $^{55-57}$.

No ferromagnetismo, alguns tipos de materiais, principalmente os metálicos, possuem um momento magnético permanente mesmo na ausência de um campo magnético externo e geralmente manifestam magnetizações muito grandes e permanentes. Isso ocorre devido a alguns efeitos cooperativos entre os momentos magnéticos dos átomos do material, que resulta em um alinhamento dos dipolos magnéticos atômicos e propicia uma magnetização remanente ou remanência $(R)$ mesmo na ausência do campo externo.

Nos materiais ferromagnéticos estendidos, existem regiões em que os momentos magnéticos estão alinhados de formas diferentes, e estas regiões se chamam domínios. Estes domínios são separados por interfaces nas quais os momentos magnéticos mudam gradualmente. Essas interfaces são denominadas paredes de domínio, e essas paredes são móveis dependendo de algumas mudanças físicas que podem ocorrer nesses materiais, como a aplicação de um campo magnético externo. Os domínios magnéticos e as paredes de domínio são representados na Figura 2..$^{56}$

Figura 2 - Representações esquemáticas dos (a) Domínios magnéticos como regiões com grupos de dipolos magnéticos alinhados em um mesmo sentido (setas vermelhas), separados por paredes de domínio (linhas azuis); e (b) mudança gradual dos dipolos magnéticos na região da parede entre os domínios magnéticos.
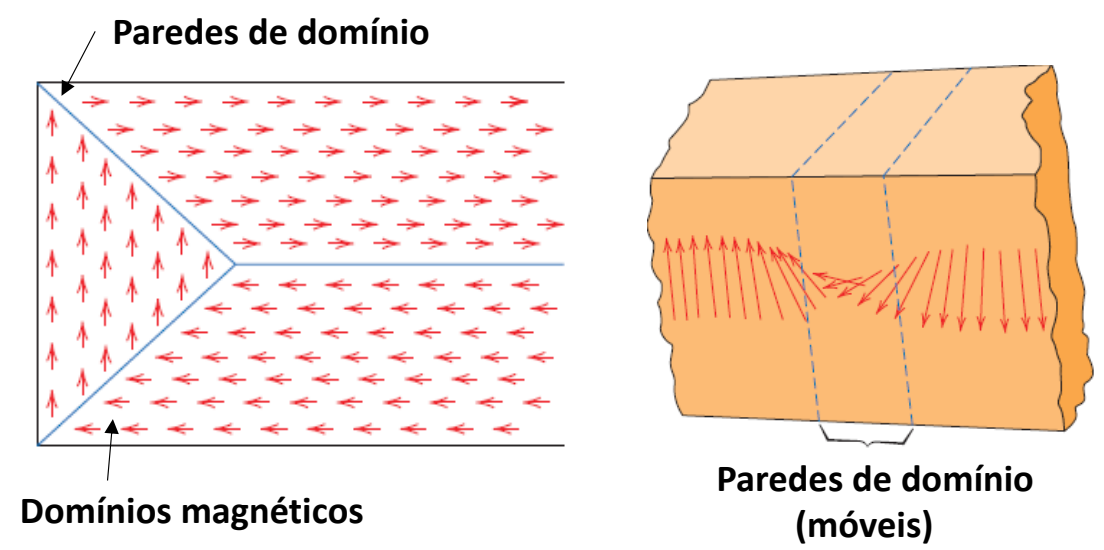

Com a aplicação de um campo magnético externo em um sólido ferromagnético estendido, ocorre um movimento das paredes de domínio desse material (Figura 3), de tal forma que os domínios com dipolos magnéticos mais favoráveis à direção e ao sentido do campo magnético externo aumentam, e os domínios com dipolos magnéticos com sentido contrário ao 
campo externo diminuem. No momento em que todos os domínios estão alinhados a favor do campo, o material chega a uma saturação em sua magnetização, e esta propriedade é denominada magnetização de saturação (Ms). Porém, quando o campo magnético externo é retirado destes materiais ferromagnéticos, ocorre uma histerese na curva de magnetização (Figura 3), devido ao forte acoplamento dos domínios magnéticos no mesmo sentido, que é formado após aplicação do campo externo. Com isso, mesmo na ausência total de um campo magnético externo, o material possui uma magnetização residual, e esta é chamada de remanência. Para retirar essa remanência do material é necessário aplicar um campo externo contrário ao sentido destes dipolos acoplados, de tal forma que torne essa remanência nula novamente, e para isso, o campo necessário para tornar a remanência nula chama-se coercividade $\left(H_{C}\right)$.

Figura 3 - Representação esquemática da (a) magnetização do material até sua Ms; e (b) curva de histerese com um ciclo de magnetização e desmagnetização do material ferromagnético.

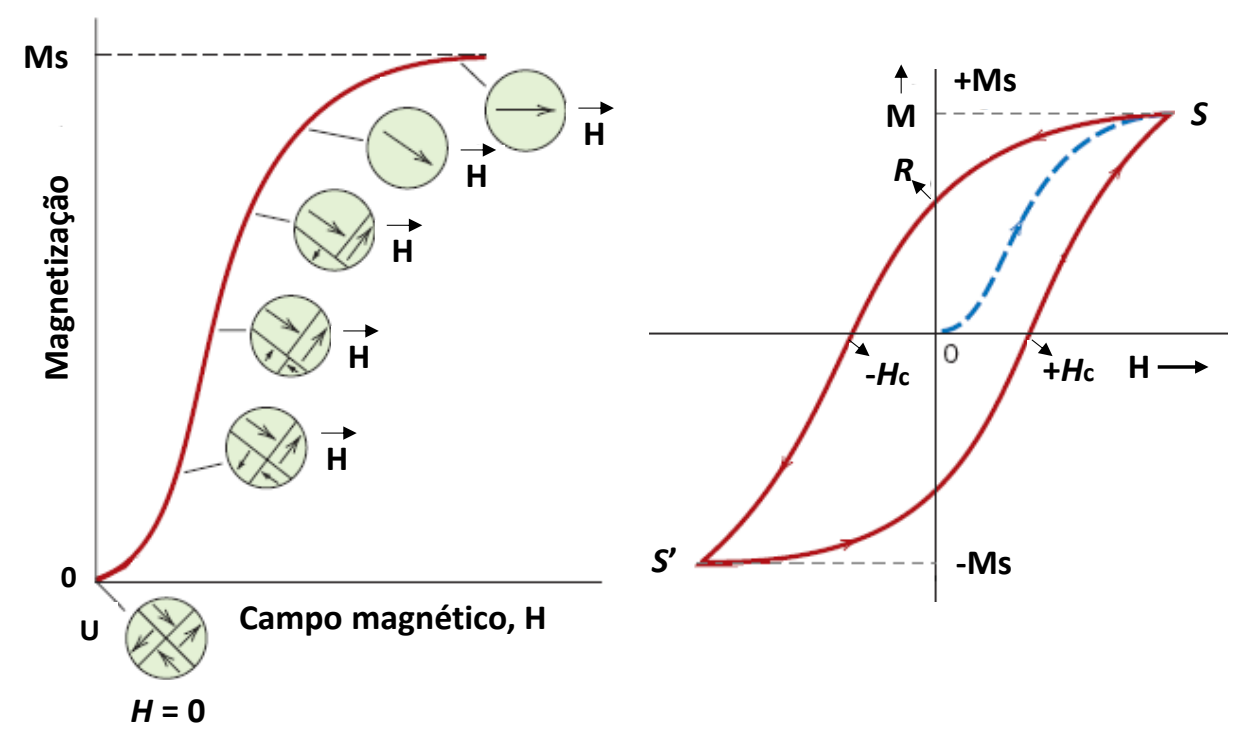

A coercividade das partículas é dependente do seu tamanho, o que pode ser observado na Figura 4, a qual mostra a variação da coercividade intrínseca do material $\left(H_{C i}\right)$ em função do diâmetro da partícula $(D)$. Na região do material estendido composto por multidomínios, a coercividade aumenta com a diminuição do diâmetro da partícula. Medidas experimentais comprovaram que, em alguns materiais, a dependência da coercividade com o tamanho da partícula é definida pela equação 1 , onde $a$ e $b$ são constantes:

$$
\mathrm{H}_{\mathrm{ci}}=\mathrm{a}+\frac{\mathrm{b}}{\mathrm{D}}
$$


Em um determinado diâmetro critico $\left(D_{S}\right)$, podendo variar de um tipo de material para outro, a partícula torna-se monodomínio e a coercividade atinge um valor máximo. Continuando com a diminuição da partícula, abaixo do $D_{S}$, a coercividade da partícula diminui, de acordo com e equação 2 , onde $g$ e $h$ são constantes:

$$
\mathrm{H}_{\mathrm{ci}}=\mathrm{g}-\frac{\mathrm{h}}{\mathrm{D}^{3 / 2}}
$$

Quando a partícula alcança um outro diâmetro critico $\left(D_{P}\right)$, a coercividade da partícula se torna nula e estas partículas são chamadas de superparamagnéticas ${ }^{58-60}$.

Figura 4 - Gráfico da coercividade em função do diâmetro da partícula e o limite superparamagnético. ${ }^{\text {Adaptada de } 56}$

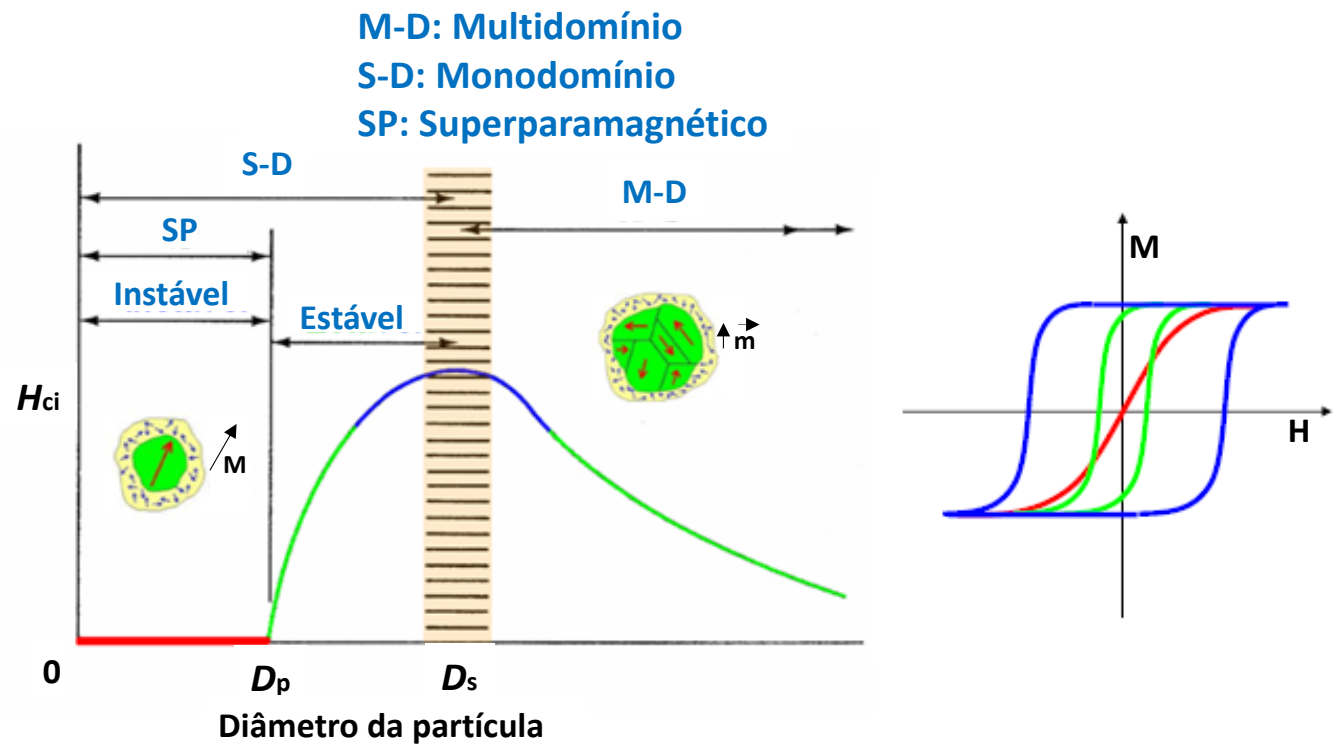

Em termos energéticos, a energia anisotrópica magnética, que é responsável por manter o momento magnético em uma determinada direção e, é dependente do volume da partícula, é mostrada na equação 3:

$$
\mathrm{E}(\theta)=\mathrm{K}_{\mathrm{ef}} \mathrm{V} \operatorname{sen}^{2} \theta
$$

onde $\mathrm{V}$ é o volume da partícula, Kef é a constante anisotrópica e $\theta$ é o ângulo entre a magnetização e o eixo de fácil magnetização. À medida que o tamanho da partícula diminui, a energia anisotrópica também diminui até que no momento que é alcançado o diâmetro critico $D_{P}$, que é o diâmetro critico que abaixo deste valor a energia anisotrópica se torna menor que a energia térmica do sistema $\left(\mathrm{K}_{\mathrm{B}} \mathrm{T}\right)$, isto causa uma flutuação do alinhamento dos dipolos magnéticos das partícula, e neste ponto o limite superparamagnético. Normalmente, o limite 
superparamagnético é atingido na faixa de tamanho que geralmente é na ordem de nanômetros. ${ }^{56,61,62}$

Para aplicações biológicas, é essencial que as NPM tenham comportamento superparamagnético à temperatura ambiente, isto é, que apresentarem valores nulos de remanência e coercividade, pois as NPM com este comportamento só apresentam magnetização quando é aplicado um campo magnético externo, sendo totalmente desmagnetizado na ausência deste campo magnético. ${ }^{57,62,63}$

\subsection{Pontos quânticos luminescentes e suas propriedades}

Nanoestruturas semicondutoras (pontos quânticos, ou do inglês, quantum dots) são partículas emissoras de luz em escala nanométrica. A principal característica dos pontos quânticos advém do efeito de confinamento quântico, o qual induz a um aprisionamento de carreadores de carga eletrônica dentro da nanoestrutura. ${ }^{64,65}$

No caso de pontos quânticos luminescentes, o efeito de confinamento quântico ocorre quando o tamanho da partícula se torna menor ou igual ao diâmetro do éxciton de $\operatorname{Bohr}\left(a_{\mathrm{B}}\right)$, que é o diâmetro para o estado de menor energia de um par elétron-buraco eletrostaticamente ligado (éxciton). $\mathrm{O} a_{\mathrm{B}}$ normalmente tem uma dimensão espacial definida entre 1 e $100 \mathrm{~nm}$, dependendo do tipo do material. Para o caso, por exemplo, de materiais compostos por seleneto de cádmio (CdSe), $a_{\mathrm{B}}=9,6 \mathrm{~nm}$. Desta forma, pontos quânticos de CdSe na faixa entre 2 e $8 \mathrm{~nm}$ apresentam propriedades ópticas e eletrônicas diferenciadas. Dentre as propriedades advindas de nanoestruturas semicondutoras de CdSe nessa faixa de tamanho estão os espectros de absorção e emissão dependentes do tamanho com transições eletrônicas discretas. Outra característica muito importante dos pontos quânticos de CdSe é que a natureza cristalina dessas partículas está associada à alta densidade de estados eletrônicos, rendendo altos valores de coeficiente de extinção e amplo espectro de absorção, que não são encontrados em fluoróforos orgânicos convencionais. ${ }^{64}$ Pela Figura 5 pode-se observar a influência do tamanho nas propriedades ópticas em pontos quânticos de CdSe. 
Figura 5 - Esquema ilustrativo para representação da influência do tamanho nas propriedades ópticas de pontos quânticos luminescentes de CdSe. Adaptado de 25,64

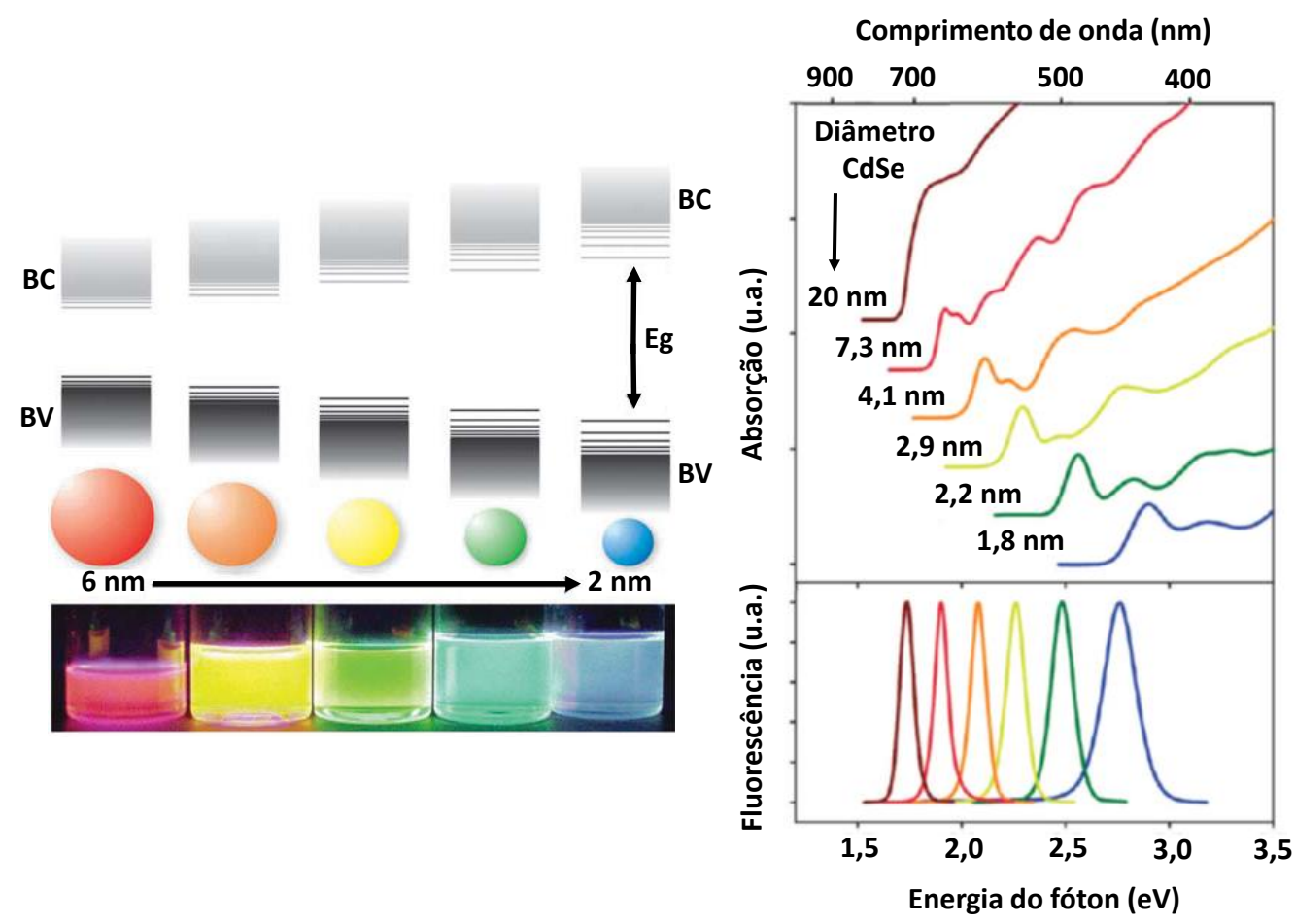

Diversas estratégias na obtenção dos pontos quânticos podem ser encontradas na literatura, visando o controle de alguns fatores e parâmetros que possam levar essas partículas a altos valores de rendimento quântico de fluorescência $\left(\Phi_{\mathrm{F}}\right)$, que é definido como à razão do número de fótons emitidos por fluorescência pelo número de fótons que foram absorvidos pelas partículas. Dentre os fatores que mais influenciam nas propriedades ópticas e no $\Phi_{\mathrm{F}}$ dos pontos quânticos estão os relacionados aos átomos de superfície da nanoestrutura. ${ }^{66,67}$

Sabe-se que a dependência das propriedades ópticas de partículas são muito relacionadas à sua estrutura interna. Entretanto, com partículas com tamanho reduzido, como ocorre com pontos quânticos com tamanho entre 2 e $8 \mathrm{~nm}$, a quantidade relativa de átomos na superfície da nanoestrutura aumenta, o que torna-se impactante na influência da superfície nas propriedades da nanoestrutura. Por exemplo, átomos na superfície de cristais facetados são incompletamente ligados ou coordenados com a rede interna da nanoestrutura. Em outras palavras, os átomos na superfície têm orbitais que não são completamente preenchidos ou passivados (do inglês, dangling bond ou dangling orbital). ${ }^{25}$ Se estes estados de energia de superfície estiverem relacionados a estrutura de bandas do ponto quântico semicondutor, eles podem interceptar os carreadores de carga na superfície da nanoestrutura e, desta forma, reduzir a sobreposição entre o par elétron-buraco formado após o processo de absorção do ponto quântico, aumentando a 
probabilidade de eventos de decaimentos não radiativos, o que diminui drasticamente o $\Phi_{\mathrm{F}}$ da nanoestrutura. Por esta razão, é essencial controlar a qualidade da superfície dos pontos quânticos, de tal forma a evitar os dangling orbitals, e este processo é conhecido como processo de passivação de superfície dos pontos quânticos. ${ }^{25}$

Normalmente, o processo de passivação de pontos quânticos pode ser atingido com o recobrimento ou a formação de uma camada na superfície dos pontos quânticos, formando-se assim uma estrutura do tipo caroço/casca (do inglês, core-shell). Esta camada pode ser formada por semicondutores com maior separação entre as bandas de valência e de condução que os pontos quânticos (por exemplo, para recobrimento sobre o CdSe, essa camada pode ser de $\mathrm{ZnS}$ ou CdS) ou pelo recobrimento de superfície com polímeros orgânicos (por exemplo, TOPO, TOP e HDA) ou sílica ${ }^{46}$.

Com relação ao recobrimento de superfície dos pontos quânticos, podem ser formados diferentes tipos de estrutura caroço/casca. Na literatura, podem ser encontrados três principais tipos de estrutura que afetam as propriedades ópticas dos pontos quânticos, sendo denominadas regimes dos tipos I, $\mathrm{I}^{1 / 2}$ e II. ${ }^{25,68,69} \mathrm{Na}$ Figura 6 podem ser vistos esquemas ilustrativos de pontos quânticos em cada um dos regimes citados anteriormente.

Figura 6 - Esquema ilustrativo dos diferentes tipos de pontos quânticos com estrutura caroço/casca em cada tipo de regime de emissão de fluorescência.

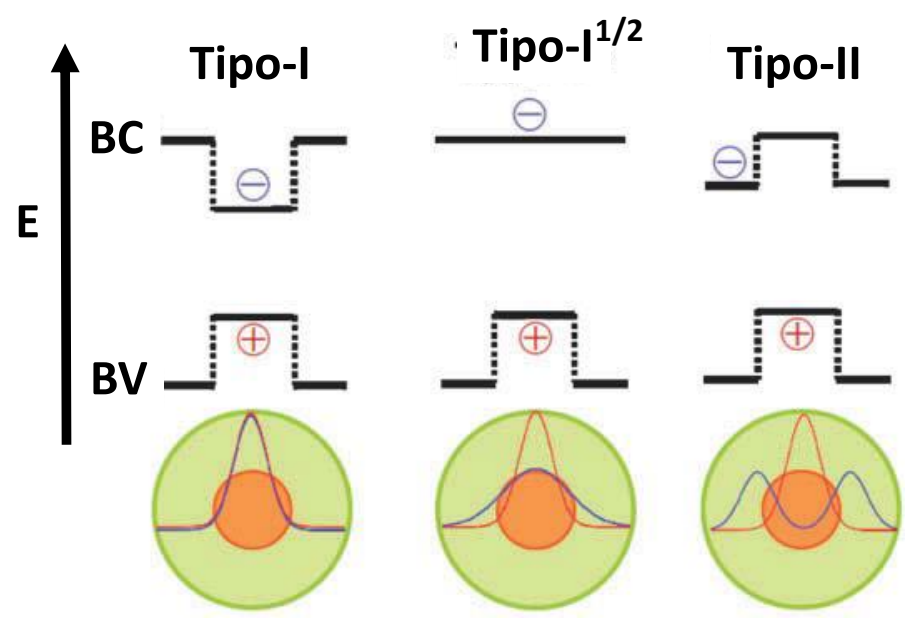

No regime do tipo I, a emissão de fluorescência do ponto quântico ocorre em bandas de valência e condução presentes na estrutura interna da semente ou material interno na estrutura caroço/casca. ${ }^{68,70}$ Portanto, nesse regime, após a fotoexcitação, o par elétron-buraco está confinado na mesma parte do ponto quântico, resultando em um éxciton direto. Alguns 
exemplos de pontos quânticos caroço/casca com regime do tipo I são: CdSe/ZnS; CdS/ZnS; entre outros. ${ }^{25}$

No regime do tipo II, os alinhamentos escalonados das bandas de energia resultam em uma separação espacial do par elétron-buraco em diferentes partes, levando a formação de um éxciton espacialmente indireto. ${ }^{69,71}$ Alguns exemplos de pontos quânticos com regime do tipo II são: CdTe/CdSe; CdSe/ZnTe; entre outros. ${ }^{25}$

Já no regime do tipo $\mathrm{I}^{1 / 2}$, o buraco formado na banda de valência do material é confinado em um dos componentes ou em uma região limitada do ponto quântico, enquanto a região com o elétron na banda de condução está deslocalizado no ponto quântico como um todo. ${ }^{72} \mathrm{Um}$ exemplo de ponto quântico com regime do tipo $\mathrm{I}^{1 / 2}$ é o $\mathrm{CdSe} / \mathrm{CdS}{ }^{25,64}$

\subsection{Princípios fundamentais para formação de heteronanoestruturas}

A formação de HNE requer a criação de uma ou mais interfaces inorgânicas entre materiais quimicamente e estruturalmente diferentes. Do ponto de vista termodinâmico, quando um material secundário é depositado sobre a superfície de uma semente e/ou substrato préexistente, a variação da energia livre de Gibbs relacionada ao processo de deposição heterogênea na superfície da semente $\left(\Delta \mathrm{G}_{\mathrm{S}}\right)$ ditará a tendência do sistema adotar diferentes modos de crescimentos. A equação 4 , que relaciona $\Delta \mathrm{G}_{\mathrm{S}}$ com as energias de superfície referentes à semente e ao material secundário pode ser definida por:

$$
\Delta \mathrm{G}_{S}=r_{1}-r_{2}+r_{1,2}
$$

onde $\Upsilon_{1}$ e $\Upsilon_{2}$ são as energias associadas à semente e ao material secundário, respectivamente; e $\Upsilon_{1,2}$ é a energia interfacial sólido/sólido. ${ }^{24-26}$

Se a energia de superfície do material secundário é menor que a energia de superfície da semente $\left(\Upsilon_{2}<\Upsilon_{1}\right)$ e/ou as duas superfícies apresentam compatibilidade cristalográfica $\left(\Upsilon_{1,2}\right.$ é muito pequeno), então a deposição do material secundário sobre a semente se dará camadasobre-camada, resultando em um recobrimento contínuo e uniforme $\left(\Delta \mathrm{G}_{\mathrm{S}}>0\right.$ : modo de crescimento de Frank-van der Merwe). Por outro lado, se o material secundário tem energia de superfície mais alta que a semente $\left(\Upsilon_{2}>\Upsilon_{1}\right)$ ou apresenta incompatibilidade de rede com a superfície da semente $\left(\Upsilon_{1,2}\right.$ é alta), então o material secundário tenderá a se depositar em forma de ilhas descontínuas, para minimizar a área interfacial em contato com a semente $\left(\Delta \mathrm{G}_{\mathrm{S}}<0\right.$ : 
modo de crescimento de Volmer-Weber). Pela Figura 7 é possível observar cada um dos modos de crescimento. ${ }^{24-27}$

Figura 7 - Diferentes modos de crescimento para formação de heteronanoestruturas entre duas diferentes nanoestruturas. ${ }^{\text {Adaptado de } 26}$

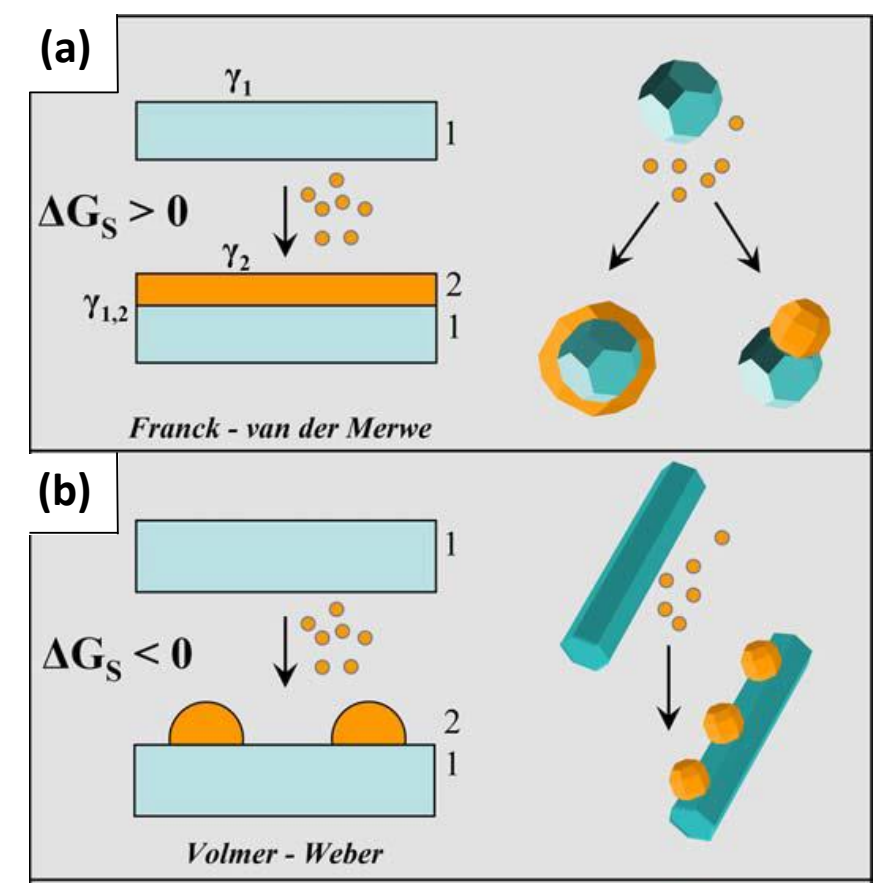

De acordo com a Teoria Clássica de Nucleação, a barreira energética necessária para o crescimento de um material por nucleação heterogênea sobre a superfície de uma semente é menor que a energia de ativação necessária para induzir uma nucleação homogênea correspondente em nanocristais separados. Nesse contexto, a nucleação heterogênea requer um potencial químico muito menor do que a nucleação homogênea para uma dada solução de monômeros que desencadeará um processo de nucleação, no qual $\Delta \mu_{h e t}<\Delta \mu_{h o m}$, sendo $\Delta \mu_{\text {het }}$ e $\Delta \mu_{\text {hom }}$ o potencial químico relacionado as nucleações heterogênea e homogênea, respectivamente. Desta forma, o processo de nucleação é facilitado na presença de superfícies de um material previamente obtido. ${ }^{24,26}$

\subsection{Recobrimentos de superfície para aplicações biológicas}

Sistemas nanoestruturados normalmente são obtidos com superfície hidrofóbica, pois majoritariamente, as estratégias de síntese envolvendo surfactante ou agentes de superfície orgânicos propiciam adequado controle de forma, tamanho e composição na obtenção das nanoestruturas. Entretanto, visando aplicações biológicas, as nanoestruturas necessitam 
apresentar superfície hidrofílica e estabilidade coloidal em meio fisiológico. Desta forma, há a necessidade de ser realizada uma troca de ligantes ou modificação dos átomos de superfície nas nanoestruturas com superfície hidrofóbica, providenciando as características desejadas para aplicações biológicas. Dentre estas características, encontram-se ${ }^{36}$ :

(1) O recobrimento da superfície das nanopartículas deve promover biocompatibilidade e reduzir interações não-específicas enquanto preserva um tamanho compacto;

(2) As nanopartículas devem exibir estabilidade em amplo intervalo de $\mathrm{pH}$, na presença de altas concentrações de eletrólitos e em meios biológicos (ricos em proteínas);

(3) Deve haver funcionalização de superfície efetiva e controlável, a qual permita ajustar o número e natureza de biomoléculas ligadas por nanopartícula, facilitando o uso desses materiais em aplicações que envolvam biodisponibilidade e especificidade.

Os principais processos de modificação de superfície citados na literatura empregam estratégias de troca de ligantes envolvendo recobrimento com sílica ou polímeros modificados com grupos reativos em uma ou nas duas extremidades, ou mesmo conjugados a biomoléculas. Alguns dos polímeros que podem ser destacados são: PEG e seus derivados; quitosana; dextrana; polivinilpirrolidona (PVP); poli(l-ácido láctico-co-ácido glicólico) PLGA; entre

outros. $^{42,73-76}$ Para este trabalho, serão utilizados o recobrimento com sílica e com compostos baseados em PEG.

\subsubsection{Recobrimento com sílica}

A sílica tem sido muito explorada como material de recobrimento para NPM, principalmente visando aplicações biológicas. Usualmente, um recobrimento inerte de sílica na superfície de NPM de magnetita previne sua agregação no líquido, promovendo estabilidade química e diminuindo a toxicidade das nanoestruturas. Esse tipo de recobrimento estabiliza as nanoestruturas geralmente de duas maneiras. A primeira delas está relacionada à blindagem parcial das interações de dipolo magnético e, a segunda, mais importante, reside na estabilização eletrostática, uma vez que a superfície da sílica encontra-se negativamente carregada em pH neutro, aumentando a repulsão coulômbica das NPM. ${ }^{1,77}$ Os recobrimentos com sílica têm muitas vantagens decorrentes de sua estabilidade em soluções aquosas, por serem de fácil modificação de superfície e de fácil controle das interações inter-partículas, tanto em solução como dentro das estruturas, através da variação da espessura da camada de recobrimento. ${ }^{1,77}$ 
O método Stöber e o processo sol-gel estão entre os processos mais utilizados para o recobrimento de NPM com sílica. ${ }^{78}$ Nesses métodos, a espessura da camada de sílica pode ser controlada pela variação da concentração de hidróxido de amônio e a razão de tetraetilortosilicato (TEOS) em água. Basicamente, esses métodos convencionais se utilizam de precursores silanos que a partir de sua hidrólise básica propicia a formação da camada de sílica quando em uma solução aquosa com as NPM presentes no meio reacional. ${ }^{1,79}$

Dentre as mais utilizadas estratégias de síntese para recobrimento com sílica, existem três que estão sendo extensamente utilizadas: (i) nanopartículas, tais como: colóides metálicos, NPM e nanoestruturas semicondutoras são recobertas utilizando-se o método de microemulsão por micela reversa (água em óleo); (ii) recobrimento de NP inorgânicas com sílica, mediados e estabilizados por agregados poliméricos e surfactantes; e (iii) organização de colóides de sílica em nano e micropartículas por diferentes estratégias de adsorção física. Na Figura 8 podem ser observadas cada uma das diferentes estratégias de recobrimento com sílica. ${ }^{47}$

Figura 8 - Esquemas ilustrativos de nanomateriais (vermelho) recobertos com sílica (azul) sintetizados de três maneiras: (a) método de microemulsão por micela reversa; (b) recobrimento com sílica mediado por surfactantes ou polímeros (camada verde intermediária na estrutura do tipo caroço/casca); e (c) nanopartículas de sílica autoorganizadas sobre nanomateriais (a camada verde retrata uma típica arquitetura camada-por-camada). ${ }^{\text {Adaptado de } 47}$

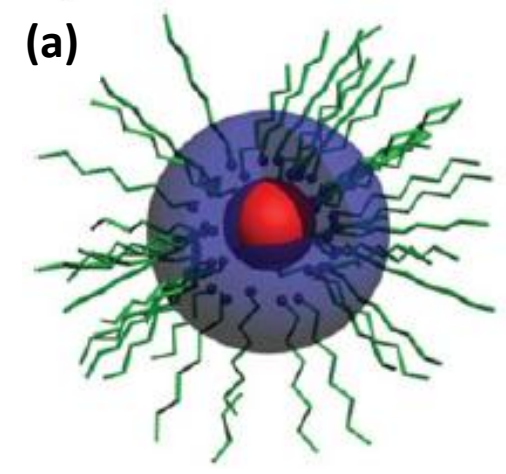

(b)

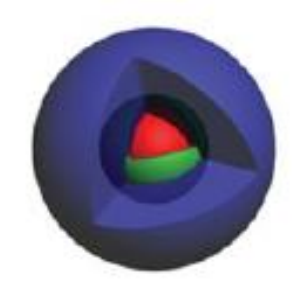

(c)

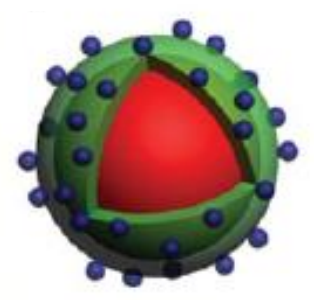

Microemulsões por micela reversa são extremamente úteis como nanoreatores confinados para síntese de partículas e recobrimento com sílica em escala nanométrica ${ }^{80}$, visto que elas podem eficientemente dissolver sais inorgânicos e precursores organometálicos, bem como nanoestruturas pré-sintetizadas, fornecendo então flexibilidade suficiente para sintetizar nanoestruturas com diversas formas, tamanhos e funções. ${ }^{46,47,81}$ Como as microemulsões são sistemas termodinamicamente estáveis, ambos os compostos contidos nas gotículas de água e as moléculas de surfactante nas interfaces são constante e rapidamente trocados entre as 
diferentes gotículas, facilitando assim reações químicas envolvidas na síntese da partícula. Isto significa que em quase todos sistemas microemulsionados, tanto o conteúdo presente na gotícula quando as moléculas de surfactante nas interfaces são trocadas entre diferentes partículas. $^{47,82}$

Várias são as abordagens para o recobrimento com sílica de NP inorgânicas dentro de microemulsões por micela reversa. $\mathrm{Na}$ mais simples e utilizada metodologia, núcleos previamente sintetizados são recobertos com sílica dentro das gotículas de água, ao passo que em um segundo procedimento, ambos a síntese dos núcleos e o processo de silanização ocorrem no interior da micela. As duas diferentes abordagens são resumidas na Figura 9. Essa figura ilustra as duas possibilidades de rota sintética para recobrimento com sílica, sendo que na primeira rota sintética, as nanoestruturas são previamente sintetizadas (1A) e transferidas para micelas reversas estáveis preparadas pela agitação de solvente orgânico, água e surfactante (2A). Na segunda síntese, ambas a solubilização e a reação dos precursores do nanomaterial acontecem dentro da micela reversa (1B e 2B) e é seguida pela hidrólise e condensação de TEOS no interior da micela (3). Após a reação e a lavagem, núcleos com tamanho e espessura de revestimento podem ser experimentalmente controlados (4). Em uma etapa complementar, os núcleos dos nanomateriais podem ser substituídos por outros, por exemplo, a partir de processos térmicos ou físicos (5) e reação de um segundo precursor (6). ${ }^{47}$

Figura 9 - Utilização da microemulsão convencional no processo de recobrimento de nanoestruturas (em vermelho) com sílica (em azul), por duas diferentes rotas sintéticas. $^{\text {Adaptado de } 47}$

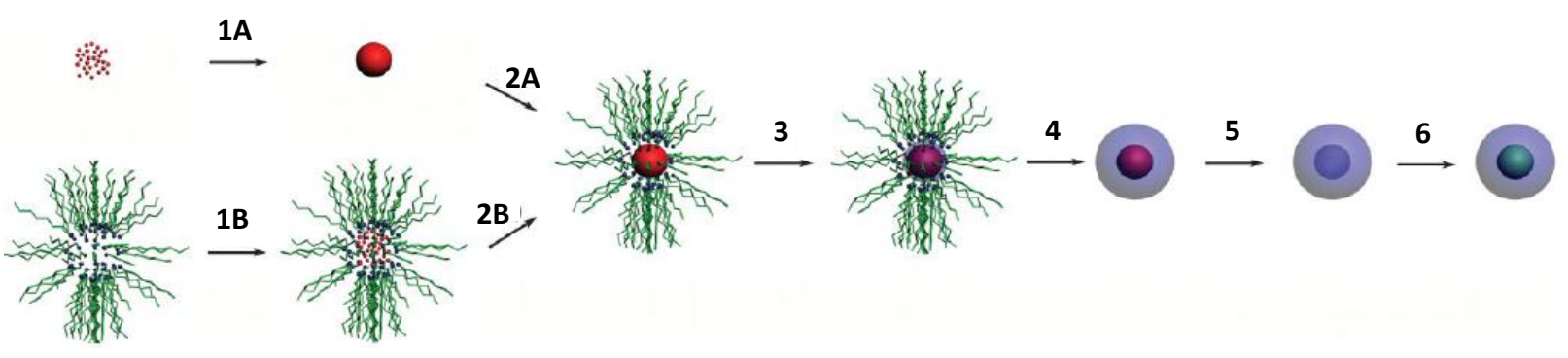

Um fator altamente relevante no projeto de uma microemulsão é a escolha do surfactante, o qual é crucial para determinar o tamanho e forma dos nanoreatores no interior da micela. $\mathrm{O}$ tamanho e a natureza do micro-reator terão forte influência na homogeneidade do recobrimento, e no tamanho e forma das nanoestruturas sintetizadas no seu interior. ${ }^{47}$ 


\subsubsection{Recobrimento com polímeros baseados em polietilenoglicol (PEG)}

Na literatura, vem sendo bastante reportada a utilização de ligantes baseados em PEG para recobrimento e estabilização de NPM de óxido de ferro, pontos quânticos luminescentes e NP de ouro. ${ }^{54,73,83-86}$ Ligantes baseados em PEG na superfície das NP aumentam drasticamente o tempo de circulação no sangue, por minimizar ou eliminar a adsorção de proteínas sobre as NP. ${ }^{11,87} \mathrm{O}$ PEG propicia também diversas propriedades adicionais às NP, dentre elas: fácil excreção pelos rins, e baixa energia livre interfacial em água. Além disso, tem sido demonstrado que NP recobertas com PEG modificados podem interagir com membranas celulares resultando em um aumento da resposta celular e seletividade a alguns tecidos. ${ }^{87}$

O recobrimento com PEG pode ser providenciado de diferentes maneiras, sendo as principais:

(1) Recobrimento direto em nanoestruturas, no qual as moléculas de PEG são diretamente adsorvidas na superfície da nanoestrutura através de interações físicas. Esse processo pode ser realizado com a presença das nanoestruturas em um meio contendo excesso de PEG;

(2) Conjugação com PEG monofuncionais, ou seja, prévia conjugação de grupos funcionais e reativos em uma das extremidades das moléculas de PEG. Esse procedimento tem sido muito utilizado para conjugação de moléculas de PEG diretamente na superfície de nanoestruturas por intermédio de fortes interações químicas. Essa estratégia é particularmente utilizada quando a superfície dos materiais nanoestruturados apresenta grande afinidade com grupos funcionais específicos, havendo uma seletividade para ligação desta extremidade das moléculas de PEG com a superfície das nanoestruturas inorgânicas;

(3) Conjugação com moléculas de PEG bifuncionais na superfície das nanoestruturas. Nessa estratégia, pode ser providenciada a conjugação de grupos funcionais em ambas extremidades das moléculas de PEG, sendo que, usualmente, em uma das extremidades é conjugado um grupo funcional ancorante, que providencia mais afinidade com a superfície inorgânica das nanoestruturas. Na outra extremidade das cadeias de PEG, normalmente são conjugadas moléculas com grupos biosseletivos, que providenciará ou será relacionada com atividades funcionais específicas no meio biológico, como bioseletividade em membranas celulares específicas, atividades terapêuticas para doenças 
específicas, ou mesmo conjugação de outros tipos de nanoestruturas que providenciarão propriedades adicionais ao material nanoestruturado.

(4) Outra estratégia que vem sendo estudada é a utilização de um polímero que atua como uma plataforma de conjugação, onde são associadas diversas moléculas de PEG, além de outras moléculas com grupos que possam coordenar na superfície inorgânica das nanoestruturas. Essa plataforma polimérica apresenta diversos grupos funcionais reativos, os quais podem ser conjugados tanto com grupos que possam ancorar na superfície de nanoestruturas, quanto com cadeias poliméricas, como o PEG, que possam providenciar biocompatibilidade, entre outras características visando aplicações biológicas. Polímeros formados com esse tipo de plataforma polimérica, conjugadas com diversas moléculas de PEG e grupos com afinidade com nanoestruturas, apresentam excelentes propriedades relacionadas à estabilidade coloidal, citotoxicidade e estabilidade química desses sistemas em meio aquoso ou biológico. ${ }^{36,40,73,83,85,86}$

Na Figura 10, podem-se observar algumas das principais maneiras citadas na literatura para recobrimento com PEG ou polímeros baseados em PEG sobre a superfície de nanoestruturas visando aplicações biológicas.

Figura 10 - Principais tipos de recobrimento de polímeros baseados em PEG sobre a superfície de nanoestruturas visando aplicações biológicas.

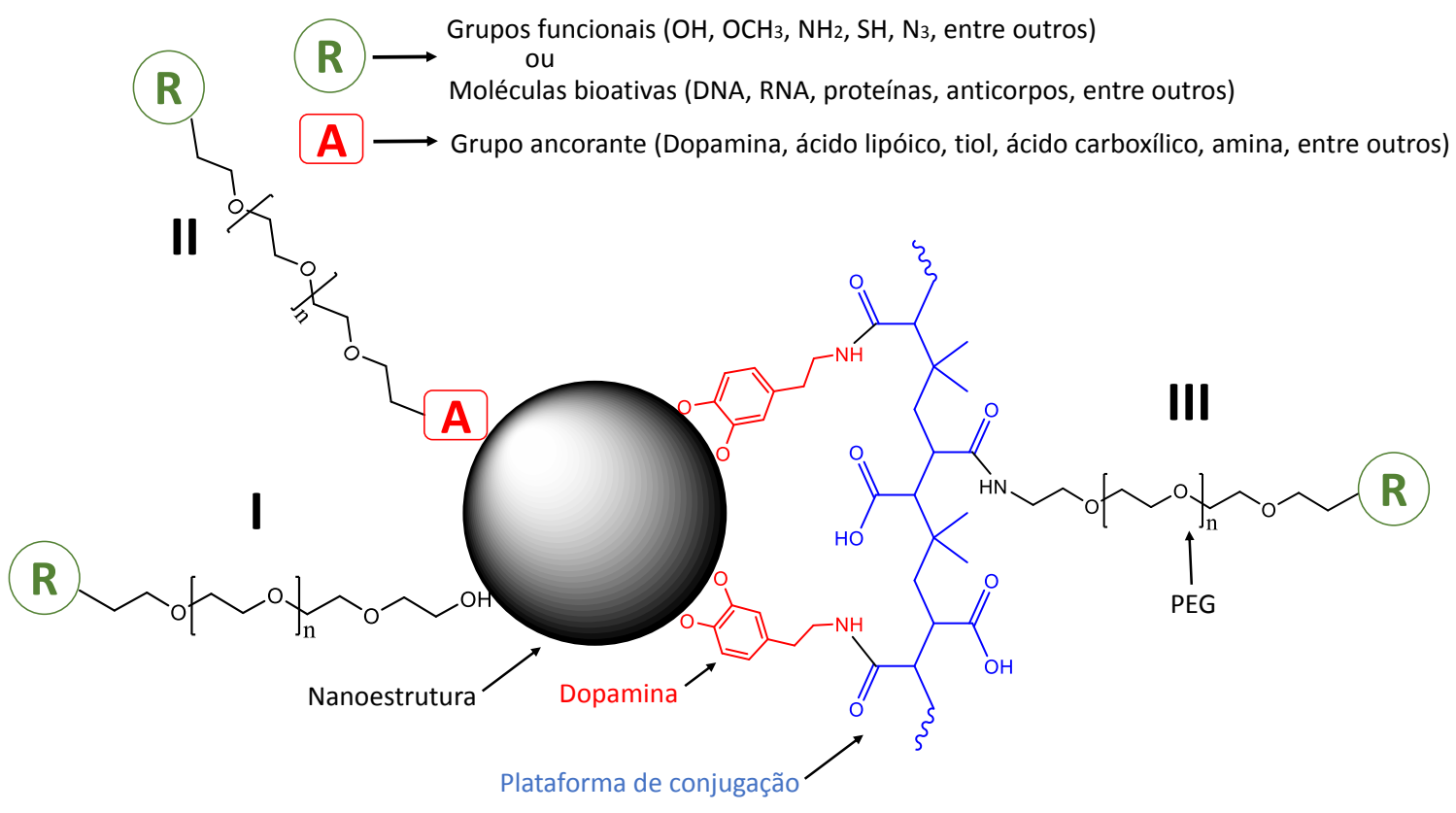


Com relação às principais estratégias de recobrimento com polímeros baseados em PEG (Figura 10), podem-se destacar três principais estratégias de recobrimento. Conforme visto na Figura 10, na região I é demonstrado um tipo de recobrimento no qual o PEG adsorve (por adsorção física ou eletrostática) diretamente na superfície das nanoestruturas, que tem a vantagem de ser um método mais simples para recobrimento, porém com estabilidade química e coloidal menor que nos outros tipos de recobrimento. Na região II, pode ser visto o PEG com uma modificação em sua extremidade, na qual é conjugado um grupo ancorante, que tem afinidade e especificidade com a superfície de nanoestruturas inorgânicas, o que aumenta a estabilidade química e coloidal das nanoestruturas com o tempo e sob diferentes condições. E, finalmente, na região III, é destacada a utilização de um polímero intermediário (entre o grupo ancorante e as cadeias de PEG) que atua como uma plataforma de conjugação. Essas plataformas poliméricas vêm sendo utilizada em diversos trabalhos por propiciarem uma forte ligação de diversas cadeias de PEG e grupos ancorantes por plataforma polimérica, o que aumenta a estabilidade química e coloidal com o tempo e sob condições extremas, quando comparado com as outras estratégias de recobrimento.

Conforme dito anteriormente, a presença do grupo ancorante em uma das extremidades das cadeias de PEG, ou mesmo das plataformas poliméricas, é essencial para aumentar drasticamente a afinidade e especificidade das cadeias poliméricas com a superfície de diversos tipos de nanoestruturas. Têm sido destacado na literatura diversos grupos funcionais que podem interagir com nanoestruturas, tais como: $\mathrm{NPM}$ de $\mathrm{Fe}_{3} \mathrm{O}_{4}, \mathrm{NP}$ de ouro ou pontos quânticos de $\mathrm{CdSe}$ e $\mathrm{CdSe} / \mathrm{ZnS}$. Por exemplo, alguns grupos funcionais que interagem fortemente com NPM de $\mathrm{Fe}_{3} \mathrm{O}_{4}$ são: carboxilato, fosfato e catecol, sendo o último presente na dopamina (Dopa, demonstrada na região III da Figura 10), moléculas que tem alta afinidade por NPM. ${ }^{36,88}$ Já para os pontos quânticos, como o $\mathrm{CdSe} / \mathrm{ZnS}$, grupos que apresentam bastante afinidade por sua superfície são: tiol, imidazola, ditiol, ou mesmo ácido lipóico, que apresenta um anel com ditiol que forma uma interação bidentada quando interage com a superfície dos pontos quânticos. ${ }^{39,89,90}$ Além disso, existem outros grupos ancorantes, tais como: amina, hidroxila, entre outros, que apresentam bastante afinidade por superfícies metálicas e de óxidos metálicos, e que podem ser utilizadas para um recobrimento efetivo na superfície de nanoestruturas.

Já com relação às plataformas de conjugação, que providenciam grupos reativos nos quais diversas moléculas ou cadeias poliméricas podem ser conjugadas, existem alguns trabalhos com polímeros, tais como: o ácido acrílico e o poli(isobutileno-alt-anidrido maléico) (PIMA), que apresentam promissoras propriedades relacionadas com estabilidade química e coloidal, e quando associadas com cadeias poliméricas tais como de PEG, podem providenciar 
biocompatibilidade e baixa toxicidade quando utilizados em aplicações biológicas. Mais especificamente, a utilização de polímeros de PIMA (que foi ilustrada como plataforma de conjugação na região III da Figura 10), propicia características muito promissoras para sistemas poliméricos de recobrimento, já que apresenta características peculiares, tais como ${ }^{88}$ :

(1) Os grupos de anidrido maléico são altamente reativos, quando na presença de moléculas que contenham grupo amina;

(2) A reação de conjugação com amina pode ser realizada em meio orgânico e sem a necessidade de reagentes adicionais (por exemplo, carbodiimida), o que simplifica as etapas de purificação e caracterização dos materiais;

(3) A grande quantidade e a disponibilidade de grupos anidrido maléico por cadeia polimérica permite uma simples e controlada inserção de diversas cadeias de PEG e de grupos coordenantes ou ancorantes no mesmo polímero, o qual melhora a estabilidade e a biocompatibilidade do ligante e a afinidade de ligação entre as nanoestruturas e o polímero;

(4) A presença de grupos dimetil entre os anéis anidridos adjacentes na estrutura do PIMA reduz o impedimento estérico e aumenta a sua reatividade, permitindo alto índice de substituição durante a reação de adição.

Além da conjugação de grupos ancorantes ou plataforma poliméricas em cadeias de PEG, outra estratégia que pode ser utilizada é a utilização de grupos funcionais na outra extremidade dessas cadeias. Em outras palavras, a conjugação de grupos funcionais e/ou moléculas bioativas na extremidade que não tem contato direto com a superfície das nanoestruturas e possam atuar em funções específicas, tais como: biosseletividade, ação terapêutica ou sensoriamento em membranas de células. ${ }^{91}$ 


\section{Objetivos}

\subsection{Objetivos Gerais}

- Desenvolver diferentes tipos de nanomateriais luminomagnéticos com propriedades magnéticas e luminescentes integradas e emanação magnética intensificada com potencialidades em aplicações biológicas.

\subsection{Objetivos Específicos}

(i) Sintetizar NPM monodispersas de $\mathrm{FePt} / \mathrm{Fe}_{3} \mathrm{O}_{4}$ (caroço/casca) pelo processo do poliol modificado acoplado com a metodologia do crescimento mediado por sementes visando a obtenção de partículas com tamanho, morfologia e composição controlados, alta magnetização de saturação e comportamento superparamagnético;

(ii) Obter HNE luminomagnéticas ancorando pontos quânticos fluorescentes de CdSe na superfície de NPM de $\mathrm{FePt} / \mathrm{Fe}_{3} \mathrm{O}_{4}$ por duas diferentes estratégias de síntese: método de injeção a quente de precursores de selênio e cádmio na presença de sementes de NPM; e método de mudança da estabilidade coloidal das NPM de $\mathrm{FePt} / \mathrm{Fe}_{3} \mathrm{O}_{4}$ e dos pontos quânticos de CdSe (previamente sintetizados) pela adição de sal;

(iii) Recobrir com sílica a superfície das HNE luminomagnéticas obtidas na etapa (ii), buscando as melhores condições de biocompatibilidade e estabilidade coloidal, além de grupos terminais que possibilitem posterior funcionalização e minimizem a supressão da luminescência dos pontos quânticos no meio fisiológico;

(iv) Obter nanomateriais luminomagnéticos com a conjugação por ligação covalente entre as $\mathrm{NPM}$ de $\mathrm{FePt} / \mathrm{Fe}_{3} \mathrm{O}_{4}$ recobertas com os ligantes de DOPA-PIMA-PEG-NH $\mathrm{NH}_{2}$ e os pontos quânticos luminescentes de CdSe/ZnS recobertos com os ligantes de LA-PEG-COOH;

(v) Caracterizar as propriedades morfológicas, estruturais, luminescentes e magnéticas, e a estabilidade coloidal dos diferentes sistemas magnéticos, luminescentes e luminomagnéticos. 


\section{Parte experimental}

Durante todas as etapas de preparação das amostras no desenvolvimento deste trabalho, foram utilizados reagentes com grau analítico e sem tratamento prévio.

\subsection{Síntese de nanopartículas magnéticas de $\mathrm{FePt} / \mathrm{Fe}_{3} \mathrm{O}_{4}$}

As NPM de $\mathrm{FePt} / \mathrm{Fe}_{3} \mathrm{O}_{4}$ utilizadas como sementes para obtenção das $\mathrm{HNE}$ luminomagnéticas foram obtidas a partir do processo do poliol modificado acoplado com a metodologia de crescimento mediado por sementes. ${ }^{92-94}$

Primeiramente, como observado na Figura 11(a), foram sintetizadas as NP de FePt, de acordo com a seguinte metodologia: uma mistura de $0,6 \mathrm{mmol}$ de acetilacetonato de platina $\left(\mathrm{Pt}(\mathrm{acac})_{2}\right), 0,73 \mathrm{mmol}$ de acetilacetonato férrico $\left(\mathrm{Fe}(\mathrm{acac})_{3}\right)$ e 1,5 $\mathrm{mmol}$ de 1,2-hexadecanodiol em $20 \mathrm{~mL}$ de dibenzileter foi inicialmente aquecida, com uma rampa de aquecimento de 3 ${ }^{\circ} \mathrm{C} / \mathrm{min}$, até $100{ }^{\circ} \mathrm{C}$, permanecendo durante $20 \mathrm{~min}$. Decorrido esse tempo, ácido oléico e oleilamina foram adicionados à mistura inicial e o sistema foi aquecido (rampa de aquecimento de $5{ }^{\circ} \mathrm{C} / \mathrm{min}$ ) à $200{ }^{\circ} \mathrm{C}$, permanecendo nessa temperatura durante $60 \mathrm{~min}$. Após isso, o sistema foi aquecido $\left(10{ }^{\circ} \mathrm{C} / \mathrm{min}\right)$ à temperatura de refluxo do dibenziléter $\left(298^{\circ} \mathrm{C}\right)$, permanecendo por 30 min em refluxo. Então, após o término desse processo, o sistema foi resfriado à temperatura ambiente e foram realizadas três lavagens das NPM obtidas com mistura de hexano/etanol, sendo separadas por centrifugação durante 15 min a $10.000 \mathrm{rpm}$.

As NPM de FePt obtidas no processo anterior foram utilizadas como semente no meio reacional para o crescimento de uma camada de magnetita $\left(\mathrm{Fe}_{3} \mathrm{O}_{4}\right)$ a partir de um processo de crescimento mediado por sementes (Figura 11(b)). O procedimento foi feito da seguinte maneira: uma mistura de $250 \mathrm{mg}$ de NPM de FePt, 5 mmol de Fe(acac), 15 mmol de 1,2hexadecanodiol, $5 \mathrm{mmol}$ de ácido oleico e $5 \mathrm{mmol}$ de oleilamina em $20 \mathrm{~mL}$ de dibenzileter foi inicialmente aquecida, com uma rampa de aquecimento de $5{ }^{\circ} \mathrm{C} / \mathrm{min}$, até $100{ }^{\circ} \mathrm{C}$, permanecendo durante 20 min. Decorrido esse tempo, o sistema foi aquecido (rampa de aquecimento de 10 ${ }^{\circ} \mathrm{C} / \mathrm{min}$ ) à $200{ }^{\circ} \mathrm{C}$, permanecendo nessa temperatura durante $60 \mathrm{~min}$. Após isso, o sistema foi aquecido $\left(15^{\circ} \mathrm{C} / \mathrm{min}\right)$ à temperatura de refluxo do dibenziléter $\left(298^{\circ} \mathrm{C}\right)$, permanecendo por 30 min em refluxo. Após o término desse processo, o sistema foi resfriado à temperatura ambiente e foram realizadas três lavagens das NPM obtidas com mistura de hexano/etanol sendo separadas por centrifugação durante 15 min a $10.000 \mathrm{rpm}$. 
Figura 11 - Fluxograma do procedimento utilizado para síntese das NPM de FePt (a); e $\mathrm{FePt} / \mathrm{Fe}_{3} \mathrm{O}_{4}(\mathrm{~b})$.

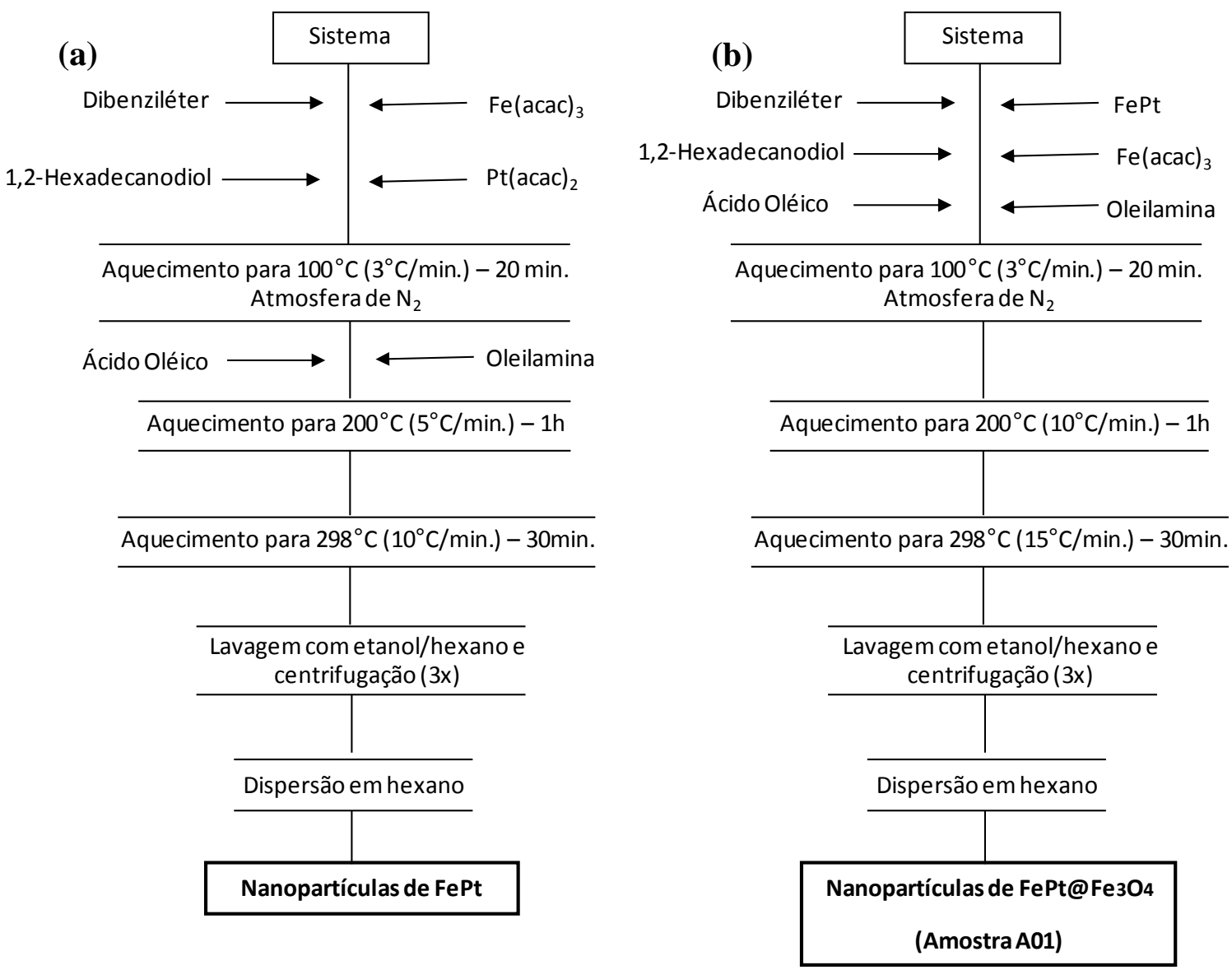

\subsection{Obtenção de heteronanoestruturas de $\mathrm{FePt} / \mathrm{Fe}_{3} \mathrm{O}_{4}-\mathrm{CdSe}$ recobertas com sílica}

\subsubsection{Síntese de pontos quânticos de CdSe}

Os pontos quânticos de CdSe utilizados para obtenção das heteroestruturas luminomagnéticas foram sintetizados pelo método de síntese denominado injeção a quente (do inglês, hot injection). ${ }^{95}$

Como observado na Figura 12, os pontos quânticos foram obtidos pela seguinte rota sintética: em um sistema com fluxo de nitrogênio, uma mistura de $0,5 \mathrm{mmol}$ de acetilacetonato de cádmio $\left(\mathrm{Cd}(\mathrm{acac})_{2}\right), 1 \mathrm{mmol}$ de ácido oleico, $1 \mathrm{mmol}$ de oleilamina e $1 \mathrm{mmol}$ de 1,2hexadecanodiol em $20 \mathrm{~mL}$ de dioctiléter foi aquecida, com rampa de aquecimento de $10{ }^{\circ} \mathrm{C} / \mathrm{min}$, à $100{ }^{\circ} \mathrm{C}$ e mantida sob agitação durante $10 \mathrm{~min}$. Após isso, o sistema foi novamente aquecido $\left(10^{\circ} \mathrm{C} / \mathrm{min}\right)$ à $220^{\circ} \mathrm{C}$, sendo que ao chegar nessa temperatura, foi realizada a injeção de 250 $\mu \mathrm{L}$ de uma solução 2 mol.L $\mathrm{L}^{-1}$ de dióxido de selênio $\left(\mathrm{SeO}_{2}\right)$ em etanol. Após a adição do precursor de selênio, o sistema foi mantido por 1 min sob agitação e, então, foi resfriado 
rapidamente em banho de gelo até o meio reacional chegar à temperatura ambiente. Os pontos quânticos obtidos foram lavados três vezes com mistura hexano/etanol e separados por centrifugação a $10.000 \mathrm{rpm}$, por $15 \mathrm{~min}$.

Figura 12 - Fluxograma (a) e patamares e rampas de aquecimento com o tempo (b) do procedimento utilizado para síntese dos pontos quânticos de CdSe.
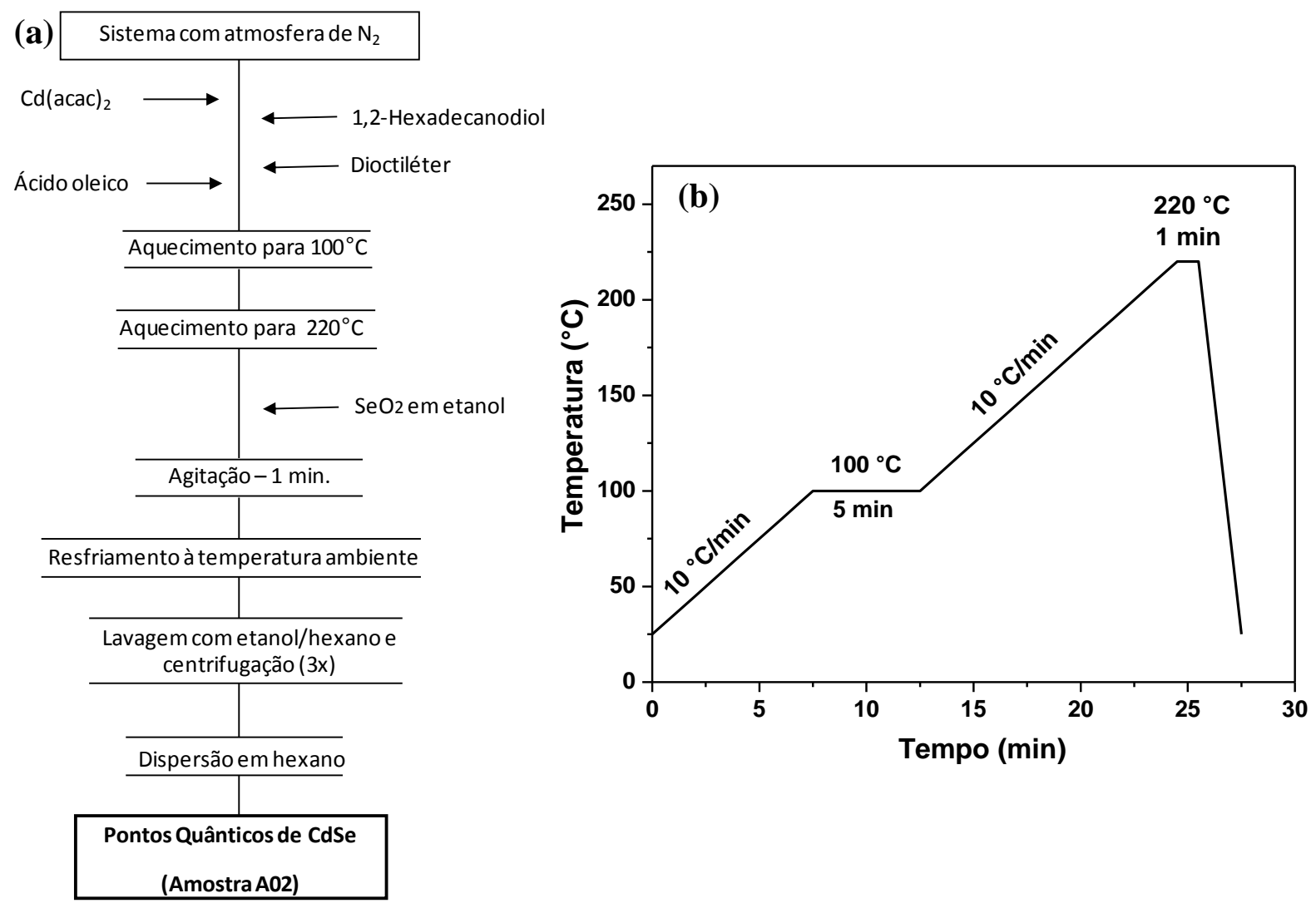

\subsubsection{Síntese dos nanomateriais luminomagnéticos de $\mathrm{FePt} / \mathrm{Fe}_{3} \mathrm{O}_{4}$ conjugados com $\mathrm{CdSe}$}

Para a síntese dos nanomateriais de NPM conjugados com CdSe, foram testados dois procedimentos, sendo denominados: método de mudança da estabilidade coloidal do meio por adição de sal $^{30}$; e método de injeção a quente (do inglês, hot injection). ${ }^{24,26}$

\subsubsection{Método de mudança da estabilidade coloidal do meio por adição de sal}

Esta metodologia foi realizada utilizando-se as NPM de $\mathrm{FePt} / \mathrm{Fe}_{3} \mathrm{O}_{4}$ (amostra A01) e os pontos quânticos de $\mathrm{CdSe}$ (amostra $\mathrm{A} 02$ ) previamente sintetizados como descritos nos itens 4.1 e 4.2.1, respectivamente. Inicialmente, as nanopartículas das amostras A01 e A02 foram 
dispersas separadamente em mistura de 1-hexanol/dietilenoglicol (4:1, v/v) com concentração de $10 \mathrm{mg} / \mathrm{mL}$. Além disso, foi preparada uma solução $\left(10 \mathrm{mmol} \cdot \mathrm{L}^{-1}\right)$ de cloreto de sódio $(\mathrm{NaCl})$ em 1-hexanol/dietilenoglicol (4:1, v/v). O processo de conjugação das partículas contidas nas amostras A01 e A02 foi feito sob diferentes condições de concentração de $\mathrm{NaCl}$ e temperatura de conjugação, as quais podem ser observadas na Tabela 1. A metodologia básica (Figura 13) utilizada para todas as condições realizadas pode ser descrita da seguinte maneira: uma mistura de $8 \mathrm{~mL}$ de 1-hexanol, $2 \mathrm{~mL}$ de dietilenoglicol, $1 \mathrm{~mL}$ da dispersão de NPM em 1hexanol/dietilenoglicol e $1 \mathrm{~mL}$ da dispersão de pontos quânticos em 1-hexanol/dietilenoglicol foram mantidas sob agitação e atmosfera de nitrogênio. Após a agitação, o sistema foi aquecido a uma temperatura de $120^{\circ} \mathrm{C}$ ou $159^{\circ} \mathrm{C}$ e, então, foram adicionadas diferentes quantidades (90 $\mu \mathrm{L}, 200 \mu \mathrm{L}$ ou $300 \mu \mathrm{L}$ ) da solução de $\mathrm{NaCl}$ em 1-hexanol/detilenoglicol, sendo mantido durante 30 min nessa temperatura. Após este tempo, a solução foi resfriada à temperatura ambiente e foram feitas três lavagens das NP obtidas com etanol, sendo separadas por centrifugação, e outras três lavagens com etanol por separação magnética.

Figura 13 - Fluxograma do procedimento utilizado para síntese das heteronanoestruturas luminomagnéticas de NPM de $\mathrm{FePt} / \mathrm{Fe}_{3} \mathrm{O}_{4}$ conjugadas com pontos quânticos de $\mathrm{CdSe}$, a partir da mudança de estabilidade coloidal do meio por adição de sal.

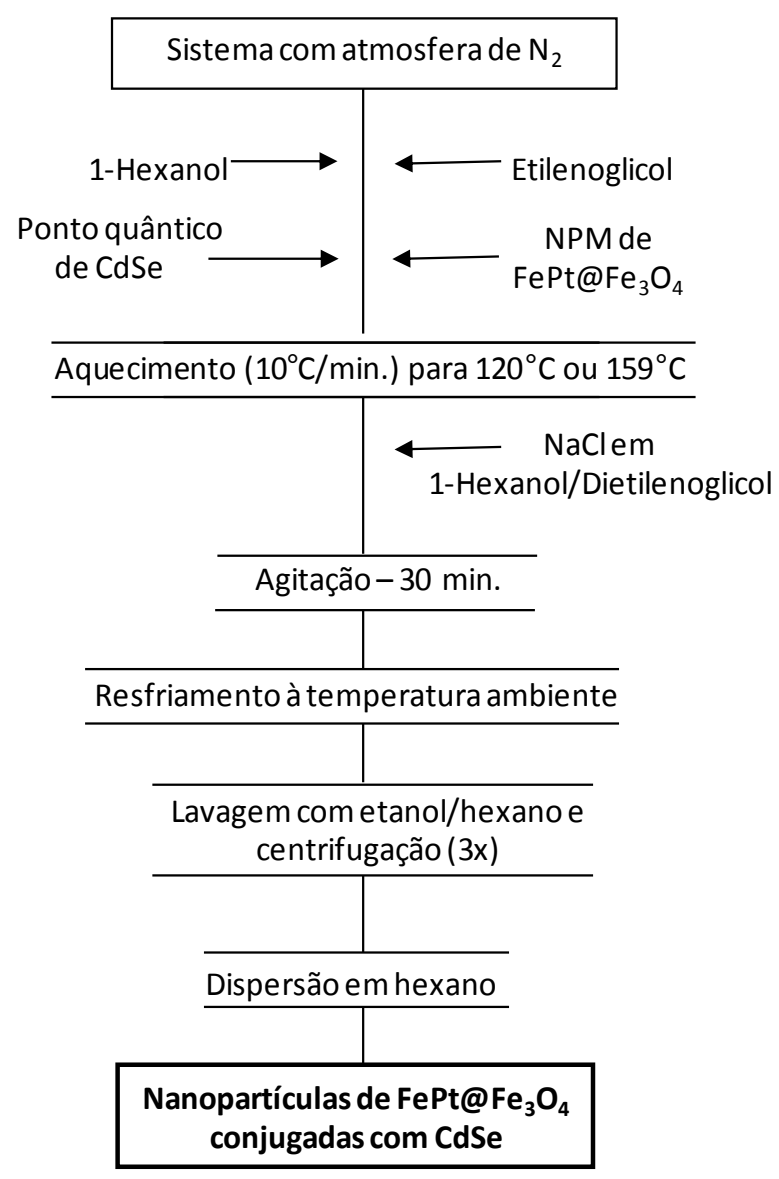


Tabela 1 - Condições de síntese e reagentes utilizados para obtenção das heteronanoestruturas luminomagnéticas de NPM de $\mathrm{FePt} / \mathrm{Fe}_{3} \mathrm{O}_{4}$ conjugadas com pontos quânticos de $\mathrm{CdSe}$, a partir da mudança de estabilidade coloidal do meio por adição de sal.

\begin{tabular}{l|c|c|c|c}
\hline \multicolumn{1}{c|}{ Condição Reacional } & Amostra A03 & Amostra A04 & Amostra A05 & Amostra A06 \\
\hline $\mathrm{NPM} \mathrm{FePt} / \mathrm{Fe}_{3} \mathrm{O}_{4}$ & $10 \mathrm{mg}$ & $10 \mathrm{mg}$ & $10 \mathrm{mg}$ & $10 \mathrm{mg}$ \\
\hline Pontos quânticos CdSe & $10 \mathrm{mg}$ & $10 \mathrm{mg}$ & $10 \mathrm{mg}$ & $10 \mathrm{mg}$ \\
\hline $\mathrm{NaCl}\left(10 \mathrm{mmol} . \mathrm{L}^{-1}\right)^{*}$ & $90 \mu \mathrm{L}$ & $200 \mu \mathrm{L}$ & $300 \mu \mathrm{L}$ & $200 \mu \mathrm{L}$ \\
\hline 1-Hexanol & $8 \mathrm{~mL}$ & $8 \mathrm{~mL}$ & $8 \mathrm{~mL}$ & $8 \mathrm{~mL}$ \\
\hline Etilenoglicol & $2 \mathrm{~mL}$ & $2 \mathrm{~mL}$ & $2 \mathrm{~mL}$ & $2 \mathrm{~mL}$ \\
\hline Temperatura & $120^{\circ} \mathrm{C}$ & $120^{\circ} \mathrm{C}$ & $120^{\circ} \mathrm{C}$ & $159^{\circ} \mathrm{C}$ \\
\hline
\end{tabular}

* NaCl solubilizado em mistura 1-Hexanol/Dietilenoglicol (4:1 (v/v)).

\subsubsection{Método de injeção a quente}

Para o método de injeção a quente, foram utilizadas as NPM de $\mathrm{FePt} / \mathrm{Fe}_{3} \mathrm{O}_{4}(\operatorname{amostra} \mathrm{A01})$ como sementes no meio reacional. Adicionalmente, como precursores dos pontos quânticos de $\mathrm{CdSe}$ foram usados $\mathrm{Cd}(\mathrm{acac})_{2} \mathrm{e} \mathrm{SeO}_{2}$; como agentes de superfície foram usados ácido oleico e/ou oleilamina; e dioctiléter, dibenziléter ou octadeceno como solventes. A partir desses sistemas, foram realizadas algumas modificações de parâmetros de síntese para observar as influências na nucleação e crescimento das HNE de NPM decoradas com os pontos quânticos de CdSe (Tabela 2). De maneira geral, de acordo com a Figura 14, todas as sínteses foram realizadas como segue: foram adicionadas $\mathrm{NPM}$ de $\mathrm{FePt} / \mathrm{Fe}_{3} \mathrm{O}_{4}$ (amostra $\mathrm{A} 01$ ), $\mathrm{Cd}(\mathrm{acac})_{2}$, ácido oleico e oleilamina em dioctiléter, dibenziléter ou octadeceno à temperatura ambiente. Após isso, sob atmosfera de nitrogênio, o sistema foi aquecido, com rampa de aquecimento de $5{ }^{\circ} \mathrm{C}$, para $100{ }^{\circ} \mathrm{C}$ sendo mantido durante $5 \mathrm{~min}$. Após isso, o sistema foi aquecido novamente (5 ${ }^{\circ} \mathrm{C} / \mathrm{min}$ ) para $160{ }^{\circ} \mathrm{C}, 220^{\circ} \mathrm{C}$ ou $280{ }^{\circ} \mathrm{C}$, e então, após chegar nessa temperatura, foi injetada no meio reacional solução de $\mathrm{SeO}_{2}$ em etanol, permanecendo durante 1 min sob agitação. Posteriormente, o sistema foi resfriado em banho de gelo até a temperatura ambiente. Os nanomateriais obtidos em todas as condições foram lavados três vezes com mistura de hexano/etanol e centrifugados por $15 \mathrm{~min}$ a $10.000 \mathrm{rpm}$, e outras cinco vezes com hexano/etanol coletando as partículas por separação magnética. 
Figura 14 - Fluxograma do procedimento utilizado para síntese das heteronanoestruturas luminomagnéticas de NPM de $\mathrm{FePt} / \mathrm{Fe}_{3} \mathrm{O}_{4}$ conjugadas com pontos quânticos de $\mathrm{CdSe}$, a partir do método de injeção à quente do precursor de selênio no meio reacional.

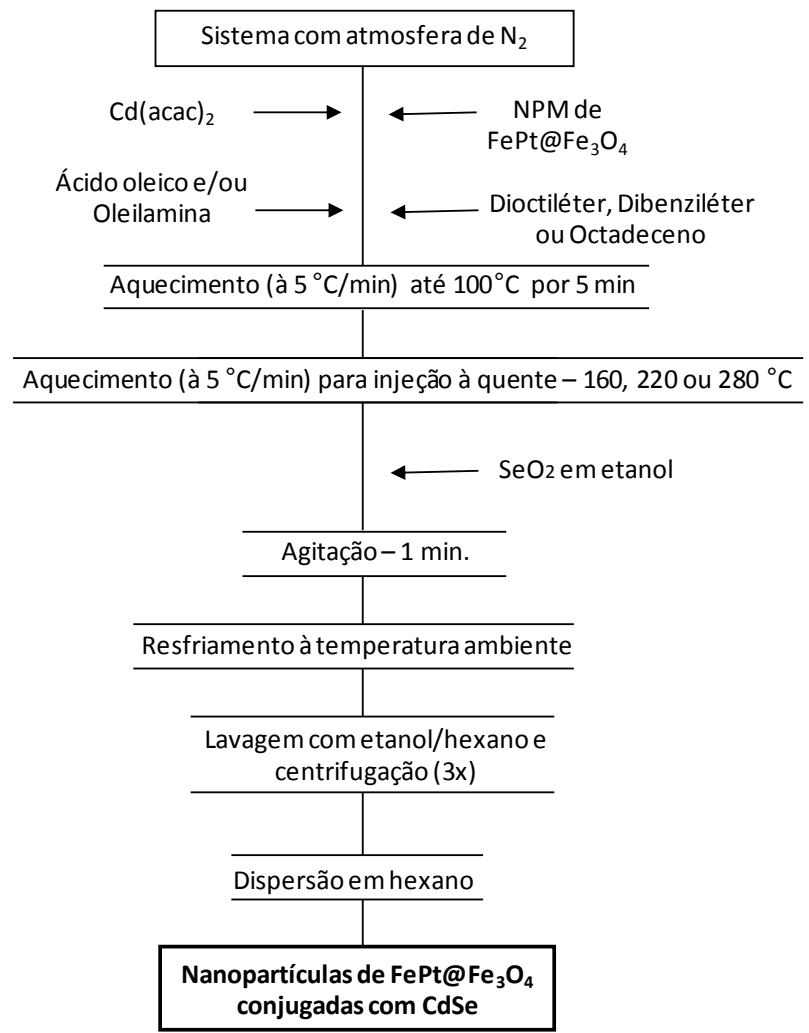

Tabela 2 - Condições de síntese e reagentes utilizados para obtenção das heteronanoestruturas luminomagnéticas de NPM de $\mathrm{FePt} / \mathrm{Fe}_{3} \mathrm{O}_{4}$ conjugadas com pontos quânticos de $\mathrm{CdSe}$, a partir do método de injeção a quente do precursor de selênio no meio reacional.

\begin{tabular}{c|c|c|c|c|c|c|c|c|c|c}
\hline \multirow{2}{*}{ Condição Reacional } & \multicolumn{10}{|c}{ Amostra } \\
\cline { 2 - 12 } & $\mathbf{A 0 7}$ & $\mathbf{A 0 8}$ & $\mathbf{A 0 9}$ & $\mathbf{A 1 0}$ & $\mathbf{A 1 1}$ & $\mathbf{A 1 2}$ & $\mathbf{A 1 3}$ & $\mathbf{A 1 4}$ & $\mathbf{A 1 5}$ & $\mathbf{A 1 6}$ \\
\hline $\mathrm{NPM}^{*}(\mathrm{mg})$ & 10,0 & 10,0 & 10,0 & 10,0 & 10,0 & 10,0 & 10,0 & 10,0 & 10,0 & 30,0 \\
\hline $\mathrm{Cd}(\mathrm{acac})_{2}(\mathrm{mmol})$ & 0,1 & 0,1 & 0,1 & 0,1 & 0,1 & 0,1 & 0,1 & 0,1 & 0,1 & 0,1 \\
\hline $\mathrm{SeO}_{2}(2 \mathrm{M})^{\#}(\mu \mathrm{L})$ & 50,0 & 50,0 & 50,0 & 50,0 & 50,0 & 50,0 & 50,0 & 50,0 & 50,0 & 50,0 \\
\hline Ácido Oléico $(\mathrm{mL})$ & 0,1 & 0,4 & 0,2 & - & 0,4 & 0,2 & 0,2 & 0,2 & 0,2 & 0,2 \\
\hline Oleilamina $(\mathrm{mL})$ & 0,2 & 0,4 & 0,2 & 0,4 & - & 0,2 & 0,2 & 0,2 & 0,2 & 0,2 \\
\hline Dioctiléter $(\mathrm{mL})$ & 20,0 & 20,0 & 20,0 & 20,0 & 20,0 & 20,0 & 20,0 & - & - & 20,0 \\
\hline Dibenziléter $(\mathrm{mL})$ & - & - & - & - & - & - & - & 20,0 & - & - \\
\hline Octadeceno $(\mathrm{mL})$ & - & - & - & - & - & - & - & - & 20 & - \\
\hline Temperatura $\left({ }^{\circ} \mathrm{C}\right)$ & 220 & 220 & 220 & 220 & 220 & 160 & 280 & 160 & 160 & 160 \\
\hline
\end{tabular}

* NPM de $\mathrm{FePt} / \mathrm{Fe}_{3} \mathrm{O}_{4}(\mathrm{Amostra} \mathrm{A} 01) ;{ }^{\#} \mathrm{SeO}_{2}$ solubilizado em etanol $\left(2 \mathrm{~mol} . \mathrm{L}^{-1}\right)$. 


\subsubsection{Recobrimento das heteronanoestruturas luminomagnéticas com sílica}

A etapa de recobrimento com sílica na superfície das HNE luminomagnéticas foi feita a partir do processo de microemulsão por micela reversa ${ }^{93}$ da seguinte maneira (Figura 15): primeiramente, adicionou-se $0,7 \mathrm{~mL}$ de Igepal CO-520 em $10 \mathrm{~mL}$ de ciclohexano, mantendose o sistema sob agitação por 15 min. Posteriormente, adicionou-se no meio reacional 4,0 mL de uma dispersão $\left(2,5 \mathrm{mg} \cdot \mathrm{mL}^{-1}\right)$ das NPM em ciclohexano, mantendo-se o sistema em agitação durante 15 min. Em seguida, adicionou-se $110 \mu \mathrm{L}$ de uma solução aquosa de hidróxido de amônio $\left(\mathrm{NH}_{4} \mathrm{OH}, 30 \%\right)$, mantendo-se o sistema sob agitação por mais 15 min. Então, adicionou-se vagarosamente $130 \mu \mathrm{L}$ de tetraetilortosilicato (TEOS), mantendo a mistura reacional sob agitação por $24 \mathrm{~h}$. Ao final deste processo, as NPM resultantes foram lavadas e centrifugadas três vezes com metanol e duas vezes com isopropanol a $10.000 \mathrm{rpm}$ por $15 \mathrm{~min}$. Após as lavagens, para manutenção da estabilidade coloidal as HNE foram dispersas e estocadas em água.

Figura 15 - Fluxograma do procedimento utilizado para recobrimento com sílica na superfície das heteronanoestruturas luminomagnéticas.

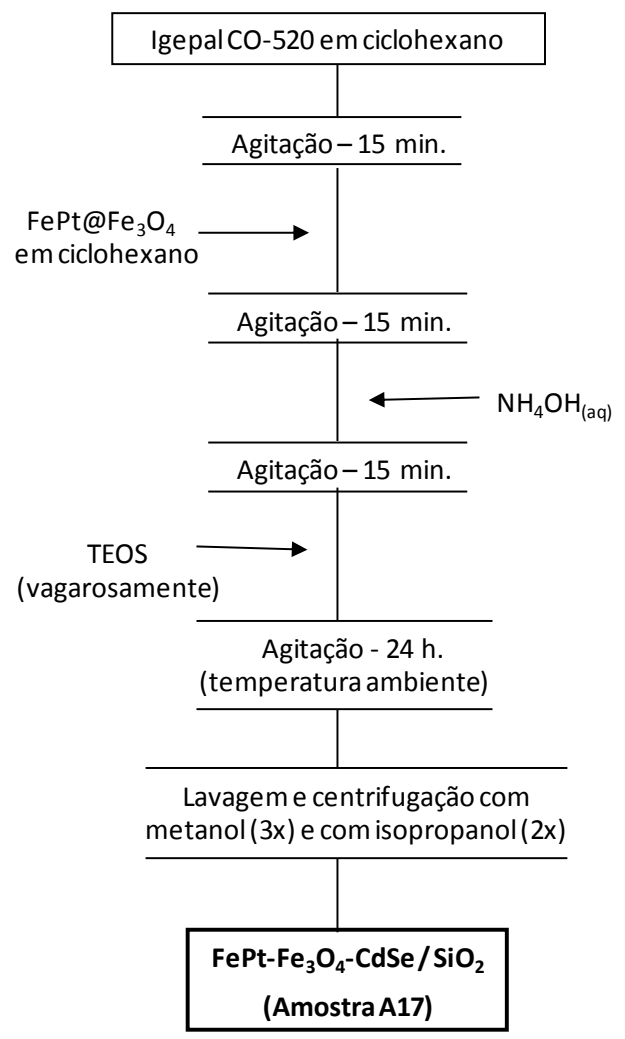




\subsection{Síntese dos nanomateriais luminomagnéticos de $\mathrm{FePt} / \mathrm{Fe}_{3} \mathrm{O}_{4}$ e $\mathrm{CdSe} / \mathrm{ZnS}$ recobertos com polímeros baseados em PEG}

\subsubsection{Obtenção dos ligantes baseados em PEG}

Neste trabalho, as etapas envolvendo os ligantes baseados em PEG são baseadas em trabalhos previamente publicados por Mattoussi e colaboradores ${ }^{50,51,88,96}$, durante o período de estágio de doutorado realizado pelo estudante no grupo do Prof. Dr. Hedi Mattoussi.

\subsubsection{Obtenção do LA-PEG-COOH}

A etapa de obtenção do LA-PEG-COOH é baseada no protocolo estabelecido por Mattoussi e colaboradores. ${ }^{51}$ A obtenção desse ligante é feita partindo de polímeros de PEG de cadeia curta $\left(\mathrm{Mw}=600 \mathrm{~g} \cdot \mathrm{mol}^{-1}\right)$ e realizando-se modificações químicas nas extremidades do PEG. Em seguida, serão discriminadas cada etapa do processo de obtenção desse ligante.

Etapa 1 - Síntese de N3-PEG-N3: em um balão de duas bocas de fundo redondo de $1 \mathrm{~L}$, equipado com funil de adição e barra magnética de agitação foram adicionados 0,175 mol de PEG e 0,402 mol de cloreto de metanossufonila ( $\mathrm{MsCl}$ ) em $200 \mathrm{~mL}$ de tetrahidrofurano (THF). Após isso, foi adicionado no funil de adição 0,43 mol de trietilamina $\left(\mathrm{Et}_{3} \mathrm{~N}\right)$, o sistema foi purgado com $\mathrm{N}_{2}$ e mantido sob agitação em banho de gelo e foi gotejada, vagarosamente, a trietilamina na mistura reacional com PEG. Após o término da adição, o sistema foi mantido em temperatura ambiente e sob agitação por aproximadamente $18 \mathrm{~h}$. Após isso, a mistura reacional foi diluída com $200 \mathrm{~mL}$ de água e adicionou-se 0,149 mol de bicarbonato de sódio e 0,477 mol de azida de sódio, para então o sistema ser anexado a uma cabeça de destilação conectada a um balão de fundo redondo em banho de gelo como um coletor de solvente. Então, o sistema reacional com a mistura bifásica foi aquecido à temperatura de ebulição do THF ( $67^{\circ} \mathrm{C}$ ) para destilá-lo. O sistema foi mantido em refluxo sob agitação por, aproximadamente, 12 h. Após o término da separação do THF da mistura reacional, os resíduos foram transferidos para um funil de separação e foi adicionado $100 \mathrm{~mL}$ de clorofórmio (em torno de 5 vezes) para serem coletadas as frações formadas de $\mathrm{N}_{3}-\mathrm{PEG}-\mathrm{N}_{3}$. Para retirar o restante de água presente no clorofórmio com os ligantes coletados, foi adicionado em torno de $50 \mathrm{~g}$ de sulfato de sódio com o sistema mantido sob agitação. O sistema foi filtrado com papel de filtro e, finalmente, o produto foi secado em rotaevaporador, para remover todo o clorofórmio. 
Etapa 2 - Síntese de N3-PEG-NH2: foi adicionado 12 g de $\mathrm{N}_{3}-\mathrm{PEG}_{3} \mathrm{~N}_{3}, 150 \mathrm{~mL}$ de acetato de etila (EtOAc) e $60 \mathrm{~mL}$ de solução aquosa de $\mathrm{HCl}(1 \mathrm{M})$ em um balão de duas bocas de fundo redondo equipado com barra de agitação magnética e funil de adição. Após isso, foi adicionado $2,83 \times 10^{-2}$ mol de trifenilfosfina $\left(\mathrm{PPh}_{3}\right)$ e $100 \mathrm{~mL}$ de acetato de etila no funil de adição. A mistura reacional foi purgada com $\mathrm{N}_{2}$ e colocada em banho de gelo sob agitação e, então foi gotejado, vagarosamente, o conteúdo do funil de adição dentro da mistura reacional. Uma vez que a adição foi finalizada, a mistura reacional foi elevada à temperatura ambiente e permaneceu sob agitação durante $12 \mathrm{~h}$. Após o término da reação, a mistura reacional foi transferida para um funil de separação e a mistura aquosa foi coletada e lavada 2 vezes com $100 \mathrm{~mL}$ de acetato de etila. Após a lavagem, a solução aquosa com os ligantes foi transferida para um balão equipado com barra de agitação magnética e colocada em banho de gelo. Adicionou-se, vagarosamente, 0,535 mol de hidróxido de potássio dentro da solução aquosa e o sistema foi mantido sob agitação até a dissolução da base. Após isso, a solução aquosa foi colocada em funil de separação novamente e os ligantes em solução aquosa foram extraídos utilizando-se acetato de etila (a extração foi repetida em torno de 5 vezes). Após isso, os ligantes em acetato de etila foram transferidos para um balão de fundo redondo e foram secos utilizando-se $50 \mathrm{~g}$ de sulfato de sódio, mantendo-se sob agitação durante, aproximadamente, 20 min. Após esse período, a mistura foi filtrada com papel de filtro e o solvente foi evaporado utilizando-se rotaevaporador.

Etapa 3 - Síntese de LA-PEG-N3: adicionou-se 3 g de N 3 -PEG-NH $2,1,38$ mmol de 4-(N,Ndimetilamino)piridina (DMAP), 7,03 mmol de N,N'-diciclohexilcarbodiimida (DCC) e $40 \mathrm{~mL}$ de diclorometano em um balão de fundo redondo equipado a um funil de adição e uma barra de agitação magnética. Então, a mistura foi mantida sob agitação em banho de gelo. Após isso, foi adicionado 6,83 mmol de ácido lipóico (LA) em $25 \mathrm{~mL}$ de diclorometano dentro do funil de adição. O conteúdo do funil de adição foi gotejado vagarosamente sob atmosfera de $\mathrm{N}_{2}$ e agitação. Uma vez que a adição foi completa a mistura reacional foi colocada em temperatura ambiente e mantida durante $12 \mathrm{~h}$ sob atmosfera de $\mathrm{N}_{2}$ e agitação magnética. A mistura foi filtrada em funil de Buchner com celite, sendo usado diclorometano para enxaguar resíduos da mistura no papel de filtro. Após a filtração, o diclorometano da mistura foi evaporado utilizando-se um rotaevaporador. Após a secagem do resíduo, foi adicionada água e transferido o conteúdo para um funil de separação. Após isso, a mistura foi lavada 3 vezes com $100 \mathrm{~mL}$ de hexano, a solução aquosa foi saturada com bicarbonato de sódio e foi adicionado diclorometano para extração dos ligantes da fase aquosa para a fase orgânica (esse processo de extração foi repetido em torno de 3 vezes). Ao final, para extrair o restante de água na mistura dos ligantes 
com diclorometano, foi adicionado sulfato de sódio, permanecendo em agitação durante alguns minutos, e após isso a mistura foi filtrada com papel de filtro e o solvente foi evaporado utilizando-se o rotaevaporador.

Etapa 4 - Síntese de LA-PEG-NH2: foi dissolvido 2,75 g de LA-PEG-N 3 em 50 mL de THF em um balão com barra de agitação magnética. Foi adicionado 6,6 mmol de trifenilfosfina e o sistema foi mantido sob agitação em temperatura ambiente durante $30 \mathrm{~min}$ com atmosfera de $\mathrm{N}_{2}$. Após isso, foi adicionado $44 \mathrm{mmol}$ de água na mistura reacional e o sistema permaneceu em agitação magnética durante 12 h. Após o término desse período, o solvente da mistura reacional foi evaporado em rotaevaporador e então, foi adicionado acetato de etila e o resíduo foi transferido para um funil de separação. Posteriormente, adicionou-se $100 \mathrm{~mL}$ de solução aquosa de $1 \mathrm{M}$ de $\mathrm{HCl}$ e, vagarosamente foi removendo-se a fase orgânica do funil de separação, sendo esse procedimento repetido por mais uma vez, para remover os resíduos de trifenilfosfina, óxido de trifenilfosfina e LA-PEG-N 3 não reagido. Após essa etapa, adicionou-se na fase aquosa uma quantidade suficiente de carbonato de sódio para elevar o pH da solução até 9,0. Após isso, o produto foi extraído com aproximadamente $100 \mathrm{~mL}$ de clorofórmio (sendo este procedimento de extração repetido por 3 vezes) e, então utilizou-se sulfato de sódio seguido de filtração com papel de filtro para eliminar resíduos de água presentes na mistura dos ligantes com clorofórmio. Finalmente, para evaporação do clorofórmio, foi utilizado o rotaevaporador, obtendo-se os ligantes desejados ao final desse processo.

Etapa 5 - Síntese de LA-PEG-COOH: foi adicionado 0,748 g de LA-PEG-NH 2 , 2,5 mmol de anidrido succínico, $10 \mathrm{~mL}$ de diclorometano e 3,2 mmol de trietilamina em um balão de 100 $\mathrm{mL}$ equipado com uma barra de agitação magnética. A mistura reacional permaneceu em agitação durante $12 \mathrm{~h}$ em temperatura ambiente e atmosfera de $\mathrm{N}_{2}$. Após o término da reação, a mistura foi despejada em $60 \mathrm{~mL}$ de solução aquosa de $1 \mathrm{M}$ de $\mathrm{HCl}$ e foi extraído em clorofórmio utilizando-se um funil de separação (a extração com clorofórmio foi realizada 3 vezes). Após isso, os resíduos em clorofórmio foram saturados com sultato de sódio, a mistura permaneceu em agitação durante aproximadamente $20 \mathrm{~min}$, depois a mistura foi filtrada utilizando-se papel de filtro e o clorofórmio foi evaporado utilizando-se rotaevaporador. Para uso posterior, os ligantes de LA-PEG-COOH foram estocados secos com atmosfera de $\mathrm{N}_{2}$ no refrigerador. 


\subsubsection{Obtenção do Dopa-PIMA-PEG-NH2}

Primeiramente, 2,5 mmol de PIMA foi dissolvido em $10 \mathrm{~mL}$ de dimetilformamida e mantido sob agitação em um balão de três bocas equipado com barra de agitação magnética e funil de adição. Após 10 min, o conteúdo no balão foi purgado com $\mathrm{N}_{2}$ e aquecido para $70{ }^{\circ} \mathrm{C}$. Separadamente, foi realizada a ativação da dopamina, da seguinte maneira: 1,25 mmol de hidrocloreto de dopamina foi dissolvido em $2 \mathrm{~mL}$ de dimetilformamida, sendo após isso adicionado um equivalente molar de trietilamina. Após adição da trietilamina a solução tornouse túrbida e permaneceu agitando durante $2 \mathrm{~h}$ em temperatura ambiente e atmosfera de $\mathrm{N}_{2}$. Após o tempo de reação, a mistura reacional foi centrifugada para remover alguns sais formados (por exemplo, hidrocloreto de trietilamina) e o sobrenadante, contendo dopamina ativada, foi adicionado no funil de adição juntamente com $0,7 \mathrm{~g}$ de $\mathrm{H}_{2} \mathrm{~N}-\mathrm{PEG}-\mathrm{OCH}_{3}$ (sendo este polímero preparado baseado em trabalho de Mattoussi e colaboradores $)^{50}$, para ser adicionado na mistura com o PIMA. Após isso, foi feito o gotejamento, vagarosamente, do conteúdo no funil de adição dentro da solução no balão. Após a adição, a mistura reacional foi aquecida até $70{ }^{\circ} \mathrm{C}$ e permaneceu agitando durante $3 \mathrm{~h}$. Após isso, uma solução de 0,22 g de $\mathrm{NH}_{2}-\mathrm{PEG}-\mathrm{NH}_{2}$ (polímero preparado de maneira semelhante às etapas 1 e 2 do item 4.3.1.1, sendo a única diferença a adição do dobro da quantidade de trifenilfosfina no meio reacional) foi dissolvida em $2 \mathrm{~mL}$ de dimetilformamida, adicionada no funil de adição e gotejada, vagarosamente, na mistura reacional. Após o término da adição, a mistura reacional permaneceu em $70{ }^{\circ} \mathrm{C}$ durante $12 \mathrm{~h}$ sob atmosfera de $\mathrm{N}_{2}$. Após o término da reação, a dimetilformamida foi removida sob vácuo e os ligantes obtidos foram estocados sob refrigeração.

\subsubsection{Síntese de CdSe/ZnS pelo método de decomposição térmica}

A síntese dos pontos quânticos de $\mathrm{CdSe} / \mathrm{ZnS}$ caroço/casca foi baseada no protocolo estabelecido por Mattoussi e colaboradores ${ }^{97}$. Nessa síntese, primeiramente preparou-se uma solução estoque $1 \mathrm{M}$ de seleneto de trioctilfosfina (TOP:Se) pela dissolução de 7,9 g de selênio em pó em $100 \mathrm{~mL}$ de TOP. Após isso, foram adicionados $20 \mathrm{~g}$ de óxido de trioctilfosfina (TOPO), $10 \mathrm{~g}$ de hexadecilamina (HDA) e $5 \mathrm{~mL}$ de TOP em um balão de três bocas com fundo redondo equipado com um termopar e uma linha para fluxo de $\mathrm{N}_{2}$ ou adaptor para vácuo. A mistura foi aquecida a $140^{\circ} \mathrm{C}$ sob vácuo durante $2 \mathrm{~h}$. Após isso, a linha de vácuo foi retirada e o sistema foi purgado com $\mathrm{N}_{2}$ e mantido sob temperatura de $350{ }^{\circ} \mathrm{C}$. Em um frasco separado, foi feita uma mistura de $620 \mathrm{mg}$ de $\mathrm{Cd}$ (acac) $2,1,2 \mathrm{~g}$ de 1,2-hexadecanodiol e $10 \mathrm{~mL}$ de TOP e 
o sistema foi aquecido para $100{ }^{\circ} \mathrm{C}$ sob vácuo. Após alguns minutos, a mistura foi mantida a 80 ${ }^{\circ} \mathrm{C}$ e foi adicionado $10 \mathrm{~mL}$ da solução estoque de TOP:Se $(1 \mathrm{M})$ e a mistura foi mantida em agitação por alguns minutos. Após isso, foi realizada rapidamente uma injeção da solução com a mistura dos precursores de cádmio e selênio dentro do balão de três bocas contendo TOP, TOPO e HDA a $350^{\circ} \mathrm{C}$ e, rapidamente, o sistema foi resfriado para $260^{\circ} \mathrm{C}$, o qual foi mantido por diversas horas para o crescimento dos pontos quânticos de $\mathrm{CdSe}$. O crescimento dos pontos quânticos foi controlado pela retirada de alíquotas durante a reação e, realizando-se espectros de absorção para o controle do seu tamanho pelo deslocamento da primeira banda de absorção com a varredura do comprimento de onda do fóton absorvido. O crescimento dos pontos quânticos foi cessado com o resfriamento da solução para em torno de $70^{\circ} \mathrm{C}$, com a adição de hexano e butanol, seguida de centrifugação para remover os precursores não-reagidos e outras impurezas. A segunda lavagem foi realizada utilizando-se excesso de etanol nas partículas, seguida de centrifugação e descarte do sobrenadante. Ao final desse processo, os pontos quânticos de CdSe foram estocados dispersos em hexano.

No processo de recobrimento dos pontos quânticos de $\mathrm{CdSe}$ com $\mathrm{ZnS}$, primeiramente, foi montado um sistema com balão de fundo redondo equipado com funil de adição e, então misturado $25 \mathrm{~g}$ de TOPO, sendo o sistema mantido sob vácuo durante $3 \mathrm{~h}$ e temperatura de 130 ${ }^{\circ} \mathrm{C}$. Após isso, em uma temperatura de $80{ }^{\circ} \mathrm{C}$ foram adicionados os pontos quânticos de $\mathrm{CdSe}$ purificados e dispersos em hexano (concentração em torno de $1 \mathrm{mM}$ ), sendo o hexano evaporado sob vácuo durante alguns minutos. A temperatura da solução foi então aumentada para $180^{\circ} \mathrm{C}$ e mantida em agitação magnética. Separadamente, foi preparado $5 \mathrm{~mL}$ de TOP, e quantidades equimolares dos precursores dietilzinco e hexametildisilatiano em um frasco, sendo coletado esse conteúdo com uma seringa. Os precursores do recobrimento com $\mathrm{ZnS}$ foram adicionados no funil de adição e gotejados vagarosamente no balão contendo os pontos quânticos de CdSe de TOPO previamente preparados. Uma vez que essa adição foi completa, a temperatura do conteúdo do balão foi diminuída para $80^{\circ} \mathrm{C}$ e mantida sob agitação durante em torno de $12 \mathrm{~h}$. Após o término do processo de recobrimento, foram adicionados em torno de $10 \mathrm{~mL}$ de butanol e hexano no balão, e os pontos quânticos de CdSe/ZnS foram precipitados utilizando-se metanol. Após a adição de metanol, os pontos quânticos foram coletados por centrifugação e o sobrenadante foi descartado. Os pontos quânticos de $\mathrm{CdSe} / \mathrm{ZnS}$ foram estocados dispersos em hexano. 


\subsubsection{Recobrimento dos pontos quânticos de CdSe/ZnS com LA-PEG-COOH}

O procedimento para recobrimento dos pontos quânticos de $\mathrm{CdSe} / \mathrm{ZnS}$ com os ligantes LA-PEG-COOH foi baseado em um protocolo publicado por Mattoussi e colaboradores ${ }^{35}$, no qual foi realizada uma reação de troca de ligantes fotoinduzida utilizando-se irradiação UV com a mistura dos pontos quânticos e de ligantes de LA-PEG-COOH e LA-PEG-OCH 3 em excesso em agitação magnética, sendo que a proporção utilizada entre os dois ligantes foi de 3\% e 97\%, respectivamente.

Esta etapa foi realizada da seguinte maneira: em um frasco, foram adicionados $96,99 \mathrm{mg}$

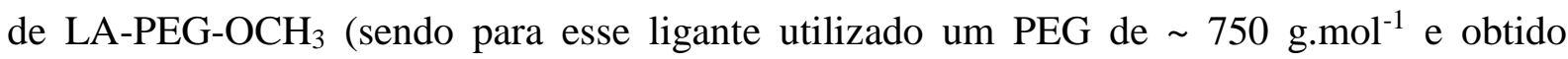
conforme protocolo de Mattoussi e colaboradores ${ }^{50}$ ) em $500 \mu \mathrm{L}$ de metanol. Em um outro frasco, foi adicionado 3,0 mg de LA-PEG-COOH (conforme obtido na seção 4.3.1.1) e aproximadamente 3 a 4 pastilhas de hidróxido de tetrametilamônio. Os dois frascos foram misturados e permaneceram em torno de 10 min sob sonificação. Após isso, no frasco contendo os ligantes em metanol, foi adicionado $750 \mu \mathrm{L}$ de uma dispersão $(\sim 3,0 \mu \mathrm{M})$ de $\mathrm{CdSe} / \mathrm{ZnS}$ em hexano. A mistura reacional de duas fases contendo os pontos quânticos e os ligantes foi mantida em um fotoreator de luz UV (comprimento de onda do fóton de $350 \mathrm{~nm}$ e potência de 4,5 $\mathrm{mW} / \mathrm{cm}^{2}$ ) sob agitação magnética durante $40 \mathrm{~min}$. Após o término da reação de troca de ligantes, o solvente foi removido em vácuo e os pontos quânticos foram redispersos em mistura de etanol/clorofórmio. E então, hexano foi vagarosamente adicionado para precipitar os pontos quânticos $\mathrm{CdSe} / \mathrm{ZnS}$ após a troca de ligantes, o conteúdo foi centrifugado e o sobrenadante foi removido. Após isso, os pontos quânticos foram secos em vácuo e dispersos em solução fosfato salina (PBS) com $\mathrm{pH}=7$. A dispersão aquosa foi filtrada utilizando-se filtro de seringa de 0,45 $\mu \mathrm{m}$ e, em seguida, purificada utilizando-se dispositivo da Milipore de filtração por membrana para remover o excesso de ligantes TOP e TOPO solubilizados. Ao final do processo de lavagem, os pontos quânticos foram estocados em solução PBS com pH = 7 .

\subsubsection{Recobrimento das NPM de $\mathrm{FePt} / \mathrm{Fe}_{3} \mathrm{O}_{4}$ com Dopa-PIMA-PEG-NH2}

Esta etapa de troca de ligantes foi baseada em trabalho publicado por Mattoussi e colaboradores $^{88}$. Primeiramente, foi adicionado $10 \mathrm{mg}$ de $\mathrm{NPM}$ de $\mathrm{FePt} / \mathrm{Fe}_{3} \mathrm{O}_{4} \mathrm{em} 500 \mu \mathrm{L}$ de THF em um frasco. Então, no conteúdo com as NPM foram adicionados $100 \mathrm{mg}$ de DopaPIMA-PEG-NH 2 (conforme descrito na seção 4.3.1.2) e o frasco reacional foi purgado com atmosfera de $\mathrm{N}_{2}$ e aquecido para $50{ }^{\circ} \mathrm{C}$ utilizando-se um banho de óleo. O sistema foi mantido 
em agitação magnética durante $12 \mathrm{~h}$. Após o término da troca de ligantes, foi adicionado excesso de hexano no conteúdo do frasco e centrifugado para coletar as NPM, descartando o sobrenadante. Após isso, foram adicionados $0,5 \mathrm{~mL}$ de THF e 0,3 $\mathrm{mL}$ de etanol para redispersar a amostra, seguido de adição de excesso de hexano para precipitá-la novamente. Após a precipitação, a amostra foi centrifugada, o sobrenadante foi descartado, e o precipitado foi seco em vácuo. Após isso, as partículas foram dispersas em água deionizada e, após sonificação, a dispersão aquosa foi filtrada com filtro de seringa de $0,45 \mu \mathrm{m}$ e o excesso de ligantes livres foi eliminado utilizando-se um dispositivo de filtração de centrífuga da Milipore (com porosidade de $\mathrm{M}_{\mathrm{w}}=100 \mathrm{kDa}$ ). Ao final do processo de purificação, as NPM com Dopa-PIMA-PEG-NH 2 na superfície foram estocadas em solução PBS com $\mathrm{pH}=7$.

\subsubsection{Conjugação de $\mathrm{FePt} / \mathrm{Fe}_{3} \mathrm{O}_{4}$-Dopa-PIMA-PEG-NH 2 e CdSe/ZnS-LA-PEG-COOH}

Para conjugação das NPM de $\mathrm{FePt} / \mathrm{Fe}_{3} \mathrm{O}_{4}$ recobertas com Dopa-PIMA-PEG-NH $\mathrm{N}_{2}$ e dos pontos quânticos de $\mathrm{CdSe} / \mathrm{ZnS}$ recobertos com LA-PEG-COOH foi adequado um método utilizando-se carbodiimida (N-(3-dimetilaminopropil)-N'-etilcarbodiimida, EDC), a qual em solução aquosa permite a reação entre os grupos amina (proveniente das NPM) e ácido carboxílico (proveniente dos pontos quânticos) para a formação de uma ligação amida.

Primeiramente, adicionou $250 \mu \mathrm{L}$ de solução PBS de pontos quânticos de CdSe/ZnS (4 $\mu \mathrm{M}$ ) em um frasco e após isso, foi adicionado $500 \mu \mathrm{L}$ de solução PBS com $\mathrm{pH}=6$. O sistema foi mantido em agitação na presença de banho de gelo e, então, foram adicionados $10 \mu \mathrm{L}$ de EDC em solução aquosa $\left(1 \mathrm{mg} \cdot \mathrm{mL}^{-1}\right)$ e $20 \mu \mathrm{L}$ de solução aquosa de N-hidroxisuccinimida (1 mg.mL $L^{-1}$, NHS). Após a adição, a temperatura da mistura reacional foi aumentada para temperatura ambiente e mantida em agitação magnética durante 3 h. Após isso, a solução foi centrifugada e o sobrenadante foi descartado. Então, foi imediatamente adicionado $500 \mu \mathrm{L}$ de solução PBS em $\mathrm{pH}=8$ e o sistema foi sonificado para redispersar os pontos quânticos e, finalmente, foi adicionado $50 \mu \mathrm{L}$ de solução aquosa de NPM de FePt/ $\mathrm{Fe}_{3} \mathrm{O}_{4}\left(40 \mathrm{mg} \cdot \mathrm{mL}^{-1}\right)$. Após a mistura dos pontos quânticos e das NPM, a mistura reacional foi mantida em agitação magnética durante $12 \mathrm{~h}$, para formação da ligação amida entre os sistemas magnético e luminescente. Após o processo de conjugação, o conteúdo do sistema reacional foi filtrado com filtro de seringa de $0,45 \mu \mathrm{m}$ e o excesso de EDC e NHS foram eliminados utilizando-se um dispositivo de filtração de centrífuga da Milipore (com porosidade de $\mathrm{M}_{\mathrm{w}}=100 \mathrm{kDa}$ ), sendo esta purificação repetida 3 vezes. Após a purificação, a amostra com os nanomateriais 
luminomagnéticos foi estocada em solução PBS de $\mathrm{pH}=7$ e no refrigerador com temperatura de $4{ }^{\circ} \mathrm{C}$.

\subsection{Caracterização dos sistemas obtidos}

Os nanomateriais obtidos em cada uma das etapas deste trabalho foram analisados através das seguintes técnicas:

\subsubsection{Microscopia Eletrônica de Transmissão (MET)}

As análises de morfologia, distribuição de tamanho e estrutura das NP sintetizadas foram feitas utilizando-se o microscópio eletrônico Philips CM120, operado a $120 \mathrm{kV}$, e o microscópio eletrônico TECNAI operado a 200 kV, ambos localizados no DeMa-UFSCar. Para realizar o procedimento, as amostras foram dispersas e diluídas em hexano, exceto no caso das amostras recobertas com sílica ou polímeros baseados em PEG, que foram dispersas e diluídas em isopropanol ou água. Em todos os casos, uma gota da dispersão resultante foi depositada sobre um suporte de cobre previamente recoberto com filme polimérico de Formvar e sputtering de carbono. O diâmetro médio e o desvio-padrão das NP foram determinados estatisticamente pela contagem de pelo menos 50 partículas a partir das micrografias.

\subsubsection{Difratometria de Raios X (DRX)}

Para a análise cristalográfica e a identificação das estruturas cristalinas presentes nas amostras, utilizou-se o difratômetro Siemens D-5005, localizado no DeMa-UFSCar. As amostras foram preparadas gotejando-se uma dispersão dos nanomateriais em hexano na lâmina de vidro e deixando o solvente evaporar a temperatura ambiente. Para o caso da amostra recoberta com sílica, compactou-se a amostra em pó na lâmina de vidro utilizada como portaamostra.

\subsubsection{Espectroscopia UV-Vis}

Para confirmação da presença dos pontos quânticos de CdSe e CdSe/ZnS nas amostras, utilizou-se o espectrômetro UV-Vis JASCO-V 630, no IQSC-USP. Todas as aquisições foram realizadas a partir da utilização das amostras dos nanomateriais em dispersões diluídas em hexano, água ou isopropanol. 


\subsubsection{Espectroscopia de Fluorescência}

As análises de propriedades luminescentes, tais como bandas de excitação e de emissão das amostras, foram realizadas utilizando-se o espectrofluorímetro Hitachi F-4500, localizado no IQSC-USP. As amostras foram dispersas e diluídas em hexano, isopropanol ou água.

\subsubsection{Magnetometria de Amostra Vibrante}

A caracterização magnética das amostras foi realizada em magnetômetro de amostra vibrante (VSM), localizado no IF-USP. As amostras foram preparadas compactando uma pequena quantidade das amostras em pó, cuja massa foi previamente determinada, em uma ampola de remédio utilizada como porta-amostra.

\subsubsection{Ressonância Magnética Nuclear de $\mathbf{H}^{1}$}

A caracterização dos ligantes baseados em PEG foi feita por um equipamento de ressonância magnética nuclear de próton da Bruker Avance III $600 \mathrm{MHz}$, localizado no NMR Lab, Department of Chemistry and Biochemistry, Florida State University. As amostras para RMN de $\mathrm{H}^{1}$ foram preparadas com dissolução de em torno de $30 \mathrm{mg}$ de amostra em $500 \mu \mathrm{L}$ de clorofórmio deuterado em um tubo fino de vidro.

\subsubsection{Espalhamento de luz dinâmico (DLS)}

As medidas de raio hidrodinâmico das NPM, antes e após a troca de ligantes, com polímeros baseados em PEG foram realizadas em um equipamento de espalhamento de luz dinâmico com sistema de goniômetro compacto de modelo ALV/CGS-3, coletando-se ângulo de espalhamento de $90^{\circ}$. Cada padrão espalhado teve um resultado médio de três aquisições com período de $10 \mathrm{~s}$ cada. As amostras foram preparadas com dispersões diluídas das partículas em tolueno (para partículas hidrofóbicas) ou em água deionizada (para partículas hidrofílicas). 


\section{Resultados e Discussão}

\subsection{Síntese das NPM de $\mathrm{FePt} / \mathrm{Fe}_{3} \mathrm{O}_{4}$}

Inicialmente, foi realizada a síntese do núcleo magnético de $\mathrm{FePt} / \mathrm{Fe}_{3} \mathrm{O}_{4}$, na qual foi utilizado o método poliol modificado combinado com o crescimento mediado por sementes, que é reportado na literatura por diversos pesquisadores como um excelente método para síntese de NPM monodispersas com composição, tamanho e morfologia controlados. ${ }^{93,94,98,99}$ Essas NPM foram utilizadas devido à sua alta magnetização de saturação e ao seu comportamento superparamagnético, propriedades desejadas visando aplicações biológicas. O método do poliol modificado combinado com o crescimento mediado por sementes já foi bem estabelecido em trabalhos publicados anteriormente pelo Grupo de Materiais Coloidais do IQSC-USP ${ }^{93,94}$, e as condições utilizadas serão baseadas na rota experimental que apresentou melhor controle de forma, tamanho e composição, além de alta magnetização e comportamento superparamagnético, o qual é importante para as aplicações desejadas neste trabalho.

Primeiramente, para a síntese das NP de $\mathrm{FePt}$, a proporção de sais metálicos $\left(\mathrm{Fe}(\mathrm{acac})_{3} \mathrm{e}\right.$ $\mathrm{Pt}(\mathrm{acac})_{2}$ ) adicionados no meio reacional foi calculada para a obtenção da fase $\mathrm{Fe}_{5} \mathrm{Pt}_{45}$, a qual é considerada a composição química em NP de FePt que apresenta as melhores propriedades magnéticas visando aplicações biológicas. Como relatado na literatura, as $\mathrm{NP}$ de $\mathrm{FePt}$ sintetizadas pelo processo poliol modificado possuem estrutura cristalina cúbica de face centrada (fcc), dita quimicamente desordenada em função de ocorrer a formação de uma liga substitucional, na qual os átomos de ferro substituem os átomos de platina em posições aleatórias na estrutura fcc da platina. Após a formação das NPM de FePt, essas partículas foram utilizadas como sementes na etapa posterior, denominada de crescimento mediado por sementes. Nesta etapa, foram adicionados precursores de ferro (Fe(acac) $\left.)_{3}\right)$ para a formação de uma camada de óxido de ferro sobre à superfície das NPM de FePt, formando-se a estrutura caroço/casca de $\mathrm{FePt} / \mathrm{Fe}_{3} \mathrm{O}_{4}$. Vale ressaltar que o controle de tamanho das NPM de FePt e do crescimento da camada de $\mathrm{Fe}_{3} \mathrm{O}_{4}$ foram controlados pela presença de agentes de superfície (ácido oleico e oleilamina), que controlaram o crescimento dessas partículas.

De acordo com os resultados de MET da amostra A01, Figura 16 (a) e (b), observou-se que as NPM obtidas apresentam tamanho médio de 10,6 nm com desvio-padrão de 1,7 nm, ocasionando uma polidispersividade de $16 \%$. Esses resultados foram satisfatórios, pois as NPM apresentaram um bom controle de forma, com morfologia esférica, um tamanho controlado e estreita distribuição de tamanho. Vale ressaltar que a presença de ácido oleico e oleilamina na 
superfície das NPM providenciaram estabilidade coloidal, sendo constatado pela distribuição das partículas na micrografia da Figura 16 (a), sem a ocorrência de aglomerados.

Figura 16 - (a) MET e (b) histograma de distribuição de tamanho com ajuste gaussiano da amostra A01.
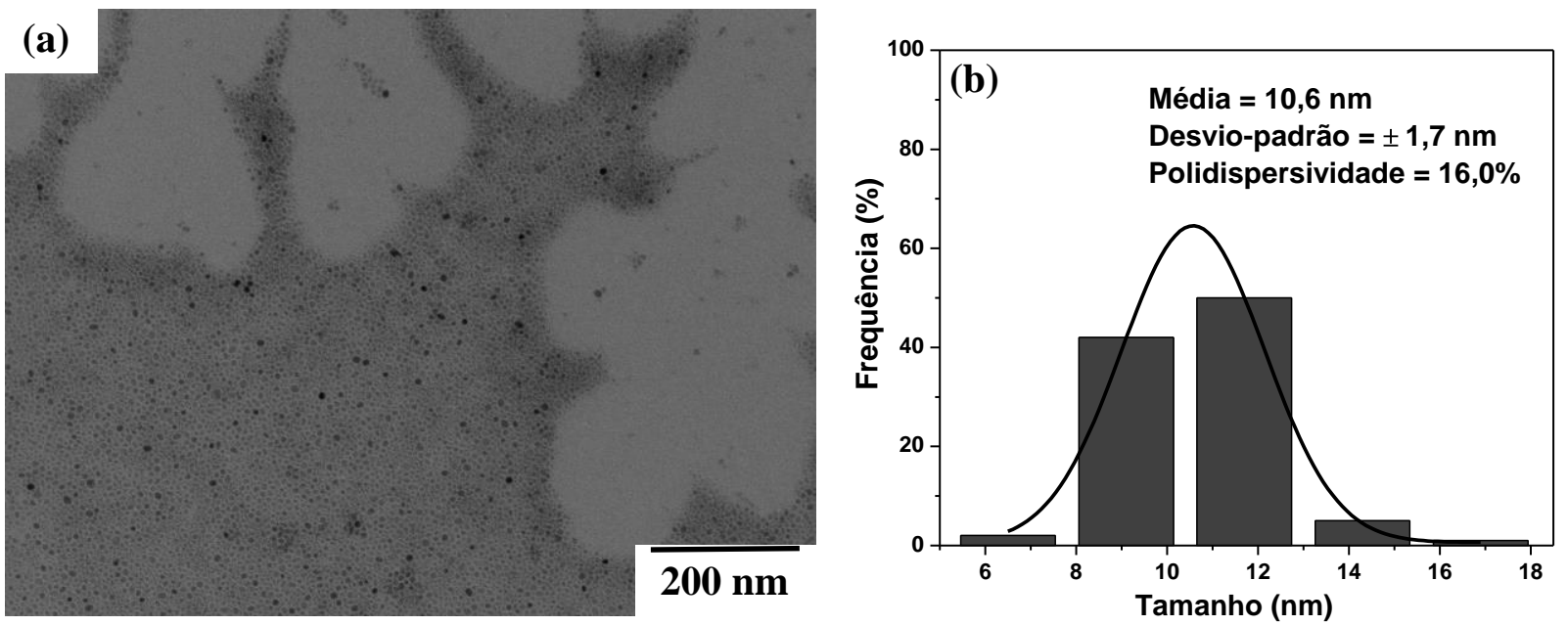

Figura 17 - DRX com os respectivos padrões de difração da amostra A01.

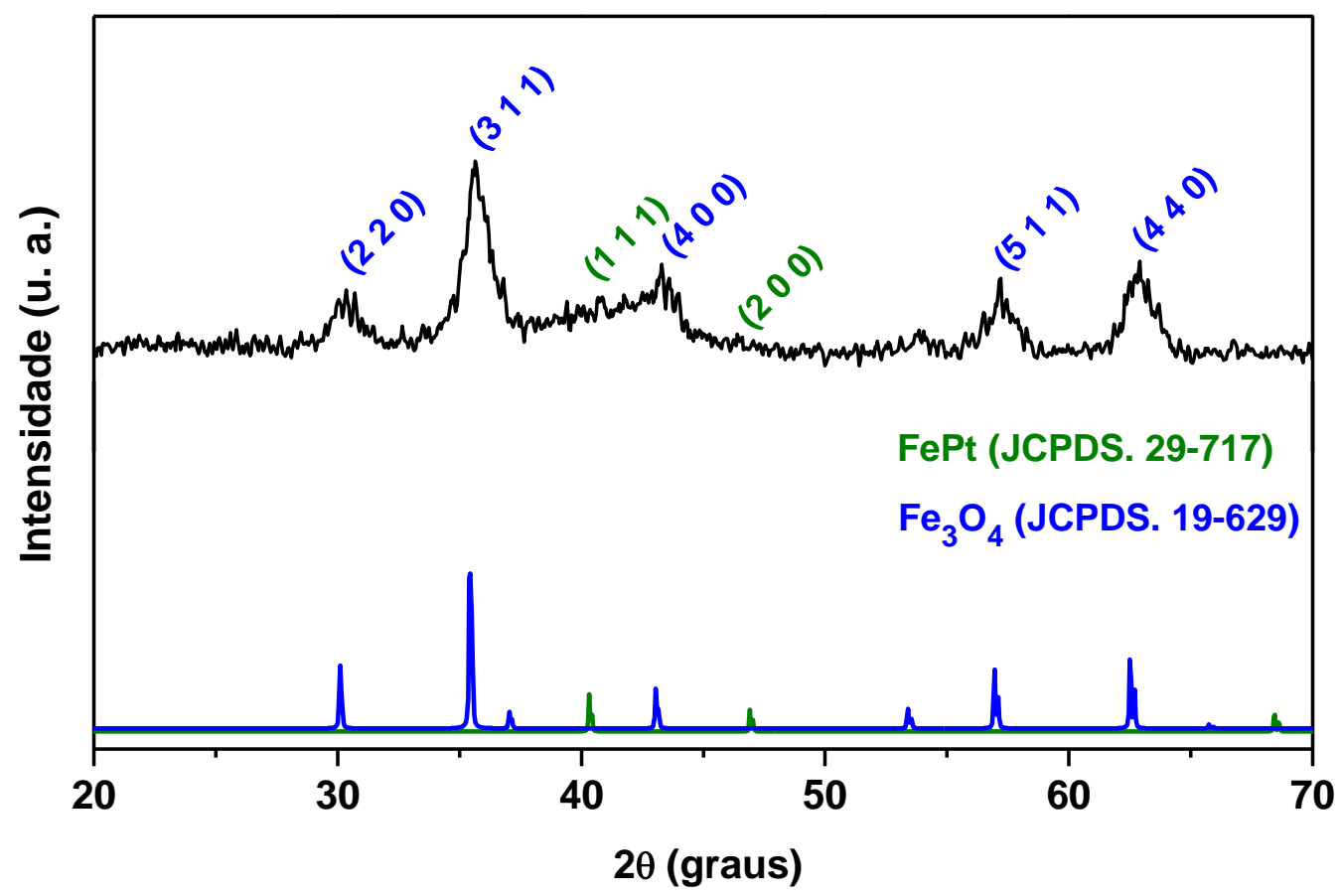

Com os resultados de DRX, na Figura 17, constatou-se a formação das fases cúbicas de FePt e $\mathrm{Fe}_{3} \mathrm{O}_{4}$ nas NPM de $\mathrm{FePt} / \mathrm{Fe}_{3} \mathrm{O}_{4}$ da amostra A01. A fase cúbica da FePt foi observada principalmente devido à formação do pico de difração do plano (111), centrado em $40,7^{\circ} \mathrm{em}$ 20. Já a fase cúbica da magnetita $\left(\mathrm{Fe}_{3} \mathrm{O}_{4}\right)$, fase majoritária nessas NPM, apresentou picos de 
difração dos planos (220), (311), (400), (511) e (440) centrados nos seguintes valores em 20: $30,5^{\circ} ; 35,6^{\circ} ; 43,5^{\circ} ; 57,2^{\circ}$ e $63^{\circ}$, respectivamente. As baixas intensidades dos picos de difração da fase cúbica da FePt quando comparada à fase cúbica da magnetita, são relacionados à pequena parcela da liga metálica FePt formada na síntese, em detrimento da formação de grande quantidade de magnetita na composição das NPM.

Pela curva de magnetização das NPM obtidas na amostra A01 (Figura 18), foi possível inferir um valor de magnetização de saturação (Ms) de 46,8 emu.g ${ }^{-1}$, considerado um alto valor de magnetização para NPM nessa faixa de tamanho. Além disso, analisando a região ampliada da curva constatou-se uma pequena histerese magnética com um valor de coercividade próximo de 0,04 emu.g ${ }^{-1}$, o que evidencia uma propriedade muito próxima do comportamento superparamagnético.

Figura 18 - Curva de magnetização da amostra A01. Em destaque região ampliada da curva de magnetização da mesma amostra.

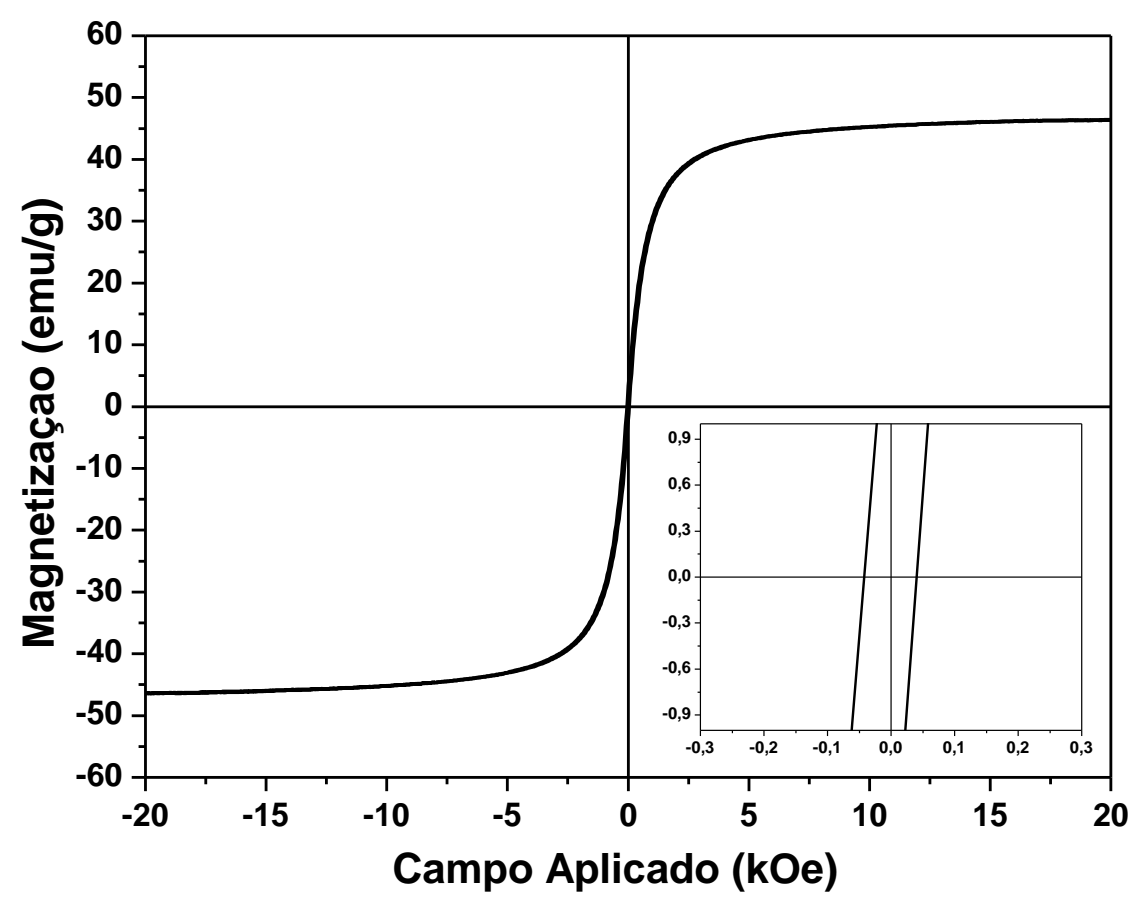

Com os resultados analisados na amostra A01, observou-se que estas NPM estão em concordância com os resultados esperados para sua utilização nas próximas etapas deste trabalho, já que apresentam alta magnetização de saturação e comportamento superparmagnético. Desta forma, a amostra A01 foi utilizada como semente de NPM para a obtenção das HNE luminomagnéticas e nanomateriais luminomagnéticos recobertos com polímeros baseados em PEG obtidos neste trabalho. 


\subsection{Obtenção de heteronanoestruturas de $\mathrm{FePt} / \mathrm{Fe}_{3} \mathrm{O}_{4}-\mathrm{CdSe}$ recobertas com sílica}

\subsubsection{Síntese dos pontos quânticos de CdSe}

Para a síntese dos pontos quânticos de seleneto de cádmio (CdSe) foi utilizado o método de injeção à quente (do inglês, hot injection), método muito utilizado na literatura para obtenção de pontos quânticos, pois propicia a formação de partículas com estreita distribuição de tamanho e controle de forma e tamanho. ${ }^{95}$

A injeção a quente, método que foi primeiramente produzido por Bawendi e colaboradores $^{95}$, é uma metodologia que produz alto grau de supersaturação no meio reacional devido à rápida injeção de precursor em uma solução à quente com a presença de agentes de superfície no meio, resultando em um rápido processo de nucleação de partículas pelo excesso de energia livre causado pela supersaturação do sistema. Durante o processo de nucleação, a concentração de monômeros utilizado na injeção a quente decai rapidamente, o que ocasiona um desaceleramento na taxa de nucleação.

Para explicar o fenômeno de nucleação e crescimento dos pontos quânticos há a necessidade de se utilizar do diagrama de LaMer $^{100}$, elaborado após um estudo do efeito da diminuição da concentração de monômeros e consequente formação de partículas com o tempo. Basicamente, a principal característica do processo de nucleação rápida é que há um determinado momento no processo de nucleação, no qual a quantidade de monômeros no processo reacional para de aumentar, no qual a sua concentração alcança um máximo. Após esse período, o sistema reacional entra em estágio de crescimento e, com isso, a quantidade de monômeros ou permanece constante ou diminui em pequena quantidade.

Podemos explicar esse fenômeno, explicado pelo diagrama de LaMer, em função da nucleação e crescimento dos pontos quânticos de CdSe. Na presença do precursor de cádmio e de agentes de superfície em solução, após a etapa da injeção a quente do precursor de selênio no meio, há a rápida formação de clusters, e consenquentemente, a formação de pequenas partículas no meio reacional, em pouco tempo após a injeção do precursor. Ou seja, devido ao processo de nucleação, há um grande aumento na concentração de clusters de CdSe no meio, em um curto período de tempo. Após isso, a concentração de clusters alcança um máximo, e nesta etapa começa o processo de crescimento dos pontos quânticos de $\mathrm{CdSe}$. No processo de crescimento, há uma diminuição na concentração de pontos quânticos formados, em detrimento da difusão e associação desses clusters, formando-se partículas maiores. O controle no estágio de crescimento dessas partículas pode ser feito, principalmente, pela quantidade de precursor 
injetada, pela temperatura e pelo efeito dos agentes de superfície no meio reacional, que logo após o crescimento, envolverão a superfície das partículas e fornecerão estabilidade coloidal no meio reacional. ${ }^{25}$

Neste trabalho, os pontos quânticos de CdSe foram obtidos a partir de um meio reacional contendo inicialmente o precursor de cádmio $\left(\mathrm{Cd}(\mathrm{acac})_{2}\right)$, solubilizado em dioctiléter e na presença de ácido oléico e oleilamina como agentes de superfície. O sistema foi aquecido a 100 ${ }^{\circ} \mathrm{C}$ para completa dissolução dos reagentes em dioctiléter e após 5 min foram aquecidos novamente para $220^{\circ} \mathrm{C}$, temperatura na qual foi feita a injeção do precursor de selênio $\left(\mathrm{SeO}_{2}\right.$ em etanol). Após a injeção do selênio, observou-se que o sistema mudou de coloração rapidamente, e deixou-se um período de 1 min após a injeção, para o processo de crescimento dos pontos quânticos. Para cessar o crescimento das partículas, além da presença dos agentes de superfície, o sistema foi rapidamente resfriado em banho de gelo até a temperatura ambiente. As lavagens das partículas foram feitas com mistura de hexano/etanol com subsequente centrifugação, para retirar reagentes em excesso que estavam na superfície das partículas. Para maiores detalhes sobre o processo de síntese ver a seção 4.3.2 na Parte Experimental.

Na Figura 19, é possível observar os resultados obtidos por MET para a síntese dos pontos quânticos de CdSe (amostra A02). Pela Figura 19 (a) pode ser visto que os pontos quânticos foram formados com tamanho bastante reduzido e com morfologia esférica. Para maiores detalhes quanto à distribuição de tamanho dos pontos quânticos foi feito um histograma (Figura 19 (b)), o qual mostrou que o tamanho médio dos pontos quânticos foi de $\mathrm{d}=3,12 \mathrm{~nm}$, o desviopadrão foi de $\mathrm{SD}= \pm 0,46 \mathrm{~nm}$, e a polidispersividade foi de $\sigma=15,1 \%$. Considerando-se que as partículas são bastante pequenas, pode se afirmar que houve controle adequado de forma, distribuição e tamanho dos pontos quânticos de CdSe.

Foi feita uma medida de DRX, com o intuito de identificar o tipo de estrutura e as fases cristalográficas dos pontos quânticos de CdSe (amostra A02) obtidos pelo método de injeção a quente. É possível observar o difratograma da amostra A02 e o respectivo padrão de difração da estrutura cúbica do CdSe (65-2891) pela Figura 20. Analisando-se o difratograma da amostra A02 foi possível identificar os picos de difração da estrutura cúbica do CdSe centrados em $2 \theta$ na região de: $25,4^{\circ} ; 42,6^{\circ}$ e 49,9 , referentes aos planos de difração (111), (220) e (311), respectivamente. 
Figura 19 - (a) MET e (b) histograma de distribuição de tamanho com ajuste gaussiano da amostra A02.
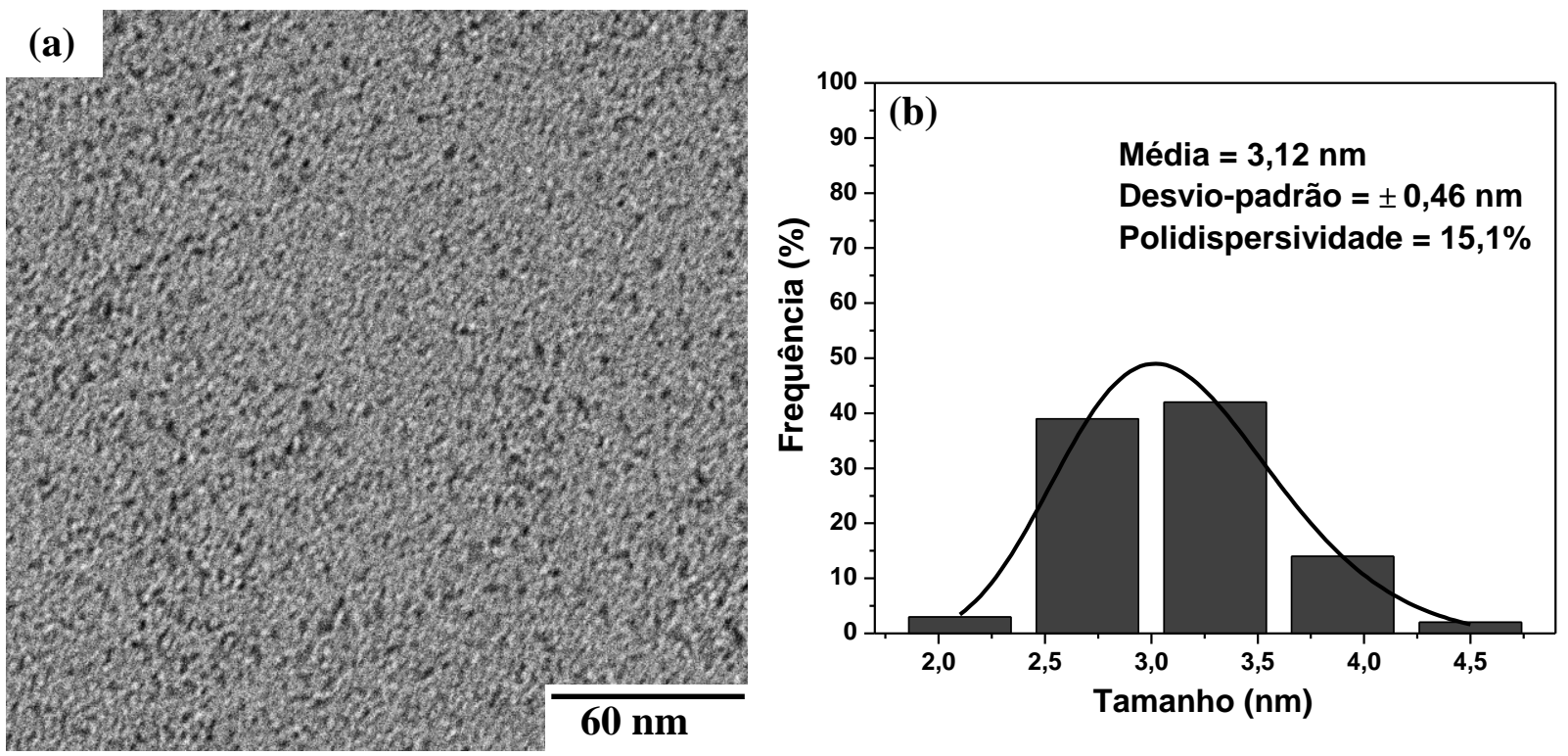

Figura 20 - DRX com o respectivo padrão de difração do CdSe com estrutura cúbica da amostra A02.

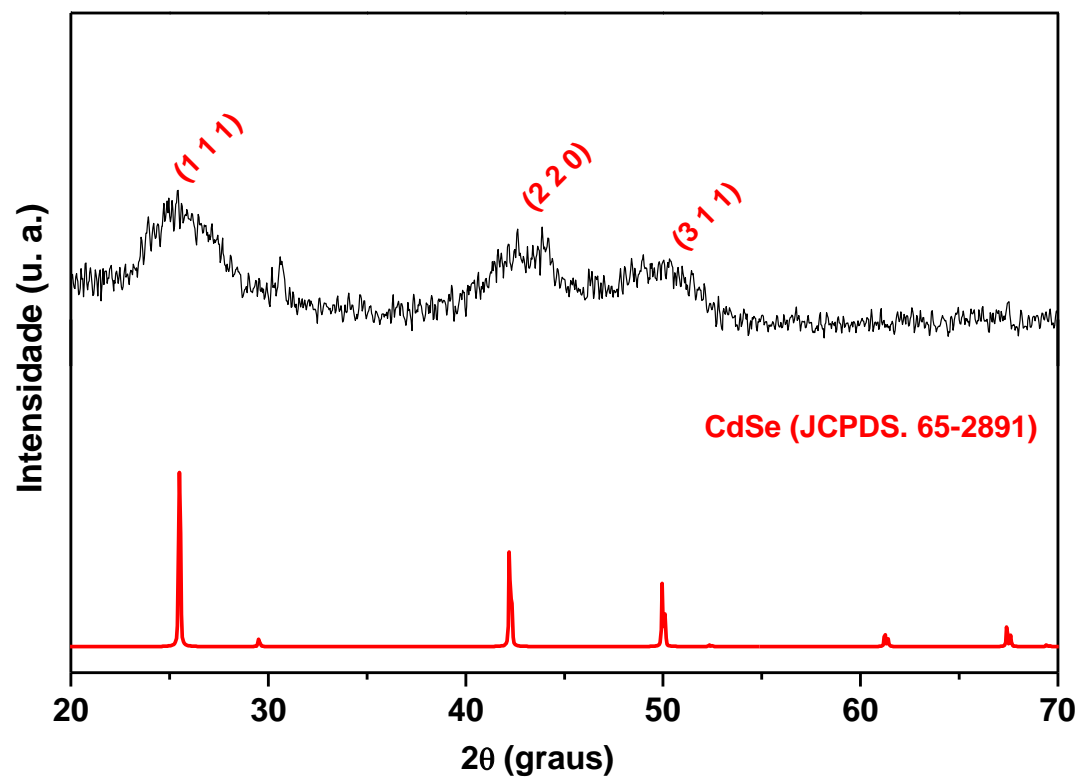

Na Figura 21, são apresentados os espectros de absorção (a) e de emissão (b) dos pontos quânticos obtidos na amostra A02. Analisando o espectro de absorção, pode-se inferir que com a diminuição do comprimento de onda houve um aumento na intensidade do processo de espalhamento. Além disso, foi também observada uma banda de absorção centrada em $517 \mathrm{~nm}$, que está de acordo com alguns resultados na literatura para os pontos quânticos nessa faixa de tamanho. E pela análise do espectro de emissão, com excitação em $400 \mathrm{~nm}$, observou-se uma 
banda de emissão bastante intensa centrada em 534 nm, o que é também bastante coerente com resultados da literatura.

Os pontos quânticos da amostra A02 obtidos nesta etapa foram utilizados como sementes para o método de mudança de estabilidade coloidal para a formação de HNE luminomagnéticas entre NPM de $\mathrm{FePt} / \mathrm{Fe}_{3} \mathrm{O}_{4}$ e pontos quânticos de CdSe.

Figura 21 - Espectros de absorção (a) e de emissão (excitação em 400 nm) (b) para a amostra A02.
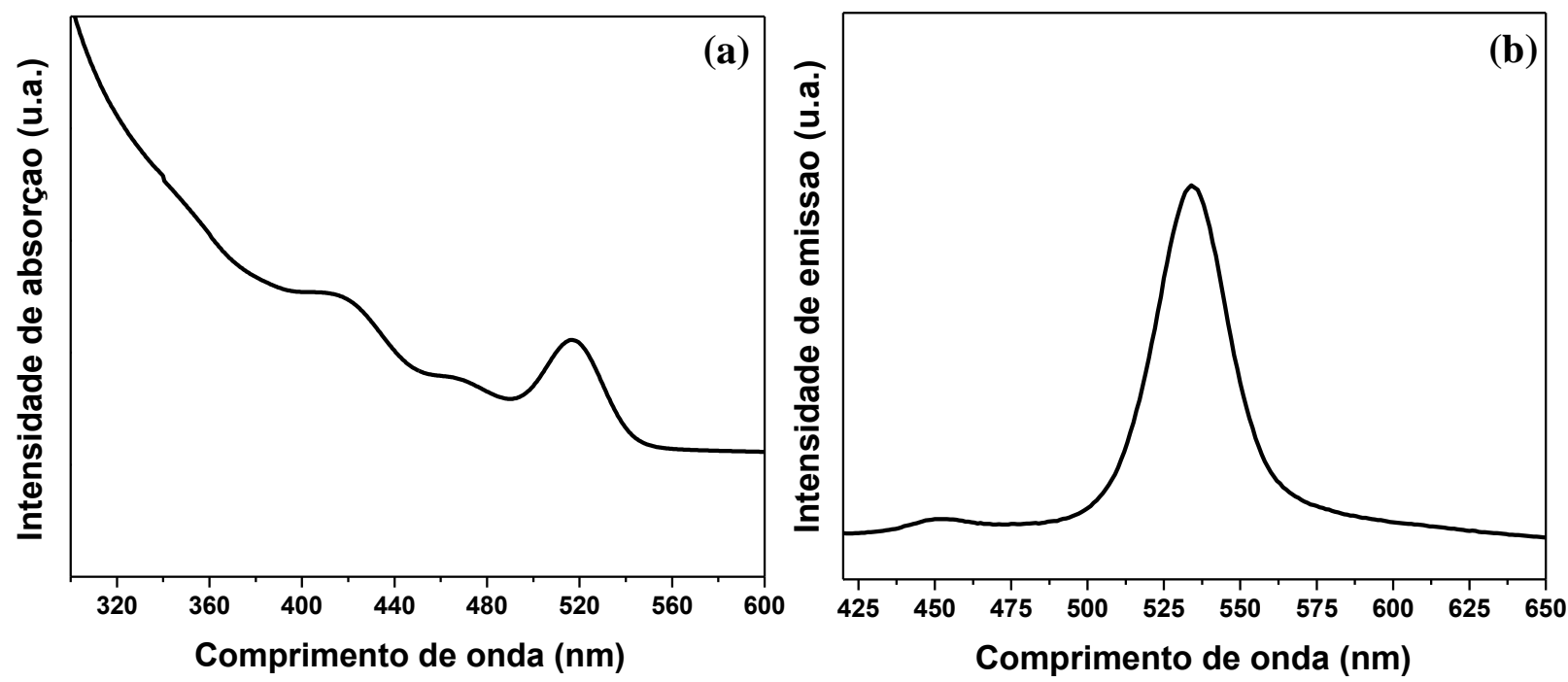

5.2.2 Obtenção das heteronanoestruturas luminomagnéticas de $\mathrm{NPM}$ de $\mathrm{FePt} / \mathrm{Fe}_{3} \mathrm{O}_{4} \mathrm{e}$ pontos quânticos de CdSe

Foram realizados dois métodos para a síntese das $\mathrm{HNE}$ de $\mathrm{NPM}$ de $\mathrm{FePt} / \mathrm{Fe}_{3} \mathrm{O}_{4}$ conjugadas aos pontos quânticos de $\mathrm{CdSe}$. O primeiro método é baseado na mudança da carga de superfície das NPM e dos pontos quânticos luminescentes preparados previamente e da força iônica do meio, para diminuir a estabilidade coloidal dos sistemas nanoparticulados e induzir a formação das HNE por meio dos sucessivos choques entre as NP. ${ }^{30}$ Já o segundo método foi baseado na injeção a quente do precursor de selênio no meio reacional contendo as NPM, ácido oleico, oleilamina e $\mathrm{Cd}(\mathrm{acac})_{2}$ em solvente orgânico, para formação e crescimento do ponto quântico na superfície das NPM. 


\subsubsection{Método de modificação da estabilidade coloidal do meio reacional por adição de sal}

Alguns trabalhos na literatura demonstraram que a mudança da estabilidade coloidal de um meio reacional contendo NP pode induzir à formação de estruturas conjugadas de NP, devido às pequenas adições de sal que podem modificar a força iônica do meio e a carga de superfície das partículas contidas neste mesmo ambiente. ${ }^{30,101}$

Para explicar a formação das HNE a partir da interação de NP em um meio reacional e da concentração de $\mathrm{NaCl}$ neste meio, pode ser usada a teoria DLVO. Essa teoria, que foi proposta pelos pesquisadores Derjaguin, Landau, Verwey e Overbeek durante a década de 1940, fornece bases teóricas para elucidar a interação entre partículas coloidais e a estabilidade coloidal. De acordo com essa teoria, a estabilidade coloidal pode ser determinada pelo balanço entre a repulsão da dupla camada elétrica (de curto alcance) e atrações por interações de van der Waals (de longo alcance). Como duas partículas se aproximam uma da outra em solução, uma barreira repulsiva aparece devido à repulsão eletrostática entre as duplas camadas elétricas das duas partículas. Quando esta barreira repulsiva é maior que $10 \mathrm{k}_{\mathrm{B}} \mathrm{T}$, onde $\mathrm{k}_{\mathrm{B}}$ é a constante de Boltzmann e $\mathrm{T}$ é a temperatura do sistema, as colisões ocorridas devido ao movimento Browniano serão suficientes para superar a barreira energética e, portanto, não ocorrer a aglomeração das partículas. Entretanto, quando a barreira repulsiva é reduzida para uma escala abaixo de $10 \mathrm{k}_{\mathrm{B}} \mathrm{T}$, é então possível que ocorra a dimerização, ou até mesmo, alto grau de agregação entre as partículas. ${ }^{30}$

Além disso, a estabilidade coloidal de partículas carregadas tem uma dependência direta com a concentração de eletrólitos no meio reacional, e por meio dessa dependência pode-se inferir que com o aumento da concentração de eletrólitos no meio, torna-se mais favorável a agregação de partículas dispersas neste sistema. Logo, há a necessidade do controle da concentração de sal adicionado ao meio reacional, para adequar a formação das HNE sem ocorrer um processo de agregação irreversível das partículas coloidais, o que acarretaria em perda de algumas propriedades das nanoestruturas contidas no sistema. ${ }^{30}$

Desta forma, utilizou-se desse conhecimento para a obtenção de HNE luminomagnéticas, a partir da conjugação de NPM e pontos quânticos previamente preparados a partir da adição de pequenas quantidades de $\mathrm{NaCl}$ e consequente modificação da estabilidade coloidal do meio, para conjugação das NP. Pela figura 22 é possível observar um esquema ilustrativo da metodologia utilizada para a obtenção das HNE luminomagnéticas com a conjugação das NPM 
de $\mathrm{FePt} / \mathrm{Fe}_{3} \mathrm{O}_{4}$ com os pontos quânticos de $\mathrm{CdSe}$ previamente preparados pelo método de decomposição térmica na seção 4.3.2 da parte experimental.

Figura 22 - Esquema ilustrativo do método da mudança de estabilidade coloidal para a formação das heteronanoestruturas luminomagnéticas de $\mathrm{FePt} / \mathrm{Fe}_{3} \mathrm{O}_{4}$ conjugadas aos pontos quânticos de CdSe previamente preparados.

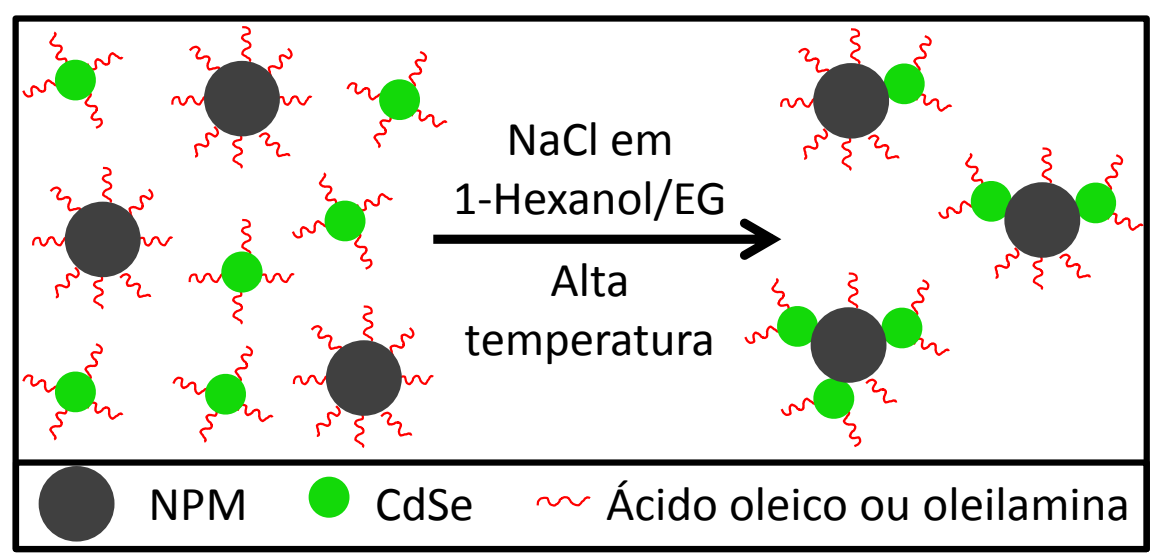

De maneira geral, neste trabalho foram utilizadas NPM de $\mathrm{FePt} / \mathrm{Fe}_{3} \mathrm{O}_{4}$ (amostra A01) e pontos quânticos de CdSe (amostra A02) previamente preparados e dispersos em uma mistura de 1-hexanol/etilenoglicol (4:1 (v/v)), e foram realizadas adições de pequenas quantidades de $\mathrm{NaCl}$ no meio reacional, com o intuito de induzir a dimerização e consequente formação de HNE devido à mudança da estabilidade coloidal do sistema. A preparação da mistura 1hexanol/etilenoglicol (4:1 (v/v)) para dispersar as nanoestruturas e o sal no meio reacional, foi necessária devido à baixa dispersividade das NP em etilenoglicol, o que tornou necessário a mistura com 1-hexanol, por se tratar de um solvente que dispersa adequadamente as partículas. A utilização de etilenoglicol na mistura foi necessária para solubilizar as pequenas quantidades de sal no meio reacional, caso que não ocorria com adição de 1-hexanol, pois o $\mathrm{NaCl}$ não se solubilizava somente nesse solvente. Foram verificados dois parâmetros reacionais para a formação das $\mathrm{HNE}$, sendo: a concentração de $\mathrm{NaCl}$ no meio reacional; e a temperatura de injeção de $\mathrm{NaCl}$.

\subsection{Efeito da concentração de cloreto de sódio}

O primeiro parâmetro verificado para o método da mudança da estabilidade coloidal por adição foi a mudança da concentração de $\mathrm{NaCl}$ no meio reacional, visando adequar a concentração ideal de eletrólitos no meio, para a formação das HNE. 
Nas amostras, foram adicionados $90 \mu \mathrm{L}, 200 \mu \mathrm{L}$ e $300 \mu \mathrm{L}$ (soluções 10 mmol. $\mathrm{L}^{-1}$ de $\mathrm{NaCl}$ em 1-hexanol/etilenoglicol (4:1 (v/v))) de solução de $\mathrm{NaCl}$ no meio com as amostras A03, A04 e A05, respectivamente. Estas adições originaram soluções com concentrações de 7,5 $\mu \mathrm{mol}$. L' 1, 16,7 $\mu$ mol. $\mathrm{L}^{-1}$ e $25 \mu \mathrm{mol} . \mathrm{L}^{-1}$, nas amostras A03, A04 e A05, respectivamente.

Figura 23 - MET das amostras: A03 (a), A04 (b) e A05 (c); e histograma de distribuição de tamanho com ajuste gaussiano da amostra A04 (d).

(a)

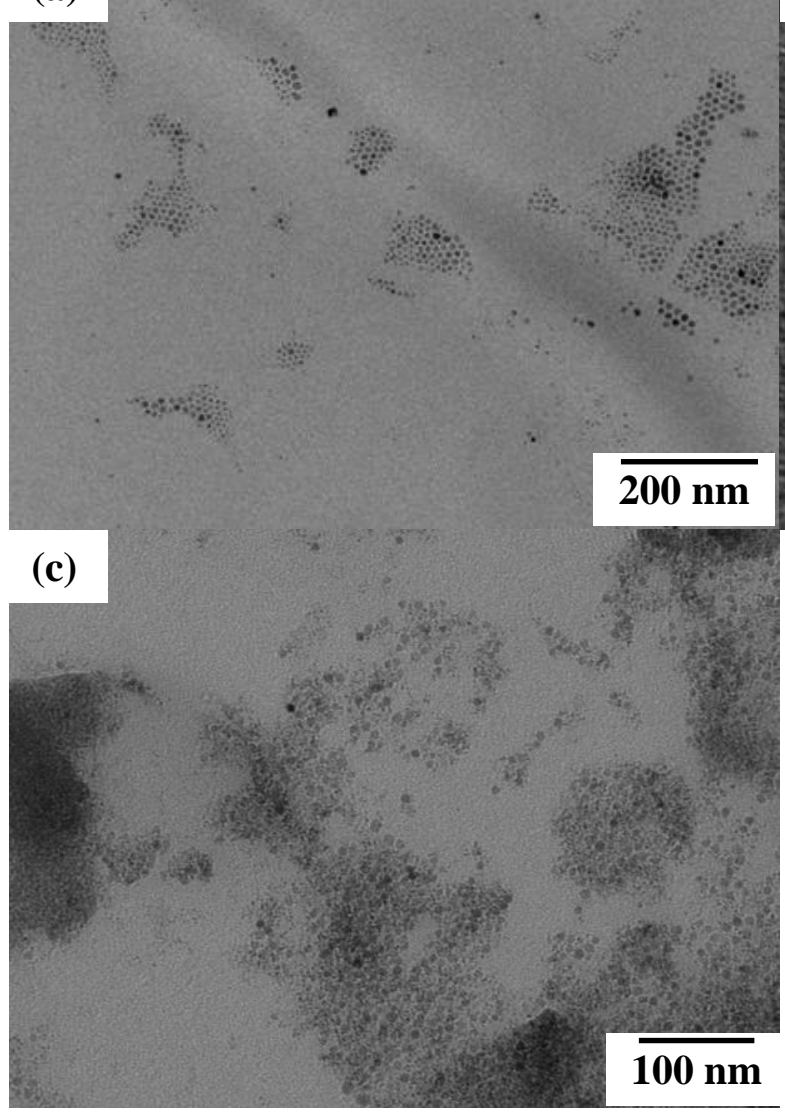

(b)

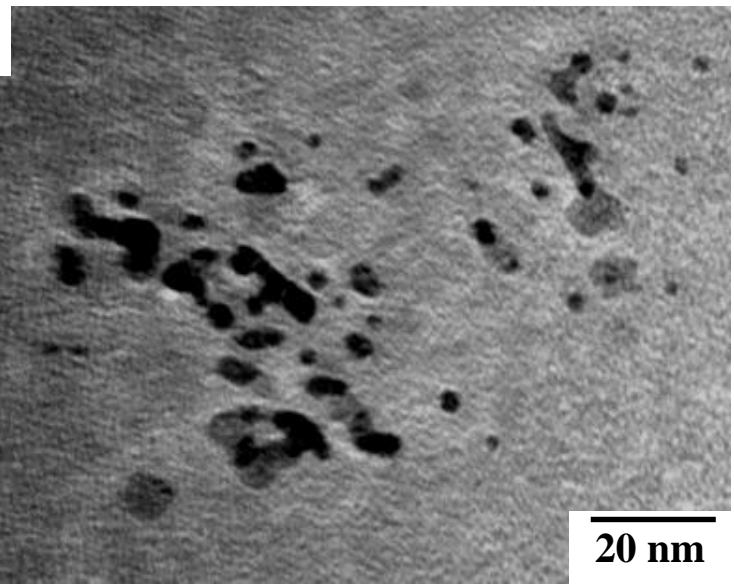

(d)

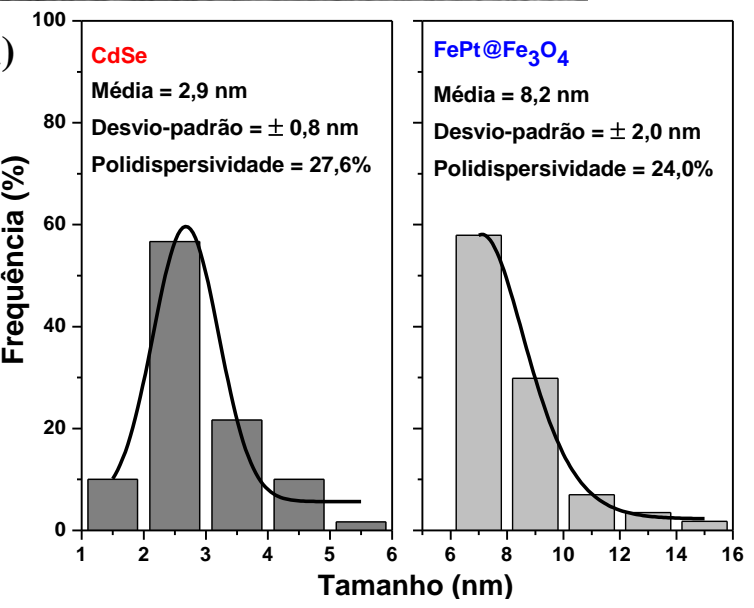

Nas micrografias da Figura 23, observa-se os resultados de MET para as amostras A03 (Figura 23(a)), A04 (Figura 23(b)) e A05 (Figura 23(c)). Na amostra A03, observou-se a autoorganização das NPM e dos pontos quânticos, o que constatou a influência da adição de sal na aproximação das nanoestruturas, porém não houve a conjugação das mesmas. Com o aumento da concentração de sal (amostra A04), observou-se a conjugação entre as NPM (partículas maiores e com menor contraste) e os pontos quânticos (partículas menores e com maior contraste). Já para a amostra A05, observou-se que a concentração de sal chegou a um limiar, pois ocasionou o início de agregação entre as partículas, o que não é desejado para a manutenção das propriedades individuais de cada nanoestrutura. Na Figura 23 (d) pode ser visto um 
histograma de distribuição de tamanho para a amostra A04, na qual os pontos quânticos de CdSe apresentaram um tamanho médio de $\mathrm{d}=2,9 \mathrm{~nm}$, com um desvio-padrão de $\mathrm{SD}= \pm 0,8$ nm e uma polidispersividade $\sigma=27,8 \%$, e as NPM apresentaram um tamanho médio $\mathrm{d}=8,2$ $\mathrm{nm}$, um desvio-padrão de $\mathrm{SD}= \pm 2,0 \mathrm{~nm}$ e uma polidispersividade de $\sigma=24,0 \%$. Apesar da alta polidispersividade, esta amostra foi a que apresentou maior formação das HNE, pela análise das micrografias obtidas para amostra A04.

A Figura 24 mostra os espectros de absorção (a) e de emissão (b) para as amostras A03 (em preto), A04 (em azul) e A05 (em vermelho). A análise dos espectros de absorção dessas amostras revela, pela inclinação de suas curvas, a presença de espalhamento em todas elas, o que é bastante comum nos espectros de absorção de pontos quânticos de CdSe na faixa de tamanho médio de 3,2 nm, de acordo com a literatura. Já nos espectros de emissão, com excitação em $400 \mathrm{~nm}$, observaram-se bandas de emissão de 450 nm, $452 \mathrm{~nm}$ e $453 \mathrm{~nm}$ para as amostras A03, A04 e A05, respectivamente. Houve um pequeno deslocamento para maiores comprimentos de onda nas amostras, entretanto, a presença dessas bandas de emissão na região do visível constatou a formação de pontos quânticos com tamanho controlado. Salienta-se que a amostra A03 apresentou uma pequena banda de emissão próxima de $520 \mathrm{~nm}$, o que pode ser explicado pela proximidade e interação entre os pontos quânticos presentes na amostra, já que houve auto-organização nesse sistema.

Figura 24 - (a) Espectros de absorção e (b) de emissão (excitação em 400 nm) das amostras: A03 (em preto), A05 (em vermelho) e A04 (em azul).
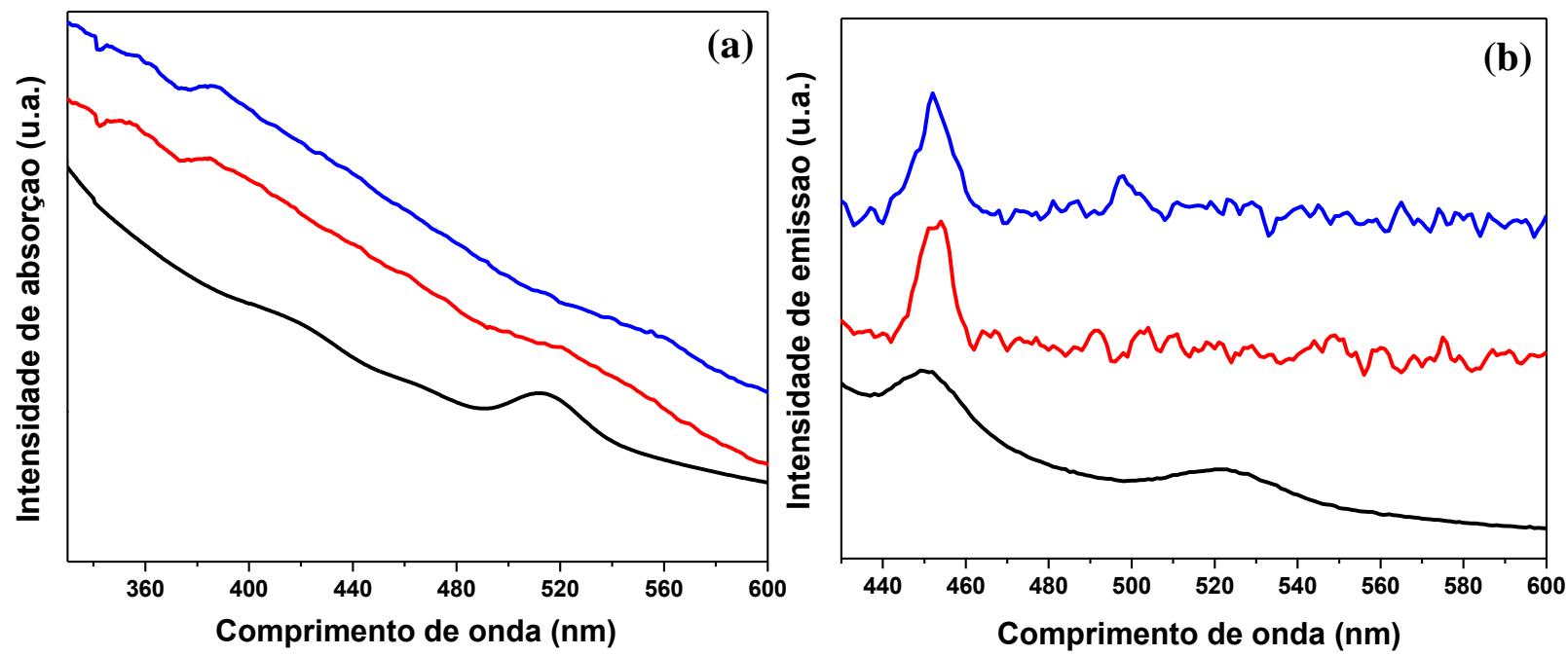

Como os resultados obtidos pela amostra A04 foram mais satisfatórios em relação à formação de HNE, realizou-se a medida de DRX dessa amostra (Figura 25). De acordo com a 
Figura 25, quando se comparou os padrões de difração das estruturas cúbicas da FePt (29-717), da $\mathrm{Fe}_{3} \mathrm{O}_{4}$ (19-629) e do CdSe (65-2891) com a amostra A04, foram observadas as principais fases cristalográficas dessas estruturas, porém com um grande sinal-ruído no difratograma, o que demonstra pouca cristalinidade dessa amostra. Para a fase da FePt foram observados pequenos picos centrados em $2 \theta$ na região de: $40^{\circ}$ e $46,5^{\circ}$, referentes aos planos de difração (111) e (200), respectivamente. Para a magnetita $\left(\mathrm{Fe}_{3} \mathrm{O}_{4}\right)$ foram observados picos mais intensos centradas em $2 \theta$ na região de: $30,4^{\circ} ; 35,7^{\circ} ; 57,5^{\circ}$; e $63^{\circ}$, referentes aos planos de difração $(220)$, (311), (511) e (440), respectivamente. Já para o CdSe foram observados pequenos picos centrados em $2 \theta$ na região de: $24^{\circ} ; 43^{\circ}$; e $50^{\circ}$, referentes aos planos de difração (111), (220) e (311), respectivamente.

Figura 25 - DRX com os respectivos padrões de difração da amostra A04.

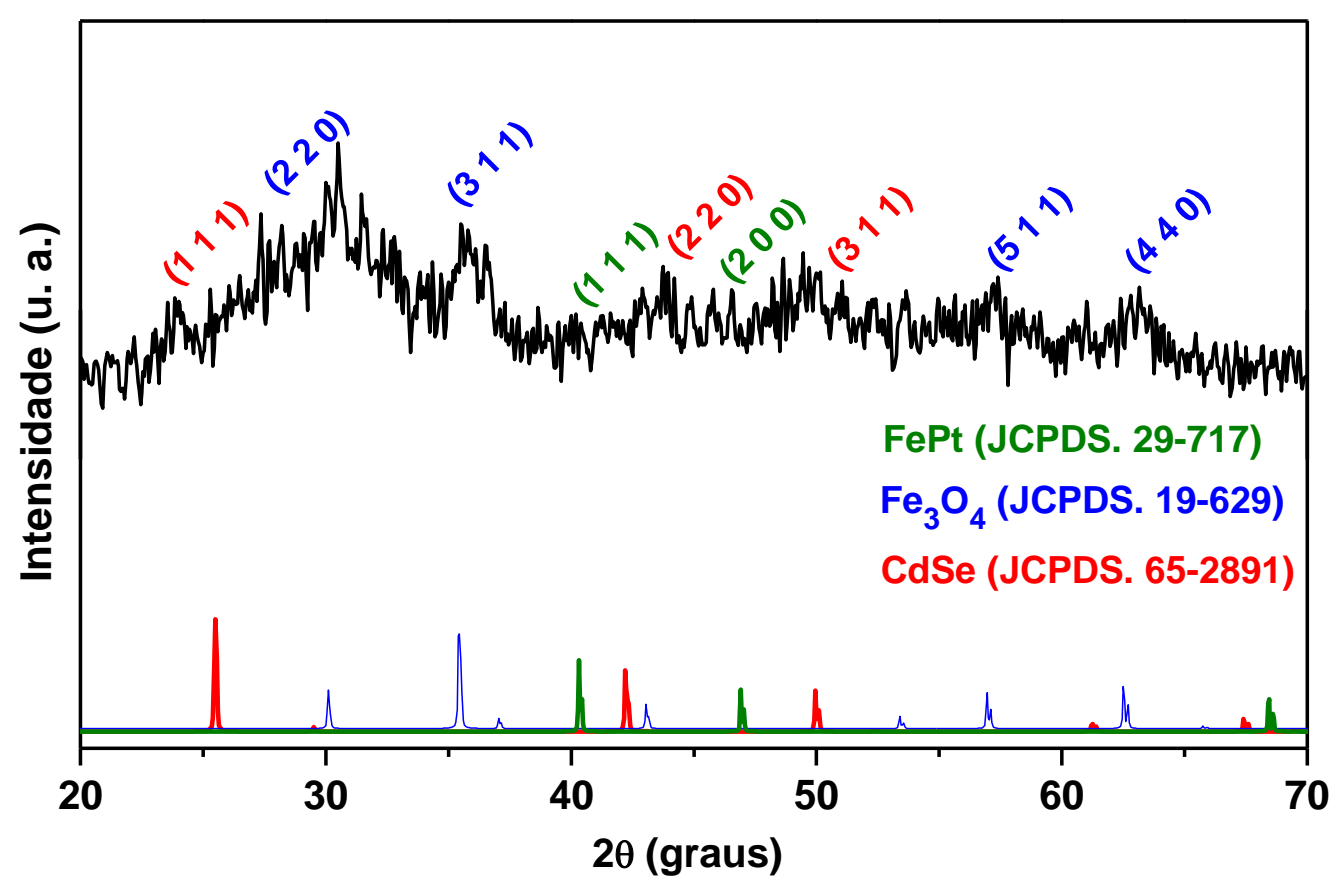

\subsection{Efeito da temperatura}

Outro efeito analisado pelo método de mudança da estabilidade coloidal por adição de sal foi a temperatura. Sabe-se que o aumento da temperatura pode facilitar a formação das HNE, conforme explicado na seção 5.2.2.1 da parte experimental. Desta forma, os procedimentos foram realizados na temperatura de $120^{\circ} \mathrm{C}$ (amostra A04) e a temperatura de refluxo do sistema que é $159^{\circ} \mathrm{C}$ (amostra A06). 
De acordo com os resultados de MET na Figura 26, para amostras A04 (a) e A06 (b), observou-se que a amostra A06 apresentou maior formação de HNE que a amostra A04, pois na maior parte do sistema constatou-se a presença de NPM e pontos quânticos conjugados por suas superfícies. A partir do histograma da Figura 26(c), observou-se que nas HNE da amostra A06, os pontos quânticos obtiveram tamanho médio de $\mathrm{d}=3,1 \mathrm{~nm}$, com um desvio-padrão de $\mathrm{SD}= \pm 0,6 \mathrm{~nm}$ e uma polidispersividade $\sigma=19,6 \%$, e as NPM apresentaram um tamanho médio $\mathrm{d}=8,0 \mathrm{~nm}$, um desvio-padrão de $\mathrm{SD}= \pm 1,2 \mathrm{~nm}$ e uma polidispersividade de $\sigma=15,0$ \%. Comparando-se os histogramas das amostras A04 (Figura 23(d)) e A06 (Figura 26(c)), é possível afirmar que o aumento na temperatura foi satisfatório para a formação das HNE, devido ao maior controle da polidispersividade apresentado nas partículas da amostra A06.

Figura 26 - MET das amostras: A04 (a) e A06 (b); e histograma de distribuição de tamanho com ajuste gaussiano da amostra A06 (c).

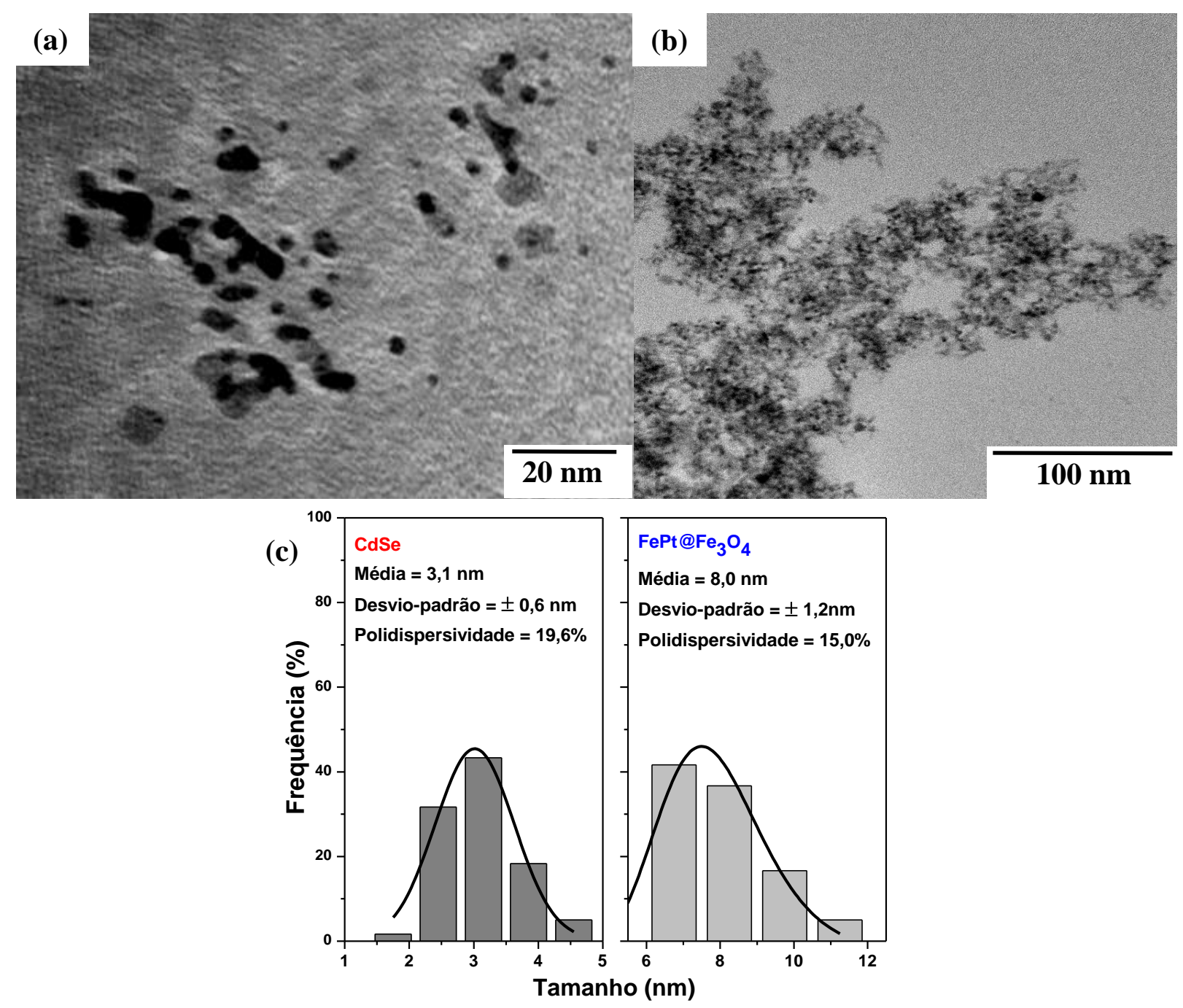


Figura 27 - (a) Espectros de absorção e (b) de emissão (excitação em $400 \mathrm{~nm}$ ) das amostras: A04 (em preto) e A06 (em azul).
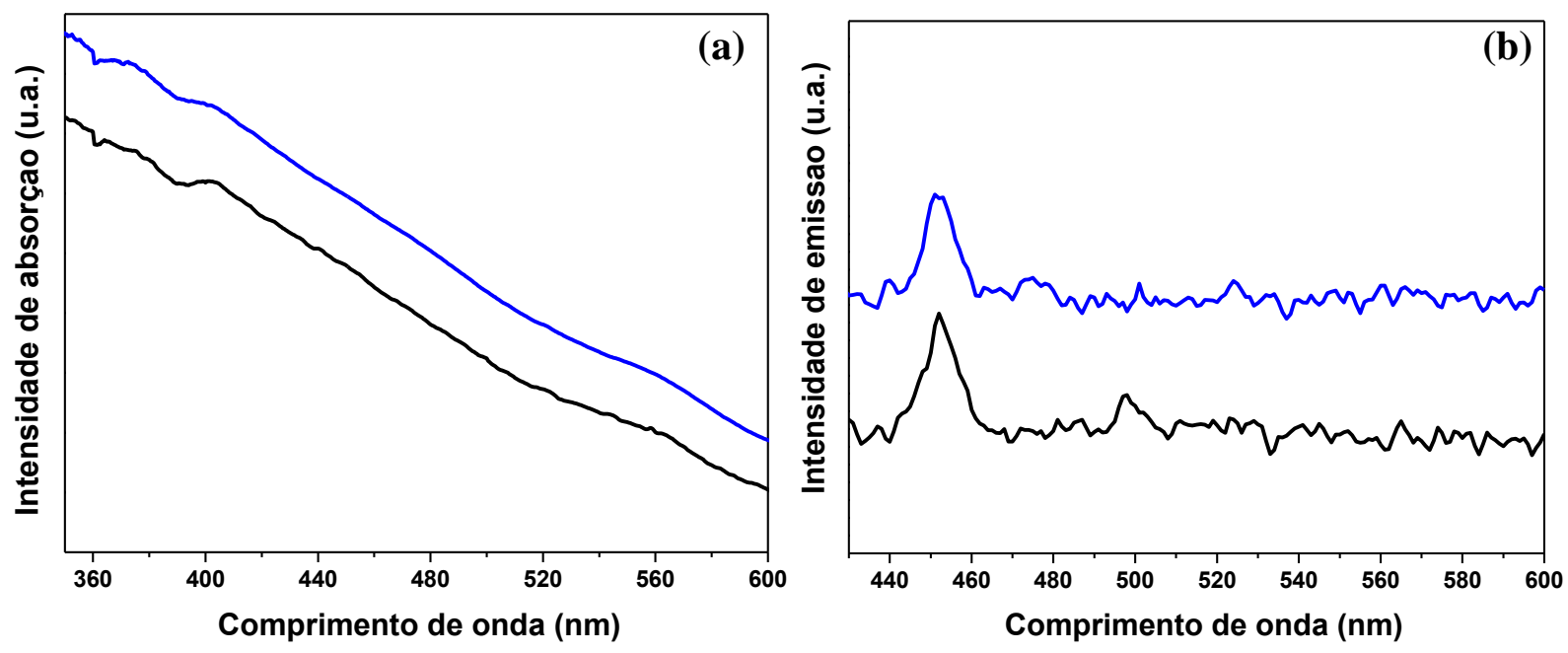

Na Figura 27 podem ser observados os espectros de absorção (figura 27(a)) e de emissão (figura 27(b)) para as amostras A04 (em preto) e A06 (em azul). Pelos espectros de absorção das duas amostras, a inclinação das curvas de absorção demonstrou um processo de espalhamento com a diminuição do comprimento de onda de absorção, o que é característico para os pontos quânticos nesta faixa de tamanho. Já no espectro de emissão, com excitação em $400 \mathrm{~nm}$, observou-se que as duas amostras tiveram bandas de emissão centradas em $452 \mathrm{~nm}$, o que pode ser correlacionado com os tamanhos médios próximos dos pontos quânticos nestas duas amostras.

Na Figura 28 pode-se observar a análise de DRX da amostra A06. Foram observadas as principais fases cristalográficas quando se comparou a amostra A06 com os padrões de difração das estruturas cúbicas da FePt (29-717), da $\mathrm{Fe}_{3} \mathrm{O}_{4}$ (19-629) e do CdSe (65-2891). Para a fase da FePt foram observados pequenos picos centrados em $2 \theta$ na região de: $40,5^{\circ}$ e $46,8^{\circ}$, referentes aos planos de difração (111) e (200), respectivamente. Para a magnetita $\left(\mathrm{Fe}_{3} \mathrm{O}_{4}\right)$ foram observados picos mais intensos centrados em $2 \theta$ na região de: $30,3^{\circ} ; 35,6^{\circ} ; 57^{\circ}$; e $62,8^{\circ}$, referentes aos planos de difração (220), (311), (511) e (440), respectivamente. Já para o CdSe foram observados também picos intensos centrados em $2 \theta$ na região de: $25^{\circ} ; 42,2^{\circ}$; e $49^{\circ}$, referentes aos planos de difração (111), (220) e (311), respectivamente. Comparando-se os resultados de DRX para as amostras A04 (Figura 15) e A06 (Figura 18) pode-se inferir que as heteroestruturas da amostra A06 (produzida em maior temperatura) apresentaram maior cristalinidade das fases presentes no difratograma. 
Figura 28 - DRX com os respectivos padrões de difração da amostra A06.

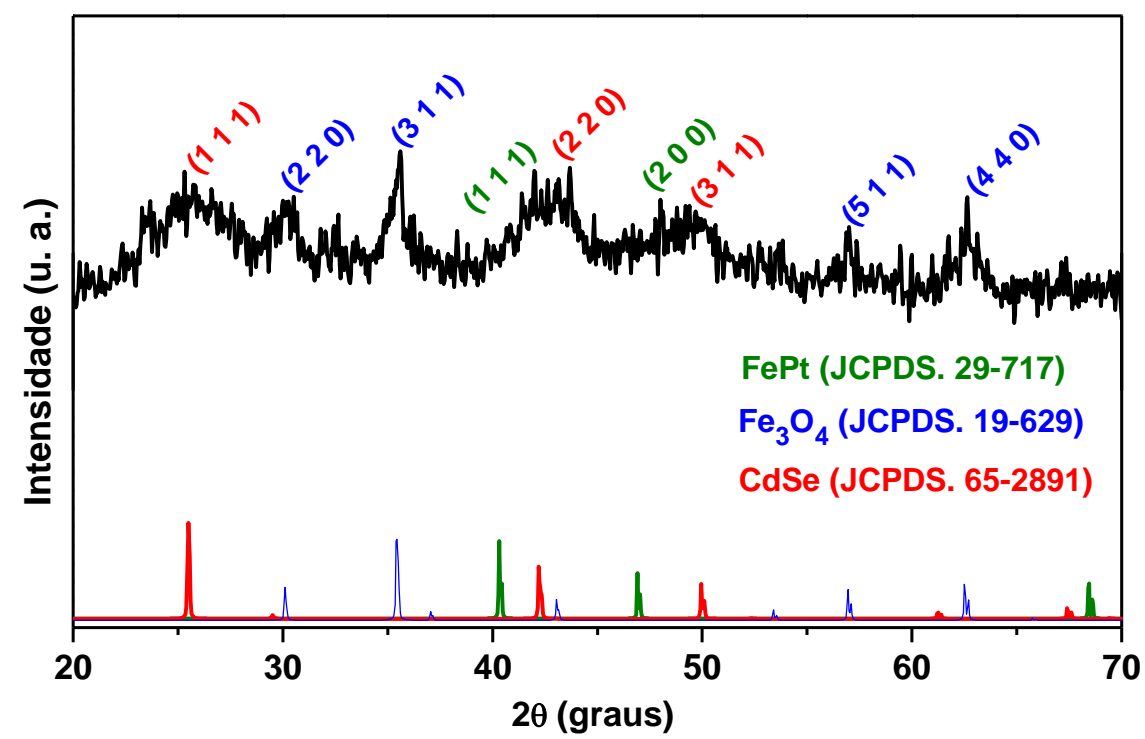

\subsubsection{Método de injeção a quente na presença de sementes de NPM}

Este método se baseia na formação de HNE a partir da injeção à quente do precursor de selênio no meio reacional, na presença de sementes de NPM de $\mathrm{FePt} / \mathrm{Fe}_{3} \mathrm{O}_{4}$, do precursor de cádmio $\left(\mathrm{Cd}(\mathrm{acac})_{2}\right)$ e dos agentes de superfície (ácido oléico e oleilamina). A importância da injeção a quente para a formação e crescimento das heteroestruturas é baseada nos mesmos conceitos discutidos no item 5.2.1 dos resultados e discussão. A grande diferença desta etapa da síntese em comparação com a metodologia discutida na formação e crescimento dos pontos quânticos de CdSe, é que neste caso há a presença de sementes de NPM previamente preparadas no meio reacional, e a nucleação e crescimento dos pontos quânticos de $\mathrm{CdSe}$ se darão na superfície das NPM de $\mathrm{FePt} / \mathrm{Fe}_{3} \mathrm{O}_{4}$. Pela figura 29 é possível observar um esquema ilustrativo para a obtenção das $\mathrm{HNE}$ luminomagéticas de $\mathrm{FePt} / \mathrm{Fe}_{3} \mathrm{O}_{4}-\mathrm{CdSe}$ a partir do método de injeção a quente dos precursores dos pontos quânticos na presença das NPM. Para isto serão discutidos alguns conceitos teóricos da formação de HNE com a presença de sementes que apresentam estrutura e propriedades diferenciadas da nanoestrutura adicional que será formada posteriormente em sua superfície. 
Figura 29 - Esquema ilustrativo da formação das heteronanoestruturas luminomagnéticas de $\mathrm{FePt} / \mathrm{Fe}_{3} \mathrm{O}_{4}-\mathrm{CdSe}$ pelo método de injeção a quente na presença de NPM como sementes.

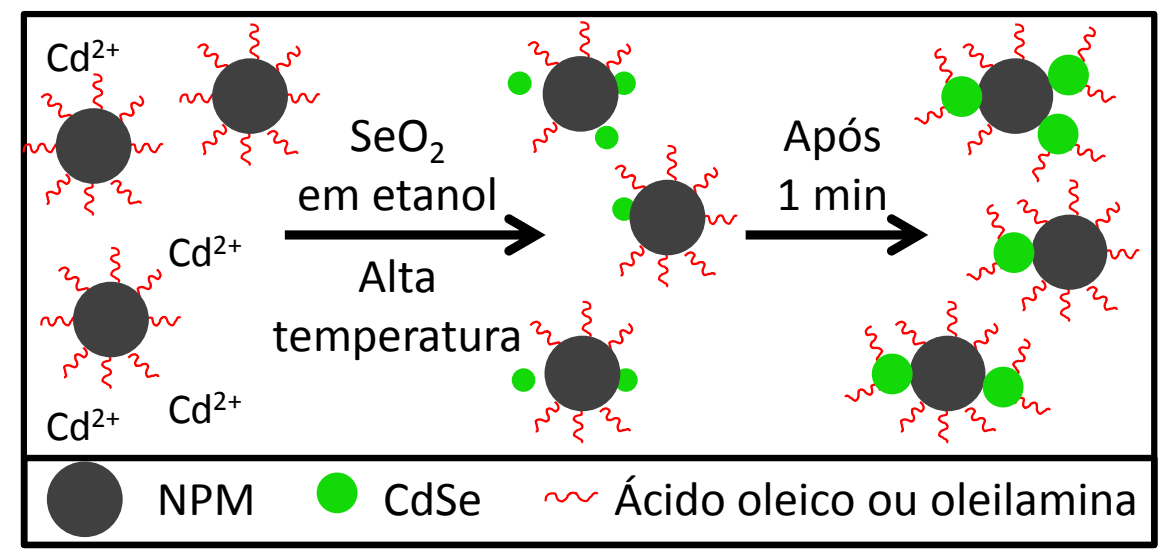

Primeiramente, a formação de uma HNE requer a formação de uma ou múltiplas interfaces inorgânicas entre materiais estruturalmente e quimicamente diferentes. ${ }^{26}$ Do ponto de vista termodinâmico, se o nanomaterial que será formado possuir energia de superfície ou interfacial menor que o nanomaterial que atua como semente no meio reacional, ou mesmo que os nanomateriais tenham alta similaridade cristalográfica, então sua deposição será comumente realizada camada sobre camada, resultando em um recobrimento uniforme e contínuo. Entretanto, se o nanomaterial que será formado possuir energia de superfície ou interfacial maior que a semente no meio reacional, ou forem cristalograficamente incompatíveis, a tendência é o novo material se depositar de tal forma a minimizar a área interfacial de contato com a semente, formando-se domínios descontínuos na superfície da semente. Outro caminho para entendimento da nucleação e crescimento das HNE é a partir da teoria da nucleação clássica. De acordo com esta teoria, a barreira energética para a nucleação homogênea de nanocristais isolados em solução é relativamente mais alta, quando comparada com a barreira energética de nucleação heterogênea sobre sementes pré-existentes no meio reacional, o que favorece a formação de HNE quando formadas na presença de nanomateriais pré-existentes. ${ }^{26}$ Para maiores detalhes ver na seção 2.3 da fundamentação teórica.

Desta forma, no processo de nucleação e crescimento dos pontos quânticos de $\mathrm{CdSe}$ na superfície das NPM de $\mathrm{FePt} / \mathrm{Fe}_{3} \mathrm{O}_{4}$, devido à alta energia de superfície dos pontos quânticos de CdSe quando nucleados na superfície das NPM, a tendência é que haja um crescimento dos pontos quânticos em domínios descontínuos, ocasionando a formação de diversas ilhas de nanocristais de CdSe associadas às NPM. Porém, para o controle da nucleação e crescimento dos pontos quânticos na superfície das NPM existem muitos fatores que podem influenciar na 
formação das HNE, entre eles: natureza e concentração dos precursores; quantidade e tamanho das sementes no meio reacional; natureza, quantidade e proporção de agentes de superfície; temperatura da reação; natureza do solvente; entre outros. ${ }^{25,26}$

Neste trabalho, para obtenção das HNE luminomagnéticas de $\mathrm{FePt} / \mathrm{Fe}_{3} \mathrm{O}_{4}-\mathrm{CdSe}$ foram ajustados alguns parâmetros reacionais, tendo em vista o controle morfológico, estrutural e as propriedades magnéticas e luminescentes destes sistemas. Os parâmetros ajustados foram: efeito dos agentes de superfície (ácido oleico e oleilamina); efeito da temperatura de injeção à quente $\left(160^{\circ} \mathrm{C}, 220^{\circ} \mathrm{C}\right.$ ou $\left.280^{\circ} \mathrm{C}\right)$; efeito do solvente (dioctiléter, dibenziléter e octadeceno); e efeito da quantidade inicial de sementes de NPM. Em seguida, será discutido cada um destes estudos.

\subsection{Efeito dos agentes de superfície}

Para o método de injeção a quente de precursor de selênio na presença de NPM e precursor de cádmio no meio reacional, o primeiro parâmetro adequado foi a quantidade e proporção dos agentes de superfície no sistema (maiores detalhes das condições experimentais estão na seção 4.2.2.2 da Parte Experimental).

Os agentes de superfície são essenciais no controle do processo de crescimento dos pontos quânticos de CdSe nas HNE luminomagnéticas. Eles atuam na diminuição da energia de superfície das HNE, o que aumenta a estabilidade coloidal destes sistemas no meio reacional, além de propiciar um controle na taxa de crescimento das partículas do sistema.

Os agentes de superfície que foram utilizados na síntese das HNE foram o ácido oleico e a oleilamina. A utilização destas moléculas se deve à capacidade destas em se coordenar em superfícies metálicas e de óxidos metálicos, além da alta solubilidade delas nos solventes orgânicos utilizados nestas sínteses.

Pela Figura 30 foram analisadas as micrografias feitas por MET para as amostras A07 (a), A08 (b), A09 (c), A10 (d) e A11 (e). Na amostra A07 foi adicionada na síntese quantidades de $0,1 \mathrm{mmol}$ de ácido oleico e 0,2 mmol de oleilamina, e isto ocasionou a formação de algumas HNE, porém com muitas regiões com agregados. Com isso, foram adicionados ácido oleico e oleilamina em excesso (amostra A08), sendo 0,4 mmol de cada um dos agentes de superfície, e isto não resultou no controle da nucleação e crescimento das HNE. Desta forma, na amostra A09 diminuíram-se as quantidades de ácido oleico e oleilamina (mantendo-se a proporção (1:1)) para 0,2 mmol de cada um deles. A condição da amostra A09 foi a melhor condição de quantidades e proporção de ácido oléico e oleilamina até então, pois foi adequada para manter 
uma proximidade entre as NPM e os pontos quânticos, evitando a agregação, e também ocorreu um aumento na formação de HNE.

Após uma condição ideal encontrada, foram analisadas a influência que teria a presença de apenas um dos dois agentes de superfície no meio reacional, e com isso foram utilizadas somente 0,4 mmol de oleilamina na amostra A10 e no caso da amostra A11 somente 0,4 mmol de ácido oleico como agente de superfície. Foi possível observar que nos dois casos ocorreram alta agregação, destacando-se a importância de se utilizar os dois agentes de superfície na síntese.

Na Figura 30(e) pode ser visto um histograma de distribuição de tamanho para a amostra A09. Analisando o histograma observou-se que nas HNE desta amostra, os pontos quânticos obtiveram tamanho médio de $\mathrm{d}=2,2 \mathrm{~nm}$, com um desvio-padrão de $\mathrm{SD}= \pm 0,4 \mathrm{~nm}$ e uma polidispersividade $\sigma=18,2 \%$, e as NPM apresentaram um tamanho médio $\mathrm{d}=9,2 \mathrm{~nm}$, um desvio-padrão de $\mathrm{SD}= \pm 1,4 \mathrm{~nm}$, resultando em uma polidispersividade de $\sigma=15,2 \%$.

Figura 30 - MET das amostras: A07 (a), A08 (b), A09 (c), A10 (d) e A11 (e); e histograma de distribuição de tamanho com ajuste gaussiano da amostra A09 (f).

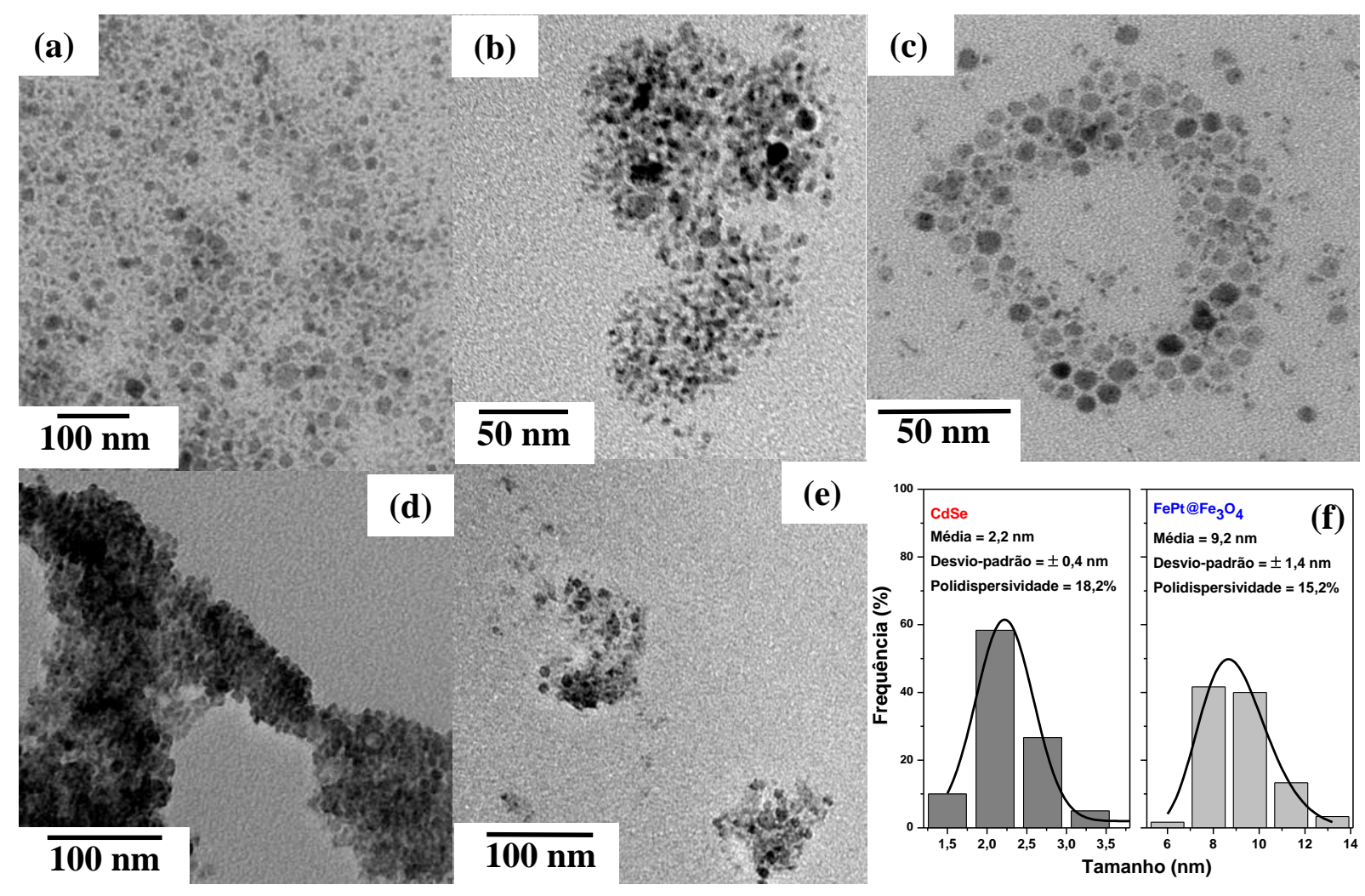

A Figura 31 mostra os espectros de absorção (a) e de emissão (b) para as amostras A07 (em preto), A08 (em vermelho), A09 (em azul), A10 (em amarelo) e A11 (em verde). Os 
espectros de absorção de todas as amostras seguiram a característica espectral de pontos quânticos de CdSe em tamanho reduzido, que é um alto espalhamento conforme o comprimento de onda do feixe incidente diminui. Com relação aos espectros de emissão, com excitação em $400 \mathrm{~nm}$, observou-se que todas as amostras tiveram bandas de emissão com comprimento de onda em torno de $452 \mathrm{~nm}$. Com os resultados obtidos pode-se inferir que mesmo nas amostras A10 e A11, que as partículas ficaram mais agregadas, não houve alta agregação dos pontos quânticos de CdSe, uma possível explicação é que pode ter ocorrido a agregação das NPM de $\mathrm{FePt} / \mathrm{Fe}_{3} \mathrm{O}_{4}$, que atuou como uma matriz para os pontos quânticos conjugados permanecerem na mesma faixa de tamanho após nucleação e crescimento.

Figura 31 - (a) Espectros de absorção e (b) de emissão (excitação em $400 \mathrm{~nm}$ ) das amostras: A07 (em preto) e A09 (em azul), A08 (em vermelho), A11 (em verde), A10 (em amarelo).
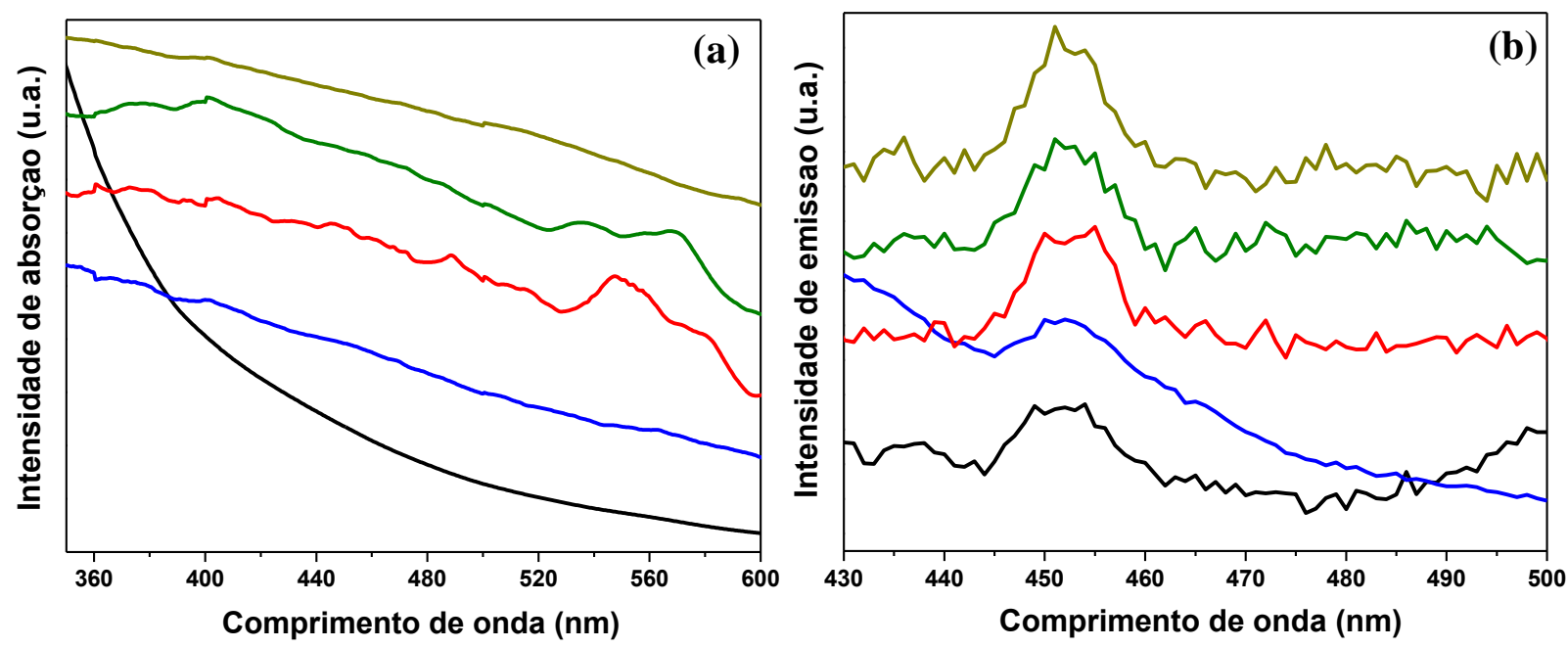

Para a amostra com a melhor condição de síntese encontrada (amostra A09) foi feito uma análise de DRX (Figura 32) para verificar as fases cristalográficas presentes nas HNE obtidas. Foram utilizados como padrões de difração as estruturas cúbicas da $\mathrm{FePt}$ (29-717), da $\mathrm{Fe}_{3} \mathrm{O}_{4}$ (19-629) e do CdSe (65-2891). Para a fase da FePt foram observados picos muito pequenos centrados em $2 \theta$ na região de: $40^{\circ}$ e em $47,5^{\circ}$, referentes aos planos de difração (111) e (200), respectivamente. Para a magnetita $\left(\mathrm{Fe}_{3} \mathrm{O}_{4}\right)$ foram observados picos mais intensos centrados em $2 \theta$ na região de: $30,4^{\circ} ; 35,7^{\circ} ; 57,1^{\circ}$; e $62,9^{\circ}$, referentes aos planos de difração (220), (311), (511) e (440), respectivamente. Já para o CdSe foram observados também picos intensos centrados em $2 \theta$ na região de: $25,7^{\circ} ; 42,7^{\circ}$; e $49,7^{\circ}$, referentes aos planos de difração (111), (220) e (311), respectivamente. 
Figura 32 - DRX com os respectivos padrões de difração da amostra A09.

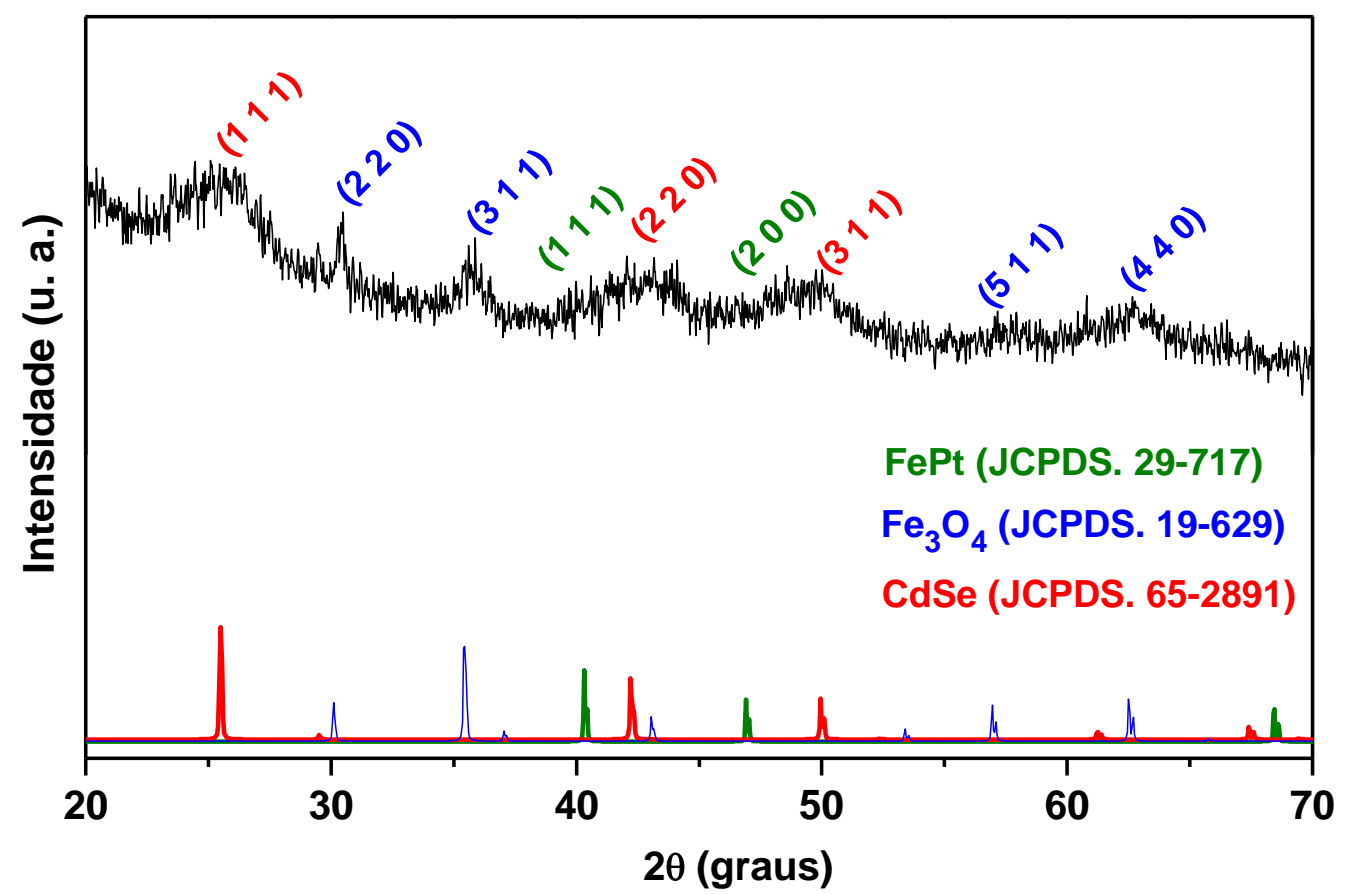

\subsection{Efeito da temperatura}

Outro efeito analisado no método de injeção a quente foi a temperatura de injeção do CdSe. Este parâmetro é muito importante, pois pode afetar tanto na cinética de crescimento dos pontos quânticos na superfície das sementes de NPM, como na difusão dos pontos quânticos e das NPM na superfície um do outro para a formação da HNE. As temperaturas de injeção analisadas para nucleação e crescimento das $\mathrm{HNE}$ foram $160^{\circ} \mathrm{C}, 220^{\circ} \mathrm{C}$ e $280^{\circ} \mathrm{C}$ (próximo da temperatura de refluxo do dioctiléter, utilizado como solvente).

Conforme é apresentado na Figura 33, foram analisados os resultados por MET para as amostras A09 (a), A12 (b) e A13 (c), nas quais as HNE foram obtidas com temperatura de injeção de 160,220 e $280{ }^{\circ} \mathrm{C}$, respectivamente. Comparando-se as amostras para análise do efeito da temperatura de injeção, para nucleação e crescimento dos pontos quânticos nas HNE, constatou-se que a temperatura de injeção mais adequada foi de $160{ }^{\circ} \mathrm{C}$ (amostra A12). A amostra com temperatura de injeção de $280{ }^{\circ} \mathrm{C}$ não apresentou condição propicia para formação das HNE, pois houve a formação de agregados nesta temperatura.

Na Figura 33(d) foi feito um histograma de distribuição de tamanho para a amostra A12. Analisando o histograma observou-se que nas HNE desta amostra, os pontos quânticos obtiveram tamanho médio de $\mathrm{d}=2,6 \mathrm{~nm}$, com um desvio-padrão de $\mathrm{SD}= \pm 0,4 \mathrm{~nm}$ e uma 
polidispersividade $\sigma=15,4 \%$, e as NPM apresentaram um tamanho médio $\mathrm{d}=8,9 \mathrm{~nm}$, um desvio-padrão de $\mathrm{SD}= \pm 1,0 \mathrm{~nm}$, e uma polidispersividade de $\sigma=11,2 \%$.

Figura 33 - MET das amostras: A09 (a), A12 (b), A13 (c), e histograma de distribuição de tamanho com ajuste gaussiano da amostra A12 (d).

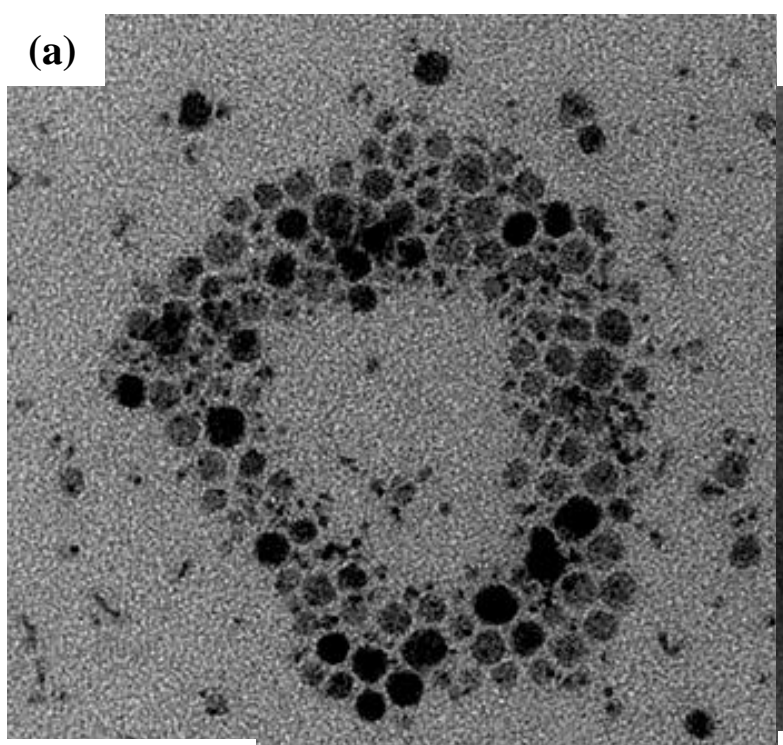

(b)

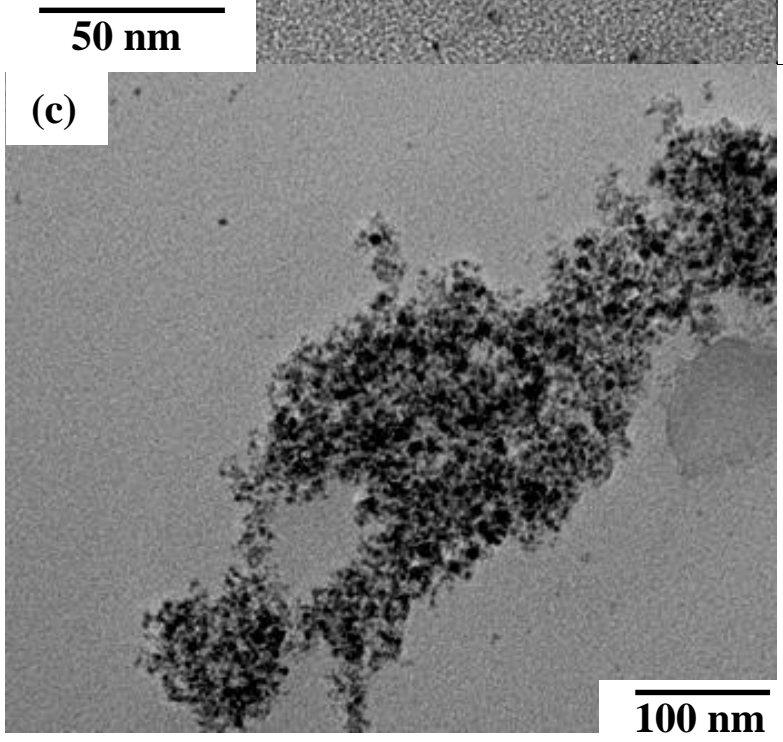

\section{$\overline{10 ~ n m}$}

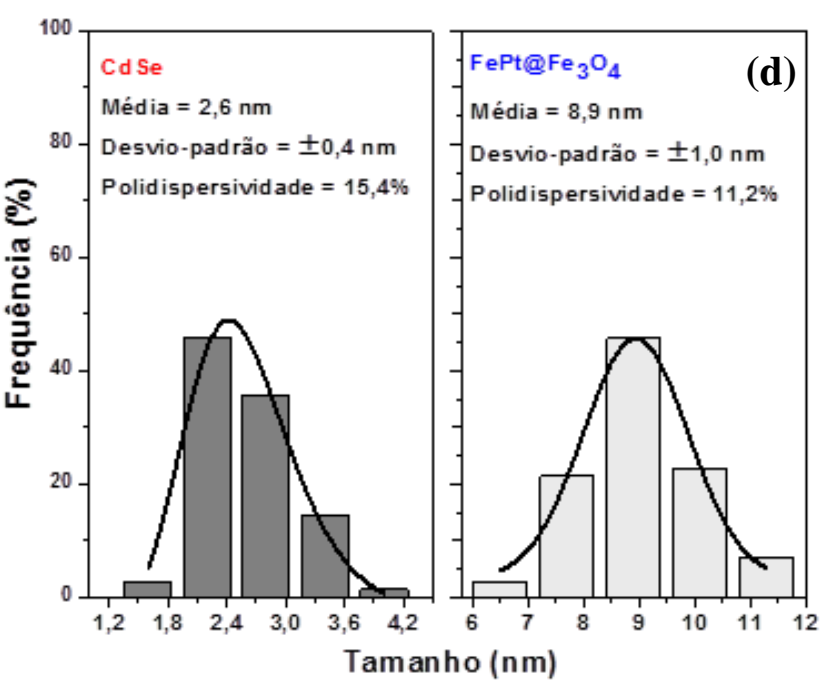

Comparando-se os histogramas das amostras A09 e A12 (Figuras 30(f) e 33(d), respectivamente), observou-se que a polidispersividade tanto dos pontos quânticos quanto das NPM foram menores para a amostra A12. Além disso, houve maior formação de HNE luminomagnéticas na amostra A12, o que evidenciou que a temperatura de $160{ }^{\circ} \mathrm{C}$ foi mais adequada para a injeção. Uma possível explicação é que, neste caso, a menor temperatura para nucleação e crescimento propiciou um crescimento mais lento dos pontos quânticos na 
superfície das NPM, o que levou a uma maior difusão das nanoestruturas na superfície das NPM. Além disso, a menor temperatura não prejudicou muito a etapa rápida de nucleação, o que pode ser evidenciado pela pequena polidispersividade da amostra A12.

Na Figura 34 são apresentados espectros de absorção (a) e emissão (b) para amostras A09 (em azul), A12 (em preto) e A13 (em vermelho). Pelos espectros de absorção das três amostras, a inclinação das curvas de absorção demonstrou um processo de espalhamento com a diminuição do comprimento de onda de absorção, o que é característico para os pontos quânticos nesta faixa de tamanho. Já no espectro de emissão, com excitação em $400 \mathrm{~nm}$, observou-se que as três amostras tiveram bandas de emissão centradas na mesma região de 452 nm, o que pode ser correlacionado com os tamanhos médios próximos dos pontos quânticos nestas três amostras.

Figura 34 - (a) Espectros de absorção e (b) de emissão (excitação em 400 nm) das amostras: A12 (em preto), A09 (em azul), A13 (em vermelho).
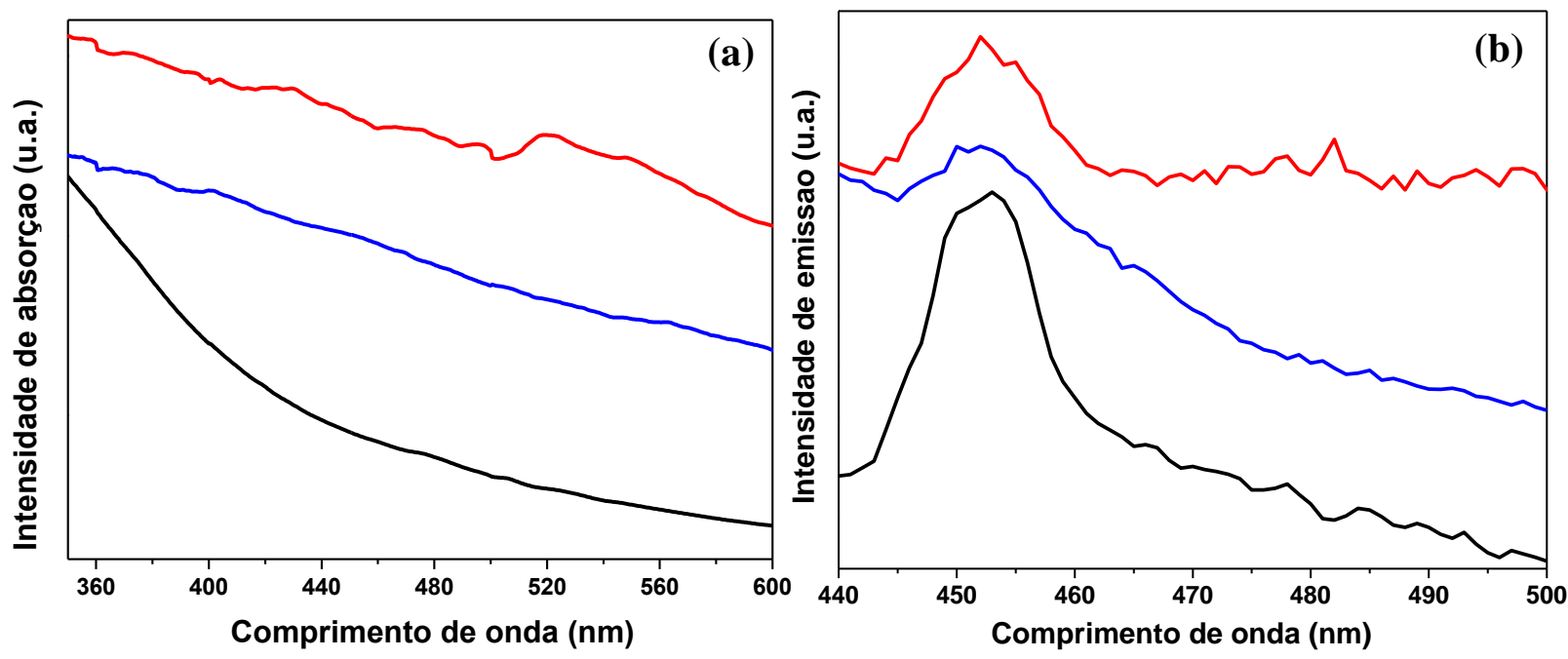

Como a amostra com menor temperatura de injeção (amostra A12) foi a mais adequada para formação das heteroestruturas, foi realizada uma análise de DRX (Figura 35), para identificação das principais fases cristalográficas presentes nesta amostra. Como todas as outras HNE foram utilizados como padrões de difração as estruturas cúbicas da FePt (29-717), da $\mathrm{Fe}_{3} \mathrm{O}_{4}$ (19-629) e do CdSe (65-2891). Analisando-se cada uma das fases, observou-se que para a FePt foram identificados picos muito pequenos centrados em $2 \theta$ na região de: $40,4^{\circ}$ e $46,7^{\circ}$, referentes aos planos de difração (111) e (200), respectivamente. Já para a fase de magnetita $\left(\mathrm{Fe}_{3} \mathrm{O}_{4}\right)$ foram identificados picos centrados em $2 \theta$ na região de: $30,5^{\circ} ; 35,5^{\circ} ; 57,5^{\circ}$; e $62,8^{\circ}$, referentes aos planos de difração (220), (311), (511) e (440), respectivamente. E para o CdSe 
foram observados picos bastante intensos centrados em $2 \theta$ na região de: $25,8^{\circ} ; 42,6^{\circ}$; e $50^{\circ}$, referentes aos planos de difração (111), (220) e (311), respectivamente. Comparando-se os difratogramas das amostras A09 e A12 (Figuras 21 e 24, respectivamente), observou-se que a amostra A12 apresentou maior cristalinidade, principalmente nas fases relacionadas com a estrutura cúbica do CdSe.

Figura 35 - DRX com os respectivos padrões de difração da amostra A12.

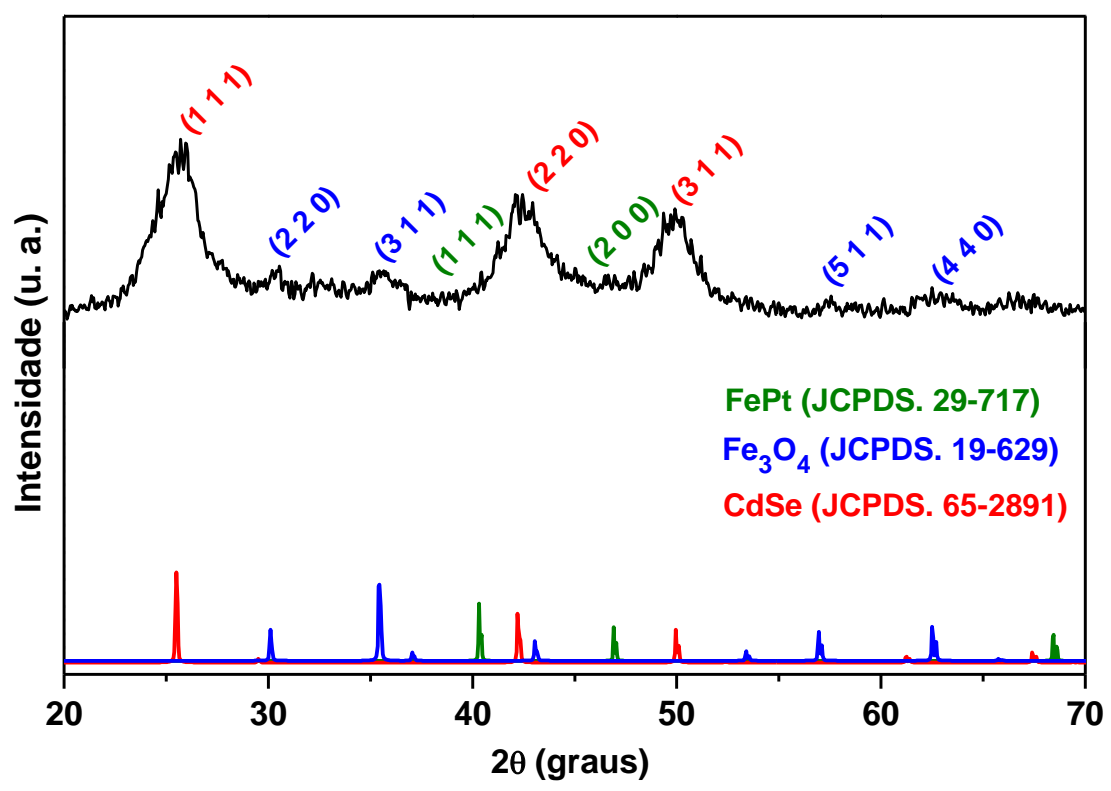

\subsection{Efeito do solvente}

Outro efeito importante para ser ajustado é o solvente do meio reacional. Algumas das características importantes que o solvente neste tipo de síntese deve apresentar são: coordenar e solubilizar adequadamente as sementes de NPM de $\mathrm{FePt} / \mathrm{Fe}_{3} \mathrm{O}_{4}$, os precursores de cádmio e selênio e os agentes de superfície (ácido oleico e oleilamina); propiciar um alto ponto de ebulição para formação das HNE (normalmente pontos de ebulição entre 200 e $300{ }^{\circ} \mathrm{C}$ são adequados); e apresentar estabilidade química frente aos reagentes utilizados na síntese.

Neste trabalho foram testados três diferentes solventes como meio para nucleação e crescimento das HNE luminomagnéticas. Os solventes utilizados foram o dioctiléter, o dibenziléter e o octadeceno, que são bastante comuns na literatura para síntese de nanoestruturas em meio orgânico, ou mesmo em sínteses que envolvem decomposição térmica.

Na Figura 36 é possível observar as micrografias obtidas por MET para as HNE presentes nas amostras A12 (a), A14 (b) e A15 (c), as quais foram sintetizadas utilizando como solventes o dioctiléter, o bibenziléter e o octadeceno, respectivamente. Foi observado que a síntese 
realizada com dibenziléter (amostra A14) não mostrou resultados satisfatórios, pois as heteroestruturas formadas ficaram bastante agregadas. Já a síntese realizada em octadeceno (amostra A15) obteve um bom controle na formação das HNE, assim como a síntese realizada em dioctiléter (amostra A12). Foram apresentados na Figura 36(d) os histogramas de distribuição de tamanho dos pontos quânticos e das NPM presentes nas HNE da amostra A14. Os pontos quânticos obtiveram tamanho médio de $\mathrm{d}=2,7 \mathrm{~nm}$, com um desvio-padrão de $\mathrm{SD}=$ $\pm 0,6 \mathrm{~nm}$ e uma polidispersividade $\sigma=22,2 \%$, e as NPM apresentaram um tamanho médio $\mathrm{d}=$ $10,3 \mathrm{~nm}$, um desvio-padrão de $\mathrm{SD}= \pm 1,5 \mathrm{~nm}$ e uma polidispersividade de $\sigma=14,6 \%$.

Figura 36 - MET das amostras: A12 (a), A14 (b), A15 (c), e histograma de distribuição de tamanho com ajuste gaussiano da amostra A15 (d).
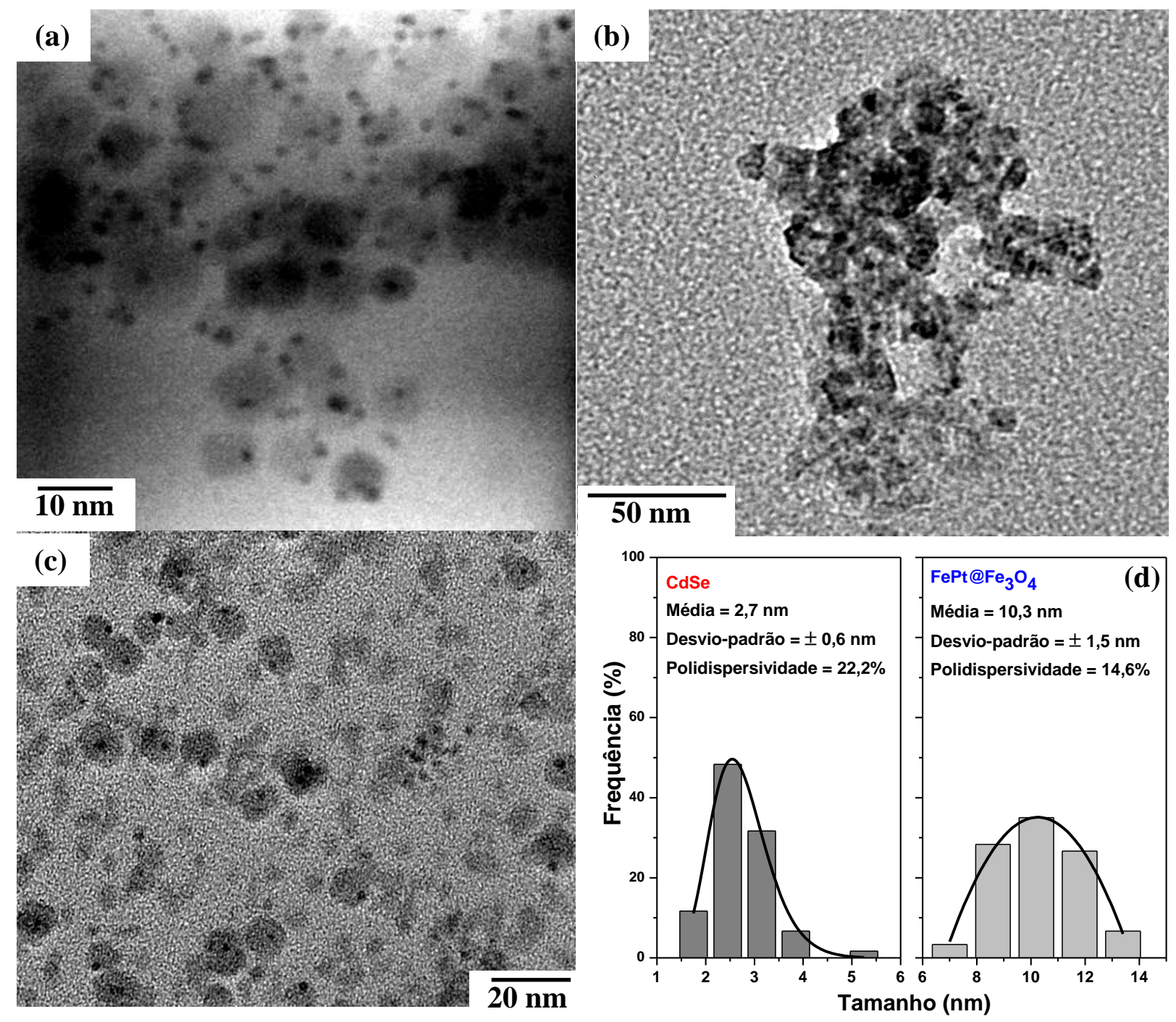

Comparando-se os resultados obtidos a partir das Figuras 33(d) e 36(d), constatou-se que a polidispersividade tanto das sementes de NPM de $\mathrm{FePt} / \mathrm{Fe}_{3} \mathrm{O}_{4}$, quanto dos pontos quânticos 
de CdSe na superfície das NPM, foram menores para a síntese realizada em dioctiléter. Logo, o diooctiléter mostrou melhores características como solvente para obtenção das HNE luminomagnéticas, quando comparado com dibenziléter e octadeceno.

Para as sínteses que testaram o efeito do solvente, foram também obtidos os espectros de absorção e de emissão, dispostos na Figura 37 (a) e (b), respectivamente. De acordo com os espectros de absorção, as três amostras apresentam características muito semelhantes, pois todas as curvas de absorção mostraram um aumento na intensidade de espalhamento com a diminuição do comprimento de onda do feixe incidente. Já os espectros de emissão, com excitação em 400 nm, mostraram também comportamentos similares entre as amostras, já que todas elas apresentaram banda de emissão centrada em $452 \mathrm{~nm}$.

Foi realizada uma medida de DRX para a amostra A15 (Figura 38), com o intuito de comparar a sua cristalinidade com a amostra A12. Para isto, foram utilizados como padrões de difração as estruturas cúbicas da FePt (29-717), da $\mathrm{Fe}_{3} \mathrm{O}_{4}$ (19-629) e do CdSe (65-2891). Analisando-se cada uma das fases, observou-se que para a FePt foram identificados picos muito pequenos centrados em $2 \theta$ na região de: $40,5^{\circ}$ e $47^{\circ}$, referentes aos planos de difração (111) e (200), respectivamente. Já para a fase de magnetita $\left(\mathrm{Fe}_{3} \mathrm{O}_{4}\right)$ foram identificados picos centrados em $2 \theta$ na região de: $30,3^{\circ} ; 35,5^{\circ} ; 57,1^{\circ}$; e $62,8^{\circ}$, referentes aos planos de difração $(220),(311)$, (511) e (440), respectivamente. E para o CdSe foram observados picos centrados em $2 \theta$ na região de: $25,6^{\circ} ; 42,6^{\circ}$; e 49,7 , referentes aos planos de difração (111), (220) e (311), respectivamente.

Figura 37 - (a) Espectros de absorção e (b) de emissão (excitação em 400 nm) das amostras: A12 (em preto), A15 (em vermelho), A14 (em azul).
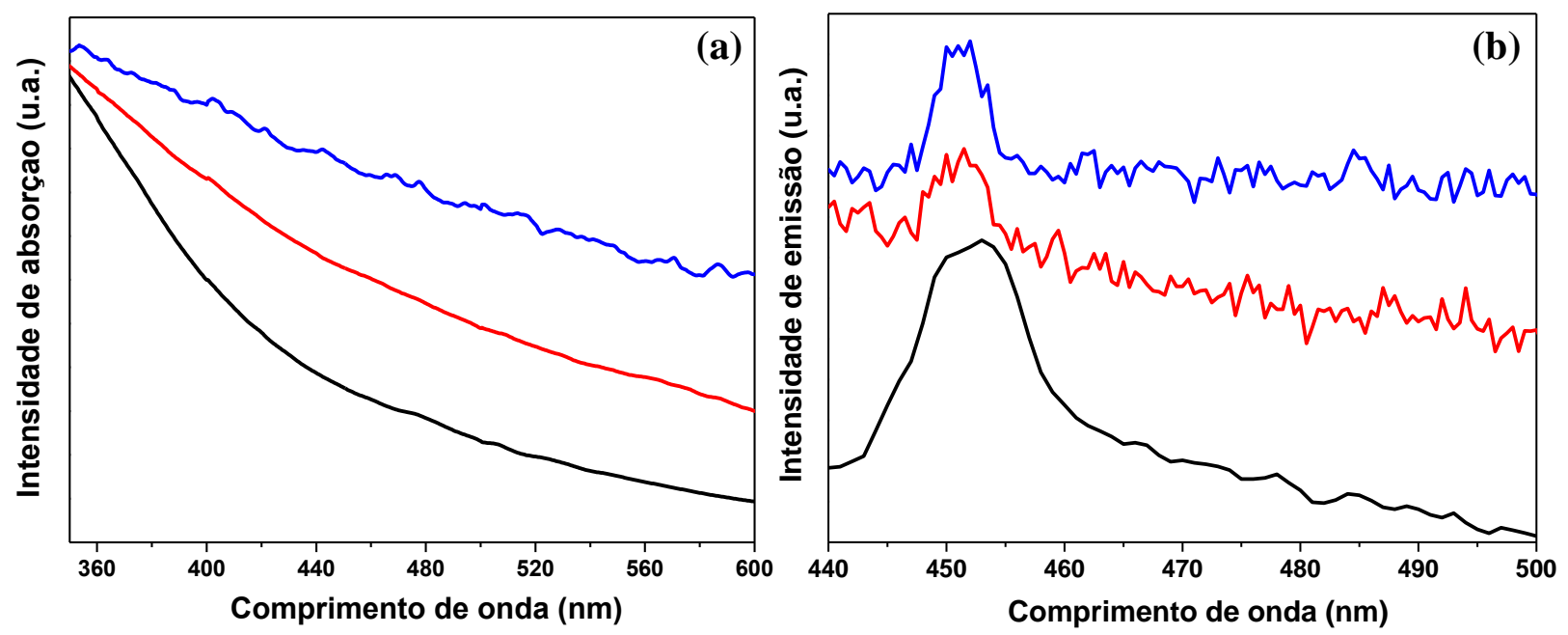
Comparando os resultados de difração das amostras A12 e A15, verificou-se que as duas amostras apresentaram cristalinidades similares, entretanto, a amostra A12 apresentou picos mais intensos para as fases cristalográficas relacionadas à estrutura cúbica do CdSe e a amostra A15 mostrou maior intensidade dos picos de difração relacionados à fase cúbica da magnetita.

Figura 38 - DRX com os respectivos padrões de difração da amostra A15.

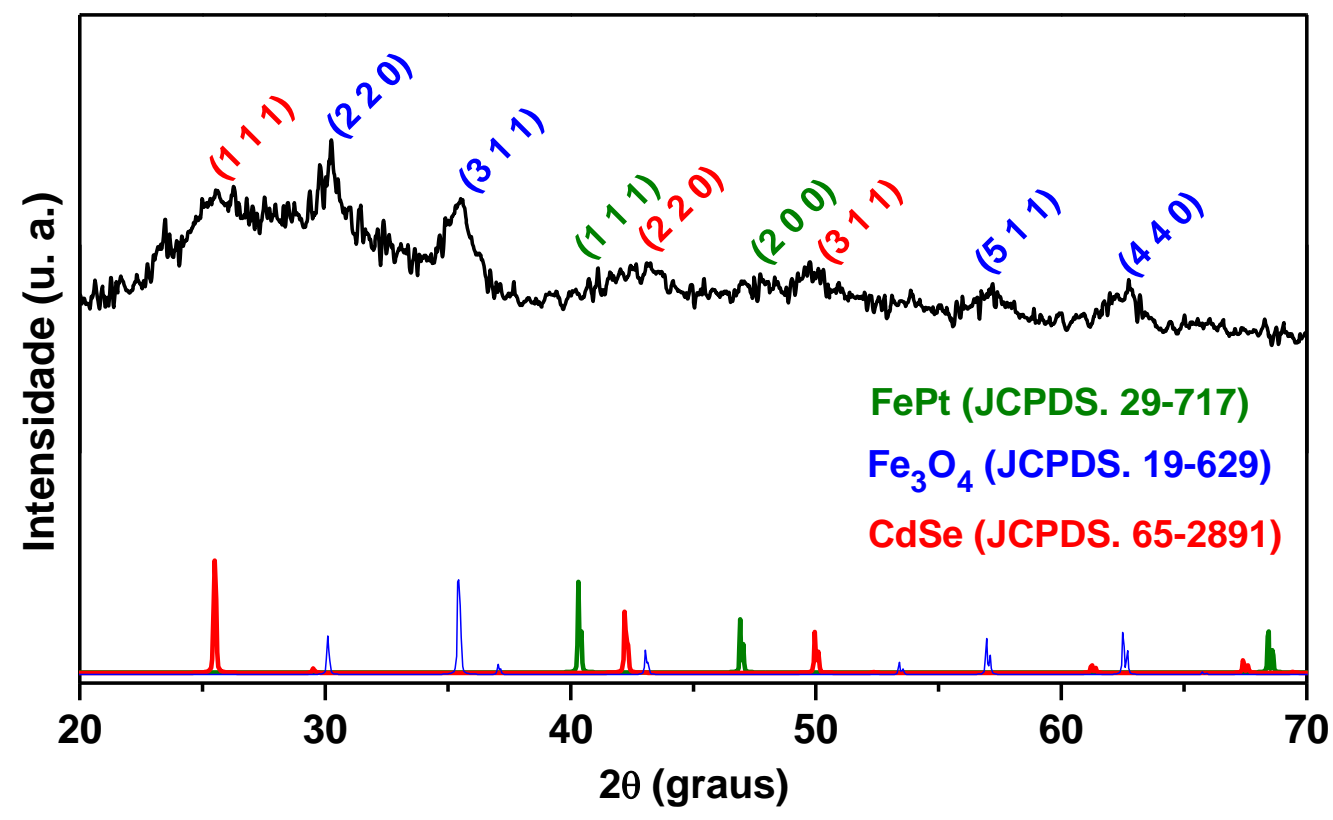

\subsection{Efeito da quantidade de NPM}

O último efeito analisado para o estudo dos parâmetros que afetam a formação de HNE luminomagnéticas foi a quantidade inicial de sementes de NPM de $\mathrm{FePt} / \mathrm{Fe}_{3} \mathrm{O}_{4}$ no meio reacional. As sementes atuam como um substrato para crescimento dos pontos quânticos luminescentes em sua superfície. A quantidade inicial de sementes de NPM no meio reacional pode influenciar em fatores como: a disponibilidade de superfície para o crescimento dos pontos quânticos sobre as NPM; em quantidades suficientes, pode facilitar o crescimento dos pontos quânticos com uma quantidade elevada de formação de HNE, entretanto, se em quantidade excessiva pode prejudicar a nucleação e crescimento dos pontos quânticos e causar a formação de agregados entre as partículas. As condições utilizadas para a quantidade inicial de sementes foram a utilização de $10 \mathrm{mg}$ ou $30 \mathrm{mg}$ de NPM da amostra A01, e estas amostras foram denominadas de amostras A12 e A16, respectivamente.

Na Figura 39 são apresentadas as amostras A12 (a) e A16 (b) caracterizadas por MET, além do histograma de distribuição de tamanho das partículas de $\mathrm{CdSe}$ e $\mathrm{FePt} / \mathrm{Fe}_{3} \mathrm{O}_{4}$ da amostra 
A16 (c). Analisando-se a micrografia da amostra A16 (com maior quantidade de sementes), pode-se inferir que nela houve menor formação de quantidade de HNE, além de serem observadas algumas regiões com a formação de agregados de NPM, o que se torna indesejável para a manutenção das propriedades das HNE individuais. Já a amostra A12 foi o melhor ajuste deste trabalho para a a proporção entre quantidade de NPM como sementes e de precursores de cádmio e selênio para formação dos pontos quânticos.

Figura 39 - MET das amostras: A12 (a) e A16 (b); e histograma de distribuição de tamanho com ajuste gaussiano da amostra A16 (c).
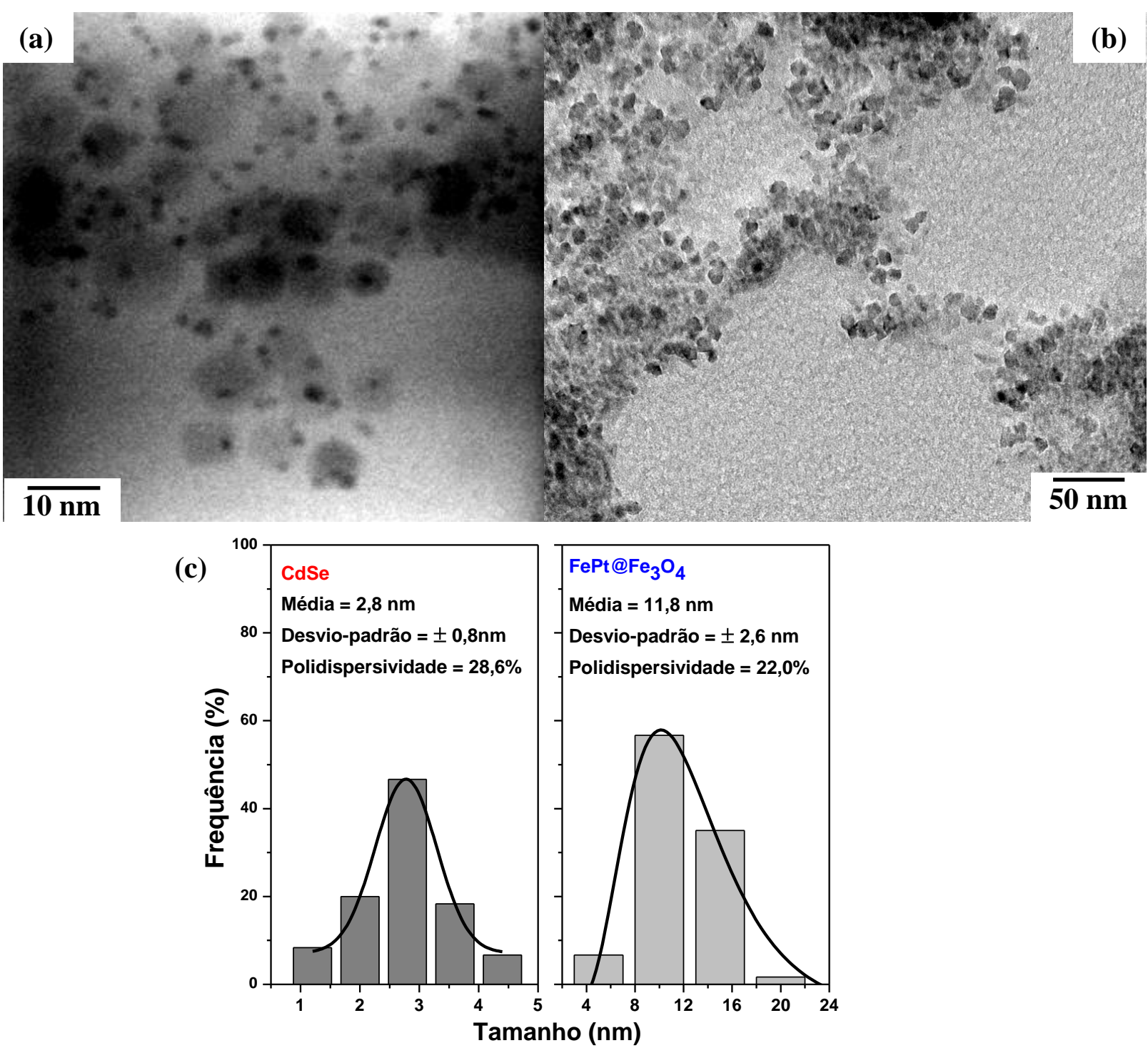

Além disso, foi realizado o histograma de distribuição de partículas para a amostra A16 (Figura 39(c)), com o intuito de realizar uma comparação quantitativa entre as duas amostras. Para esta amostra os pontos quânticos obtiveram tamanho médio de $d=2,6 \mathrm{~nm}$, com um desvio- 
padrão de $\mathrm{SD}= \pm 0,8 \mathrm{~nm}$ e uma polidispersividade $\sigma=28,6 \%$, e as NPM apresentaram um tamanho médio $\mathrm{d}=11,8 \mathrm{~nm}$, um desvio-padrão de $\mathrm{SD}= \pm 2,6 \mathrm{~nm}$ e uma polidispersividade de $\sigma=22,0 \%$. Comparando-se os dados obtidos por este histograma e o histograma da amostra A12 (Figura 33d) observou-se que a amostra A16 teve uma polidispersidade maior que amostra A12 tanto na população de pontos quânticos de CdSe, quanto na população de NPM de $\mathrm{FePt} / \mathrm{Fe}_{3} \mathrm{O}_{4}$. Esse resultado pode ter sido ocasionado pelo excesso de NPM presente no meio reacional, o que levou as partículas a processos de agregação.

Na figura 40 mostrou-se os espectros de absorção (a) e emissão (b) para as amostras A12 (em preto) e A16 (em azul). De acordo com o espectro de absorção das duas amostras pode-se verificar que possuem características muito similares, as quais foram verificadas que com a diminuição do comprimento de onda as curvas tornam-se inclinadas, devido provavelmente a efeitos de espalhamento das partículas presentes nestas amostras, o que deve-se provavelmente ao tamanho reduzido dos pontos quânticos de CdSe. Já pelos espectros de emissão, com excitação em $400 \mathrm{~nm}$, observou-se que as duas amostras apresentaram comportamentos muito semelhantes também de emissão, porém a amostra A16 apresentou maior quantidade de pequenos sinais de emissão, conforme houve o aumento do comprimento de onda nos espectros. As duas amostras apresentaram uma banda mais intensa de emissão centrada em $452 \mathrm{~nm}$, o que pode inferir que o tamanho médio dos pontos quânticos de CdSe formados são de magnitudes semelhantes, conforme foi constado nos histogramas apresentados de cada uma destas amostras.

Figura 40 - (a) Espectros de absorção e (b) de emissão (excitação em 400 nm) das amostras: A12 (em preto), A16 (em azul).
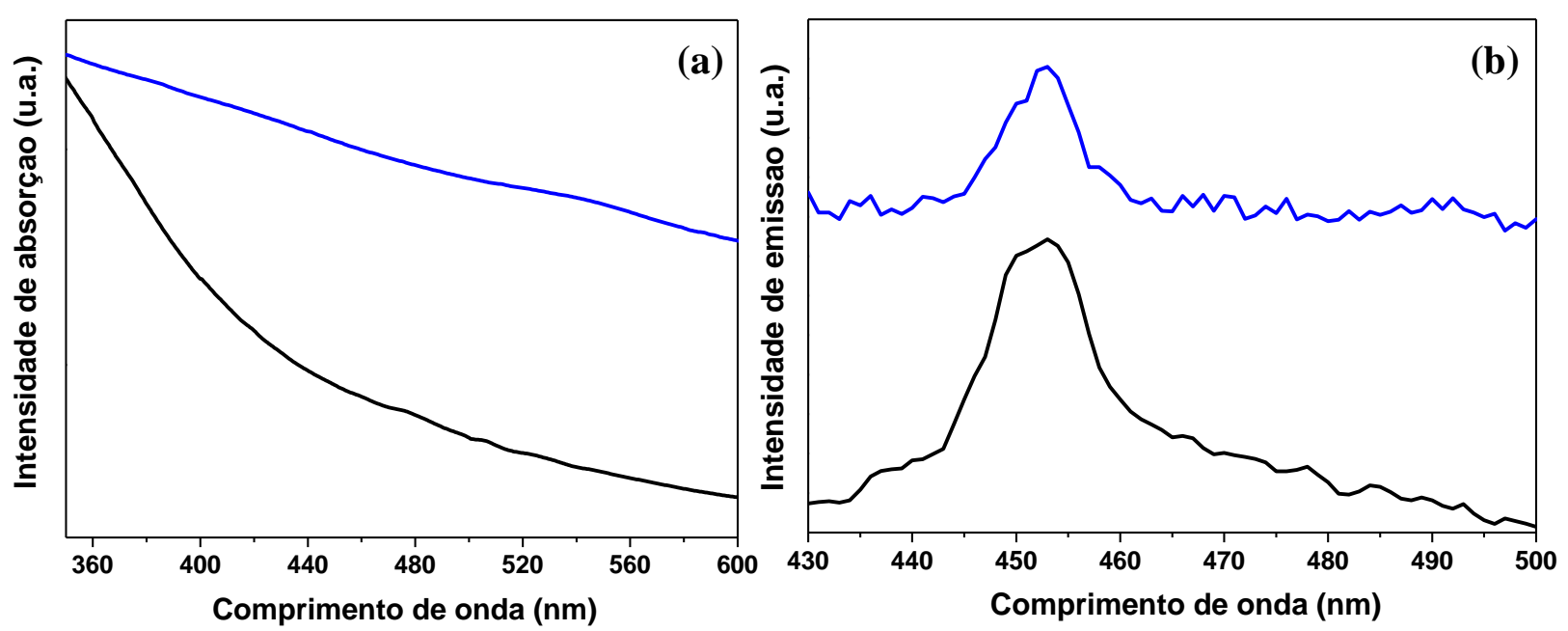
Foi realizada uma medida de DRX para analisar as fases cristalográficas formadas nas HNE da amostra A16, conforme apresentado na Figura 41. Para isto, foram utilizados como padrões de difração as estruturas cúbicas da FePt (29-717), da $\mathrm{Fe}_{3} \mathrm{O}_{4}$ (19-629) e do CdSe (652891). Analisando-se as fases, observou-se que para a FePt foram identificados picos muito pequenos centrados em $2 \theta$ na região de: $41^{\circ}$ e $46,8^{\circ}$, referentes aos planos de difração (111) e (200), respectivamente. Já para a fase de magnetita $\left(\mathrm{Fe}_{3} \mathrm{O}_{4}\right)$ foram identificados picos intensos centrados em $2 \theta$ na região de: $30,4^{\circ} ; 35,5^{\circ} ; 57,3^{\circ}$; e $62,7^{\circ}$, referentes aos planos de difração (220), (311), (511) e (440), respectivamente. E para o CdSe foram observados picos com pequena intensidade centrados em $2 \theta$ na região de: $25,4^{\circ} ; 42,9^{\circ}$; e $49,9^{\circ}$, referentes aos planos de difração (111), (220) e (311), respectivamente. Comparando-se as amostras A12 e A16 foi possível inferir que a cristalinidade da fase cúbica de CdSe para a amostra A16 foi bastante pequena comparada com a amostra A12. Já a cristalinidade da fase cúbica da magnetita já foi maior na amostra A16, o que pode ser explicado com a maior quantidade inicial de NPM presentes na síntese para formação das HNE luminomagnéticas.

Figura 41 - DRX com os respectivos padrões de difração da amostra A16.

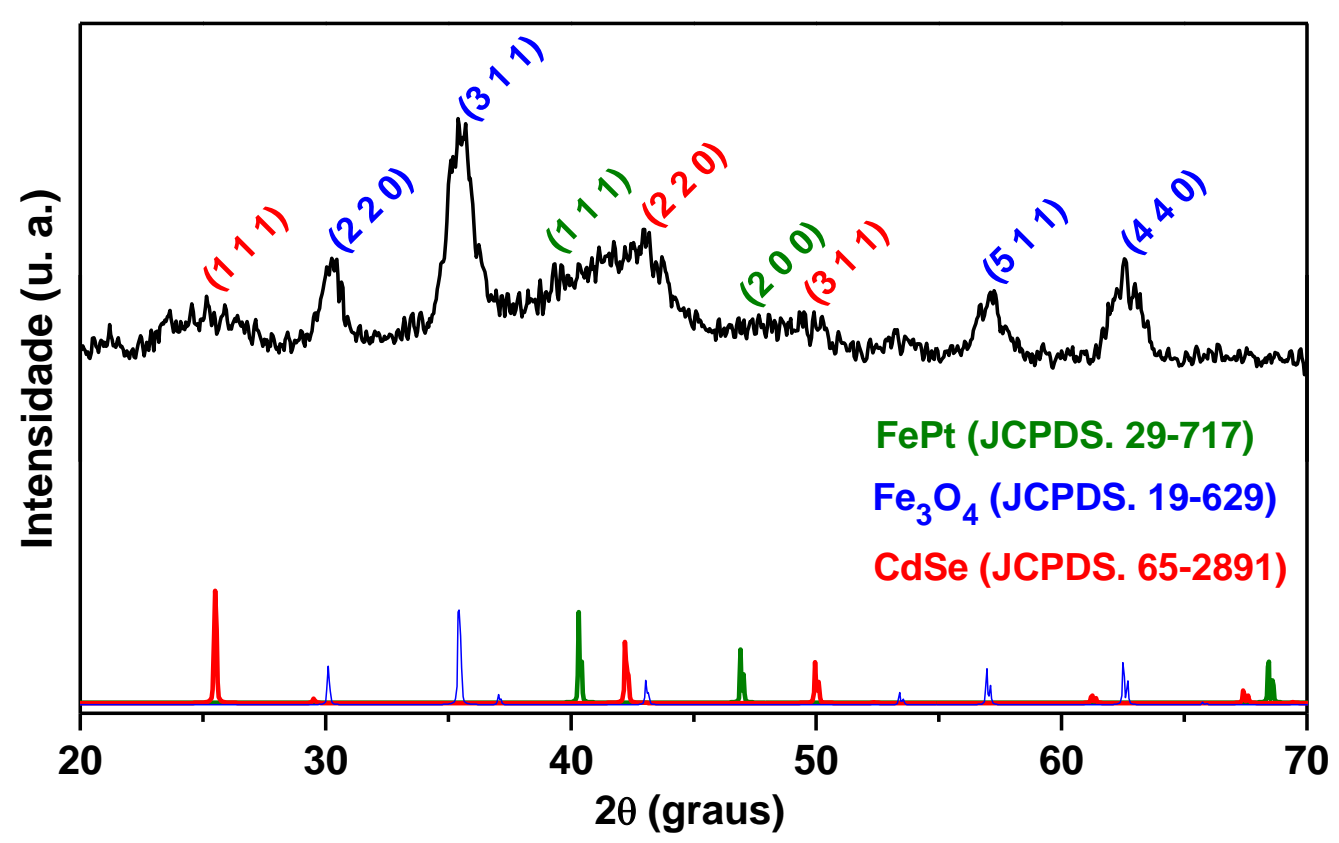

\subsubsection{Recobrimento com sílica na superfície das heteronanoestruturas luminomagnéticas}

A estratégia utilizada para propiciar estabilidade coloidal às HNE luminomagnéticas de $\mathrm{FePt} / \mathrm{Fe}_{3} \mathrm{O}_{4}$ conjugadas com pontos quânticos de $\mathrm{CdSe}$ e transferi-las para o meio aquoso, foi o 
recobrimento da superfície destes nanomateriais com uma fina camada de sílica. A sílica tem sido muito explorada como material de recobrimento para nanopartículas magnéticas, pontos quânticos luminescentes e, até mesmo, nanomateriais de nanoestruturas conjugadas, principalmente visando aplicações biológicas. ${ }^{1,7,47}$

A preferência pelo recobrimento com sílica na superfície das heteroestruturas é pelo fato de a silica previnir a agregação das NP, promovendo estabilidade química e coloidal, além de diminuir drasticamente a toxicidade das HNE luminomagnéticas em sistemas biológicos. Este tipo de recobrimento estabiliza as partículas geralmente de duas maneiras. A primeira delas está relacionada à blindagem parcial das interações de dipolo magnético e a segunda, mais importante, reside na estabilização eletrostática, uma vez que a superfície da sílica encontra-se negativamente carregada em pH neutro, aumentando a repulsão coulômbica entre as HNE. Outras vantagens dos recobrimentos com sílica são decorrentes de sua estabilidade em soluções aquosas e ser de fácil modificação de superfície. ${ }^{1,7}$

A metodologia utilizada para controle do recobrimento das HNE com fina camada de sílica foi o processo de microemulsão por micela reversa. ${ }^{82}$ Neste processo, na presença de fase aquosa, fase óleo e surfactantes, há a formação de um nanoreator aquoso com volume definido dentro de sistemas micelares formado por surfactantes, com uma fase orgânica na parte externa das micelas. Os surfactantes são moléculas que possuem, normalmente, uma extremidade com características polares (que interage com a fase aquosa) e uma longa cadeia orgânica com características apolares (que interage com a fase orgânica). Pela figura 42 é possível observar um esquema ilustrativo do processo de microemulsão por micela reversa para recobrimento das $\mathrm{HNE}$ de $\mathrm{FePt} / \mathrm{Fe}_{3} \mathrm{O}_{4}-\mathrm{CdSe}$.

Figura 42 - Esquema ilustrativo do processo de recobrimento das heteronanoestruturas de $\mathrm{FePt} / \mathrm{Fe}_{3} \mathrm{O}_{4}-\mathrm{CdSe}$ pelo processo de microemulsão por micela reversa.

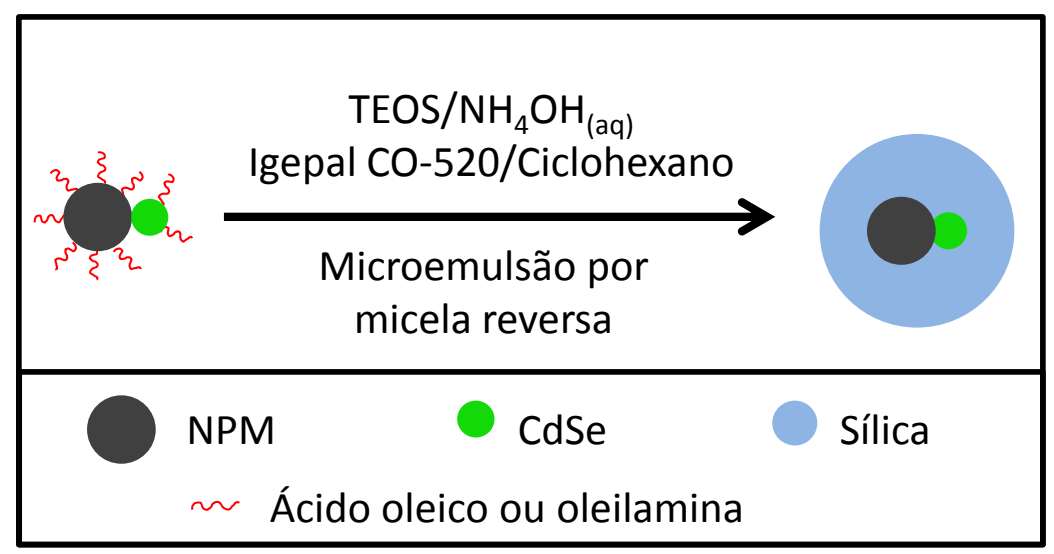


As microemulsões são sistemas termodinamicamente estáveis, o que facilita processos que envolvem reações químicas, ou mesmo, troca de ligantes, por exemplo, que permitam transferência de nanopartículas de fase orgânica para fase aquosa. Entretanto, existem alguns parâmetros neste tipo de recobrimento que precisam ser adequados para que o processo de recobrimento seja satisfatório. Entre os parâmetros, destacam-se: escolha do surfactante que formarão as micelas; quantidade e proporção da fase aquosa e da fase orgânica; no caso especifico do recobrimento com sílica, quantidade e proporção do precursor de sílica e do catalisador para formação da camada de silica; entre outros. ${ }^{82}$

O grupo no qual foi realizado este trabalho tem um procedimento de recobrimento com sílica a partir da microemulsão por micela reversa já adequado ${ }^{93}$ (ver procedimento na seção 4.2.3 da Parte Experimental). No processo de recobrimento, na presença das HNE luminomagnéticas de $\mathrm{FePt} / \mathrm{Fe}_{3} \mathrm{O}_{4}-\mathrm{CdSe}$ (amostra A12), foi utilizado como surfactante o Igepal CO-520, como fase aquosa e catalisador da hidrólise básica para formação da sílica foi utilizado o $\mathrm{NH}_{4} \mathrm{OH}_{(\text {aq.) }}$, e como fase orgânica foi usado o ciclohexano.

Na Figura 43 (a) e (b) são apresentadas as análises por MET das heteronanoestruturas recobertas com sílica da amostra A17. Pela análise de MET pode-se dizer que a amostra A17 teve um controle de forma, distribuição e tamanho muito satisfatório. Além disso, pela Figura 43(b) observou-se que houve o encapsulamento de uma heteronanoestrutura por partícula o que demonstra ótima eficiência do método utilizado para recobrimento.

De acordo com as análises dos histogramas para as heteronanoestruturas recobertas com sílica da amostra A17, pode-se inferir que o tamanho médio das partículas foi de $\mathrm{d}=25,0 \mathrm{~nm}$, com desvio-padrão de $\mathrm{SD}= \pm 2,1 \mathrm{~nm}$ e polidispersividade de $8,4 \%$. Com a análise dos tamanhos médios obtidos para as amostras A12 e A17 pode-se considerar que a espessura aproximada do recobrimento com sílica em cada heteroestruturas foi de $7 \mathrm{~nm}$, o que mostra bastante controle no crescimento desta camada. Além disso, o sistema como um todo não apresentou grandes formações de aglomerados, o que está diretamente relacionado com a alta estabilidade coloidal das partículas recobertas com sílica. 
Figura 43 - MET da amostra A17 (a) e (b); e histograma de distribuição de tamanho com ajuste gaussiano da mesma amostra (c).

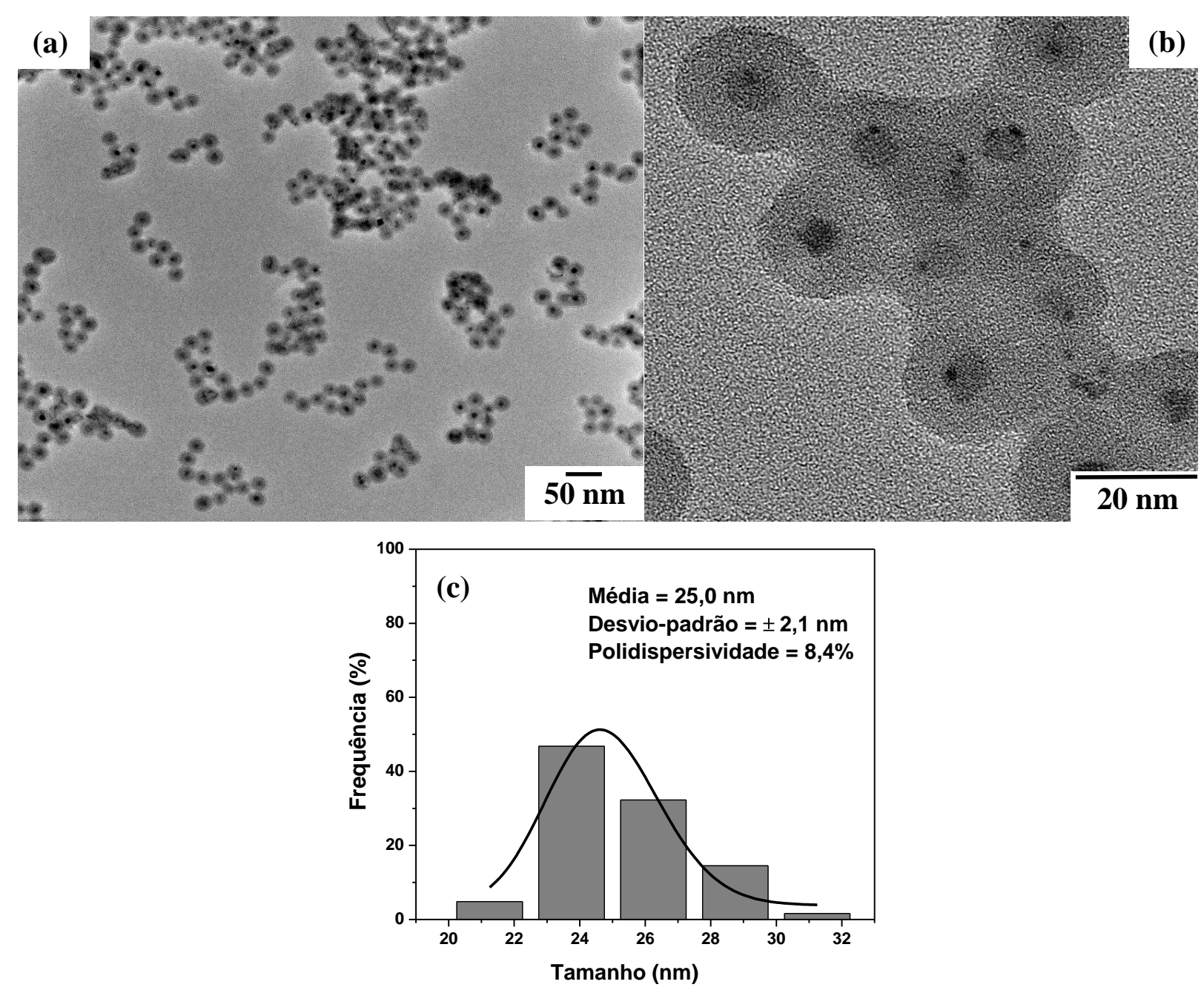

Os espectros de absorção e de emissão das amostras A12 (em preto) e A17 (em azul) são apresentados na Figura 44 (a) e (b), respectivamente. Os resultados dos espectros de absorção das HNE anteriormente (amostra A12) e após o recobrimento com sílica (amostra A17) mostraram que com a diminuição do comprimento de onda do feixe incidente, as duas amostras apresentaram processos de espalhamento. Este resultado, como comentado anteriormente, é comum na literatura para os espectros de absorção de pontos quânticos de CdSe, o que demonstra uma coerência com os espectros obtidos pelas duas amostras. Os espectros de emissão, com excitação em $400 \mathrm{~nm}$, das duas amostras demonstraram uma banda de emissão centrada em $452 \mathrm{~nm}$. Entretanto, para amostra A17 houve a presença de outra banda de emissão centrada em $472 \mathrm{~nm}$, o que pode ser explicado pela presença da formação de pontos quânticos com maior faixa de tamanho na superfície das NPM, no processo recobrimento com sílica ou 
uma emissão fluorescente relacionada com a camada de sílica, que é da ordem de nanômetros e pode apresentar efeitos devido as propriedades adquiridas nessa faixa de tamanho.

Figura 44 - (a) Espectros de absorção e (b) de emissão (excitação em $400 \mathrm{~nm}$ ) das amostras: A12 (em preto), A17 (em azul).
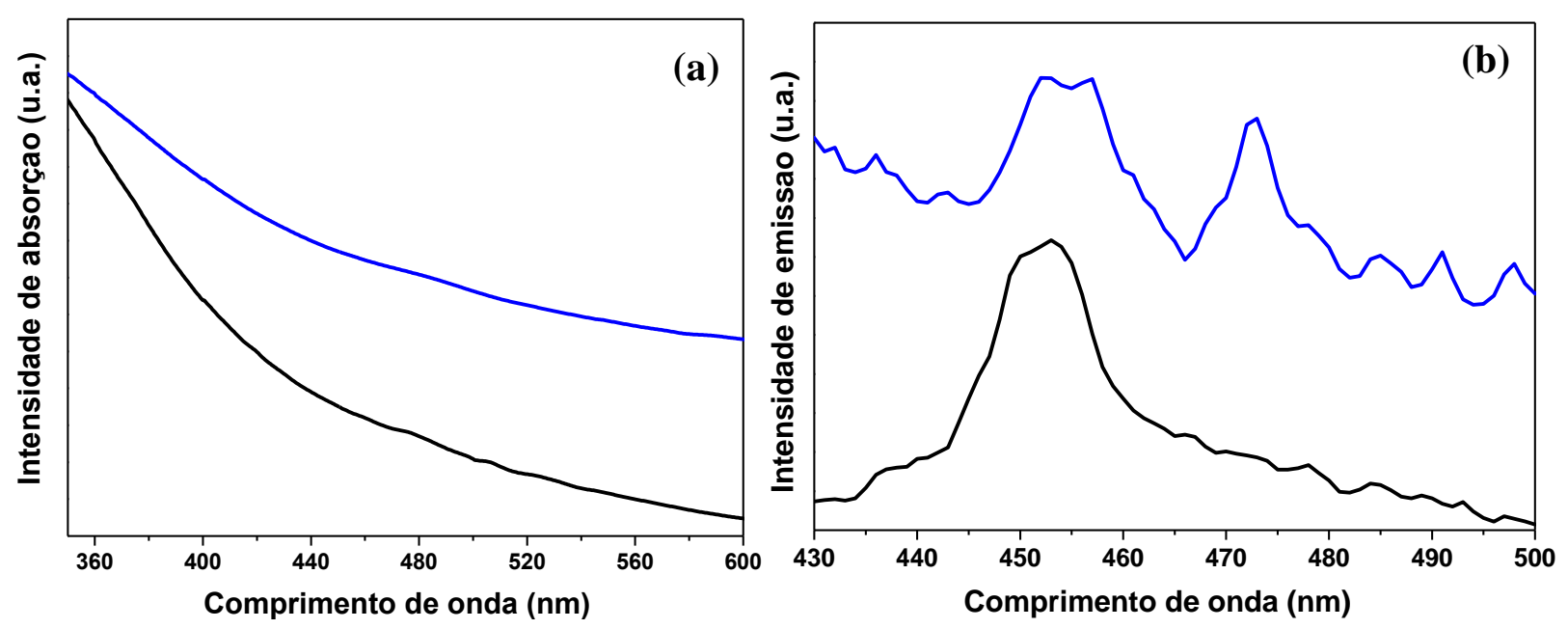

Para análise das propriedades magnéticas tanto das HNE luminomagnéticas de $\mathrm{FePt} / \mathrm{Fe}_{3} \mathrm{O}_{4}-\mathrm{CdSe}$ (amostra A12), quanto das $\mathrm{HNE}$ recobertas com sílica (amostra A17), foi realizada uma medida de magnetização por VSM, podendo ser observada na figura 33. Para efeito comparativo, a figura 45 foi feita com a curva de magnetização da amostra que atuou como semente (amostra A01) para obtenção das HNE luminomagnéticas.

As curvas de magnetização (Figura 45) das amostras A01 (em preto), A12 (em vermelho) e A17 (em azul) apresentaram valores de Ms de 46,8; 24,1 e 11,1 emu.g ${ }^{-1}$. Como observado nos valores de Ms, eles foram diminuindo em intensidade conforme foram adicionadas outras estruturas na superfície das NPM de $\mathrm{FePt} / \mathrm{Fe}_{3} \mathrm{O}_{4}$. Quando foram conjugados os pontos quânticos de CdSe, os valores de Ms caíram aproximadamente pela metade, e novamente diminuiu pela metade quando as HNE foram recobertas com sílica. Esta diminuição de Ms ocorreu provavelmente porque a adição de componentes com propriedades diamagnéticas ou paramagnéticas não contribuem para a magnetização dos nanomateriais da semente magnética, entretanto, causa um aumento de massa nas nanoestruturas e isto ocasiona uma diminuição nos valores de magnetização em emu.g ${ }^{-1}$.

Adicionalmente, observando-se as regiões ampliadas das curvas de magnetização das amostras da Figura 45, constatou-se que todas as amostras apresentaram histerese da curva magnética muito pequena, com coercividade na ordem de $0,04 \mathrm{KOe}$, o que pode ser 
correlacionado com uma propriedade magnética muito próxima do comportamento superparamagnético. E foi também observado que a inclinação das curvas das amostras A01, A12 e A17 (em relação ao eixo da magnetização) foram aumentando, respectivamente. Isto se deve também provavelmente à conjugação do ponto quântico de CdSe e a camada de sílica na superfície das NPM, o que ocasiona uma necessidade de um campo magnético diferente para levar a amostra à magnetização de saturação.

Figura 45 - Curvas de magnetização das amostras: A01 (em preto), A12 (em vermelho) e A17 (em azul). Em destaque região ampliada das curvas de magnetização das mesmas amostras.

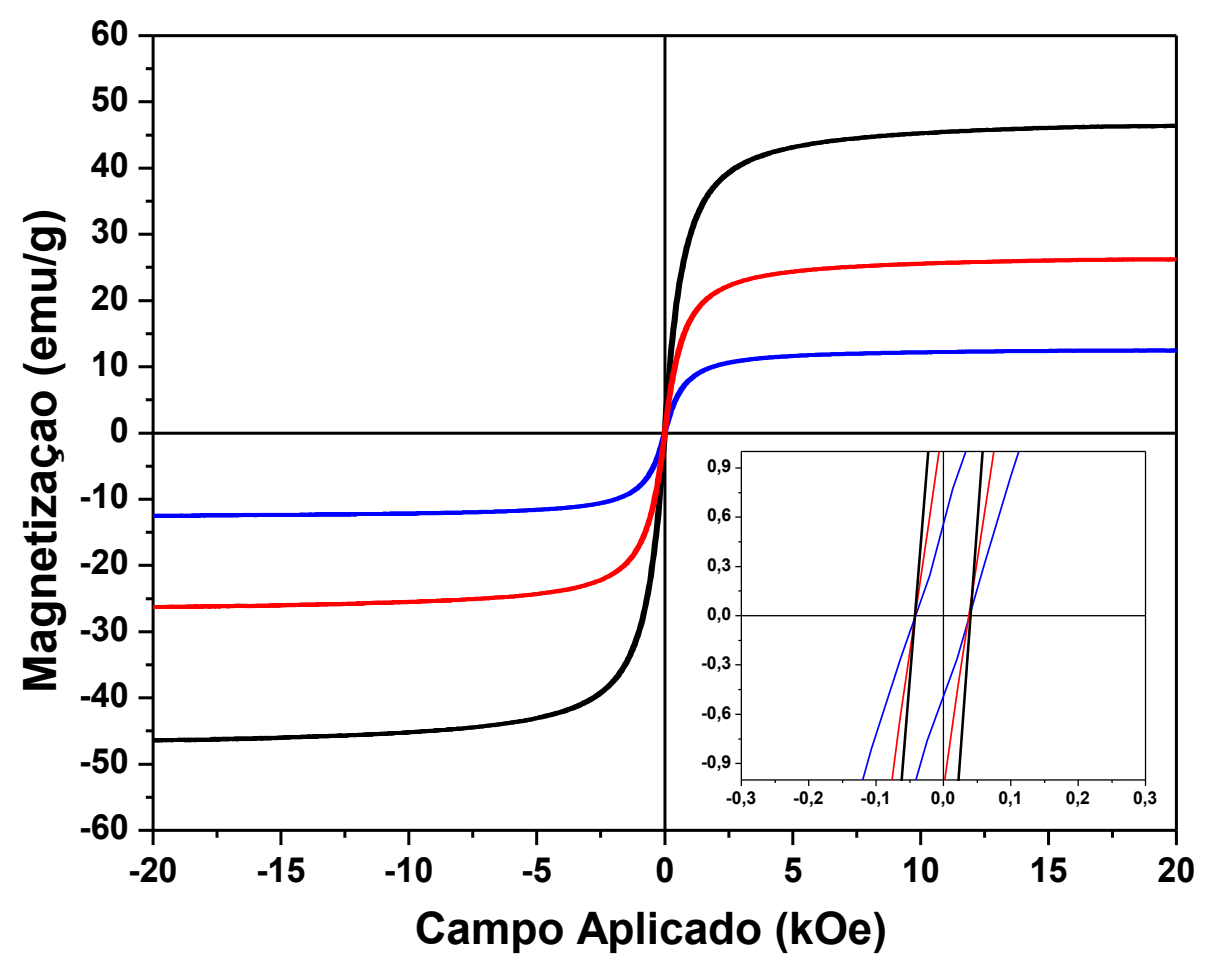

Na Figura 46 é possível observar as fotografias das HNE luminomagnéticas (amostra A12) e das HNE recobertas com sílica (amostra A17) na ausência (a) e (c) e na presença de um campo magnético externo (b) e (d), respectivamente. Foram feitas fotografias também sob a presença de luz ultra-violeta (UV) das mesmas amostras na ausência (e) e (g) e na presença (f) e (h) de um campo magnético externo, respectivamente. 
Figura 46 - Fotografias da amostras A12 e A17 na ausência (a) e (c) e na presença de campo magnético externo (b) e (d); e sob de luz UV: na ausência (e) e (g) e na presença (f) e (h) de campo magnético externo, respectivamente.
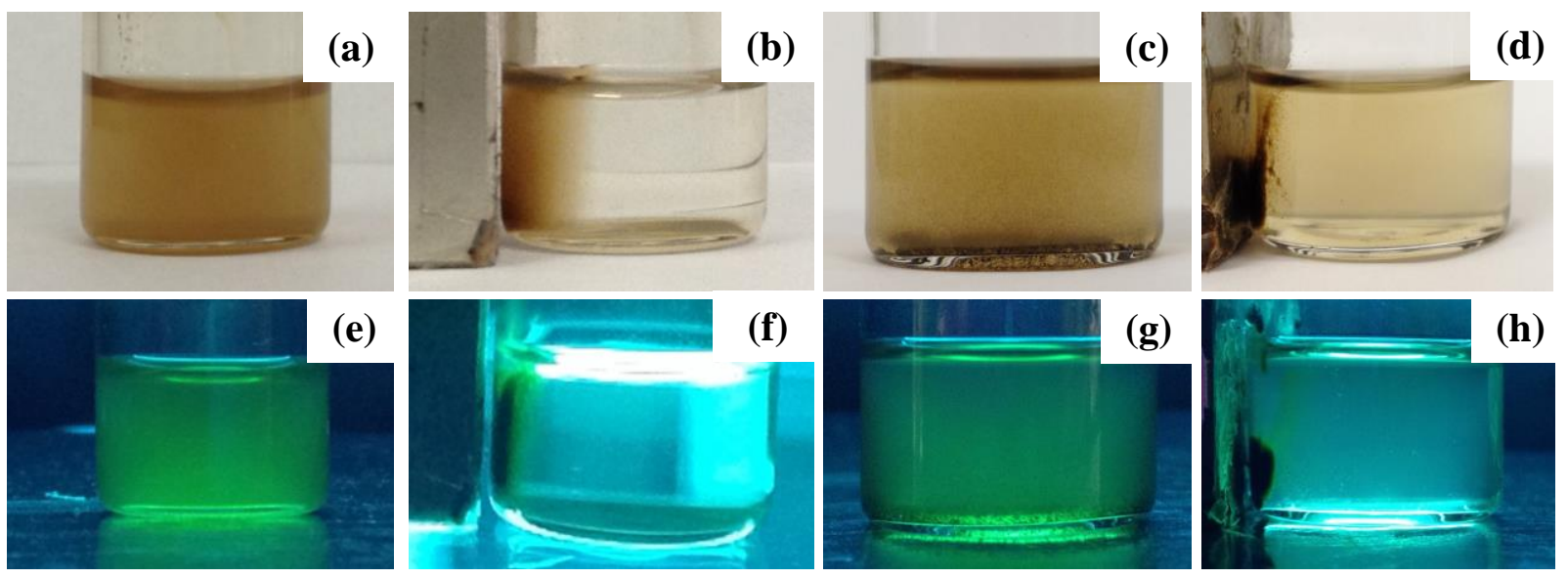

\subsection{Nanomateriais luminomagnéticos de $\mathrm{FePt}_{2} \mathrm{Fe}_{3} \mathrm{O}_{4}$ e $\mathrm{CdSe} / \mathrm{ZnS}$ recobertos com polímeros baseados em PEG}

Para a síntese dos nanomateriais de NPM de $\mathrm{FePt} / \mathrm{Fe}_{3} \mathrm{O}_{4}$ conjugados com os pontos quânticos de $\mathrm{CdSe} / \mathrm{ZnS}$, foram, inicialmente realizadas a síntese das nanoestruturas de $\mathrm{FePt} / \mathrm{Fe}_{3} \mathrm{O}_{4}$, que foi baseada no processo do poliol modificado acoplado com a metodologia do crescimento mediado por sementes (conforme descrito na seção 4.1), e de CdSe/ZnS, baseada em processo de decomposição térmica de precursores de cádmio e selênio (para a semente) e de precursores de zinco e enxofre (para a camada de recobrimento), sendo este procedimento descrito na seção 4.3.2, sendo que ambas nanoestruturas após o processo de obtenção apresentaram superfície hidrofóbica.

Paralelamente à síntese das nanoestruturas magnéticas e luminescentes, foram obtidos os ligantes baseados em PEG (seção 4.3.1) e estes foram utilizados para providenciar uma troca de ligantes na superfície das nanoestruturas magnéticas e luminescentes, transformando suas superfícies hidrofóbicas em superfícies hidrofílicas, devido as cadeias de PEG presentes após a troca de ligantes. Após o recobrimento com polímeros baseados em PEG, a superfície dos pontos quânticos de $\mathrm{CdSe} / \mathrm{ZnS}$ apresentaram grupos funcionais de ácido carboxílico e a superfície das NPM de $\mathrm{FePt} / \mathrm{Fe}_{3} \mathrm{O}_{4}$ continham grupos amina. Desta forma, a conjugação química entre as nanoestruturas magnéticas e luminescentes foram providenciadas a partir de reações destes grupos funcionais, para propiciar a formação de ligação amida e consequente formação de nanomateriais com propriedades magnéticas e luminescentes conjugadas na mesma partícula. 


\subsubsection{Ligantes baseados em PEG}

Nas etapas de preparação dos ligantes, foram planejadas a obtenção de dois diferentes ligantes poliméricos para recobrimento das nanoestruturas magnéticas e luminescentes, sendo eles o LA-PEG-COOH ${ }^{50}$ e o Dopa-PIMA-PEG- $\mathrm{NH}_{2}{ }^{88}$, respectivamente. Os dois polímeros foram elaborados de tal forma que em uma extremidade tivesse grupos ancorantes (LA e Dopa) que interagiriam com a superfície das nanoestruturas e na outra extremidade grupos funcionais reativos $\left(\mathrm{COOH}\right.$ e $\left.\mathrm{NH}_{2}\right)$ que pudessem a partir de uma reação química formar uma ligação entre as plataformas magnética e luminescente. Nos dois ligantes poliméricos obtidos foram utilizadas cadeias curtas de PEG $\left(\mathrm{M}_{\mathrm{w}}\right.$ entre 400 e 750 g.mol $\left.{ }^{-1}\right)$ para facilitar o processo de purificação das nanoestruturas, além de diminuir a quantidade de massa polimérica na superfície das mesmas. Além disso, as cadeias de PEG são essenciais para promover a solubilidade das nanoestruturas em água e reduzir interações não-específicas visando aplicações biológicas. ${ }^{49}$

Para o ligante LA-PEG-COOH, foram realizadas modificações em cada uma das extremidades das cadeias de PEG, sendo em uma extremidade a inserção do grupo funcional LA, que tem como principal função atuar como molécula de conjugação com a superfície inorgânica dos pontos quânticos de $\mathrm{CdSe} / \mathrm{ZnS}$, pois esta molécula apresenta grupos bidentados de tiol que tem especificidade e interagem fortemente com a superfície dos pontos quânticos, o que propicia estabilidade química da nanoestrutura com a camada de recobrimento. Na outra extremidade da cadeia de PEG foram inseridos grupos funcionais de ácido carboxílico (COOH), que servem para providenciar reatividade na superfície das nanoestruturas e, desta maneira, facilitar a adição de outros tipos moléculas bioativas ou mesmo, conforme neste trabalho, a conjugação de nanoestruturas que providenciem propriedades adicionais no nanomaterial.

Já para o ligante Dopa-PIMA-PEG-NH 2 , primeiramente, um diferencial foi a utilização de polímeros de PIMA como plataformas de conjugação de diversas cadeias de PEG e moléculas de Dopa. Este polímero como plataforma providencia diversas características, conforme já mencionadas na seção 2.4.2 da fundamentação teórica, porém, entre as principais almejadas para este trabalho são: a possibilidade de conjugação de muitos grupos ancorantes na superfície das nanoestruturas, o que aumenta a estabilidade química do recobrimento polimérico na superfície da nanoestrutura; e o maior controle na quantidade de cadeias de PEG e de grupos funcionais que estarão na superfície do nanomaterial, o que pode aumentar a biocompatibilidade, a seletividade e a estabilidade coloidal das nanoestruturas visando aplicações biológicas. ${ }^{88}$ As moléculas de Dopa foram conjugadas na plataforma por 
apresentarem grupos de catecol, que tem alta afinidade por superfície de óxido de ferro, além de providenciarem uma forte interação entre a superfície das NPM e a camada de recobrimento polimérico. Além disso, foram utilizadas mistura de cadeias de PEG monofuncionalizados com grupo amina, sendo a outra extremidade formada por grupos metóxi (que age como um grupo não reativo na superfície da nanoestrutura), e bifuncionalizados com grupos amina, que são cadeias de PEG funcionalizadas com grupos funcionais de amina nas duas extremidades $\left(\mathrm{NH}_{2}-\right.$ PEG-NH $\mathrm{N}_{2}$ ), sendo que os grupos amina em uma das extremidades interagem com o PIMA e da outra extremidade foram parcialmente ligadas com os grupos de ácido carboxílico dos pontos quânticos recobertos com LA-PEG-COOH.

Pela figura 47 pode-se observar um esquema ilustrativo com as cinco etapas para a obtenção dos ligantes de LA-PEG-COOH. ${ }^{50} \mathrm{Na}$ etapa 1 , os grupos hidroxila das duas extremidades das moléculas de PEG são substituídos pelo grupo azida. Após isso, na etapa 2, um dos grupos azida da extremidade do PEG são convertidos em grupo amina, com a utilização de quantidade adequada de trifenilfosfina em solução aquosa de ácido clorídrico. Na etapa 3 foi utilizado o método da carbodiimida, (utilizando-se DCC e DMAP) para a formação de uma ligação amida entre o LA e a amina primária presente em uma das extremidades da cadeia de PEG. Após isso, na etapa 4, o grupo azida da outra extremidade da cadeia de PEG foi convertido em grupo amina, com a utilização novamente de trifenilfosfina em solução aquosa ácida. E, finalmente, na etapa 5 o grupo amina da extremidade do PEG foi conjugado com a molécula de anidrido succinico na presença de trietilamina como base, que ocasionou a abertura do anel de anidrido e formação de um grupo de ácido carboxílico na extremidade da cadeia de PEG. Com isso, após as cinco etapas foi possível a obtenção do ligante LA-PEG-COOH.

$\mathrm{Na}$ figura 48 é visto o espectro de RMN de $\mathrm{H}^{1}$ para os ligantes de LA-PEG-COOH. Observando-se o espectro pode-se notar picos intensos na região entre 3,8 e 3,6 ppm que pode ser atribuído aos prótons relacionados as cadeias de PEG, e os picos multipletos ao redor de 1,$47 ; 1,68 ; 1,9 ; 2,48 ; 2,56 ; 3,13 ;$ e 3,19 ppm são relacionados a prótons da estrutura do ácido lipóico, que está presente em uma das extremidades da cadeia de PEG do ligante. ${ }^{50,51}$ 
Figura 47 - Esquema ilustrativo para formação de LA-PEG-COOH a partir de moléculas de PEG.

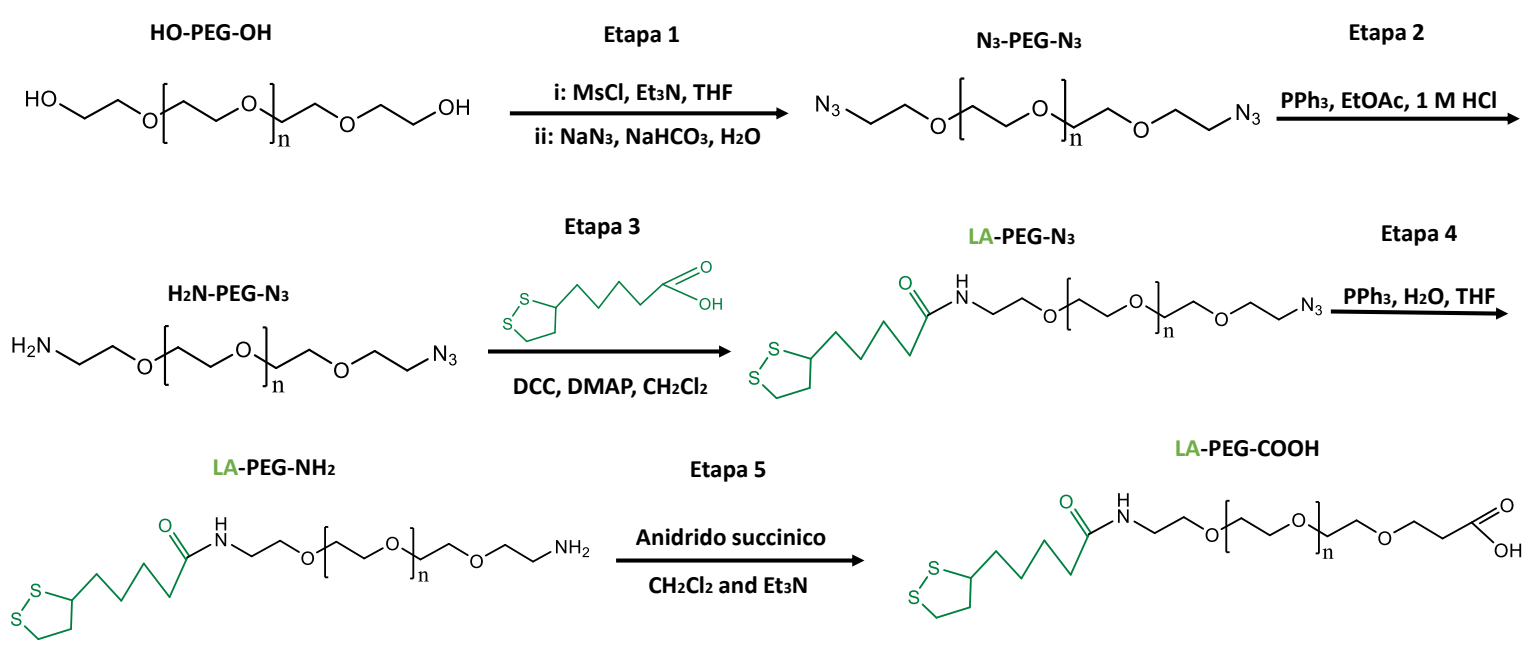

Figura 48 - Espectro de RMN de $\mathrm{H}^{1}$ dos ligantes de LA-PEG-COOH

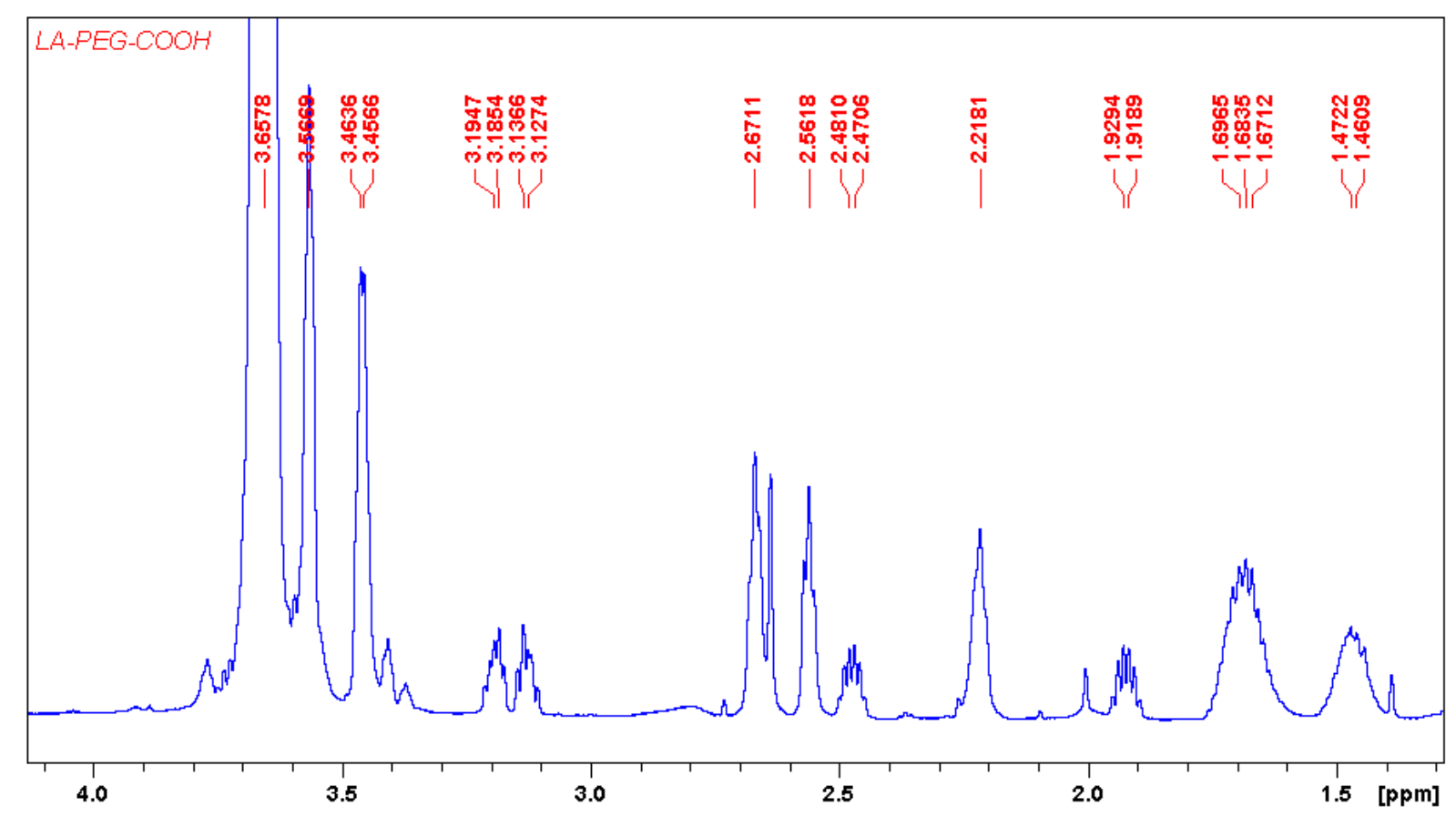

Para a formação dos ligantes de Dopa-PIMA-PEG-NH $\mathrm{N}_{2}$, foi utilizada uma rota experimental simples, pois o polímero PIMA possui diversos anéis de anidrido maléico conjugados, o qual são bastante reativos e na presença de grupos amina tem grande susceptibilidade para a reação e sua consequente abertura e formação da ligação amida. Com isso, não há a necessidade da utilização de reagentes adicionais para auxiliar na conjugação entre um grupo amina com este polímero. Desta forma, na figura 49 pode-se observar um 
esquema ilustrativo para a formação dos ligantes de Dopa-PIMA-PEG-NH2. Nesta reação, na presença de polímeros de PIMA (em azul) são adicionadas moléculas de dopamina (em vermelho), PEG com grupo amina em suas duas extremidades (em preto) e PEG com grupo amina em uma extremidade e metóxi na outra (não destacado na figura 49) que, em DMF como solvente e após algumas horas, se conjugam facilmente aos anéis de anidrido maléico, formando-se estruturas com diversas moléculas de dopamina e de amino-PEG conjugadas à cada plataforma polimérica de PIMA.

Figura 49 - Esquema ilustrativo da obtenção dos ligantes de Dopa-PIMA-PEG-NH2.
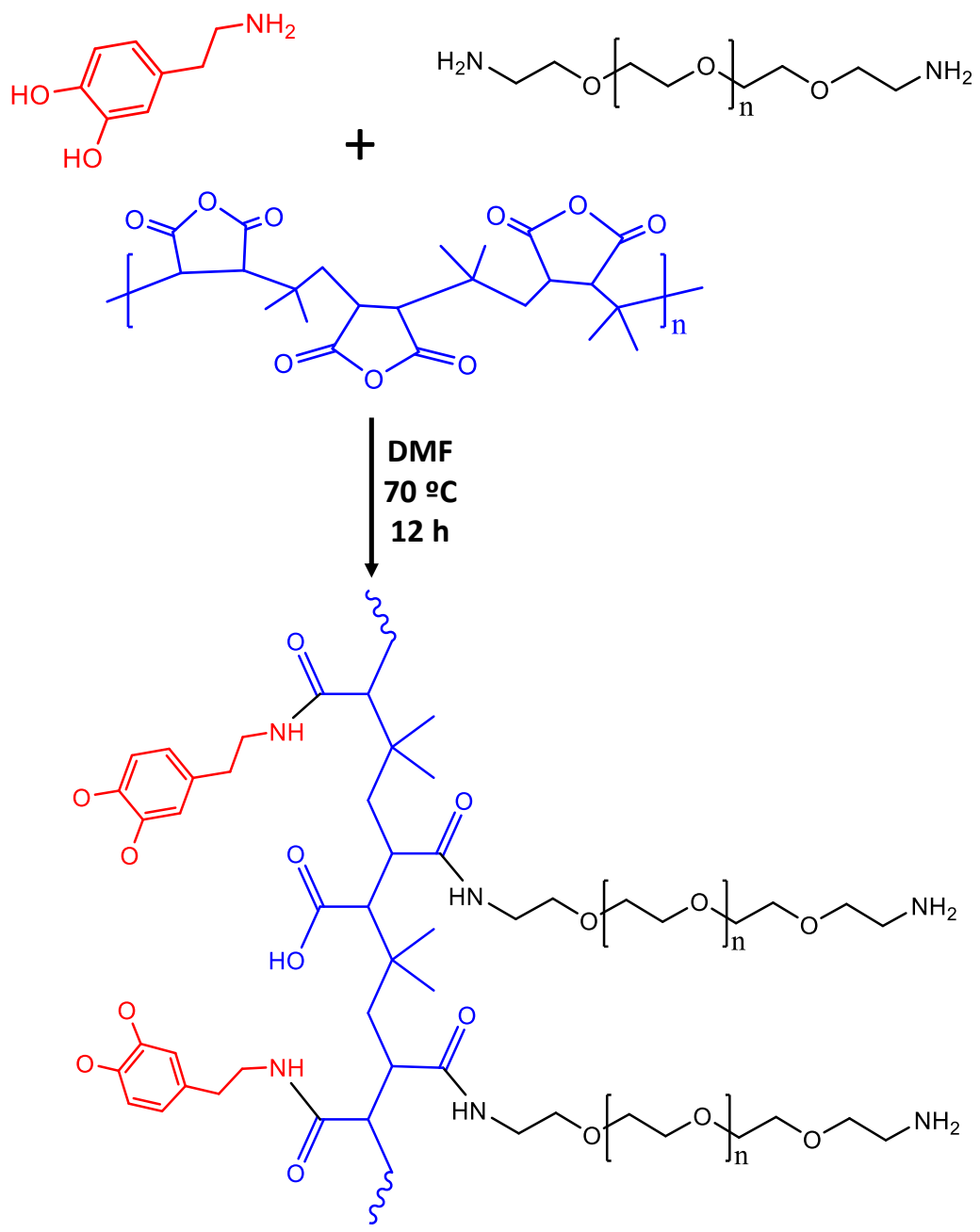

Para caracterização dos ligantes de Dopa-PIMA-PEG-NH $\mathrm{NH}_{2}$ foi realizado um espectro de RMN de $\mathrm{H}^{1}$, como pode ser visto na figura 50, no qual pode ser observado picos na região de 6,4 a 6,7 ppm que podem ser atribuídos aos prótons do anel aromático do grupo catecol presente na dopamina. Além disso, os intensos picos em 3,5 e 3,23 ppm podem ser atribuídos aos prótons 
da cadeia e do grupo metóxi do PEG, respectivamente. E, finalmente, o pico alargado em 0,91 ppm pode ser atribuído aos prótons dos grupos metila da plataforma do PIMA.

Figura 50 - Espectro de $\mathrm{RMN}$ de $\mathrm{H}^{1}$ dos ligantes de Dopa-PIMA-PEG- $\mathrm{NH}_{2}$

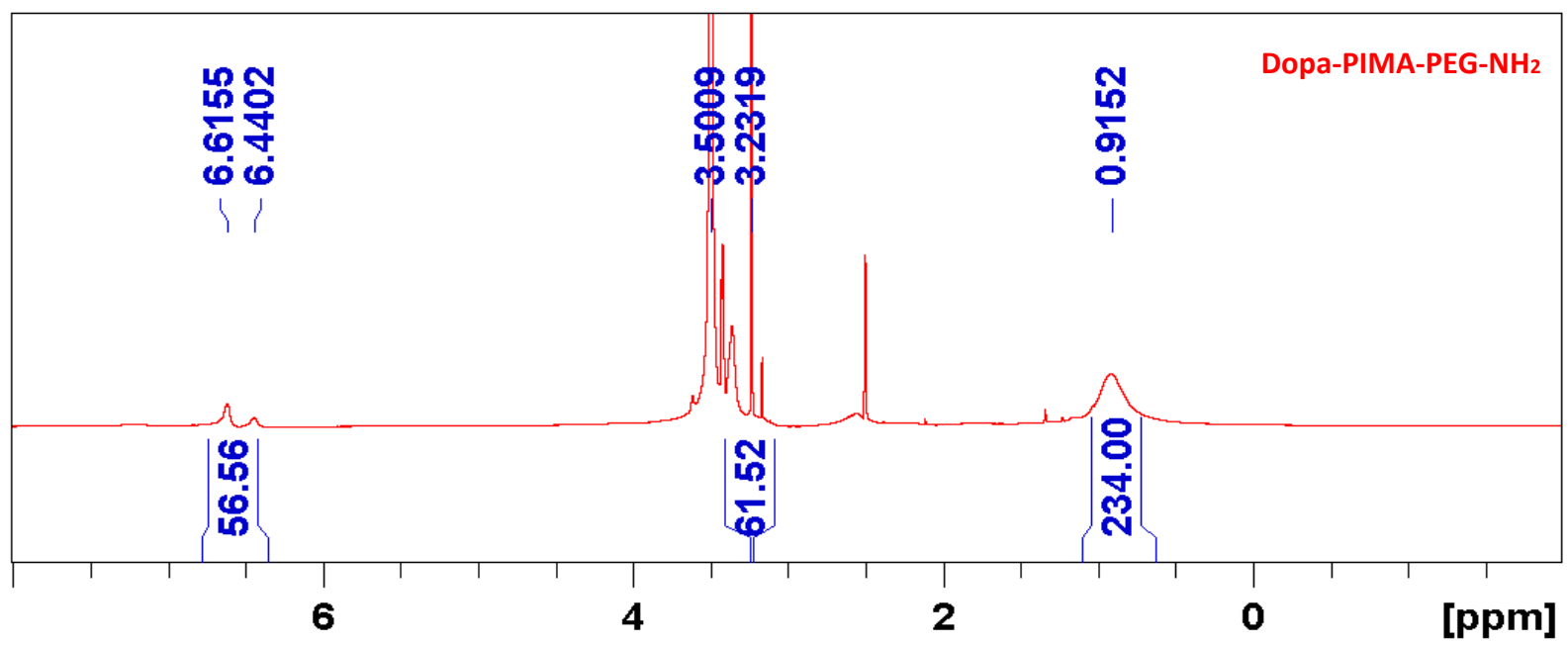

\subsubsection{Pontos Quânticos de CdSe/ZnS por decomposição térmica}

Os pontos quânticos de CdSe foram obtidos utilizando-se o método de decomposição térmica de precursores organometálicos de cádmio e selênio (maiores detalhes na seção 4.3.2 da parte experimental) em alta temperatura e na presença de mistura de solventes coordenantes para o controle da nucleação e crescimento dos pontos quânticos obtidos após injeção dos precursores. Para obtenção de pontos quânticos com alta cristalinidade e estreita distribuição de tamanho, este procedimento foi baseado no protocolo estalecido por Mattoussi e colaboradores $^{97}$, que foi também baseado em protocolo previamente publicado por Murray e colaboradores ${ }^{95}$. Após a obtenção dos pontos quânticos luminescentes de $\mathrm{CdSe}$, foi realizado um subsequente recobrimento destes pontos quânticos com 3 a 7 monocamadas de $\mathrm{ZnS}$, para providenciar pontos quânticos caroço/casca de $\mathrm{CdSe} / \mathrm{ZnS}$ com alto rendimento quântico de fluorescência e, desta forma, com propriedades luminescentes intensificadas.

Pela figura 51 pode-se observar os espectros de absorção (a) e fluorescência (b) da amostra com os pontos de $\mathrm{CdSe} / \mathrm{ZnS}$ recobertos com TOP/TOPO obtidos pelo método descrito na seção 4.3.2 da parte experimental. De acordo com o espectro de absorção, a amostra de $\mathrm{CdSe} / \mathrm{ZnS}$ recobertos com TOP/TOPO apresentou uma $1^{\circ}$ banda de absorção com máximo em $553 \mathrm{~nm}$, o que de acordo com cálculos teóricos na literatura ${ }^{102}$ representa um espectro para pontos quânticos de CdSe/ZnS com diâmetro entre 3 e 4 nm. Já pelo espectro de emissão, com 
excitação em $380 \mathrm{~nm}$, pode-se observar que os pontos quânticos apresentaram uma banda de emissão intensa centrada em $567 \mathrm{~nm}$.

Figura 51 - Espectros de absorção (a) e emissão (b) para a amostra de CdSe/ZnS recobertos com os ligantes de TOP/TOPO.
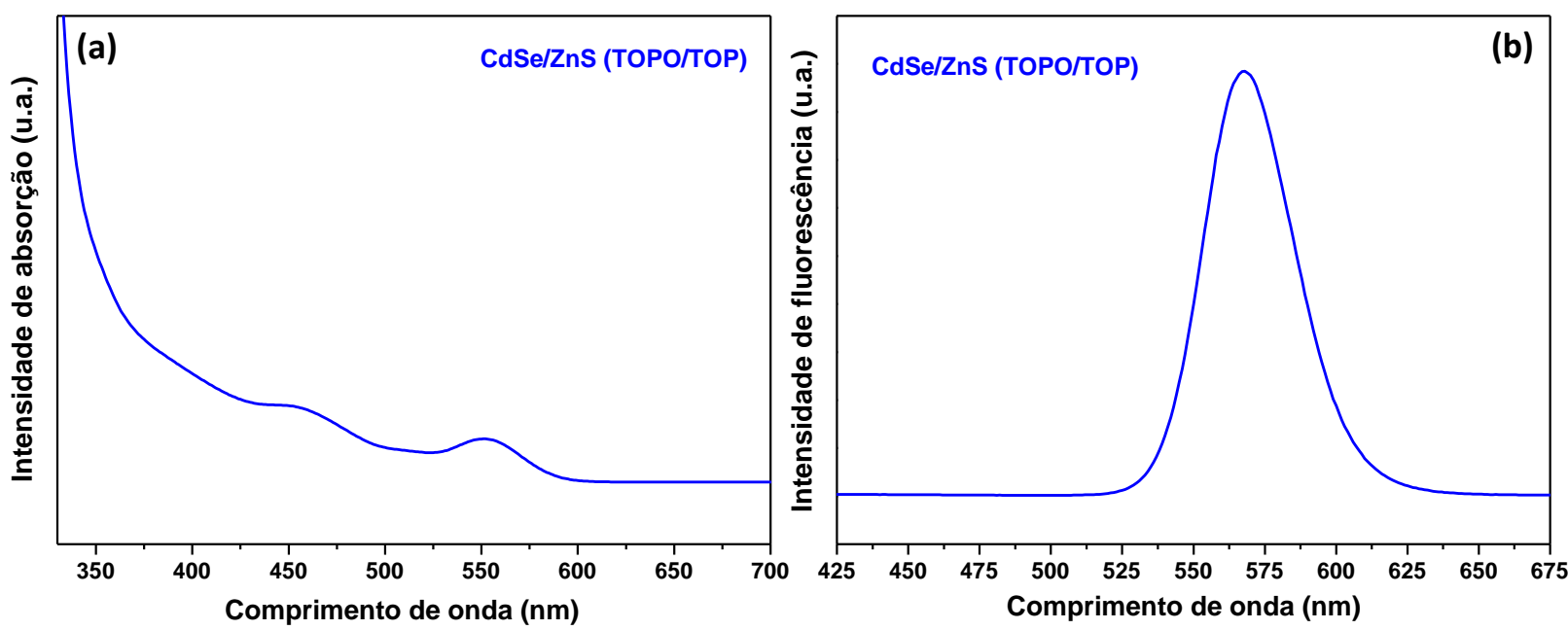

Pela figura 52 pode-se observar as fotografias da amostra contendo os pontos quânticos de $\mathrm{CdSe} / \mathrm{ZnS}$ (com TOP/TOPO na superfície) dispersos em hexano na ausência (a) e na presença de luz UV (b). Observando-se a amostra sob luz UV é possível notar que os pontos quânticos apresentam um processo de emissão de fluorescência na região do amarelo do espectro visível e com alta intensidade de fluorescência.

Figura 52 - Fotografias dos pontos quânticos de CdSe/ZnS com TOP/TOPO na superfície: na ausência (a) e na presença de luz UV (b).

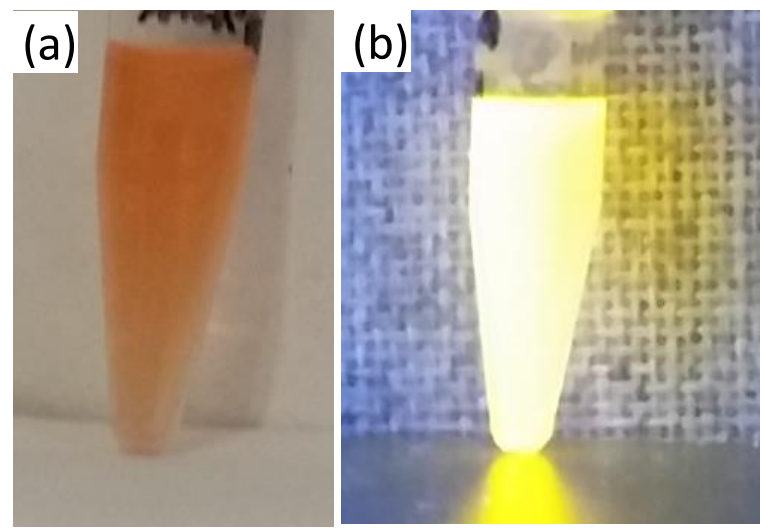




\subsubsection{Troca de ligantes fotoinduzida dos pontos quânticos de CdSe/ZnS utilizando LA- PEG-COOH e LA-PEG-OCH3}

Com o intuito de providenciar dispersibilidade e estabilidade coloidal em meio aquoso, foi realizada uma troca de ligantes fotoinduzida utilizando-se polímeros de LA-PEG-COOH na presença de luz UV (baseado em protocolo estabelecido por Mattoussi e colaboradores ${ }^{35}$ ) nos pontos quânticos de $\mathrm{CdSe} / \mathrm{ZnS}$ recobertos com TOP/TOPO e superfície hidrofóbica. Esta estratégia sugere que o processo de redução de anéis disulfeto presentes no LA é potencialmente acelerado na presença de irradiação UV e pontos quânticos de CdSe/ZnS. A partir do estudo de mecanismo de reação proposto por Mattoussi e colaboradores ${ }^{35}$, constatou-se que a irradiação UV (em torno de $350 \mathrm{~nm}$ ) pode promover uma excitação fotoquímica de um elétron presente no anel dissulfeto para um estado excitado, seguido de uma conversão inter-sistema para um estado excitado tripleto. A excitação para o estado tripleto pode ocasionar dois possíveis mecanismos de troca de ligantes: (1) ou pode produzir uma cisão da ligação disulfeto e formação do ditiol com subsequente troca dos ligantes TOP/TOPO por HDLA-PEG-COOH na superfície dos pontos quânticos; (2) ou pode ocasionar a formação de dois radicais de enxofre, seguido pela troca de ligantes.

Figura 53 - Esquema ilustrativo para a troca de ligantes na superfície dos pontos quânticos de $\mathrm{CdSe} / \mathrm{ZnS}$.
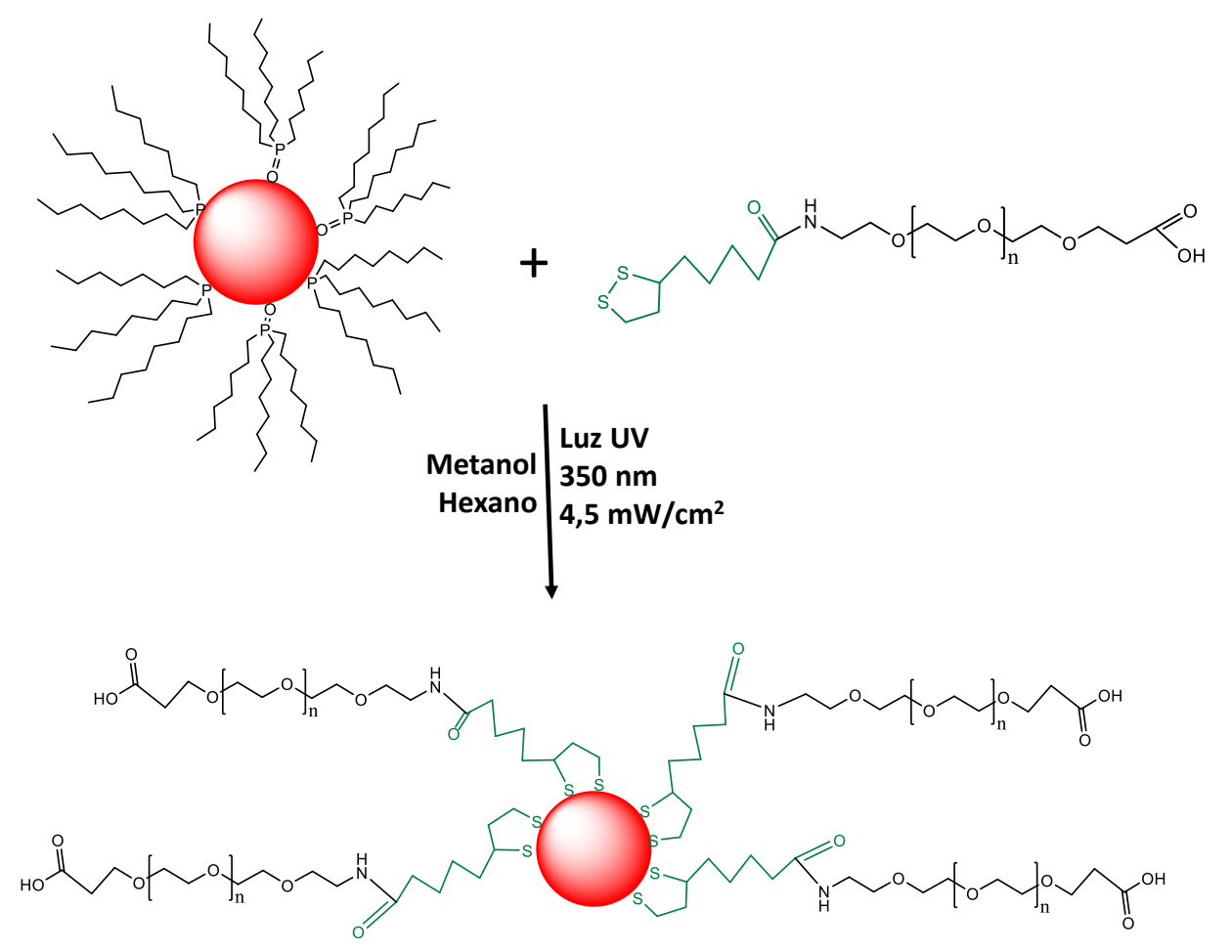
Na figura 53 é demonstrado um esquema ilustrativo para a troca de ligantes que ocorre na superfície dos pontos quânticos de CdSe/ZnS. Nesta reação, os pontos quânticos de $\mathrm{CdSe} / \mathrm{ZnS}$ com moléculas de TOP e TOPO em sua superfície, na presença de luz UV e excesso de ligantes de LA-PEG-COOH, são induzidos a uma troca dos ligantes em sua superfície, o que ocasiona a formação de CdSe/ZnS-LA-PEG-COOH com superfície hidrofílica e estabilidade coloidal em solução aquosa.

Pode ser observado pela figura 54, as fotografias dos pontos quânticos de CdSe/ZnS dispersos em hexano na ausência (a) e na presença de luz UV (b). Sendo que após o processo de troca de ligantes, há uma transferência destes pontos quânticos para a fase aquosa, o que é evidenciado pela sua dispersão em água na ausência (c) e na presença de luz UV (d).

Figura 54 - Fotografias dos pontos quânticos de CdSe/ZnS, antes da troca de ligantes dispersos em hexano, na ausência (a) e na presença de luz UV (b); e após o processo de troca de ligantes com LA-PEG-COOH, dispersos em água, na ausência (c) e na presença de luz UV (d).
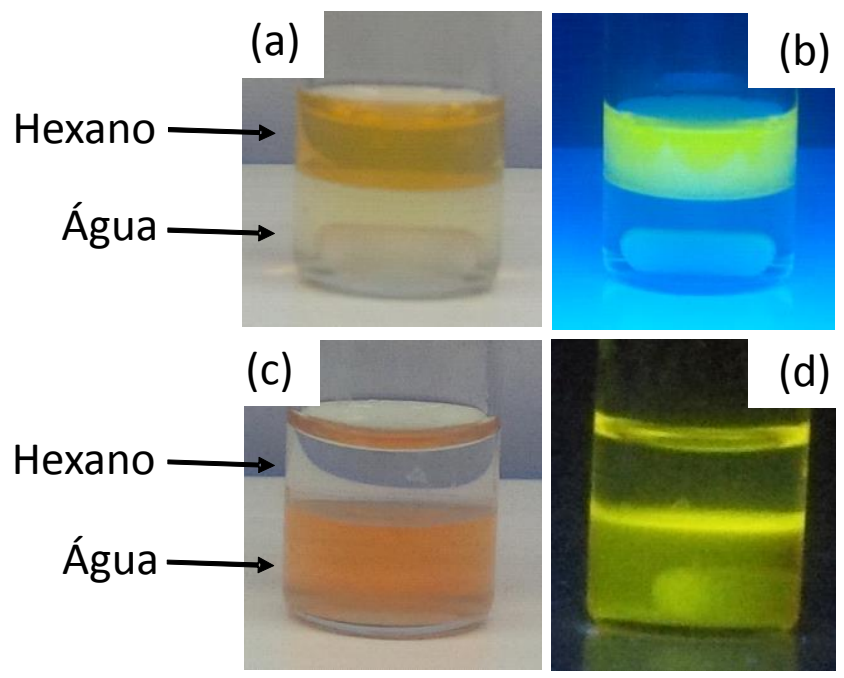

Os espectros de absorção (a) e de emissão (b) para os pontos quânticos de CdSe/ZnS após a troca de ligantes, recobertos com LA-PEG-COOH, podem ser visto na figura 55. De acordo com o espectro de absorção, os pontos quânticos após a troca de ligantes apresentaram uma $1^{\circ}$ banda de absorção com máximo centrado em $557 \mathrm{~nm}$, e uma segunda banda com máximo centrado em $460 \mathrm{~nm}$. Já de acordo com o espectro de emissão, com excitação em $380 \mathrm{~nm}$, os pontos quânticos apresentaram banda de emissão com máximo centrado em 575 nm. Comparando-se os resultados obtidos nos espectros de absorção e emissão para os pontos quânticos antes e após a troca de ligantes observou-se que, após a troca de ligantes, a $1^{\circ}$ banda de absorção e a banda de emissão dos pontos quânticos apresentaram um pequeno deslocamento 
do máximo destas bandas para comprimentos de onda maiores que a amostra de CdSe/ZnS com superfície hidrofóbica.

Figura 55 - (a) Espectros de absorção e (b) de emissão (excitação em $380 \mathrm{~nm}$ ) para os pontos quanticos de $\mathrm{CdSe} / \mathrm{ZnS}$ recobertos com LA-PEG-COOH.
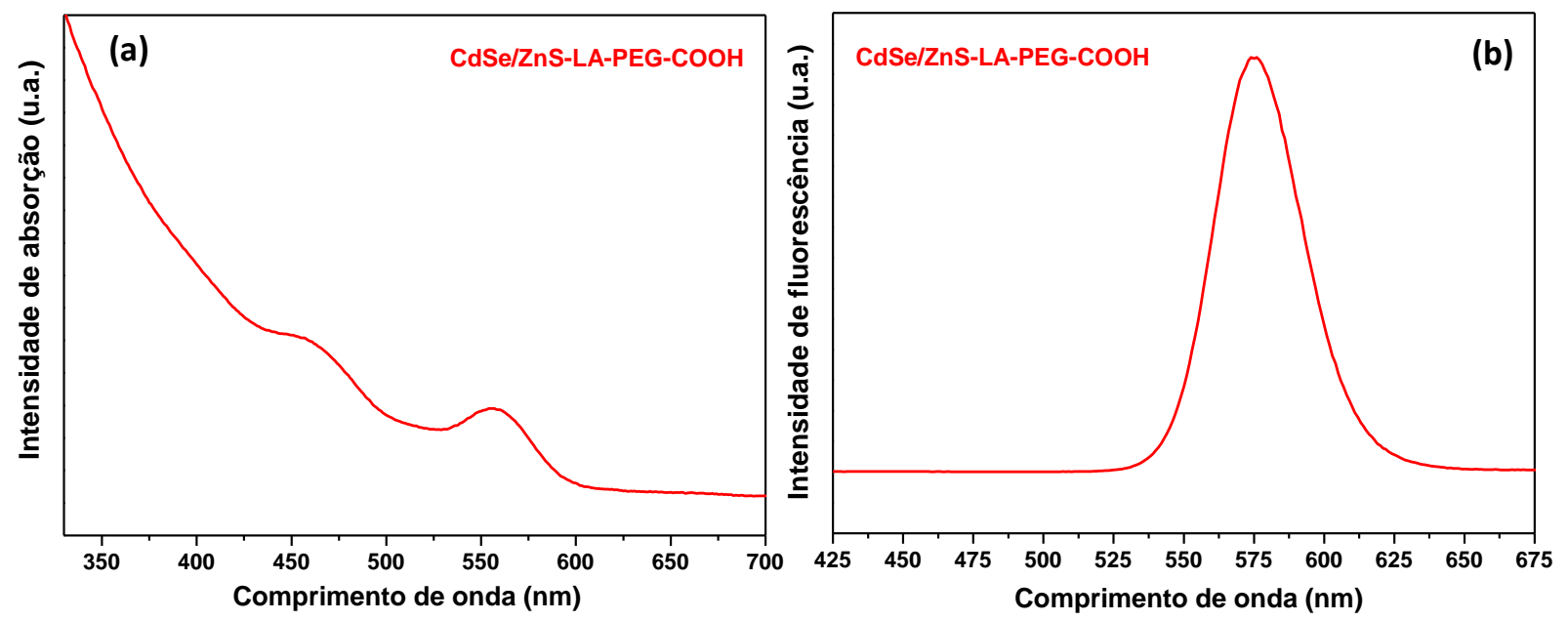

\subsubsection{Trocas de ligantes das NPM de $\mathrm{FePt}_{/} \mathrm{Fe}_{3} \mathrm{O}_{4}$ utilizando Dopa-PIMA-PEG-NH2}

Para providenciar estabilidade coloidal e dispersibilidade em meio aquoso visando aplicações biológicas, as NPM de $\mathrm{FePt} / \mathrm{Fe}_{3} \mathrm{O}_{4}$ foram recobertas com os ligantes, previamente preparados, de Dopa-PIMA-PEG-NH $\mathrm{NH}_{2}$ O processo de troca dos ligantes ácido oleico e oleilamina na superfície das NPM com polímeros de Dopa-PIMA-PEG- $\mathrm{NH}_{2}$ foi bastante efetivo, pois a interação entre a superfície das NPM e os grupos catecol presentes na dopamina são mais fortes que as oriundas dos grupos amina e carboxilato presentes nas moléculas de oleilamina e ácido oleico, respectivamente. Além disso, após a troca dos ligantes, a probabilidade das moléculas de ácido oleico e oleilamina se aproximarem novamente da superfície das NPM é bastante minimizada pela presença das platarformas poliméricas de PIMA nos ligantes, que providenciam um impedimento estérico, e também pelo fato de os ligantes de Dopa-PIMA-PEG-NH $\mathrm{NH}_{2}$ estarem em excesso quando comparado com a quantidade molar de ácido oleico e oleilamina no meio reacional.

Pela figura 56 pode-se observar um esquema ilustrativo da reação de troca das moléculas de ácido oleico e oleilamina por ligantes poliméricos de Dopa-PIMA-PEG- $\mathrm{NH}_{2}$, transformando a superfície hidrofóbica das NPM de $\mathrm{FePt} / \mathrm{Fe}_{3} \mathrm{O}_{4}$ em superfície hidrofílica. Nesta reação, os ligantes de Dopa-PIMA-PEG-NH 2 estão em excesso em meio reacional à $50^{\circ} \mathrm{C}$ em $\mathrm{THF}$. Vale 
salientar que os grupos funcionais de amina no ligante são controlados, e que em torno de $10 \%$ dos ligantes de PEG conjugados no PIMA tem essa funcionalidade em sua extremidade em contato com o ambiente externo, sendo que os outros $90 \%$ dos ligantes de PEG conjugados no PIMA tem em sua extremidade externa grupos metóxi (Dopa-PIMA-PEG-OCH 3 ), que são grupos não-reativos que diminui a reatividade da supercície das NPM após o recobrimento. Este controle na quantidade de grupo reativos na superfície das NPM é essencial para controlar a quantidade de biomoléculas que podem ser conjugadas ou mesmo, conforme neste trabalho, a quantidade de pontos quânticos luminescentes que se ligam na superfície das NPM, formandose nanomateriais multifuncionais.

Figura 56 - Esquema ilustrativo para a troca de ligantes com Dopa-PIMA-PEG-NH $\mathrm{NH}_{2}$ na superfície das NPM de $\mathrm{FePt} / \mathrm{Fe}_{3} \mathrm{O}_{4}$.

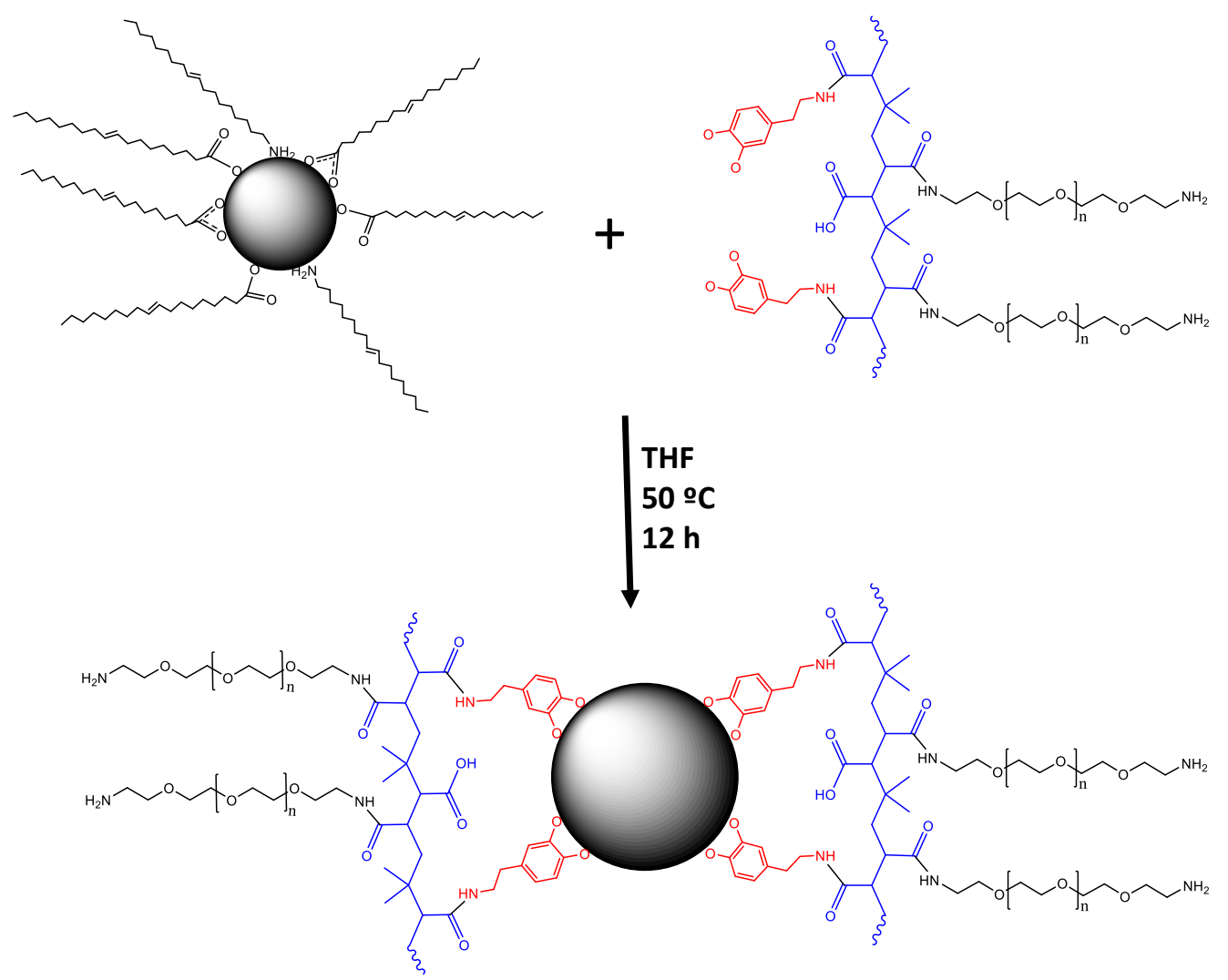

Pela figura 57 pode-se observar as fotografias das NPM de $\mathrm{FePt} / \mathrm{Fe}_{3} \mathrm{O}_{4}$ antes da troca de ligantes (com ácido oleico e oleilamina na superfície), que são dispersas na fase de hexano (a) e, as NPM após a troca de ligantes (com Dopa-PIMA-PEG-NH ${ }_{2}$ ) que apresentam superfície hidrofílica e estão dispersas na fase aquosa (b). 
Figura 57 - Fotografias das NPM de $\mathrm{FePt} / \mathrm{Fe}_{3} \mathrm{O}_{4}$ dispersas em hexano, antes a troca de ligantes (a); e dispersas em água, após a troca com os ligantes de Dopa-PIMA-PEG-NH2.

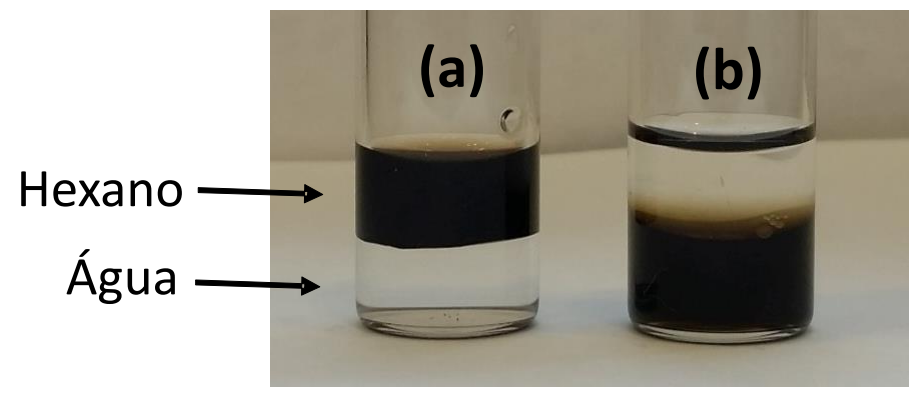

Pelas medidas de DLS na figura 58, é possível observar que as $\mathrm{NPM}$ de $\mathrm{FePt} / \mathrm{Fe}_{3} \mathrm{O}_{4}$ recobertas com Dopa-PIMA-PEG-NH 2 em solução aquosa apresentaram uma estreita distribuição de tamanho e com $\mathrm{R}_{\mathrm{H}}=12,15 \mathrm{~nm}$, o que pode-se afirmar que em solução aquosa estas NPM apresentam um diâmetro médio de aproximadamente $24 \mathrm{~nm}$, que é um tamanho bastante adequado para utilizar estas partículas para a conjugação com os pontos quânticos luminescentes e formação dos nanomateriais luminomagnéticos.

Figura 58 - Medida de DLS para a amostra contendo as NPM de $\mathrm{FePt} / \mathrm{Fe}_{3} \mathrm{O}_{4}$ recobertas com Dopa-PIMA-PEG-NH2.

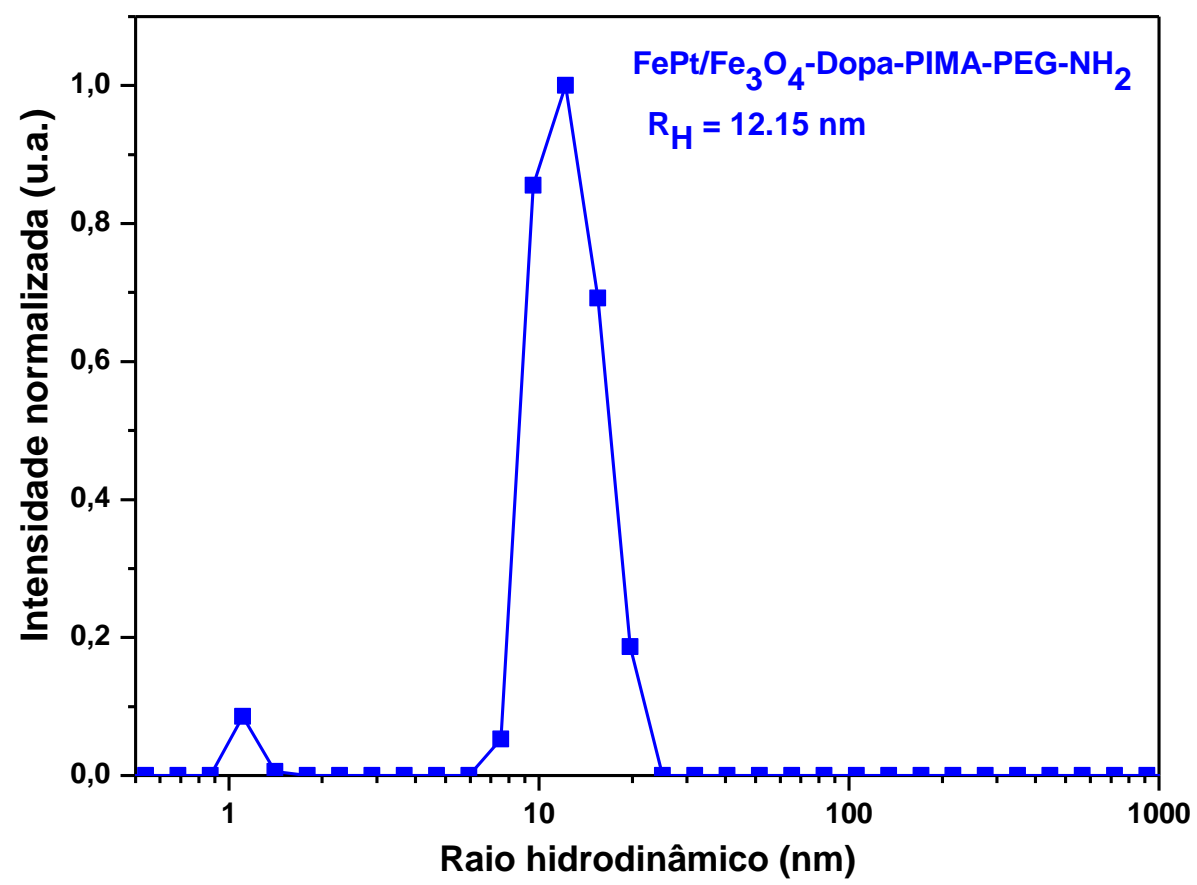


Com o intuito de avaliar a estabilidade coloidal das NPM de $\mathrm{FePt} / \mathrm{Fe}_{3} \mathrm{O}_{4}$-Dopa-PIMAPEG- $\mathrm{NH}_{2}$, foram realizados testes da estabilidade coloidal com o tempo em diferentes condições, podendo ser visto na figura 59. Os testes foram avaliados em três períodos de tempo, sendo: 1 dia, 7 dias e 21 dias após a preparação das amostras de NPM em diferentes condições. As amostras foram analisadas em diferentes $\mathrm{pH}$ (sendo variado os valores de $\mathrm{pH}$ na faixa de 4 e 12) e em diferentes condições salinas de $\mathrm{NaCl}$ (sendo testados em solução com $1 \mathrm{M}$ e $2 \mathrm{M}$ de $\mathrm{NaCl}$ ). Desta forma, a estabilidade coloidal das NPM foi avaliada em condições extremas de $\mathrm{pH}$ e salinidade, o que se torna um teste adequado para testar a viabilidade das partículas visando aplicações biológicas. Após o período de 21 dias, constatou-se que todas as amostras nas diferentes condições de $\mathrm{pH}$ e salinidade permaneceram com a dispersibilidade em solução PBS não alterada, não apresentando agregação das partículas e consequente precipitação das mesmas. Estas propriedades de estabilidade coloidal evidenciam a eficiência do recobrimento com os ligantes de Dopa-PIMA-PEG- $\mathrm{NH}_{2}$ e a viabilidade destas partículas visando futuras aplicações que envolvam a dispersão destas partículas em solução aquosa em condições extremas.

Figura 59 - Testes de estabilidade coloidal com o tempo das NPM de FePt/Fe $\mathrm{O}_{4}$ - Dopa-PIMAPEG- $\mathrm{NH}_{2}$ dispersas em solução PBS preparada em diferentes condições de $\mathrm{pH}$ e salinidade.

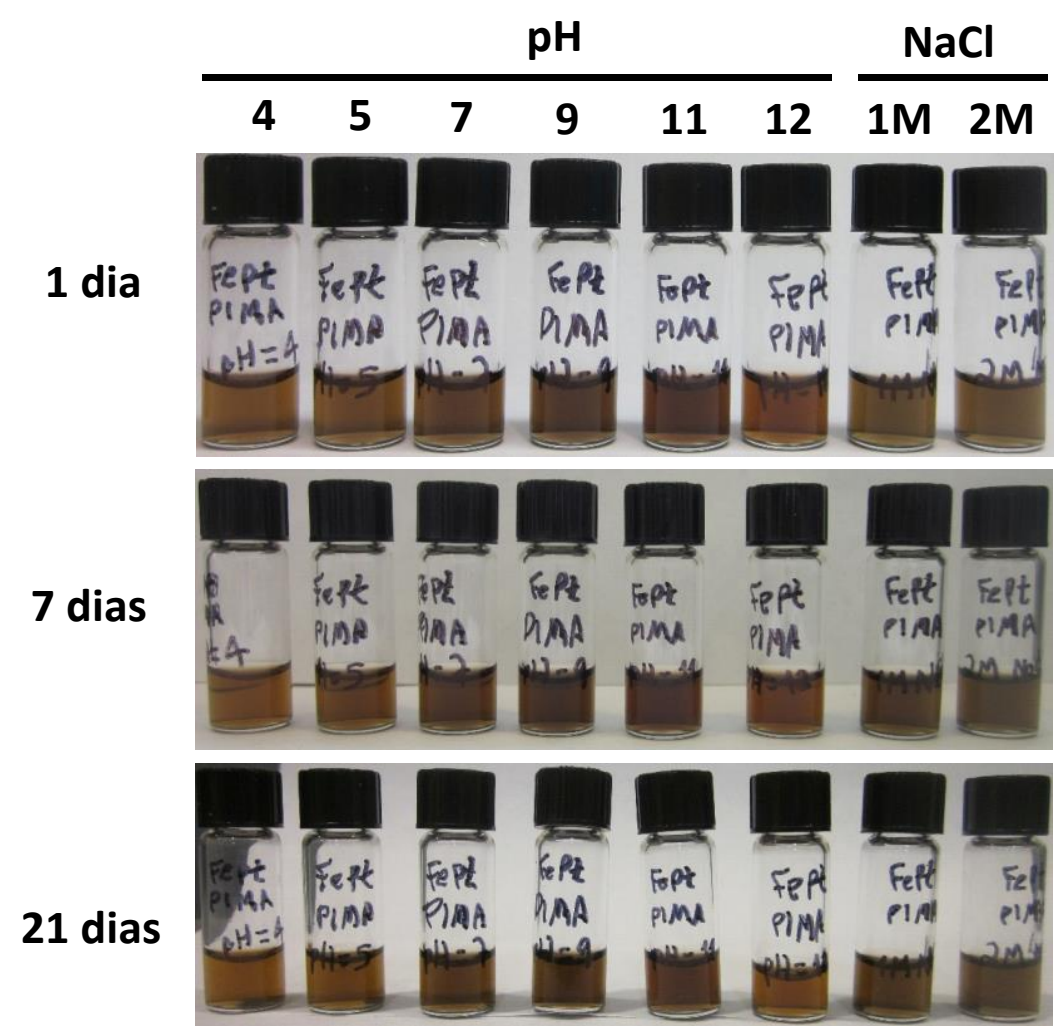


Na figura 60 é possível observar a caracterização magnética da amostra com as NPM de $\mathrm{FePt} / \mathrm{Fe}_{3} \mathrm{O}_{4}$-Dopa-PIMA-PEG-NH${ }_{2}$. De acordo com os dados de caracterização magnética, observou-se que as NPM após o processo de recobrimento não apresentaram um comportamento magnético esperado, pois apresentaram um comportamento mais próximo do paramagnético, com o aumento do campo magnético externo, pois a amostra não alcançou sua Ms rapidamente com a aplicação de campo magnético externo. P não foi possível observar o ponto de magnetização de saturação, entretanto, pela tendência da curva pode-se esperar uma Ms em torno de $10 \mathrm{emu}^{-1}{ }^{-1}$, valor adequado para o propósito deste trabalho. Além disso, pela região destacada na figura 60 , observou-se que a posição dos valores de coercividade e remanência na curva estão ligeiramente deslocados do ponto de simetria da histerese magnética, porém pela caracterização magnética foi demonstrado que os valores de coercividade e remanência são muito próximo de zero, o que é adequado visando futuras aplicações biológicas.

Figura 60 - Curva de histerese magnética para a amostra com as NPM de FePt/ $\mathrm{Fe}_{3} \mathrm{O}_{4}$-DopaPIMA-PEG-NH${ }_{2}$.

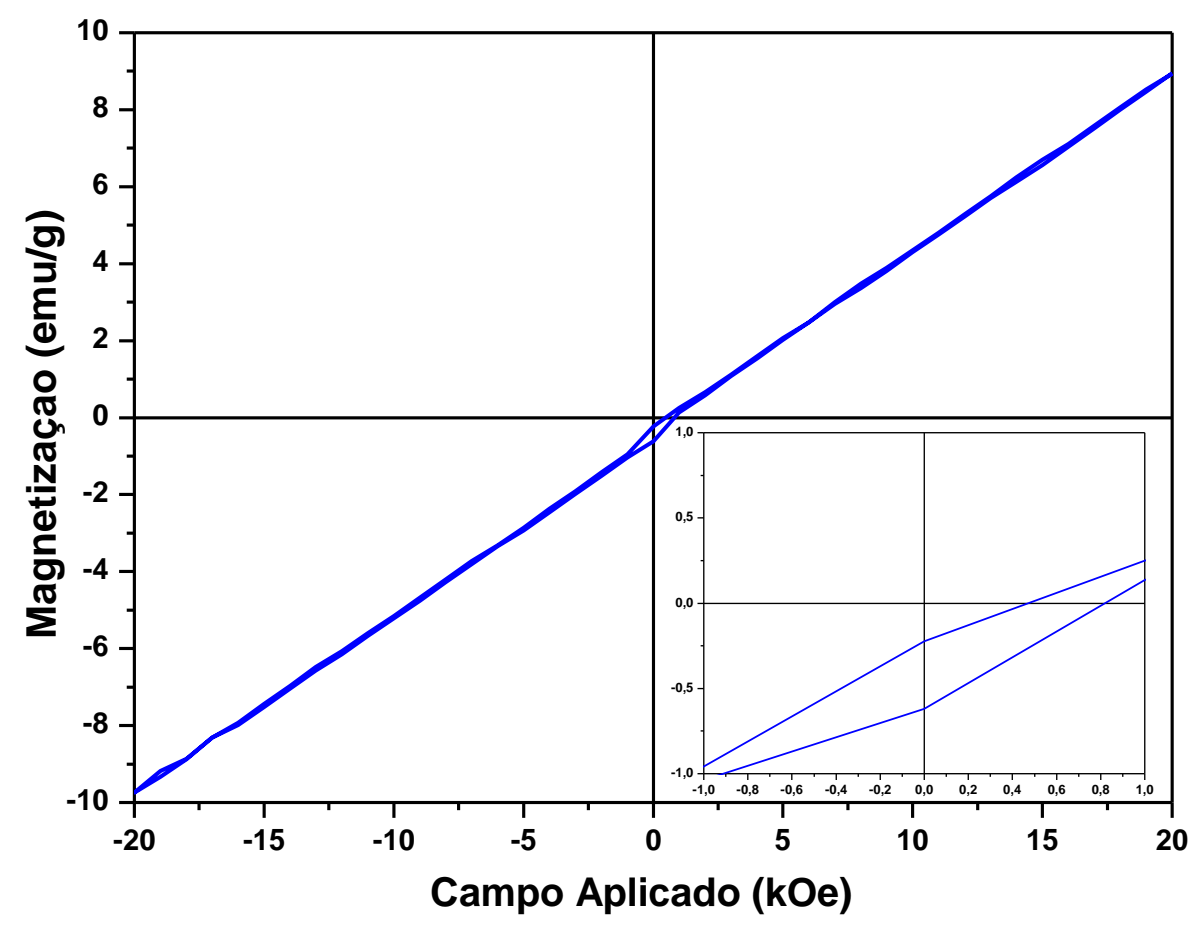

5.3.5 Conjugação das NPM e dos pontos quânticos utilizando carbodiimida em meio aquoso

A conjugação entre as NPM de $\mathrm{FePt} / \mathrm{Fe}_{3} \mathrm{O}_{4}$-Dopa-PIMA-PEG-NH $\mathrm{N}_{2}$ e os pontos quânticos de $\mathrm{CdSe} / \mathrm{ZnS}$-LA-PEG-COOH foi realizada pela formação de uma ligação amida, a partir de 
uma reação entre os grupos amina na superfície das NPM e os grupos de ácido carboxílico na superfície dos pontos quânticos. Foi utilizado o método da carbodiimida para conjugação das NPM e dos pontos quânticos, utilizando-se o EDC como o reagente ativador para formação da ligação amida e o NHS para aumentar a solubilidade e a estabilidade do intermediário ativo formado após a conjugação do EDC com a nanoestrutura. A função do EDC foi reagir com os grupos carboxilatos presentes na superfície dos pontos quânticos para formar um grupo éster ativado, que é um bom grupo de saída para o ataque nucleofílico da amina e consequente formação da ligação amida. Além disso, foi escolhido o EDC como reagente ativador da ligação amida por ele e o intermediário formado após a conjugação com os grupos carboxilatos serem solúveis em solução aquosa, o que facilita o processo de conjugação, já que ambas nanoestruturas magnéticas e luminescentes são hidrossolúveis após a conjugação com os ligantes baseados em PEG. ${ }^{52}$

Figura 61 - Esquema ilustrativo da reação de conjugação das NPM de $\mathrm{FePt} / \mathrm{Fe}_{3} \mathrm{O}_{4}$-DopaPIMA-PEG-NH${ }_{2}$ e os pontos quânticos de CdSe/ZnS-LA-PEG-COOH, utilizando-se o método da carbodiimida.
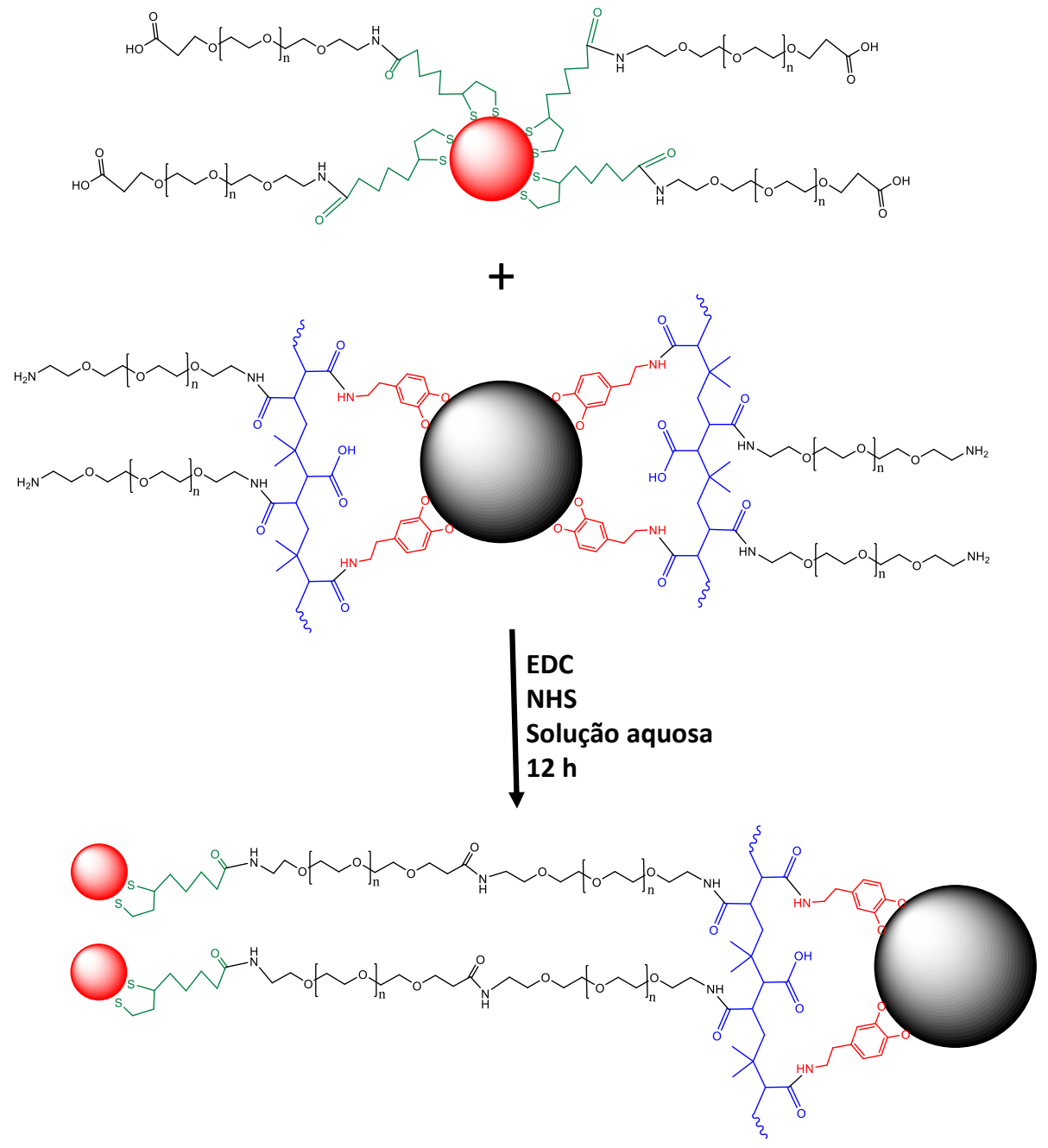
Na figura 61 pode ser visto um esquema ilustrativo para a reação entre as NPM de FePt/Fe ${ }_{3} \mathrm{O}_{4}$-Dopa-PIMA-PEG-NH 2 e os pontos quânticos de CdSe/ZnS-LA-PEG-COOH, na presença de EDC e NHS em solução aquosa. Vale salientar que este esquema ilustrativo não mostra os ligantes de Dopa-PIMA-PEG-OCH 3 (que estão ligados na superfície das NPM) e LAPEG-OCH ${ }_{3}$ (ligado na superfície dos pontos quânticos), pois não influenciam drasticamente na conjugação das nanoestruturas, por apresentarem um grupo não-reativo na extremidade das cadeias de PEG que estariam em contato com as nanoestruturas.

Com o intuito de verificar o tamanho dos nanomateriais luminomagnéticos em solução aquosa e uma confirmação da conjugação das NPM e dos pontos quânticos após o método da carbodiimida, foram realizadas medidas de DLS (figura 62). De acordo com as informações coletadas na figura 62, foram observadas três distribuições de tamanho para a amostra contendo os nanomateriais luminomagnéticos, sendo que o $\mathrm{R}_{\mathrm{H}}$ para cada uma dessas distribuições foram de: pico 1 igual a 4,28 nm, pico 2 igual a 13,36 nm, e pico 3 igual a 79,96 nm, que podem ser atribuídos para os pontos quânticos de CdSe/ZnS-LA-PEG-COOH, as NPM de FePt/ $/ \mathrm{Fe}_{3} \mathrm{O}_{4}-$ Dopa-PIMA-PEG-NH $\mathrm{NH}_{2}$ e aos nanomateriais com as nanoestruturas magnéticas e luminescentes conjugadas, respectivamente. Com isso, pela presença da distribuição com $R_{H}$ de aproximadamente $80 \mathrm{~nm}$, pode-se afirmar que houve uma efetiva conjugação entre as nanoestruturas magnéticas e luminescentes, formando-se os nanomateriais luminomagnéticos.

Figura 62 - Medida de DLS para a amostra contendo os nanomateriais luminomagnéticos das NPM de $\mathrm{FePt} / \mathrm{Fe}_{3} \mathrm{O}_{4}$ com os pontos quânticos de $\mathrm{CdSe} / \mathrm{ZnS}$ recobertos com os polímeros baseados em PEG.

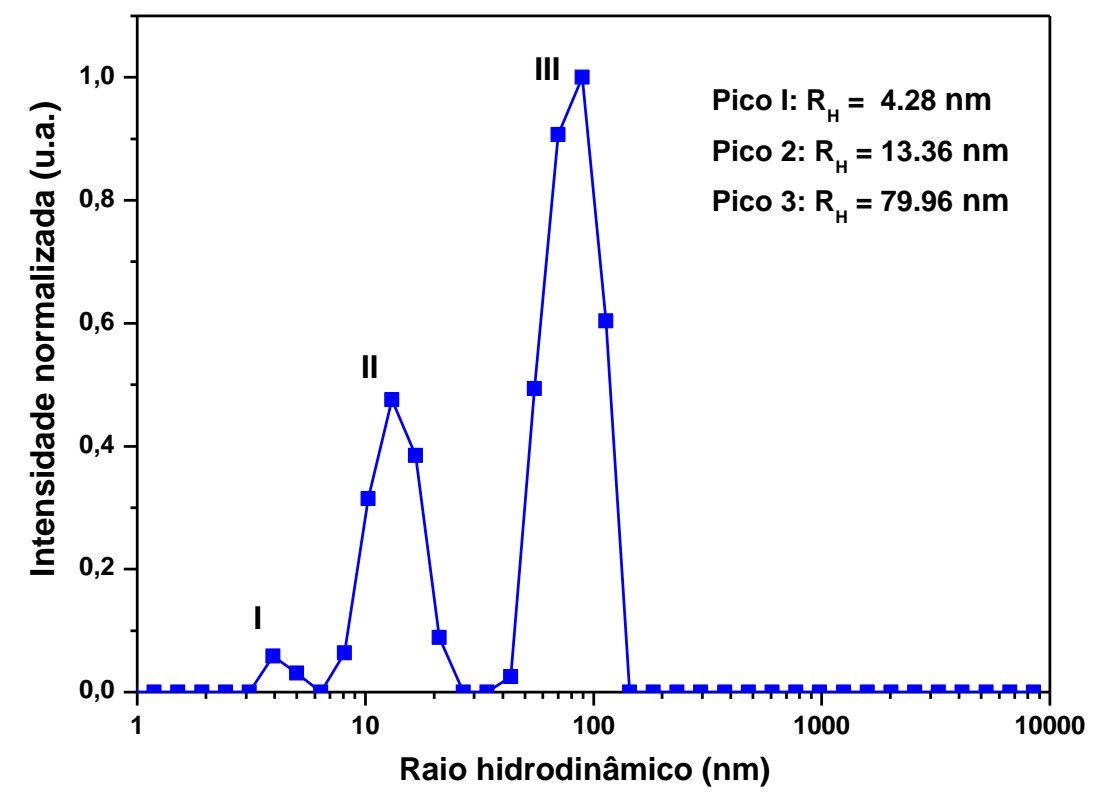


Pela figura 63 pode-se observar os resultados de MET para a amostra contendo os nanomateriais luminomagnéticos com as NPM de $\mathrm{FePt} / \mathrm{Fe}_{3} \mathrm{O}_{4}$ e os pontos quânticos de $\mathrm{CdSe} / \mathrm{ZnS}$ recobertos com os polímeros baseados em PEG. De acordo com a micrografia da figura 63, pode ser visto que existem regiões com as nanoestruturas em bastante proximidade, porém que apresentaram uma matriz orgânica, que pode ser relacionada com as cadeias de polímeros de PIMA e PEG na superfície das nanoestruturas.

Figura 63 - MET da amostra dos nanomateriais luminomagnéticos das NPM de $\mathrm{FePt} / \mathrm{Fe}_{3} \mathrm{O}_{4}$ com os pontos quânticos de $\mathrm{CdSe} / \mathrm{ZnS}$ recobertos com os polímeros baseados em PEG.
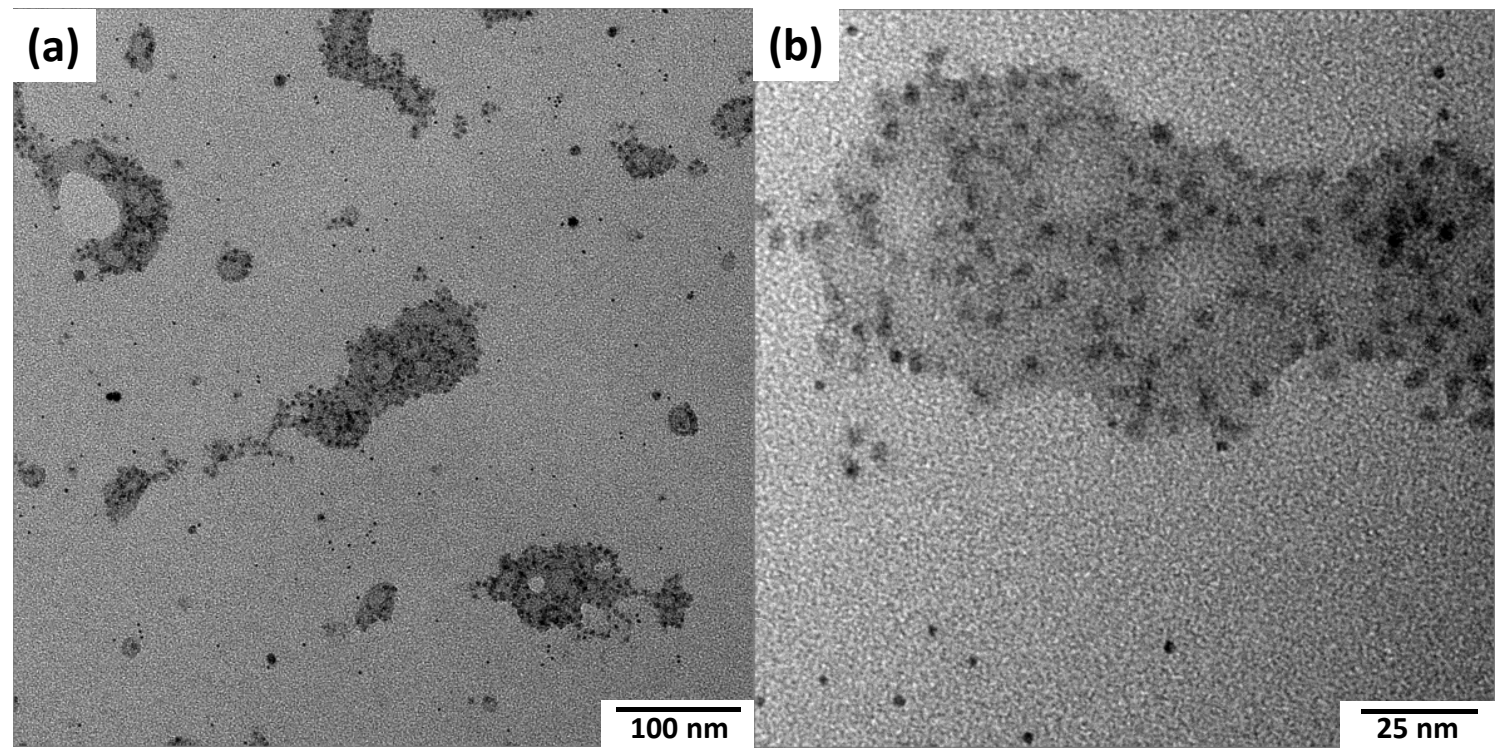

Na figura 64 mostrou-se os espectros de absorção (a) e emissão (b) para as amostras de pontos quânticos de $\mathrm{CdSe} / \mathrm{ZnS}$ recobertos com TOP/TOPO (em azul), de CdSe/ZnS recobertos com LA-PEG-COOH (em vermelho), e de CdSe/ZnS-LA-PEG-COOH após a conjugação com as $\mathrm{NPM}$ de $\mathrm{FePt} / \mathrm{Fe}_{3} \mathrm{O}_{4}$-Dopa-PIMA-PEG-NH $\mathrm{NH}_{2}$ (em verde). De acordo com o espectro de absorção, pode-se verificar que as três amostras possuem características muito similares, porém foi observado um pequeno deslocamento da $1^{\circ}$ banda de absorção para maiores comprimentos de onda, das amostras de CdSe/ZnS antes e após a troca de ligantes com LA-PEG-COOH. Além disso, a amostra dos nanomateriais luminomagnéticos apresentou uma curva com um comportamento similar aos demais, porém com bandas de absorção menos pronunciadas. Já pelos espectros de emissão, com excitação em $380 \mathrm{~nm}$, observou-se que as amostras de $\mathrm{CdSe} / \mathrm{ZnS}$ hidrofóbicas, CdSe/ZnS-LA-PEG-COOH, e os nanomateriais luminomagnéticos apresentaram bandas de emissão centradas em $567 \mathrm{~nm}, 675 \mathrm{~nm}$ e $580 \mathrm{~nm}$, respectivamente. Com esses resultados pode-se inferir que os pontos quânticos após o processo de troca de 
ligantes e a conjugação com as NPM não alterou suas propriedades luminescentes drasticamente, tendo apenas um pequeno deslocamento das bandas de absorção e emissão dos seus espectros para maiores comprimentos de onda.

Figura 64 - Espectros de absorção (a) e emissão (b) para as amostras de pontos quânticos de $\mathrm{CdSe} / \mathrm{ZnS}$ recobertos com TOP/TOPO (em azul), de CdSe/ZnS recobertos com LAPEG-COOH (em vermelho), e de CdSe/ZnS-LA-PEG-COOH após a conjugação com as $\mathrm{NPM}$ de $\mathrm{FePt} / \mathrm{Fe}_{3} \mathrm{O}_{4}$-Dopa-PIMA-PEG-NH (em verde).
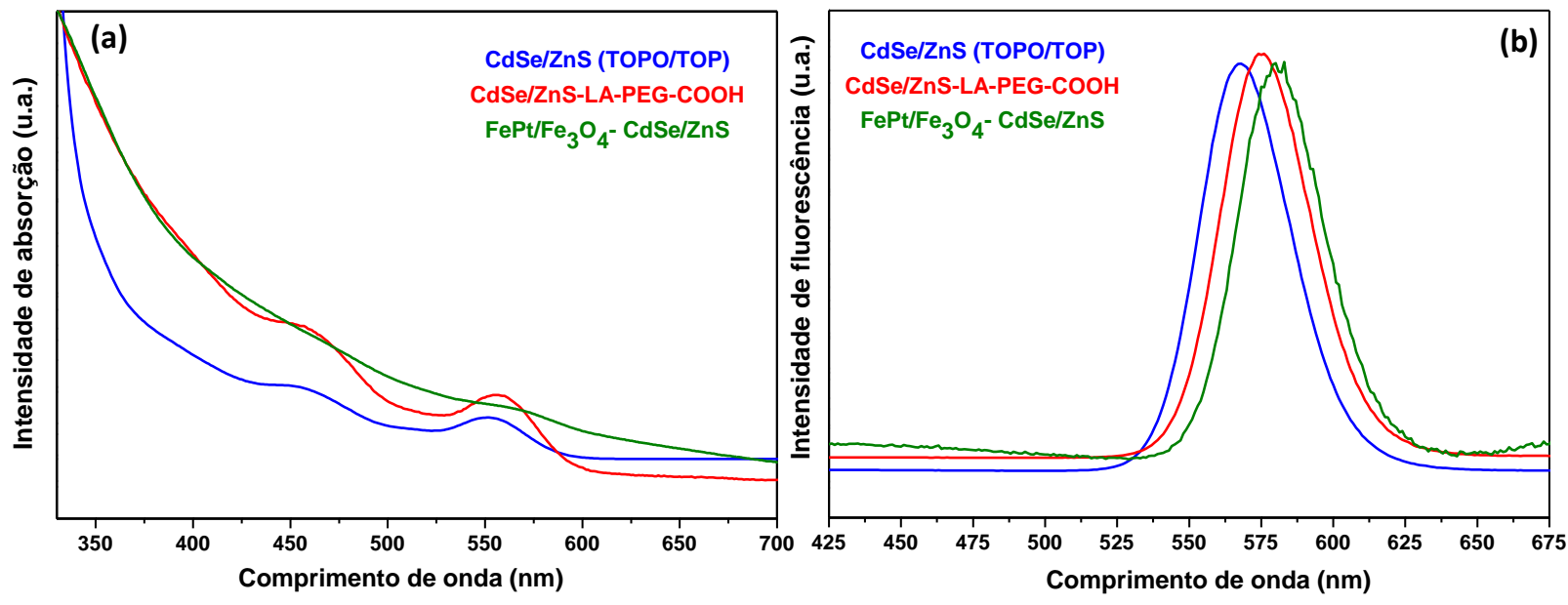


\section{Conclusões}

A síntese das NPM de $\mathrm{FePt} / \mathrm{Fe}_{3} \mathrm{O}_{4}$, baseada no processo do poliol modificado acoplado com o crescimento mediado por sementes, já adequada anteriormente pelo grupo no qual foi desenvolvido este trabalho, tem se mostrado adequada como nanoestrutura magnética para obtenção dos nanomateriais luminomagnéticos. As NPM apresentam alta magnetização de saturação $\left(\mathrm{Ms}=46,8 \mathrm{emu} \cdot \mathrm{g}^{-1}\right)$, controle morfológico e estrutural e tamanho compatível para as etapas posteriores deste trabalho.

Com relação aos métodos de obtenção das heteronanoestruturas luminomagnéticas de $\mathrm{FePt} / \mathrm{Fe}_{3} \mathrm{O}_{4}-\mathrm{CdSe}$, o método que se mostrou mais adequado para a obtenção das heteronanoestruturas foi o método de injeção a quente na presença de NPM como sementes, pelo qual, a melhor condição de síntese encontrada foi a das heteronanoestruturas presentes na amostra A12. A formação de heteronanoestruturas nesta amostra ocorreu na maior parte das partículas, obtendo baixa polidispersividade $\left(\sigma=11,2\right.$ e $15,4 \%$ para as $\mathrm{NPM}$ de $\mathrm{FePt} / \mathrm{Fe}_{3} \mathrm{O}_{4} \mathrm{e}$ os pontos quânticos de $\mathrm{CdSe}$, respectivamente), controle de forma e tamanho, apresentando todas as fases cristalográficas das estruturas cúbicas envolvidas na heteronanoestrutura, além de apresentar alta magnetização de saturação $\left(\mathrm{Ms}=24,1 \mathrm{emu}^{-1} \mathrm{~g}^{-1}\right)$ e comportamento superparamagnético.

Por esse motivo, a amostra A12 foi utilizada para o recobrimento das heteronanoestruturas com sílica. Os recobrimentos com sílica, que foram realizados na amostra A17, demonstraram resultados satisfatórios, pois o método de recobrimento utilizado propiciou o recobrimento de cada heteronanoestrutura com uma camada individual de sílica, o que é desejado para a manutenção das propriedades individuais de cada uma delas. O tamanho médio obtido foi de $25,0 \mathrm{~nm}$, com polidispersividade de $\sigma=8,4 \%$. Com relação às propriedades magnéticas e luminescentes, as heteronanoestruturas recobertas com sílica obtiveram Ms $=11,1$ emu.g ${ }^{-1}$ e comportamento superparamagnético, e duas bandas de emissão (com excitação de $400 \mathrm{~nm}$ ) centradas em $452 \mathrm{~nm}$ e $472 \mathrm{~nm}$, respectivamente.

A obtenção dos nanomateriais luminomagnéticos por conjugação entre os polímeros baseados em PEG na superfície das NPM e dos pontos quânticos foi bastante satisfatória. As trocas de ligantes na superfície hidrofóbica das NPM de $\mathrm{FePt} / \mathrm{Fe}_{3} \mathrm{O}_{4}$ pelos ligantes de DopaPIMA-PEG-NH $\mathrm{N}_{2}$, e na superfície hidrofóbica dos pontos quânticos de $\mathrm{CdSe} / \mathrm{ZnS}$ pelos ligantes de LA-PEG-COOH foram bastante efetivas, confirmadas pelos resultados obtidos. As NPM de $\mathrm{FePt} / \mathrm{Fe}_{3} \mathrm{O}_{4}$ - Dopa-PIMA-PEG-NH $\mathrm{N}_{2}$ apresentaram um $\mathrm{R}_{\mathrm{H}}$ de $12,15 \mathrm{~nm}$ e estabilidade coloidal em diversas condições de $\mathrm{pH}$ e salinidade, sendo que após 21 dias, a dispersibilidade das NPM 
hidrofílicas permaneceu inalteradas. Além disso, apesar de um comportamento mais próximo do paramagnético, apresentam coercividade e remanência quase nula e $\mathrm{M}_{\mathrm{S}}$ de aproximadamente 10 emu.g ${ }^{-1}$, características adequadas visando potenciais aplicações biológicas. Já os pontos quânticos de CdSe/ZnS-LA-PEG-COOH também apresentaram estabilidade coloidal em meio aquoso e com as propriedades ópticas evidenciando controle de distribuição de tamanho das nanoestruturas, sendo que foi possível observar que os espectros de absorção e emissão apresentaram comportamentos muito similares aos espectros dos pontos quânticos de $\mathrm{CdSe} / \mathrm{ZnS}$ hidrofóbicos, tendo somente um pequeno deslocamento para maiores comprimentos de ambos espectros. Os pontos quânticos de CdSe/ZnS-LA-PEG-COOH apresentaram uma $1^{\circ}$ banda de absorção com máximo em 557 nm e uma banda de emissão intensa centrada em 575 $\mathrm{nm}$.

Os nanomateriais luminomagnéticos com as NPM de FePt/ $\mathrm{Fe}_{3} \mathrm{O}_{4}$-Dopa-PIMA-PEG-NH e os pontos quânticos de CdSe/ZnS-LA-PEG-COOH conjugados foram obtidos pelo método da carbodiimida com EDC e NHS como reagentes facilitadores para a formação da ligação amida entre os grupos amina na superfície das NPM e os grupos carboxilato na superfície dos pontos quânticos. Esses nanomateriais luminomagnéticos apresentam estabilidade coloidal em solução aquosa, com um $R_{H}$ de 79,96 nm, o que evidencia a formação de um conjugado entre as diferentes nanoestruturas, sendo confirmada a conjugação pelo deslocamento nas curvas dos espectros de absorção e emissão da amostra contendo esses nanomateriais. Pelo espectro de emissão dos nanomateriais luminomagnéticos pode-se observar uma intensa banda de emissão centrada em $580 \mathrm{~nm}$. 


\section{Perspectivas}

As perspectivas deste trabalho são:

- Realizar estudos mais detalhados das propriedades magnéticas e fluorescentes, e estudos de estabilidade coloidal dos dois tipos de nanomateriais obtidos neste trabalho;

- Para os nanomateriais luminomagnéticos recobertos com os polímeros baseados em PEG, realizar caracterizações mais detalhadas da morfologia, composição e estrutura pelas técnicas de microscopia eletrônica de transmissão de alta resolução e difração de raio-X;

- Realizar ensaios in vitro em diferentes culturas celulares para os principais nanomateriais luminomagnéticos obtidos, com o intuito de verificar as propriedades desses nanomateriais em sistemas biológicos. 


\section{REFERÊNCIAS}

1 LU, A. H.; SALABAS, E. L.; SCHUTH, F. Magnetic nanoparticles: synthesis, protection, functionalization, and application. Angewandte Chemie-International Edition, v. 46, n. 8, p. 1222-1244, 2007.

2 DANIEL, M. C.; ASTRUC, D. Gold nanoparticles: assembly, supramolecular chemistry, quantum-size-related properties, and applications toward biology, catalysis, and nanotechnology. Chemical Reviews, v. 104, n. 1, p. 293-346, 2004.

3 MICHALET, X.; PINAUD, F. F.; BENTOLILA, L. A.; TSAY, J. M.; DOOSE, S.; LI, J. J.; SUNDARESAN, G.; WU, A. M.; GAMBHIR, S. S.; WEISS, S. Quantum dots for live cells, in vivo imaging, and diagnostics. Science, v. 307, n. 5709, p. 538-544, 2005.

4 BARRERA, C.; HERRERA, A.; ZAYAS, Y.; RINALDI, C. Surface modification of magnetite nanoparticles for biomedical applications. Journal of Magnetism and Magnetic Materials, v. 321, n. 10, p. 1397-1399, 2009

5 GUPTA, A. K.; GUPTA, M. Synthesis and surface engineering of iron oxide nanoparticles for biomedical applications. Biomaterials, v. 26, n. 18, p. 3995-4021, 2005.

6 HAO, R.; XING, R.J.; XU, Z. C.; HOU, Y. L.; GAO, S.; SUN, S. H. Synthesis, functionalization, and biomedical applications of multifunctional magnetic nanoparticles. Advanced Materials, v. 22, n. 25, p. 2729-2742, 2010.

7 LAURENT, S.; FORGE, D.; PORT, M.; ROCH, A.; ROBIC, C.; ELST, L. V.; MULLER, R. N. Magnetic iron oxide nanoparticles: synthesis, stabilization, vectorization, physicochemical characterizations, and biological applications. Chemical Reviews, v. 108, n. 6, p. 2064-2110, 2008.

8 LIONG, M.; LU, J.; KOVOCHICH, M.; XIA, T.; RUEHM, S. G.; NEL, A. E.; TAMANOI, F.; ZINK, J. I. Multifunctional inorganic nanoparticles for imaging, targeting, and drug delivery. Acs Nano, v. 2, n. 5, p. 889-896, 2008.

9 CHOI, S. H.; BIN NA, H.; PARK, Y. I.; NA, K.; KWON, S. G.; JANG, Y.; PARK, M.; MOON, J.; SON, J. S.; SONG, I. C.; MOON, W. K.; HYEON, T. Simple and generalized synthesis of oxide-metal heterostructured nanoparticles and their applications in multimodal biomedical probes. Journal of the American Chemical Society, v. 130, n. 46, p. 1557315580, 2008.

10 SELVAN, S. T.; PATRA, P. K.; ANG, C. Y.; YING, J. Y. Synthesis of silica-coated semiconductor and magnetic quantum dots and their use in the imaging of live cells. Angewandte Chemie-International Edition, v. 46, n. 14, p. 2448-2452, 2007.

11 KOHLER, N.; FRYXELL, G. E.; ZHANG, M. Q. A bifunctional poly(ethylene glycol) silane immobilized on metallic oxide-based nanoparticles for conjugation with cell targeting agents. Journal of the American Chemical Society, v. 126, n. 23, p. 7206-7211, 2004. 
12 CORR, S. A.; RAKOVICH, Y. P.; GUN'KO, Y. K. Multifunctional magnetic-fluorescent nanocomposites for biomedical applications. Nanoscale Research Letters, v. 3, n. 3, p. 87104, 2008.

13 CHEN, O.; RIEDEMANN, L.; ETOC, F.; HERRMANN, H.; COPPEY, M.; BARCH, M.; FARRAR, C. T.; ZHAO, J.; BRUNS, O. T.; WEI, H.; GUO, P.; CUI, J.; JENSEN, R.; CHEN, Y.; HARRIS, D. K.; CORDERO, J. M.; WANG, Z.; JASANOFF, A.; FUKUMURA, D.; REIMER, R.; DAHAN, M.; JAIN, R. K.; BAWENDI, M. G. Magneto-fluorescent core-shell supernanoparticles. Nature Communications, v. 5, 2014.

14 KAS, R.; SEVINC, E.; TOPAL, U.; ACAR, H. Y. A universal method for the preparation of magnetic and luminescent hybrid nanoparticles. Journal of Physical Chemistry C, v. 114, n. 17, p. 7758-7766, 2010.

15 EROGBOGBO, F.; YONG, K. T.; HU, R.; LAW, W. C.; DING, H.; CHANG, C. W.; PRASAD, P. N.; SWIHART, M. T. Biocompatible magnetofluorescent Probes: luminescent silicon quantum dots coupled with superparamagnetic iron(III) oxide. Acs Nano, v. 4, n. 9, p. 5131-5138, 2010.

16 NA, H. B.; SONG, I. C.; HYEON, T. Inorganic Nanoparticles for MRI Contrast Agents. Advanced Materials, v. 21, n. 21, p. 2133-2148, 2009.

17 LEVY, M.; QUARTA, A.; ESPINOSA, A.; FIGUEROLA, A.; WILHELM, C.; GARCIAHERNANDEZ, M.; GENOVESE, A.; FALQUI, A.; ALLOYEAU, D.; BUONSANTI, R.; COZZOLI, P. D.; GARCIA, M. A.; GAZEAU, F.; PELLEGRINO, T. Correlating magnetostructural properties to hyperthermia performance of highly monodisperse iron oxide nanoparticles prepared by a seeded-growth route. Chemistry of Materials, v. 23, n. 18, p. 4170-4180, 2011.

18 HU, S. H.; LIAO, B. J.; CHIANG, C. S.; CHEN, P. J.; CHEN, I. W.; CHEN, S. Y. Coreshell nanocapsules stabilized by single-component polymer and nanoparticles for magnetochemotherapy/hyperthermia with multiple drugs. Advanced Materials, v. 24, n. 27, p. 3627 3632, 2012.

19 KIM, B. H.; LEE, N.; KIM, H.; AN, K.; PARK, Y.; CHOI, Y.; SHIN, K.; LEE, Y.; KWON, S. G.; NA, H. B; PARK, J. G.; AHN,T. Y.; KIM, Y. W.; MOON, W. K.; CHOI, S. H.; HYEON,T. Large-scale synthesis of uniform and extremely small-sized iron oxide nanoparticles for high-resolution t-1 magnetic resonance imaging contrast agents. Journal of the American Chemical Society, v. 133, n. 32, p. 12624-12631, 2011.

20 COSTI, R.; SAUNDERS, A. E.; BANIN, U. Colloidal hybrid nanostructures: a new type of functional materials. Angewandte Chemie-International Edition, v. 49, n. 29, p. 48784897, 2010.

21 KIM, J.; LEE, J. E.; LEE, J.; YU, J. H.; KIM, B. C.; AN, K.; HWANG, Y.; SHIN, C. H.; PARK, J. G.; HYEON, T. Magnetic fluorescent delivery vehicle using uniform mesoporous silica spheres embedded with monodisperse magnetic and semiconductor nanocrystals.

Journal of the American Chemical Society, v. 128, n. 3, p. 688-689, 2006. 
22 SUN, C.; LEE, J. S. H.; ZHANG, M. Q. Magnetic nanoparticles in MR imaging and drug delivery. Advanced Drug Delivery Reviews, v. 60, n. 11, p. 1252-1265, 2008.

23 GAI, S. L.; YANG, P. P.; LI, C. X.; WANG, W. X.; DAI, Y. L.; NIU, N.; LIN, J. Synthesis of magnetic, up-conversion luminescent, and mesoporous core-shell-structured nanocomposites as drug carriers. Advanced Functional Materials, v. 20, n. 7, p. 1166-1172, 2010.

24 COZZOLI, P. D.; PELLEGRINO, T.; MANNA, L. Synthesis, properties and perspectives of hybrid nanocrystal structures. Chemical Society Reviews, v. 35, n. 11, p. 1195-1208, 2006.

25 DONEGA, C. D. Synthesis and properties of colloidal heteronanocrystals. Chemical Society Reviews, v. 40, n. 3, p. 1512-1546, 2011.

26 CARBONE, L.; COZZOLI, P. D. Colloidal heterostructured nanocrystals: synthesis and growth mechanisms. Nano Today, v. 5, n. 5, p. 449-493, 2010.

27 CASAVOLA, M.; BUONSANTI, R.; CAPUTO, G.; COZZOLI, P. D. Colloidal strategies for preparing oxide-based hybrid nanocrystals. European Journal of Inorganic Chemistry, n. 6, p. 837-854, 2008.

28 DENG, S.; RUAN, G.; HAN, N.; WINTER, J. O. Interactions in fluorescent-magnetic heterodimer nanocomposites. Nanotechnology, v. 21, n. 14, 2010.

29 ZHOU, S.; CHEN, Q.; HU, X.; ZHAO, T. Bifunctional luminescent superparamagnetic nanocomposites of $\mathrm{CdSe} / \mathrm{CdS}-\mathrm{Fe} 3 \mathrm{O} 4$ synthesized via a facile method. Journal of Materials Chemistry, v. 22, n. 17, p. 8263-8270, 2012.

30 LI, W.; CAMARGO, P. H. C.; LU, X.; XIA, Y. Dimers of silver nanospheres: facile synthesis and their use as hot spots for surface-enhanced raman scattering. Nano Letters, v. 9, n. 1, p. 485-490, 2009.

31 BUCK, M. R.; BONDI, J. F.; SCHAAK, R. E. A total-synthesis framework for the construction of high-order colloidal hybrid nanoparticles. Nature Chemistry, v. 4, n. 1, p. 3744, 2012.

32 PELLEGRINO, T.; FIORE, A.; CARLINO, E.; GIANNINI, C.; COZZOLI, P. D.; CICCARELLA, G.; RESPAUD, M.; PALMIROTTA, L.; CINGOLANI, R.; MANNA, L. Heterodimers based on CoPt3-Au nanocrystals with tunable domain size. Journal of the American Chemical Society, v. 128, n. 20, p. 6690-6698, 2006.

33 GU, H. W.; YANG, Z. M.; GAO, J. H.; CHANG, C. K.; XU, B. Heterodimers of nanoparticles: formation at a liquid-liquid interface and particle-specific surface modification by functional molecules. Journal of the American Chemical Society, v. 127, n. 1, p. 34-35, 2005. 
34 LIN, A. W. H.; ANG, C. Y.; PATRA, P. K.; HAN, Y.; GU, H.; BRETON, J. M. L.; JURASZEK, J.; CHIRON, H.; PAPAEFTHYMIOU, G. C.; SELVAN, S. T.; YING, J. Y. Seed-mediated synthesis, properties and application of gamma-Fe2O3-CdSe magnetic quantum dots. Journal of Solid State Chemistry, v. 184, n. 8, p. 2150-2158, 2011.

35 PALUI, G.; AVELLINI, T.; ZHAN, N.; PAN, F.; GRAY, D.; ALABUGIN, I.; MATTOUSSI, $\mathrm{H}$. Photoinduced phase transfer of luminescent quantum dots to polar and aqueous media. Journal of the American Chemical Society, v. 134, n. 39, p. 16370-16378, 2012.

36 BIN NA, H.; PALUI, G.; ROSENBERG, J. T.; JI, X.; GRANT, S. C.; MATTOUSSI, H. Multidentate catechol-based polyethylene glycol oligomers provide enhanced stability and biocompatibility to iron oxide nanoparticles. Acs Nano, v. 6, n. 1, p. 389-399, 2012.

37 CHEN, S.; LI, Y.; GUO, C.; WANG, J.; MA, J. H.; LIANG, X. F.; YANG, L. R.; LIU, H. Z. Temperature-responsive magnetite/PEO-PPO-PEO block copolymer nanoparticles for controlled drug targeting delivery. Langmuir, v. 23, p. 12669-12676, 2007.

38 BLANCO-CANOSA, J. B.; MEDINTZ, I. L.; FARRELL, D.; MATTOUSSI, H.; DAWSON, P. E. Rapid covalent ligation of fluorescent peptides to water solubilized quantum dots. Journal of the American Chemical Society, v. 132, n. 29, p. 10027-10033, 2010.

39 ZHAN, N.; PALUI, G.; SAFI, M.; JI, X.; MATTOUSSI, H. Multidentate zwitterionic ligands provide compact and highly biocompatible quantum dots. Journal of the American Chemical Society, v. 135, n. 37, p. 13786-13795, 2013.

40 OH, E.; SUSUMU, K.; GOSWAMI, R.; MATTOUSSI, H. One-phase synthesis of watersoluble gold nanoparticles with control over size and surface functionalities. Langmuir, v. 26, n. 10, p. 7604-7613, 2010.

41 BERTORELLE, F.; WILHELM, C.; ROGER, J.; GAZEAU, F.; MENAGER, C.; CABUIL, V. Fluorescence-modified superparamagnetic nanoparticles: intracellular uptake and use in cellular imaging. Langmuir, v. 22, n. 12, p. 5385-5391, 2006.

42 KHOMUTOV, G. B.; KOKSHAROV, Y. A. Effects of organic ligands, electrostatic and magnetic interactions in formation of colloidal and interfacial inorganic nanostructures.

Advances in Colloid and Interface Science, v. 122, n. 1-3, p. 119-147, 2006.

43 CHANG, Q.; ZHU, L. H.; YU, C.; TANG, H. Q. Synthesis and properties of magnetic and luminescent $\mathrm{Fe} 3 \mathrm{O} 4 / \mathrm{SiO} 2 / \mathrm{Dye} / \mathrm{SiO} 2$ nanoparticles. Journal of Luminescence, v. 128, n. 12, p. 1890-1895, 2008.

44 DE PALMA, R.; PEETERS, S.; VAN BAEL, M. J.; VAN DEN HUL, H.; BONROY, K.; LAUREYN, W.; MULLENS, J.; BORGHS, G.; MAES, G. Silane ligand exchange to make hydrophobic superparamagnetic nanoparticles water-dispersible. Chemistry of Materials, v. 19, n. 7, p. 1821-1831, 2007.

45 HAN, Y.; JIANG, J.; LEE, S. S.; YING, J. Y. Reverse microemulsion-mediated synthesis of silica-coated gold and silver nanoparticles. Langmuir, v. 24, n. 11, p. 5842-5848, 2008. 
46 KOOLE, R.; VAN SCHOONEVELD, M. M.; HILHORST, J.; DONEGA, C. D.; HART, D. C; VAN BLAADEREN, A.; VANMAEKELBERGH, D.; MEIJERINK, A. On the incorporation mechanism of hydrophobic quantum dots in silica spheres by a reverse microemulsion method. Chemistry of Materials, v. 20, n. 7, p. 2503-2512, 2008.

47 GUERRERO-MARTINEZ, A.; PEREZ-JUSTE, J.; LIZ-MARZAN, L. M. Recent progress on silica coating of nanoparticles and related nanomaterials. Advanced Materials, v. 22, n. 11, p. 1182-1195, 2010.

48 SPERLING, R. A.; PARAK, W. J. Surface modification, functionalization and bioconjugation of colloidal inorganic nanoparticles. Philosophical Transactions of the Royal Society a-Mathematical Physical and Engineering Sciences, v. 368, n. 1915, p. 1333-1383, 2010.

49 KARAKOTI, A. S.; DAS, S.; THEVUTHASAN, S.; SEAL, S. PEGylated inorganic nanoparticles. Angewandte Chemie-International Edition, v. 50, n. 9, p. 1980-1994, 2011.

50 MEI, B. C.; SUSUMU, K.; MEDINTZ, I. L.; MATTOUSSI, H. Polyethylene glycol-based bidentate ligands to enhance quantum dot and gold nanoparticle stability in biological media.

Nature Protocols, v. 4, n. 3, p. 412-423, 2009.

51 SUSUMU, K.; MEI, B. C.; MATTOUSSI, H. Multifunctional ligands based on dihydrolipoic acid and polyethylene glycol to promote biocompatibility of quantum dots. Nature Protocols, v. 4, n. 3, p. 424-436, 2009.

52 HERMANSON, G. T. Bioconjugate Techniques. London: Academic Press, 2008. 1323 p.

53 PALUI, G.; ALDEEK, F.; WANG, W.; MATTOUSSI, H. Strategies for interfacing inorganic nanocrystals with biological systems based on polymer-coating. Chemical Society Reviews, v. 44, n. 1, p. 193-227, 2015.

54 SUSUMU, K.; MEDINTZ, I. L.; DELEHANTY, J. B.; BOENEMAN, K.; MATTOUSSI, $\mathrm{H}$. Modification of poly(ethylene glycol)-capped quantum dots with nickel nitrilotriacetic acid and self-assembly with histidine-tagged proteins. Journal of Physical Chemistry C, v. 114, n. 32, p. 13526-13531, 2010.

55 CALLISTER JR, W. D. Materials Science and Engineering: An Introduction. New York: John Wiley. 1991, 992p.

56 CULLITY, B. D.; GRAHAM, C. D. Introduction to Magnetic Materials. Hoboken: John Wiley. 2009, 468 p.

57 JEONG, U.; TENG, X. W.; WANG, Y.; YANG, H.; XIA, Y. N. Superparamagnetic colloids: controlled synthesis and niche applications. Advanced Materials, v. 19, n. 1, p. 33 60, 2007.

58 GOESMANN, H.; FELDMANN, C. Nanoparticulate functional materials. Angewandte Chemie-International Edition, v. 49, n. 8, p. 1362-1395, 2010. 
59 BATLLE, X.; LABARTA, A. Finite-size effects in fine particles: magnetic and transport properties. Journal of Physics D-Applied Physics, v. 35, n. 6, p. R15-R42, 2002.

60 BEDANTA, S.; KLEEMANN, W. Supermagnetism. Journal of Physics D-Applied Physics, v. 42, n. 1, 2009.

61 MIKHAYLOVA, M.; KIM, D. K.; BOBRYSHEVA, N.; OSMOLOWSKY, M.; SEMENOV, V.; TASAKALAKOS, T.; MUHAMMED, M. Superparamagnetism of magnetite nanoparticles: dependence on surface modification. Langmuir, v. 20, n. 6, p. 24722477, 2004.

62 BANERJEE, R.; KATSENOVICH, Y.; LAGOS, L.; MCIINTOSH, M.; ZHANG, X; LI, C. Z. Nanomedicine: magnetic nanoparticles and their biomedical applications. Current Medicinal Chemistry, v. 17, n. 27, p. 3120-3141, 2010.

63 ZHANG, Q.; WANG, C. H.; QIAO, L.; YAN, H. S.; LIU, K. L. Superparamagnetic iron oxide nanoparticles coated with a folate-conjugated polymer. Journal of Materials Chemistry, v. 19, n. 44, p. 8393-8402, 2009.

64 SMITH, A. M.; NIE, S. Semiconductor nanocrystals: structure, properties, and band gap engineering. Accounts of Chemical Research, v. 43, n. 2, p. 190-200, 2010.

65 ALIVISATOS, A. P. Perspectives on the physical chemistry of semiconductor nanocrystals. Journal of Physical Chemistry, v. 100, n. 31, p. 13226-13239, 1996.

66 TALAPIN, D. V.; ROGACH, A. L.; KORNOWSKY, A.; HAASE, M.; WELLER, H. Highly luminescent monodisperse $\mathrm{CdSe}$ and $\mathrm{CdSe} / \mathrm{ZnS}$ nanocrystals synthesized in a hexadecylamine-trioctylphosphine oxide-trioctylphospine mixture. Nano Letters, v. 1, n. 4, p. 207-211, 2001.

67 TALAPIN, D. V.; NELSON, J. H.; SHEVCHENKO, E. V.; ALONI, S.; SADTLER, B.; ALIVISATOS, A. P. Seeded growth of highly luminescent $\mathrm{CdSe} / \mathrm{CdS}$ nanoheterostructures with rod and tetrapod morphologies. Nano Letters, v. 7, n. 10, p. 2951-2959, 2007.

68 REISS, P.; PROTIERE, M.; LI, L. Core/shell semiconductor nanocrystals. Small, v. 5, n. 2, p. 154-168, 2009.

69 IVANOV, S. A.; PIRYATINSKI, A.; NANDA, J.; TRETIAK, S.; ZAVADIL, K. R.; WALLACE,W. O.; WERDER, D.; KLIMOV, V. I. Type-II core/shell CdS/ZnSe nanocrystals: synthesis, electronic structures, and spectroscopic properties. Journal of the American Chemical Society, v. 129, n. 38, p. 11708-11719, 2007.

70 WANG, X.; REN, X.; KAHEN, K; HAHN, M. A.; RAJESWARAN, M.; MACCAGNANO-ZACHER, S.; SILCOX, J.; CRAGG, G. E.; EFROS, A. L.; KRAUSS, T. D. Non-blinking semiconductor nanocrystals. Nature, v. 459, n. 7247, p. 686-689, 2009.

71 DONEGA, C. D. M. Formation of nanoscale spatially indirect excitons: evolution of the type-II optical character of CdTe/CdSe heteronanocrystals. Physical Review B, v. 81, n. 16, 2010. 
72 STEINER, D.; DORFS, D.; BANIN, U.; SALA, F. D.; MANNA, L.; MILLO, O.

Determination of band offsets in heterostructured colloidal nanorods using scanning tunneling spectroscopy. Nano Letters, v. 8, n. 9, p. 2954-2958, 2008.

73 STEWART, M. H.; SUSUMU, K.; MEI, B. C.; MEDINTZ, I. L.; DELEHANTY, J. B.; BLANCO-CANOSA, J. B.; DAWSON, P. E.; MATTOUSSI, H. Multidentate poly(ethylene glycol) ligands provide colloidal stability to semiconductor and metallic nanocrystals in extreme conditions. Journal of the American Chemical Society, v. 132, n. 28, p. 9804-9813, 2010 .

$74 \mathrm{HO}, \mathrm{K} . \mathrm{M}$.; LI, P. Design and synthesis of novel magnetic core-shell polymeric particles. Langmuir, v. 24, n. 5, p. 1801-1807, 2008.

75 BAUTISTA, M. C.; BOMATI-MIGUEL, O.; MORALES, M. D.; SERNA, C. J.; VEINTEMILLAS-VERDAGUER, S. Surface characterisation of dextran-coated iron oxide nanoparticles prepared by laser pyrolysis and coprecipitation. Journal of Magnetism and Magnetic Materials, v. 293, n. 1, p. 20-27, 2005.

76 ICHIKAWA, S.; IWAMOTO, S.; WATANABE, J. Formation of biocompatible nanoparticles by self-assembly of enzymatic hydrolysates of chitosan and carboxymethyl cellulose. Bioscience Biotechnology and Biochemistry, v. 69, n. 9, p. 1637-1642, 2005.

77 LAURENT, S.; FORGE, D.; PORT, M.; ROCH, A.; ROBIC, C.; ELST, L. V.; MULLER, R. N. Magnetic iron oxide nanoparticles: synthesis, stabilization, vectorization, physicochemical characterizations, and biological applications. Chemical Reviews, v. 110, n. 4, p. 2574-2574, 2010.

78 HARDIKAR, V. V.; MATIJEVIC, E. Coating of nanosize silver particles with silica. Journal of Colloid and Interface Science, v. 221, n. 1, p. 133-136, 2000.

79 SHAO, D. D.; XU, K. K.; SONG, X. J.; HU, J. H.; YANG, W. L.; WANG, C. C. Effective adsorption and separation of lysozyme with PAA-modified Fe3O4@ silica core/shell microspheres. Journal of Colloid and Interface Science, v. 336, n. 2, p. 526-532, 2009.

80 ZANCHET, D.; HALL, B. D.; UGARTE, D. Inter-atomic distance contraction in thiolpassivated gold nanoparticles. Chemical Physics Letters, v. 323, n. 1-2, p. 167-172, 2000.

81 DARBANDI, M.; THOMANN, R.; NANN, T. Single quantum dots in silica spheres by microemulsion synthesis. Chemistry of Materials, v. 17, n. 23, p. 5720-5725, 2005.

82 CAPEK, I. Preparation of metal nanoparticles in water-in-oil (w/o) microemulsions. Advances in Colloid and Interface Science, v. 110, n. 1-2, p. 49-74, 2004.

83 ALDEEK, F.; MUHAMMED, M. A. H; PALUI, G.; ZHAN, N.; MATTOUSSI, H. Growth of highly fluorescent polyethylene glycol- and zwitterion-functionalized gold nanoclusters. ACS Nano, v. 7, n. 3, p. 2509-2521, 2013.

84 PALUI, G.; NA, H. B.; MATTOUSSI, H. Poly(ethylene glycol)-based multidentate oligomers for biocompatible semiconductor and gold nanocrystals. Langmuir, v. 28, n. 5, p. 2761-2772, 2012. 
85 SUSUMU, K.; UYEDA, H. T.; MEDINTZ, I. L.; PONS, T.; DELEHANTY, J. B.; MATTOUSSI, H. Enhancing the stability and biological functionalities of quantum dots via compact multifunctional ligands. Journal of the American Chemical Society, v. 129, n. 45, p. 13987-13996, 2007.

86 ZHAN, N.; PALUI, G.; GRISE, H.; TANG, H.; ALABUGIN, I.; MATTOUSSI, H. Combining ligand design with photoligation to provide compact, colloidally stable, and easy to conjugate quantum dots. ACS Applied Materials \& Interfaces, v. 5, n. 8, p. 2861-2869, 2013.

87 GUPTA, A. K.; WELLS, S. Surface-modified superparamagnetic nanoparticles for drug delivery: preparation, characterization, and cytotoxicity studies. Ieee Transactions on Nanobioscience, v. 3, n. 1, p. 66-73, 2004.

88 WANG, W.; JI, X.; BIN NA, H.; SAFI, M.; SMITH, A.; PALUI, G.; PEREZ, J. M.; MATTOUSSI, H. Design of a multi-dopamine-modified polymer ligand optimally suited for interfacing magnetic nanoparticles with biological systems. Langmuir, v. 30, n. 21, p. 61976208, 2014.

89 ZHENG, H.; MORTENSEN, L. J.; DELOUISE, L. A. Thiol antioxidant-functionalized $\mathrm{CdSe} / \mathrm{ZnS}$ quantum dots: synthesis, characterization, cytotoxicity. Journal of Biomedical Nanotechnology, v. 9, n. 3, p. 382-392, 2013.

90 MATTOUSSI, H.; MAURO, J. M.; GOLDMAN, E. R.; ANDERSON, G. P.; SUNDAR, V. C.; MIKULEC, F. V.; BAWENDI, M. G. Self-assembly of CdSe-ZnS quantum dot bioconjugates using an engineered recombinant protein. Journal of the American Chemical Society, v. 122, n. 49, p. 12142-12150, 2000.

91 KALIA, J.; RAINES, R. T. Advances in bioconjugation. Current Organic Chemistry, v. 14, n. 2, p. 138-147, 2010.

92 VARANDA, L. C.; JAFELICCI, M.; IMAIZUMI, M. Temperature dependence and magnetocrystalline anisotropy studies of self-assembled L1(0)-Fe55Pt45 ferromagnetic nanocrystals. Journal of Applied Physics, v. 101, n. 12, 2007.

93 SOUZA, C. G. S.; BECK, W.; VARANDA, L. C. Multifunctional luminomagnetic $\mathrm{FePt} @ \mathrm{Fe} 3 \mathrm{O} 4 / \mathrm{SiO} 2 / \mathrm{Rhodamine} \mathrm{B} / \mathrm{SiO} 2$ nanoparticles with high magnetic emanation for biomedical applications. Journal of Nanoparticle Research, v. 15, n. 4, p. 11, 2013.

94 BECK JR, W.; SOUZA, C. G. S.; SILVA, T. L.; JAFELICCI, M.; VARANDA, L. C. Formation mechanism via a heterocoagulation approach of FePt nanoparticles using the modified polyol process. Journal of Physical Chemistry C, v. 115, n. 21, p. 10475-10482, 2011.

95 MURRAY, C. B.; NORRIS, D. J.; BAWENDI, M. G. Synthesis and characterization of nearly monodisperse CDE ( $=\mathrm{S}, \mathrm{SE}, \mathrm{TE})$ semiconductor nanocrystallites. Journal of the American Chemical Society, v. 115, n. 19, p. 8706-8715, 1993. 
96 MEI, B. C.; SUSUMU, K.; MEDINTZ, I. L.; DELEHANTY, J. B.; MOUNTZIARIS, T. J.; MATTOUSSI, H. Modular poly(ethylene glycol) ligands for biocompatible semiconductor and gold nanocrystals with extended $\mathrm{pH}$ and ionic stability. Journal of Materials Chemistry, v. 18, n. 41, p. 4949-4958, 2008.

97 CLAPP, A. R.; GOLDMAN, E. R.; MATTOUSSI, H. Capping of CdSe-ZnS quantum dots with DHLA and subsequent conjugation with proteins. Nature Protocols, v. 1, n. 3, p. 12581266, 2006.

98 SUN, S. H.; ZENG, H.; ROBINSON, D. B.; RAOUX, S.; RICE, P. M.; WANG, S. X.; LI, G. X. Monodisperse MFe2O4 ( $\mathrm{M}=\mathrm{Fe}, \mathrm{Co}, \mathrm{Mn})$ nanoparticles. Journal of the American Chemical Society, v. 126, n. 1, p. 273-279, 2004.

99 SUN, S. H. Recent advances in chemical synthesis, self-assembly, and applications of FePt nanoparticles. Advanced Materials, v. 18, n. 4, p. 393-403, 2006.

100 LAMER, V. K.; DINEGAR, R. H. Theory, production and mechanism of formation of monodispersed hydrosols. Journal of the American Chemical Society, v. 72, n. 11, p. 48474854, 1950.

101 WILEY, B.; HERRICKS, T.; SUN, Y. G.; XIA, Y. N. Polyol synthesis of silver nanoparticles: use of chloride and oxygen to promote the formation of single-crystal, truncated cubes and tetrahedrons. Nano Letters, v. 4, n. 9, p. 1733-1739, 2004.

102 YU, W. W.; QU, L. H.; GUO, W. Z.; PENG, X. G. Experimental determination of the extinction coefficient of CdTe, CdSe, and CdS nanocrystals. Chemistry of Materials, v. 15, n. 14, p. 2854-2860, 2003. 